ar V

10361

y.
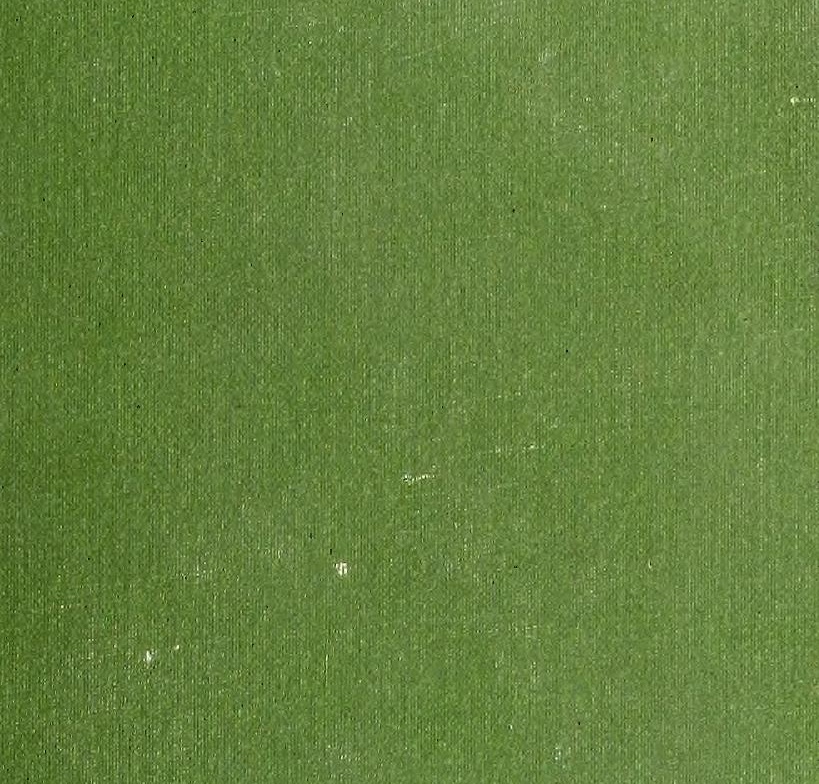

$+x^{2}$ 


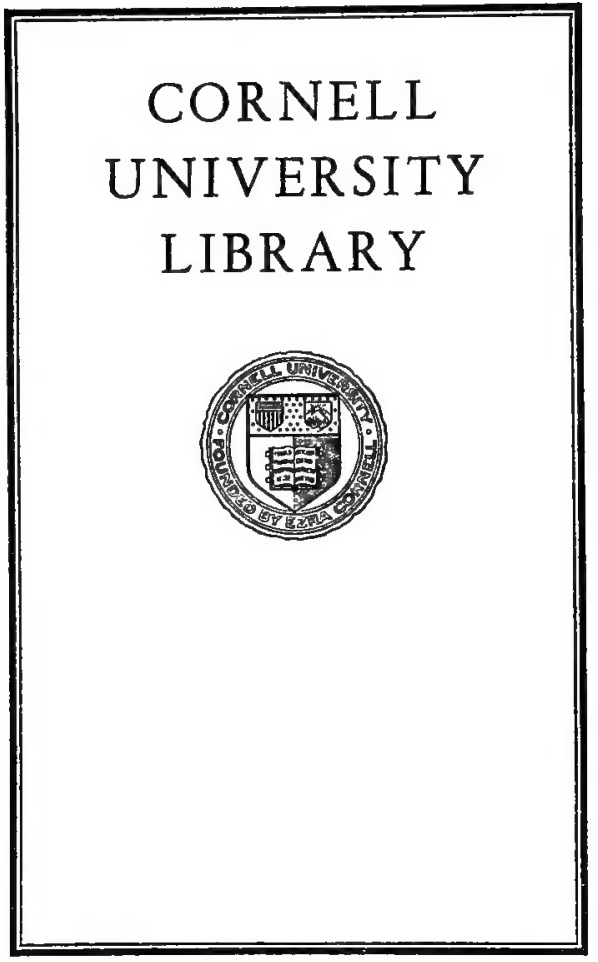




\section{arV10361 \\ Cornell University Library \\ Injurious and useful insects;

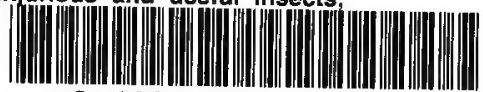 \\ $\begin{array}{rrrr}3 & 1924 & 031 & 489 \\ \text { olin,anx }\end{array}$}




\section{Cornell University Library}

The original of this book is in the Cornell University Library.

There are no known copyright restrictions in the United States on the use of the text.

http://www.archive.org/details/cu31924031489333 


\section{INJURIOUS AND USEFUL INSECTS}




\section{BELL'S SCIENCE SERIES}

\section{Edited by}

Percy Groom, D.Sc., M.A. (Cantab. et Oxon.), F.L.S. Lecturer on Botany in the Royal Indian Engineering College, Cooper's Hill

AND

G. M. Minchin, M.A., F.R.S.

Professor of Applied Mathematics in the same College

ELEMENTARY Botany. By Percy Groom, M.A., D.Sc., F.L.S., sometime Examiner in Botany to the University of Oxford. Third Edition. With 275 Illustrations. Crown 8vo, 35. $6 \mathrm{~d}$.

THE STUDENT'S DYNAMICS. Comprising Statics and Kinetics. By Prof. G. M. Minchin, M.A., F.R.S. With numerous Diagrams. 3s. $6 \mathrm{~d}$.

ELEMENTARY INORGANIC CHEMISTRY. By JAMES WALkER, D.Sc., Ph.D., F.R.S., Professor of Chemistry in University College, Dundee. 3s. $6 \mathrm{~d}$.

AN INTRODUCTION TO THE STUDY OF THE COMPARATIVE ANATOMY OF ANIMALS. BY G. C. Bourne, M.A., D.Sc., F.L.S., Fellow and Tutor of New College, Oxford. Vol. I., Animal Organization: The Protozoa and Colenterata. With numerous Illustrations. 4s. $6 \mathrm{~d}$. Vol. II., The Colomata. 45. $6 \mathrm{~d}$.

INJURIOUS AND USEFUL INSECTS. By L. C. MIALl, F.R.S., Professor of Biology in the Yorkshire College, Leeds. With roo Illustrations. 3s. $6 \mathrm{~d}$.

ELEMENTARY GENERAL SCIENCE. By D. E. JONES, B.Sc., Science Inspector, and formerly Professor of Physics in the University College of Wales, A berystwith, and D. S. MaCnair, Ph.D., B.Sc. It the Press.

PHYSIOGRAPHY. By H. N. Dickson, F.R.S.E., F.R.Met. Soc., F.R.G.S. [In Preparation.

ELECTRICITY AND MAGNETISM. By OLIVER J. LODGE, D.Sc., F.R.S., LL.D., M.I.E.E., Principal of the University of Birmingham.

[In Preparation.

LIGHT. By A. E. Tutron, B.Sc., F.R.S. [In Preparation.

LONDON : GEORGE BELL \& SONS YORK STREET, COVENT GARDEN 


\title{
INJURIOUS AND USEFUL INSECTS
}

\section{AN INTRODUCTION TO THE STUDY OF}

\section{ECONOMIC ENTOMOLOGY}

\author{
BY \\ L. C. MIALI, F.R.S. \\ Professor of Biology in the \\ Yorkshire College
}

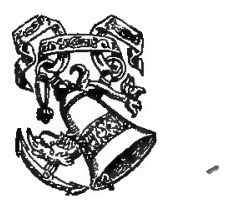

LONDON

GEORGE BELL \& SONS

1902 



\section{PREFACE}

THIs little book has been written for beginners who are willing to take some pains to acquire a practical knowledge of insects, and are specially interested in the application of entomology to agriculture, horticulture, and forestry. A practical purpose is, in my opinion, not a hindrance but a powerful motive to the acquisition of scientific knowledge. If not too narrowly prosecuted, the practical purpose may be a means of distinguishing knowledge which is really useful from knowledge which is merely curious. I feel sure that it is much more likely to exercise a wholesome influence on natural history than collecting and naming, which have been far too exclusively attended to for many years past.

I have tried to meet the wants, not only of those who are concerned with insect-ravages, but also of those who seek to inquire into the works of nature. Injurious and useful insects are as full of contrivance, and as beautifully equipped for the struggle of life, as any others. Since they are among the commonest species, they can be easily and profitably studied by those who have no purpose in view except to enlarge their knowledge of living things. The title of the book has not been so strictly interpreted as to exclude a few insects which are neither injurious nor useful, but either very plentiful or particularly instructive.

In my own teaching of economic entomology and other branches of biology, the laboratory work always comes first, and the class-work is only a means of correcting and driving home the instruction of the laboratory. Common insects are provided in large quantities, so that every student is supplied. The rarer ones are exhibited in glazed cases, each of which illustrates a single life-history. The teacher should make his own selection of types, and draw up his own syllabus of work, referring to the text-book wherever a detailed account is required. It is good to draw much from nature, and to 
study a few things carefully rather than many in haste. To observe live insects under natural conditions is infinitely more profitable to the economic entomologist than to make a collection. Such advice as this conflicts, I am afraid, with some almost universal propensities of human nature, and it would be too much to expect that it will be followed except by the few. After long experience, I think I can promise those few a reward for their trouble.

I am persuaded that in all branches of natural history too much is made of learned language, and I have used plain English as far as possible: I am not at all convinced that it is less precise than Latin or Greek.

The order of the lessons indicates the general course of study which is recommended. First, the student is put through a short course of work calculated to give him a useful acquaintance with insect structure, and some knowledge of technical processes. In Part II. a number of insects are brought before him for detailed examination. A selection from these types, most of which are of considerable practical importance, will serve as a convenient introduction to the study of life-histories. The order in which they are here presented roughly corresponds to the order of difficulty, the easier types coming first. Part III. pre-supposes a knowledge of the earlier parts, and is intended to prepare the way for systematic study, as well as to give short notices of a number of insects which are likely to attract the student's attention, but which time and space do not allow him to consider in detail. This part of the book is rather to be referred to on occasion than to be read continuously.

The publishers acknowledge with thanks the loan of figs. 23 , $24,66,67,68,90,91$, and 92 from Miall's "Natural History of Aquatic Insects" (Macmillan \& Co.); and of figs. 44-47 from Miall's "Round the Year" (Macmillan \& Co.). 


\section{CONTENTS}

\section{PART I \\ PRELIMINARY LESSONS}

I. What is an Insect?

2. (Practical) 3-5

3. (Practical.) The External Parts of an Insect (Cockroach) (Cockroach)

4. (Practical.) Dissection of a Cockroach

\section{PART II}

LESSONS ON COMMON INSECTS, CHIEFLY SUCH AS ARE EITHER INJURIOUS OR USEFUL TO MAN

\section{A. Beetles (Coleoptera)}

5. The Cockchafer (Melolontha vulgaris)

6. A Carnivorous Water-Beetle (Dytiscus marginalis).

7. Wire-Worms and Click-Beetles (various species of Agriotes,

8. The Turnip-Flea (Phyllotreta nemorum)

. $\quad 42-44$

ro. The Garden-Weevil (Otiorhynchus) . . . . 44-47

I1. The Elm-bark Beetle (Scolytus destructor) . . . $47-50$

\section{B. Moths AND Butterflies (Lepidoptera)}

12. (Practical.) Dissection of a Caterpillar

13. (Practical.) How to inflate a Caterpillar and set a Moth

14. The Tiger-Moth (Arctia caja)

15. Cabbage White Butterflies (Pierís)

I6. The Goat-Moth (Cossus ligniperda) .

I7. The Silkworm (Bombyx mori)

18. The Vapourer-Moth (Orgyia antiqua)

\section{BEE-LIKE INSECTS (Hymenoptera)}

19. The Hive-Bee (Apis mellifica)

20. The Gooseberry Saw-Fly (Nematus ribesii) .

21. The Wood-Wasp (Sirex)

22. Ichneumons and their Allies . 
23. The Harlequin-Fly (Chironomus)

24. (Practical.) The Development of an Insect (Chironomus):

I 22- 125

25. Gnats (Culex)

26. The Crane-Fly (Tipula oleracea and allied species) .

I $25-129$

27. The Hessian.Fly (Cecidomyia destmuctor)

I 29-I 32

28. (Practical.) The Structure of the Blow-Fly (Calliphora erythrocephala or C. vomitoria)

29. The Bot-Fly of the Horse (Gastrophilus equi)

30. The Warble-Fly (IIypoderma bovis) .

I 33 - 136

I 36- I 44

I 44 - I 49

I $49 \cdot$ I $^{2}$

\section{$E$. Aphids and Scale-Insects (Hemiptera)}

3I. (a) The Turnip Aphis (Rhopalosiphum dianthi)

(b) The Woolly Aphis (Schizoneura lanigera)

(c) The Phylloxera of the Vine (Phylloxera vastatrix)

32. The Mussel-Scale of the Apple-Tree (Mytilaspis pomorum) I62-I65

\section{$F$. COMmon Insects OF OTHER ORDERS}

33. Caddis-Worns and Caddis-Flies (Trichoptera)

I $66-168$

34. May-Flies (Ephemerida)

35. Dragon-Flies (Odonata)

36. Three Common Orthopterous Insects

I68-I7 I

I 7 I -175

I $75-181$

\section{PART III}

DESCRIPTIVE ACCOUNT OF THE LARGER ORDERS OF INSECTS, WITH SHORT NOTICES OF REMARKABLE FORMS

Short Characters of the Orders of Insects . . . I85-I88

Orthoptera

Rhynchota (Hemiptera)

Neuroptera.

Lepidoptera .

Diptera

Coleoptera

Hymenoptera

The Chief Kinds of Insect Larvæ and Pupæ

I 88 - 190

I90-194

I94-196

196-204

204-212

$212-222$

222-231

23 I-234

\section{PART IV}

THE DESTRUCTION OR MITIGATION OF INSECT-PESTS

The Gipsy-Moth in Massachusetts

The Fluted Scale in California .

Remedies for Injurious Insects .

The Value of Expert Knowledge 


\section{PRELIMINARY LESSONS}





\section{INJURIOUS AND USEFUL INSECTS}

\section{WHAT IS AN INSECT?}

INSECTS belong to the great primary division of animals called Arthropods. The word means animals with jointed legs, such as those of the crab or beetle. The Arthropods are the most numerous of all the primary divisions of animals, and indeed, the insects by themselves, though only a part of the Arthropods, include a majority of the animals which have been described and named.

Not only the legs, but the body is jointed in Arthropods. These animals are covered with armour for their own protection, but as they are creatures of active habits, the armour must not be rigid throughout. The armour of a mediaval knight was fashioned in many separate pieces for the sake of flexibility; the Arthropod is covered by a perfectly continuous armour, all formed at one time, flexibility being secured by the thinning away of this armour at frequent intervals. Certain Arthropods, such as spiders, shrimps and bees, are amongst the most agile of animals.

The armour of Arthropods is largely composed of a substance which resembles horn in texture, though it differs widely from horn in chemical composition. This substance is called chitin. One of its peculiarities is its great chemical stability. Alkalis and acids (except concentrated mineral acids) neither decompose nor dissolve it. It is a point of practical convenience to know that the chitinous parts of any Arthropod can be isolated by strong alkalis, which dissolve the muscles, nerves, and all the soft parts, but leave the chitin unaffected. By this means the chitinous parts of small insects can be readily prepared for microscopic examination.

The chitinous integument is formed by living cells. A regular layer of such cells, called the epidermis, covers the whole body of the Arthropod. This epidermis forms chitin, 
usually in many thin layers, which cohere to form a cuticle of whatever thickness may be requisite. Beneath the cuticle the cells of the epidermis often remain dormant for a long time, though they are always ready to resume their activity, and produce fresh chitin, when the occasion arises. In this way a new cuticle is formed from time to time to allow for the growth of the body. If enlargement of the surface is called for, the new cuticle is thrown into many folds or wrinkles, which become effaced when the old skin is cast. When all is ready the old cuticle cracks, the animal withdraws its limbs from their sheaths, and creeps out, often in a very soft and flabby condition, but sometimes

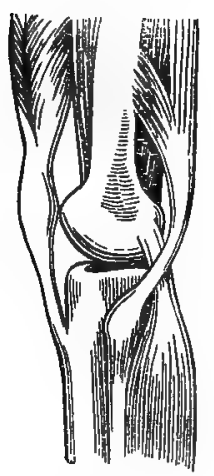

$A$

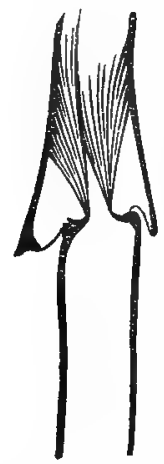

B

Fig. r. - Vertebrate and Arthropod joints. A, Vertebrate joint, the skeleton clothed with muscles. B, Arthropod joint, the skeleton enclosing the muscles. ready for active exertion the moment it becomes free.

The chitinous cuticle not only serves for protection but also for the attachment of the muscles of the trunk and limbs; it is, therefore, not only armour but skeleton as well. In vertebrate animals the skeleton is internal, and the muscles clothe the bones; but in an Arthropod the skeleton is hollow and external, and the muscles spring from its inner surface.

The arrangement of the chief organs of the body differs in Arthropods and Vertebrates. In Vertebrates the brain and spinal cord lie along the back; that is, they are dorsal in position. The digestive tube runs through the middle of the body, and the heart is ventral, lying on that side which is turned towards the ground. But in an insect or any other Arthropod, the heart is dorsal, and the nerve-cord ventral; in fact, the vertebrate arrangement is precisely reversed. One part of the nervous system, however, called the brain, is dorsal in an Arthropod, lying above the gullet. A pair of nervous threads, lying one on either side of the gullet, connect the brain with the central nerve-cord. In 
other words, the nervous chain forms an œsophageal ring, which is threaded through by the gullet.

The Arthropods are divided into four classes, which may be distinguished as follows :-

I. Crustacea. (Examples:-lobster, wood-louse, barnacle.) Nearly always live in water and breathe by gills. There are two pairs of feelers.

2. Arachnida. (Examples:- spider, scorpion, mite.) Nearly always air-breathers. The body is divided into two regions, on the foremost of which all the legs (not fewer than four pairs) are carried. There are no feelers.

3. Myriopoda. (Examples:- centipedes, millipedes.) Air-breathers, with tracheal tubes. There are many segments behind the head, and these are not grouped into regions. Each segment bears one or two pairs of legs. There is one pair of feelers.

4. Insecta. Air-breathers, with tracheal tubes. The segments are grouped into three regions, head, thorax, and abdomen. The thorax bears three pairs of legs. There is one pair of feelers. The Insecta include the only winged Arthropods, but some insects never acquire wings at all.

We must shortly explain what is meant by tracheal tubes in the foregoing table. In some Arachnida, in Myriopoda, and in Insecta, the air taken into the body for respiration is distributed by a series of branched air-tubes, called tracheæ, from their supposed resemblance to the trachea or wind-pipe of a lungbreathing vertebrate. These air-tubes are stiffened internally by a spiral chitinous thread, which, though perfectly flexible, prevents the tube from collapsing. India-rubber gas-pipes are often lined with a spiral wire to prevent collapse when the tube is accidentally trodden on, or bent at a sharp angle, and such a spiral wire is not unlike the thread of an insect's trachea.

Our answer to the question "What is an Insect?" may be given in these terms. An Insect is an Arthropod which breathes air by tracheal tubes, has one pair of feelers, a body divided into three distinct regions, head, thorax, and abdomen, and a pair of jointed legs on each of the three segments of the thorax, ${ }^{*}$ but on no others.

* Exceptions occur in insect-larvæ. 


\section{2. (PRACTICAL.) THE EXTERNAL PARTS OF AN INSECT (Cockroach)}

Wanted: fresh cockroaches. They can be instantly killed by heat. Place the number required in a beaker, and dip the outside of the beaker in boiling water, or put one or two into a test-tube, and warm over a spirit-lamp.

Distinguish the head, which bears the feelers and jaws; the thorax, which bears the legs and wings; and the abdomen, which does not bear any appendages for mastication or locomotion.

The body is made up of the following segments:-An uncertain number, at least six, compose the head; the thorax consists of three segments, and the abdomen of at least ten. A segment usually consists of a dorsal plate (tergum) and a

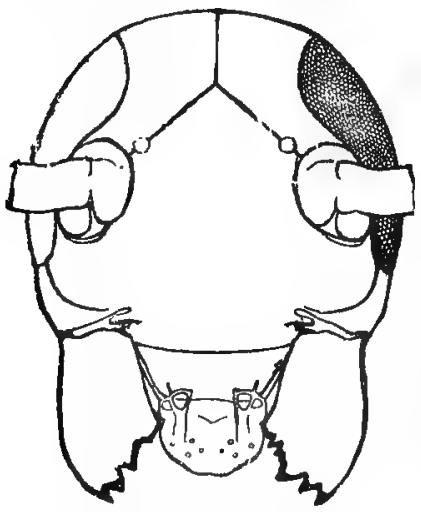

Fig. 2 .

Front of head of cockroach. $\times$ ro. ventral plate (sternum), to which side-pieces (pleura) may be added in some cases. In typical segments a pair of appendages is attached between the pleura and the sternum.

Observe the attachment of the head. It is carried on a rather long and slender neck, and can be protruded or retracted, while the lower or mouth-end can be inclined either forwards or backwards. When the insect is at rest, the head hangs nearly vertical, but sloping a little backwards. Observe the long many-jointed antennæ or feelers, the compound eyes on the sides of the head, and the jaws. A pair of white spots, which are perhaps undeveloped simple eyes, will be seen to the inner side of the base of the feelers. In front of the jaws hangs down a short flap, the labrum. On each side of the labrum is a pair of stout toothed jaws, the mandibles, which work from side to side. Separate one of these with a pin to see how it works. Examine the labrum and mandibles with a lens. 
Cut off the bead with a pair of scissors. Holding it between the finger and thumb, pass the blade of a scalpel behind the labrum and the mandibles. The blade will lie in the mouth from side to side, the labrum and mandibles being in front of it, and the other mouth-parts behind. Press the blade until it cuts through the head, dividing it into a fore and hind half. Cut off another head. Turn up the hind surface, and pass the-scalpel beneath a small flap, the labium, which hangs

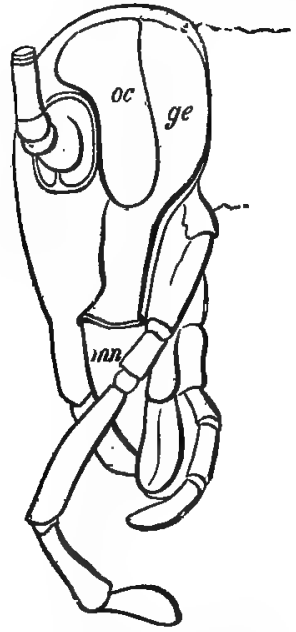

Fig. 3.-Side of head of cockroach. oc, eye ; ge, gena; $m n$, mandible. $x$ ro.

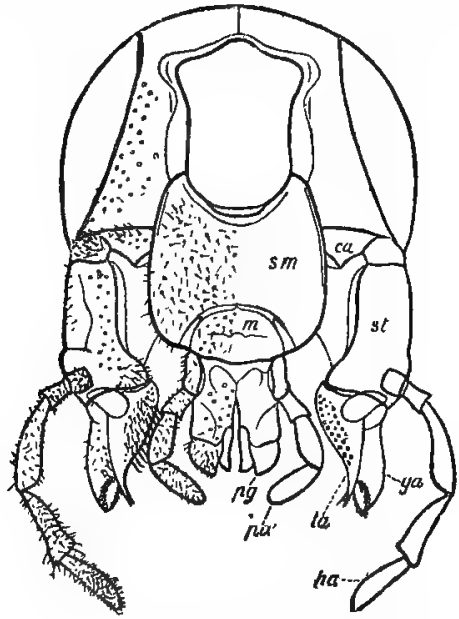

Fig. 4.-Back of head of cockroach. $c a$, cardo ; st, stipes ; ga, galea ; la, lacinia ; $p a$, palp; $s m$, submentum ; $m$, mentum ; thg, paraglossa. $\times$ ro.

down behind the mouth. Grasping this between the scalpel and the thumb, strip it off in an upward direction. From the second head take off the two maxillæ, which, now that the labium is gone, are exposed on the hinder surface. Place the bisected head, the labium and the two maxillæ in a small bottle containing a solution of caustic potash, say five per cent. Leave this to a future day, when the parts can be mounted and examined.

The thorax consists of three segments. The fore thoracic segment, or prothorax, has the tergum prolonged forwards 
above the neck; the mid thoracic segment, or mesothorax, carries the wing-covers, which in the male cockroach reach

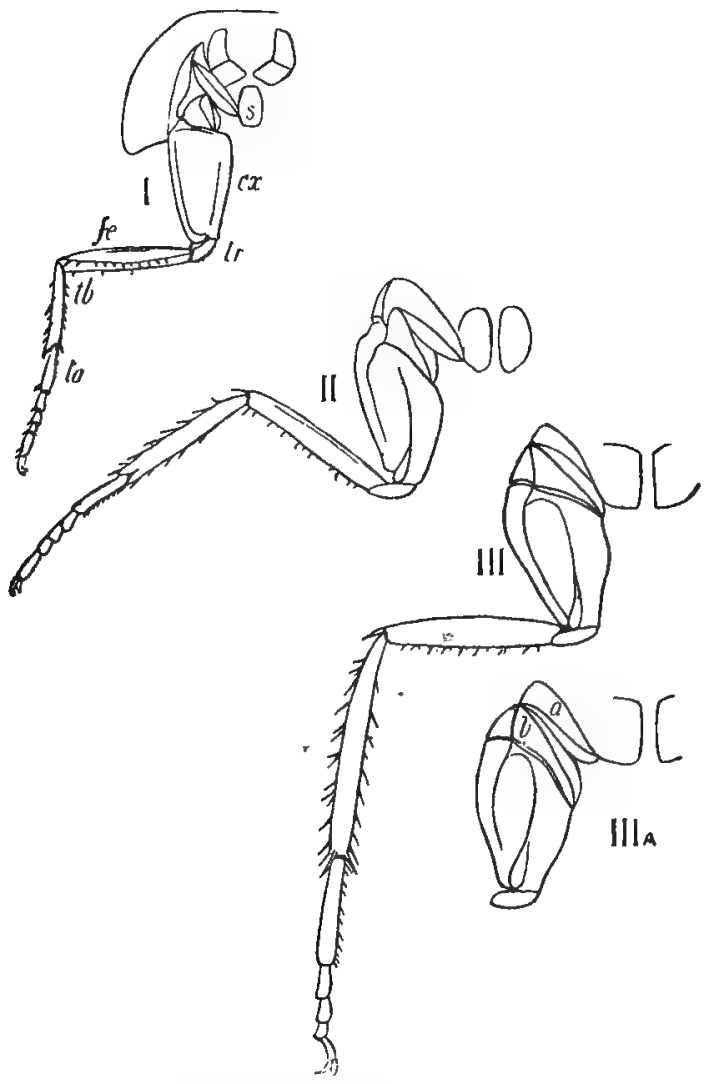

Fig. 5. -The three thoracic legs of a fentale cockroach. I. s, sternum; $c x$, coxa ; $t r$, trochanter; $f e$, femur; $t b$, tibia; $t a$, tarsus. In IIIA the coxa is abducted, and the joints $a$ (episternum) and $b$ slightly separated.

to the fifth abdominal segment; they are vestigial in the female. The hind thoracic segment, or metathorax, bears a 


\section{EXTERNAL PARTS OF A COCKROACH}

pair of well-developed wings in the male. When not in use, they are folded up fanwise, beneath the wing-covers. The female has no wings, but a reticulated pattern on the outer margin of the metathoracic tergum represents a pair of wings which have disappeared. The wing-covers of the male, though stiff in the cockroach, represent a pair of true wings, which are membranous and useful for flight in many insects. The thoracic sterna are much encroached upon by the bases of the legs, and cannot well be seen without a lens. Three pairs of legs are carried on the thorax, one pair to each segment. They regularly increase in size from the first to the third, but hardly differ otherwise. Each is divided into the five parts usual in insects. The coxa (haunch) or basal joint is broad and flattened. The trochanter is a small piece connecting the coxa with the femur (thigh), the elongate third joint of the leg.

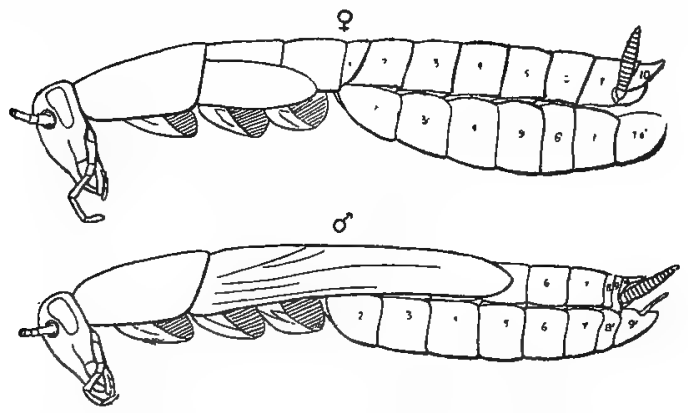

Fig. 6.-Profile of male and female cockroach.

The tibia (shin) succeeds the femur, and is of about the same length. Then comes a five-jointed tarsus (foot), which ends in a pair of claws.

The abdominal segments consist of dorsal plates (terga) and ventral plates (sterna). The first abdominal segment has only a vestige of a sternum. The hindmost plates are somewhat irregular, and the arrangement is different in the two sexes. A pair of jointed cerci project from the end of the abdomen in both sexes, and in the male a pair of slender styles can be seen between the cerci. In the abdomen of the female eight terga $(\mathrm{I}-7$, and 10$)$ are externally visible. Two more $(8,9)$ are 
readily displayed by drawing out the extremity of the abdomen with a pair of forceps; these are ordinarily concealed beneath the seventh tergum. The hind margin of the tenth tergum is deeply notched. Seven abdominal sterna (I-7) are externally visible. The first is only vestigial, being reduced to a small transverse plate; the second is of irregular outline, soft and flexible in front; the seventh is large, and its hinder-part, which is boat-shaped, is divided into lateral halves, and can be widely dilated for the reception of the large egg-capsule. In the male cockroach ten abdominal terga are visible without

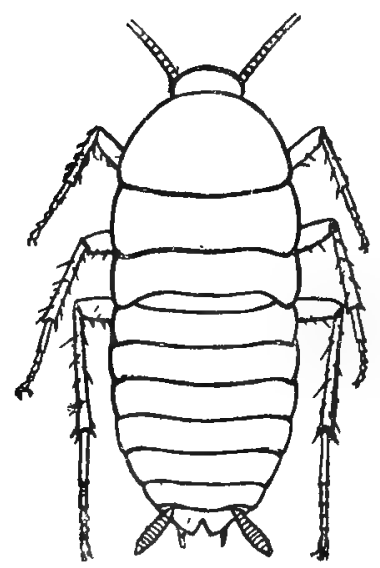

Fir. 7.-Young larva of cock. roach (nuale). $\times 6$.

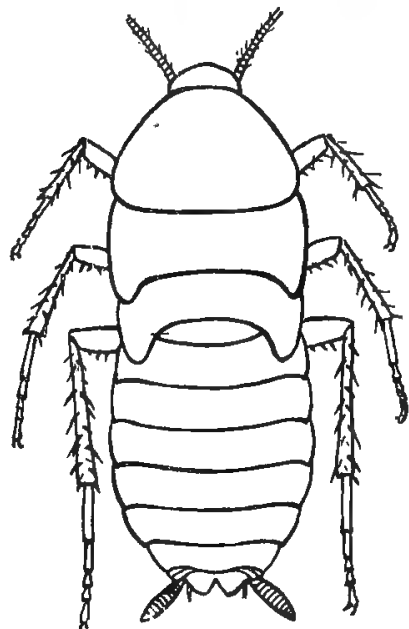

Fig. 3.-Older larva of cockroach (male) with rudiments of wings. $\times 2 \frac{1}{2}$.

dissection, though the eighth and ninth are almost hidden by the seventh. The tenth tergum is hardly notched. Nine abdominal sterna can be readily made out, the first being rudimentary, as in the female. The ninth sternum carries a pair of small styles, which project beyond the end of the body.

Look for the spiracles, or apertures by which air is taken into the tracher. In the abdomen the spiracles lie in the flexible membrane which connects one segment with the next, 
and also the terga with the sterna. The orifice of each spiracle is directed backwards. 'A large spiracle will be found between

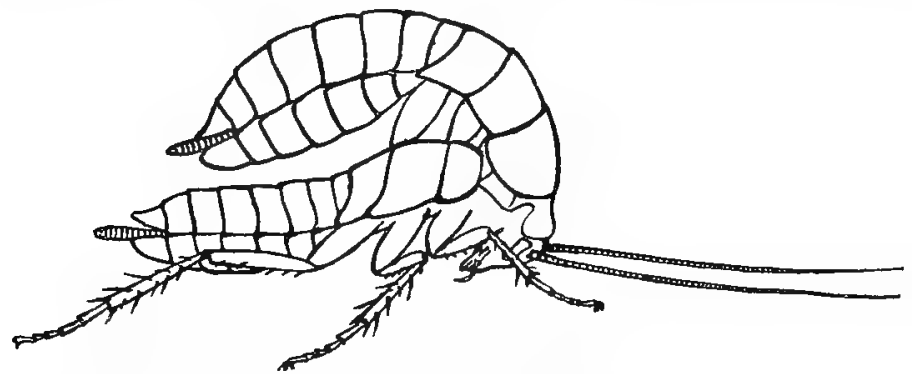

Fig. 9.-Cockroach (in last larval stage) escaping from old skin. $\times 21$.

the fore and mid legs, and a smaller one between the mid and hind legs. It will be desirable to examine the spiracles with a lens, though they can be seen by the naked eye.

Male and female cockroaches differ most conspicuously in the degree of development of the wingcovers and wings, which are very imperfect in the female. The abdomen is broader in the female than in the male, and the feelers shorter. The hinder abdominal segments differ in the two sexes. The seventh sternum is divided in the female, but not in the male. The abdomen apparently ends with the seventh sternum in the female, but with the ninth sternum in the male. The ninth sternum bears a pair of styles in the male, which are wanting in the female. The male is slighter and weaker, feeds less greedily, and stands higher than the female, whose abdomen trails

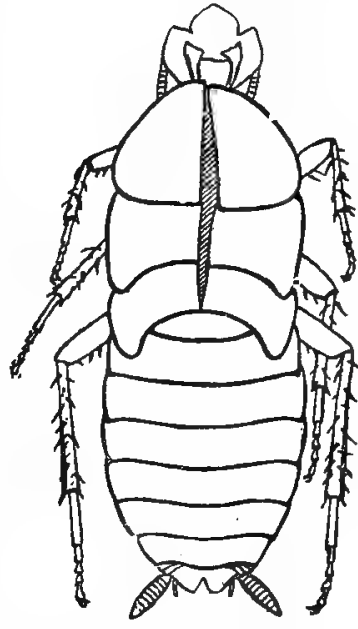

Fig. ro.-Cast skin of older larva ("pupa") of cockroach. $\times 2 \frac{2}{3}$. on the ground. Immature cockroaches have neither wingcovers nor wings in either sex. There is no resting-stage 
in Orthoptera (to which the cockroach belongs), corresponding to the pupa or chrysalis of most other orders, but the insect runs about and seeks its food throughout life. Between the last moult and the last but one, slight external indications appear of the growing wings and wing-covers. The angles of the mid and hind thoracic terga project backwards, especially in the male, and on dissection the crumpled-up wings and wing-covers are seen within the outer cuticle.

\section{3. (PRACTICAL.) THE MOUTH-PARTS OF AN ORTHOPTEROUS INSECT (Cockroach)}

The parts of the head previously removed (see p. 7) may be prepared for mounting, or else the same parts may be removed from a fresh head. If it is necessary to remove the soft parts without loss of time, proceed as recommended in the following paragraph; but if the parts have been already cleared by potash, soak in clean water, and go on from that point.

Place the bisected head, the labium, and the two maxilla (see
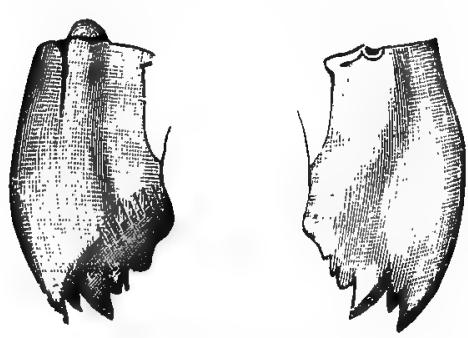

Fig. 1r.-Back (to left) and front (to right) views of the mandible of the cockroach. $\times 20$. p. 7) in a porcelain saucer containing a solution of caustic potash (say five per cent.). Heat this over a Bunsen flame, using a saucer of sand to prevent excessive heating in one place. Allow the solution to boil for ten minutes. A large number of parts may be boiled in one saucer, if several students are working together. Take care not to bring the face near the boiling liquid, which is corrosive, and rather apt to spurt when strongly heated. When the boiling has been continued for ten minutes withdraw the flame. Lift out the parts, now reduced by the action of the alkaline fluid to chitinous skeletons, and place them in a saucer of clean water. All the muscles and other soft parts will have disappeared, and the chitinous pieces will have become more 
transparent than before. After soaking in clean water for a minute or two, transfer the pieces to a saucer of water acidulated with hydrochloric, acetic or other acid, say one per cent. Transfer again to clean water. The object of this thorough washing is to remove the alkali, which is apt to cling to the preparations. Then pass through methylated alcohol and absolute alcohol, using watchglasses or other vessels of small size, for the sake of economy. If many pieces are placed in a small quantity of absolute alcohol, the liquid should be changed once or even twice; it is necessary to remove the water as completely as possible. Then transfer to a saucer of turpentine. If any appreciable quantity of water is present, the pieces will turn milky, and must be replaced in absolute alcohol. If they look clean and bright, they are ready for mounting.

Take a clean microscopic slip, and place a small drop of balsam exactly in the centre. It is convenient to rule on a card the outline of the slip, and to draw diagonals, whose intersection marks the centre of the slip when

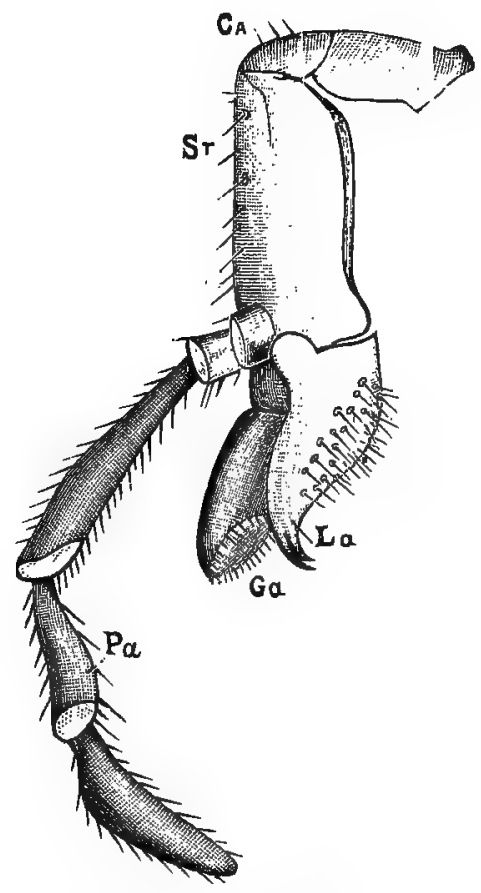

Fig 12.-Maxilla of the first pair (cockroach). Ca, cardo; $S t$, stipes; La, lacinia; $G a$, galea ; $P a$, palp. $\times 20$.

it is placed on the card exactly over the ruled outline. If any bubbles appear in the balsam, break them with a hot needle. Take out one of the preparations with a section-lifter, and arrange it neatly on a glass cover. Lower the cover upon the balsam with a needle, so that it gradually takes the horizontal 
position. The balsam should be just enough to fill neatly the space beneath the cover. If too little has been used, more may be added afterwards by touching with a glass rod dipped in

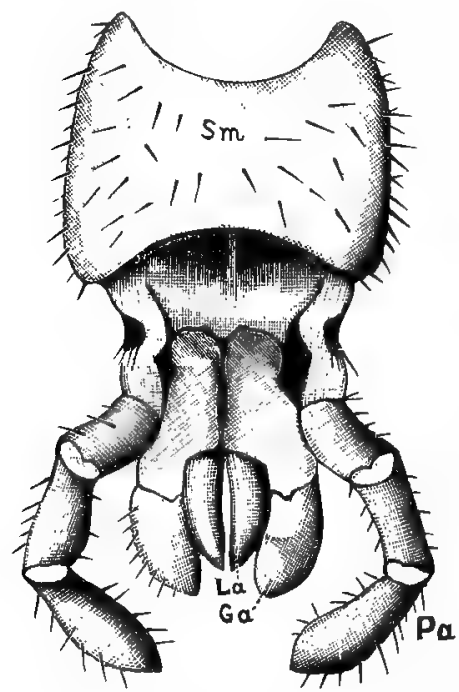

Fig. 13.-Labium of cockroach (united maxilla of the second pair). Sm, submentum; the other letters as in fig. 12. balsam one of the angles where the balsam recedes from the edge of the cover. Any small excess of balsam can be removed when perfectly dry-i.e. after some weeks or months. If there is a considerable excess, remount the piece. Do not try to force the balsam to fill a vacant space by pressure. When the preparations indicated have been mounted, examine them by a low power of the microscope, compare them with the figures, and draw them.

The mouth-parts of the cockroach, and of other insects with biting jaws, consist of a flap, the labrum, which hangs down in front of the mouth; a pair of stout mandibles, usually adapted either for cutting or crushing, or both; a pair of maxillæ; and a second pair of maxillæ, which become more or less fused together, and constitute the organ called labium. It is unfortunate that words so similar as labrum and labium should have been accepted, as there is a tendency, even among experienced entomologists, to mistake one for the other. Here is a diagram of the typical mouth-parts, such as occur in the cockroach:

Labrum

First pair of jaws (mandibles).

Second " (maxillæ).

Third " (labium, or second pair of maxillæ).

The jaws of insects and other Arthropods are modified legs, 
and differ both in their origin and in their mode of action from the jaws of Vertebrates. They work from side to side, and not up and down, nor backwards and forwards.

The mandible of the cockroach, as of other insects, is simple and unjointed; it is articulated by a condyle, and again by a small cup, to separate parts of the head. The free end is armed with strong, tooth-like processes. The maxillæ of the first pair lie behind the mandibles. In each we can make out a two-jointed basal part, a five-jointed palp, which is used in feeding and exploration, and two terminal pieces, set side by side. These last are the galea and lacinia; the galea (external piece) is soft in the cockroach; the lacinia (internal piece) is hard, curved,

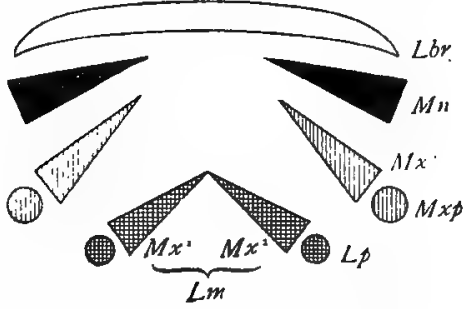

Fig. 14.-Diagram of jaws of cockroach, in horizuntal.section.

and armed with a two-pronged tooth. The maxillre of the second pair are fused to form the labium, a hanging flap, which closes-in the mouth behind. The broad shield-like base is divided into an upper and larger piece, the submentum, and a lower piece, the mentum. A pair of three-jointed palps are attached to the sides of the mentum, and parts answering to the galea and lacinia of the first pair of maxillæ will be easily recognised. It is evident that the labium consists of a pair of appendages, similar to maxillæ, but fused together in the middle line.

\section{4. (PRACTICAL.) DISSECTION OF A COCKROACH *}

Kill with heat (see Lesson 2). Cut off the wing-covers and wings (if present). Hold the insect in the hand, and with fine scissors cut round the edges of the dorsal surface. Remove the dorsal integument thus detached.

Examine the under side of the dorsal integument. The

* A fuller account of the anatomy of the cockroach will be found in Marshall and Hurst's "Practical Zoology," or Miall and Denny's "Structure and Life-History of the Cockroach." 
muscles and heart will have been removed with it, unless special pains have been taken to leave them behind. Observe the segmentally arranged muscles and the heart, which looks

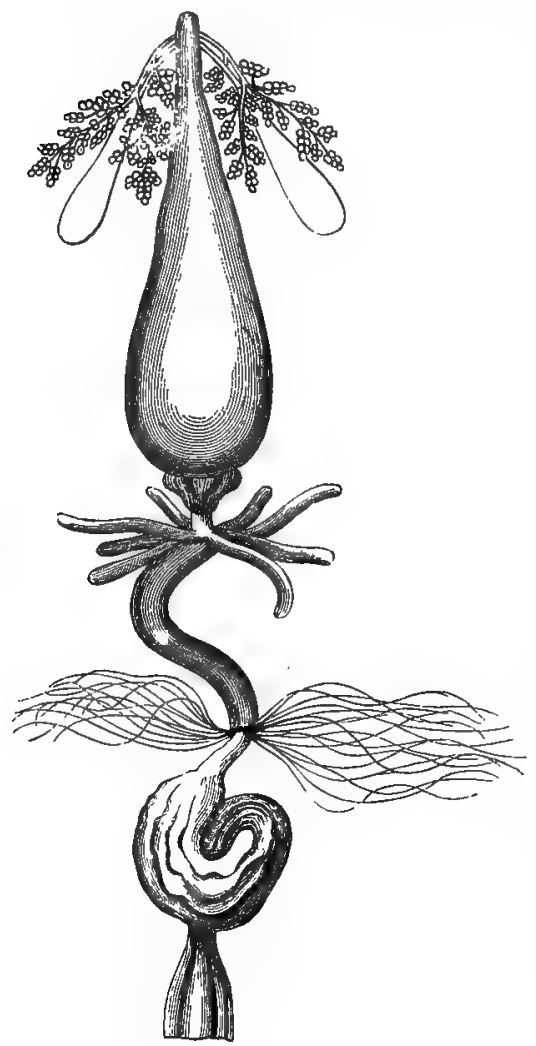

Fig. 15.-Alimentary canal of cockroach. $\times 2$.

like a transparent streak running along the middle line.

To examine the details of the heart, it is best to harden it with chromic acid or some other fixing agent, and alcohol. It must then be carefully separated from the cuticle, stained and mounted in balsam. Beginners are not advised to attempt this.

Pin the insect down in a dissecting dish, and add water until it is just covered. The pins must not stand up vertically, lest they should get in the way of the dissecting instruments, but should be inserted nearly horizontally. Free the turns of the alimentary canal, and lay it out on one side of the dissection (outside the body), but without cutting it through at any point.

Notice the component parts of the alimentary canal. These are, in order from before backwards: (I) The œsophagus or gullet, which issues from the head, and soon dilates into (2) the crop, a large pear-shaped, thin-walled sac, widest behind; (3) the gizzard or proventriculus, a firm and thick- 
walled muscular division, closely applied to the crop. I, 2, and 3 belong to the fore-gut, which is developed as an infolding of the integument of the embryo from the mouth. It is lined throughout by chitinous cuticle. (4) The stomach or mid-gut, a narrow cylindrical tube, marked at its beginning by eight blind tubes which open into it, and at its termination by a large number of fine threads, the Malpighian tubules or excretory organs. The stomach has no chitinous cuticle of its own. Beyond it comes the intestine or hind-gut, an infolding of the integument of the embryo from the anus. It is lined, like the fore-gut, with chitinous cuticle. The hind-gut is divided into the following parts :- (5) The small intestine, very short and narrow. To this the Malpighian tubules properly belong. (6) The colon, wide in front, but narrowing gradually backwards. It is thrown into a single coil. (7) The rectum, a dilated muscular chamber ending at the anus.

Clear and examine the salivary glands. These are two pairs of white branching glands, lying on either side of the crop. Between the glands of each pair lies a salivary receptacle. The ducts from the glands unite, and open into the much larger duct of the receptacles, which discharges into the mouth. Cut out one salivary gland. Stain it with carmine, mount in glycerine, and examine with the microscope. Observe the nucleated epithelium and the chitinous lining of the duct with its spiral thickening. Cut out the gizzard and lay it open on one side. Then remove the soft parts with hot caustic potash solution, and mount in balsam. Observe the six stout teeth (thickenings of the chitinous lining) and their varying shape, the folds between the teeth, the hairy patches, one below each tooth, and the hairy ridges beyond. The chitinous lining is continued beyond the gizzard into the stomach, where it forms a free inner tube which is thrown into many longitudinal folds.

The food is first of all received into the crop, where it is mixed with the salivary fluid, and undergoes maceration and partial digestion. It is passed on to the gizzard, which acts as a masticatory organ, and also as a strainer, detaining coarse particles. When the food enters the stomach, absorption of the dissolved matter takes place, and the nutritive fluids enter the blood, which bathes the exterior of the alimentary canal. 
The eight blind tubes are believed to secrete a fluid which aids in digestion. The Malpighian tubules contribute no useful product, but remove waste nitrogenous matter from the blood, and deliver it into the intestine. The intestine receives and discharges the waste products. The food undergoes a twofold digestion. (I) In the crop it is acted upon by the salivary

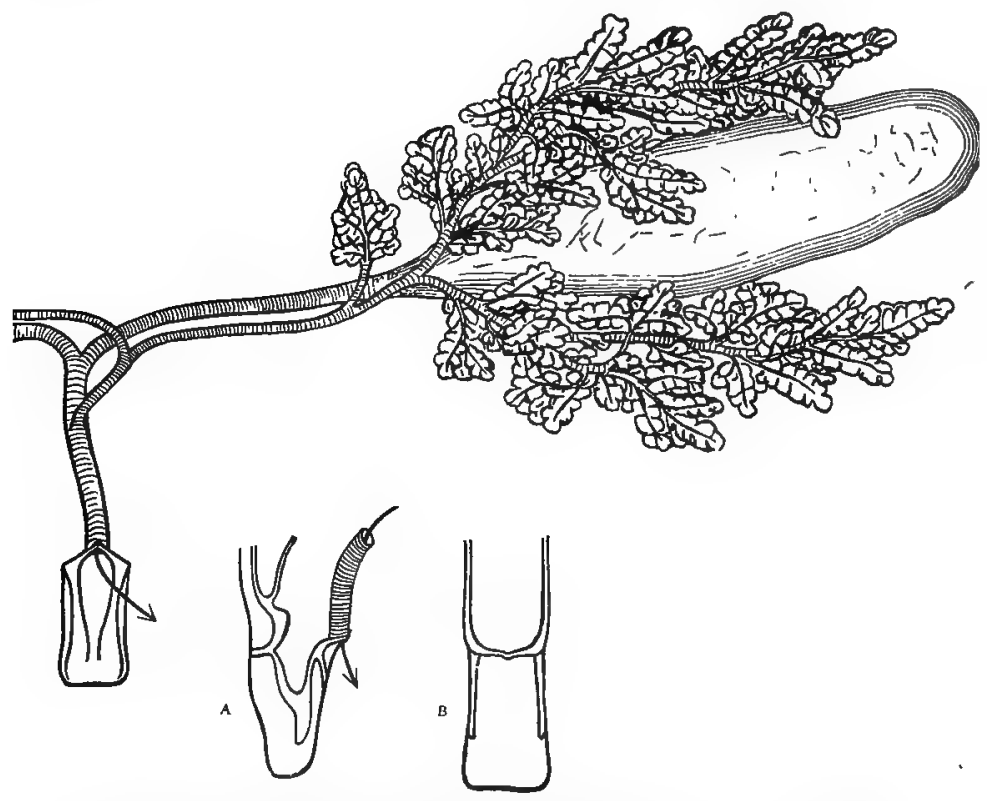

Fig. 16.-Salivary glands and receptacle of cockroach, right side. The arrow marks the opening of the common duct on the back of the lingua. A, side view of lingua; $B$, front view of lingua (a tongue-like projection from the floor of the mouth).

fluid, which changes starch into glucose, and thus renders starchy food soluble. The dissolved glucose is absorbed by the wall of the crop, and passes into the blood. (2) In the stomach fats are emulsified, so that they become capable of absorption, and flesh or foods of similar composition become dissolved by the secretion of the eight tubes. The fluid secretion of these tubes can be forced into the crop, while the 
muscular wall of the gizzard can be contracted, so as to prevent the passage of the food to the stomach until it has become fluid or semi-fluid. Then the gizzard is relaxed, and the more or less fluid food passed into the stomach to be absorbed.

The cockroach is particularly addicted to starchy food, but will devour bits of flesh, and almost everything which is eaten by man.

The alimentary canal is partly embedded in a mass of white substance, the fat-body, which is made up of a multitude of small fatparticles, attached together and overspread by fine tracheal tubes. When the alimentary canal is displaced, the fat-body is fully exposed to view. Pull out some pieces with the forceps, and place them under the microscope to observe the tracheal branches. Add ether to the preparation, and replace the loss from evaporation as required; the fat slowly dissolves. Add osmic acid (one per cent. solution); the fat turns brown, and ultimately black. These tests for small quantities of fatty substance are often resorted to by the microscopic observer.

Between the wall of the body and the alimentary canal is an irregular space (the body-cavity) partly occupied by the salivary glands, Malpighian tubules, ovaries, etc. It is of no great extent in the cockroach, but becomes large in proportion to the body in some insect-larvæ.

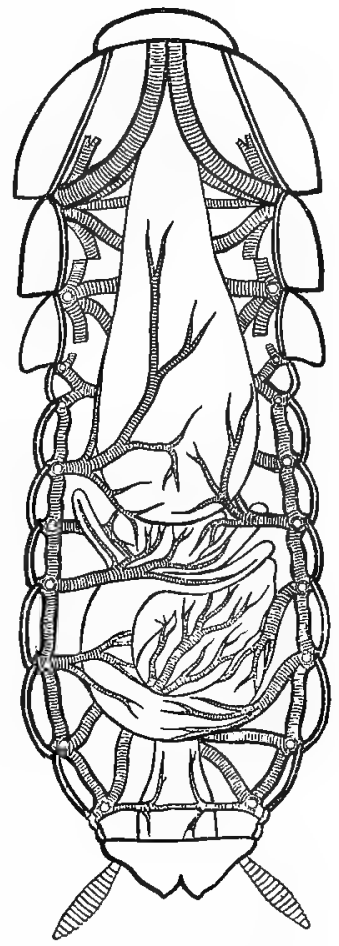

Fig. 17.-Tracheal system of cockroach. The dorsal integument removed and the viscera in place.

Through it the blood courses, after escaping from the open fore end of the heart, and returns again to the heart by lateral inlets. The circumstance that such organs as the 
salivary glands and Malpighian tubules of insects are bathed in the blood, and not injected with blood, as in higher animals, probably explains their diffuse form.

By tearing away the fat-body bit by bit the student will

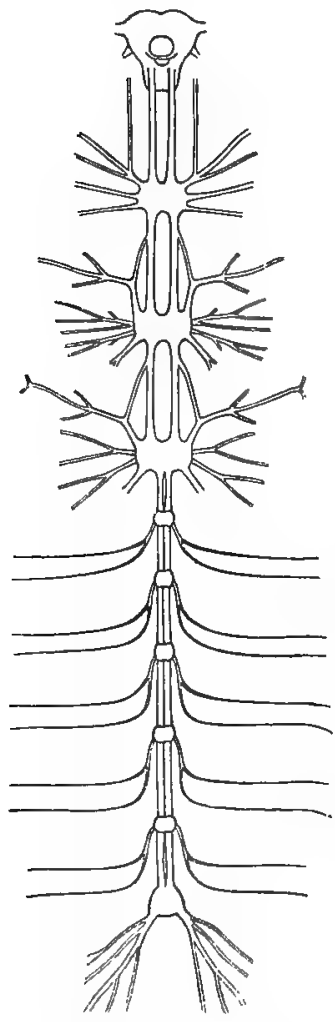

Fig. 18. - Nervous system of female cockroach. bring into view the two large tracheal tubes which run along the sides of the body. They send out branches to all the viscera, and communicating branches to one another, besides receiving short branches from the spiracles. Cut out a piece of a tracheal trunk, and examine it with the microscope. Notice the spiral thickening of the lining cuticle; the silvery or dark appearance of the tubes varies according to the direction in which the light falls upon them, and is due to contained air.

Clear the nervous system. Note the ganglia and the connectives. which unite them.

Follow the nerve cord into the head. The dissection is too difficult for an unpractised hand. The head must be fixed to a block of paraffin with one side uppermost. See that the head is dry externally; then melt the paraffin in one place with a piece of hot metal, and lightly press the head against it. Dissect away the side of the head. In front will be seen the brain, which gives off two very short connectives to the sub-osophageal ganglion. A chitinous plate, the tentorium, is interposed, through which the connectives pass. The osophagus lies upon the tentorium, and passes between the connectives.

In a female cockroach the ovaries, which lie in the hinder part of the abdomen, may be cleared and examined. Each 


\section{DISSECTION OF A COCKROACH}

ovary consists of eight whitish tubes, which appear beaded, in consequence of their distension by a row of eggs. The eggs at the lower end of each ovarian tube are large and almost mature; the next above are smaller and less advanced, and so on. The ovarian tubes lead backwards to a common outlet, which is concealed by the split seventh sternum. 



\section{II}

LESSONS ON COMMON INSECTS, CHIEFLY SUCH AS ARE EITHER INJURIOUS OR USEFUL TO MAN 



\section{A. BEETLES (COLEOPTERA)}

\section{THE COCKCHAFER (Melolontha vulgaris)}

There is no British beetle which is at once common, large enough for examination by the naked eye, and readily obtained in all stages. Full-grown beetles of many species are easily procured, but the larvæ are usually buried in the ground, or in the wood of trees, so that they rarely meet the eye, and the pupæ are even more carefully concealed. We shall select the common cockchafer as a type for description. The beetle is plentiful and of good size (about an inch long); the larva can be procured in most parts of the country by digging, and the pupa, though not often seen, is sometimes to be got in quantity.

Fresh beetles are to be preferred for examination. If they require to be killed, it is well to know that there are ways of killing insects which are as near as possible painless. A few drops of chloroform or ether may be put, together with the insect, into a wide-mouthed bottle. Entomologists who regularly collect insects carry with them a killing bottle; that is, a widemouthed bottle, into which a few crushed laurel leaves have been placed shortly before. Some prefer cyanide of potassium to laurel leaves. The cyanide is mixed with plaster of Paris and water, placed in the bottom of the bottle, and allowed to set. A still better plan is to put into the bottle a few crystals of cyanide wrapped in tissue paper, and also some loose shreds of blotting-paper, which prevent the insects from knocking about. The cyanide gives off a deadly vapour as long as any remains. Insects are quickly killed by a moderate degree of heat, and it is often convenient simply to place the insect in a test-tube, and warm the outside of the tube by a flame (see p. 6).

If the beetle should be dry and rigid, it will require to be relaxed. Any dried insect can be relaxed by placing it for a 
few hours in a tin box lined with strips of wet blotting-paper, when the various joints and membranes become almost as flexible as in a fresh insect.

Place a cockchafer before you with the back upwards, and note the parts which are visible in this position. These are the head, the prothorax, the elytra or wing-covers, the scutellum, a small, black, triangular plate, appearing between the wing-covers in front, and, lastly, the two hindmost abdominal segments, which are the only ones not hidden by the wing-covers. Note that the last of these is curved downwards, and tapers towards its extremity. It is characteristic

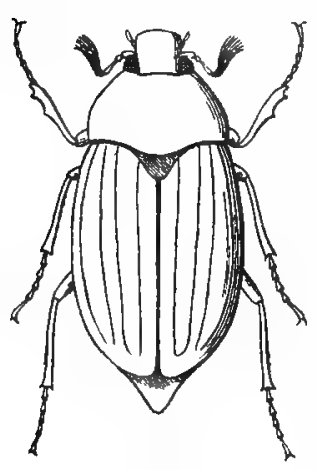

Fig. 19. of beetles that the wing-covers, if well developed, meet along a straight line (the suture), which runs down the middle of the back. The prothorax in beetles is, as here, large and tolerably mobile. Now carefully extend the wing-covers. There will be seen beneath them a pair of gauzy wings, folded up into a small space. By gently pulling out the wing with a pair of fine forceps, it can be expanded as in flight, and we shall then observe how it is folded up when at rest. It is folded fan-wise, and also transversely. In some beetles the wings Male cockchafer. $\times \frac{3}{2}$. are crumpled up in so elaborate a fashion that it takes them a minute or two either to expand them, or to pack them neatly within the wing-covers. When both the wing-covers and the wings are fully extended, all three rings of the thorax will become distinctly visible. The first ring or prothorax we have already seen. Behind this comes the mesothorax, which is by comparison short. As in most beetles, the only exposed part of the dorsal surface of the mesothorax is a triangular or rounded plate, the scutellum, which is accurately fitted in between the bases of the wing-covers; the fore part of the mesothorax is hidden by the prothorax. The third ring, or metathorax, is a good deal larger than the mesothorax. It carries the membranous wings which are employed in flying. When the wings are extended, the terga, or dorsal plates, 


\section{THE COCKCHAFER}

of the abdomen can be examined; they are eight in number.

The feelers are plainly visible upon the head; each is tenjointed. "The terminal joints are prolonged on one side so as to form leaflets, which are capable of being separated or closed. The "club" of the male cockchafer contains seven such leaflets, while that of the female has only six.

Turn the cockchafer over, and examine the under-side. We now see the jaws, which will be more particularly described later on. The under-side of the prothorax exhibits a narrow prosternum, flanked by two sockets for the fore-legs. Pull out

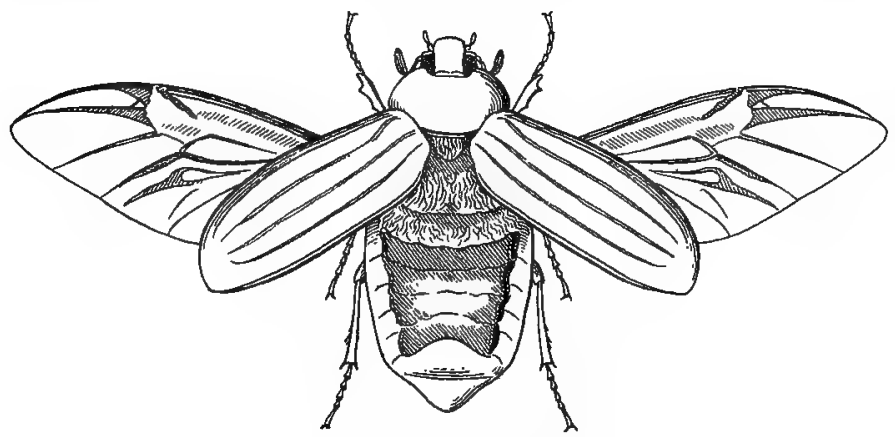

Fig, 20.

Female cockcbafer with expanded wings. $\times \frac{3}{2}$.

one fore-leg, and remark that the socket is "closed"-i.e. surrounded by the prothorax on all sides. The mesosternum is short, wide from side to side, and undivided; the sockets for the intermediate legs lie between it and the metasternum. This last is a much larger plate, marked by a median groove, which indicates that it represents paired elements; the sockets of the hind limb hardly indent it, but occupy slits lying between it and the first abdominal sternum. Six abdominal sterna are easily counted; the first is very slender, and hidden by the hind leg, so that it may easily be overlooked. The terga do not come opposite the sterna, but alternate with them, and while there are eight terga externally visible, there are only seven sterna, of which the first is insignificant in size. This inequality is partly due to the squeezing-in of the bases of 
the hind legs, and partly to the withdrawal of the terminal segments into the interior of the body, the ventral plates being more reduced than the dorsal. The terga and sterna are connected by a narrow strip of flexible membrane. In the membrane just mentioned, or in the upper part of the sterna, lie the abdominal spiracles, of which there are seven pairs. Much larger spiracles can be discovered in the thorax, one (which properly belongs to the mesothorax) lying between the prothorax and mesothorax, and a second (the metathoracic spiracle) between the mesothorax and metathorax.

The colouring of the cockchafer is largely due to a down which can be rubbed off. When the down is removed, the pale colours are lost, and the body assumes a nearly uniform black, with rusty red here and there.

The jaws, like those of beetles in general, are adapted to biting. The mandibles are short, stout, and furnished at the tip with four points, and with a grinding surface lower down. The maxillæe end in a number of prongs, of which four belong to the outer lobe (galea) and one to the inner (lacinia); there is a four-jointed maxillary palp. The labium is reduced to a basal piece, which carries the three-jointed palp, and a small transverse terminal piece. The mouth-parts should be separated and mounted according to the directions given on pp. 7, I2.

The wings and legs should now be examined more particularly. In the elytra or fore-wings note the articulation with the side-piece of the mesothorax. The exposed surface is downy, and marked by four raised lines as well as by a number of punctures. In the membranous hind-wings we remark the fewness and strength of the veins, and also the provision for folding. The legs are strong, and consist of the usual divisions - viz. (1) coxa (haunch), (2) trochanter, a small joint at the end of the coxa, (3) femur (thigh), (4) tibia (shin), armed with spines, which are particularly strong in the fore-leg, and used by the female in digging, (5) tarsus (foot), of five joints in each leg; the last joint bears two strong, curved claws.

Though the cockchafer is a common insect in the southern and midland counties of England, it is only inquiring persons who are likely to make the acquaintance of the larva and pupa, which are altogether subterranean. The larva feeds upon the 
roots of a great variety of plants. In England it occasionally attracts attention by the injury which it does to grass-land. Patches of grass turn brown and die. On digging, large, dirtywhite, sluggish larvæ are discovered, which are those of the cockchafer. The pupa lies deeper in the ground, and is only to be procured during a few weeks at the end of autumn. Having procured a supply of larvæ, we remark the soft texture, the whitish colour, and the large size. It is usual in insects that the maximum size is attained at the end of the larval or feeding-stage. Some shrinkage takes place during pupation, and the imago is still smaller than the pupa. The larva of the cockchafer is not far from being twice as long as the winged beetle. The head is horny, and bears strong, dark-coloured jaws; there are three pairs of legs. The abdomen is enlarged, especially behind, and curved into a semicircle. Spiracles, bordered with dull red, are conspicuous on every segment except the second, third, and last. They are often wanting on these particular segments of an insect-larva. Perhaps their formation is interfered with by the development of wings in the hinder thoracic segments, and of the reproductive apparatus at the end of the abdomen. In

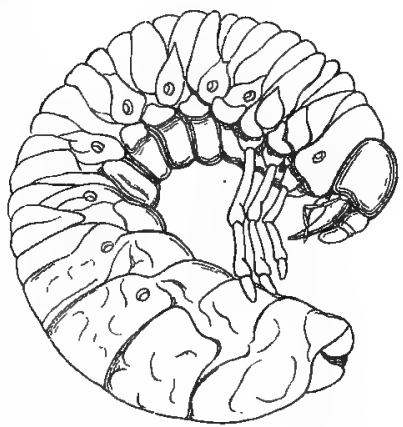

Fig. 2 .

Larva of cockchafer. $\times \frac{3}{2}$. the imago, however, the wing-bearing segments are furnished with large spiracles, while the prothorax, which never bears wings, is always devoid of spiracles, a fact which shakes our confidence in the supposed explanation. The thoracic segments of the larva bear each a pair of rather long legs, in which we can recognise the coxa, trochanter, femur, tibia, and one-jointed tarsus, the last being armed with a single claw. The dorsal plate of the prothorax is subdivided into two, those of the mesothorax, metathorax, and first six abdominal segments into three. The next two segments are undivided, while the last of all, which is enormous in comparison with any of the rest, appears to be double. On examining the head of the larva more closely, we see that there 
are no eyes; the feelers are four-jointed and about as long as the head, the mandibles stout and pointed, the maxillæ strong and bristly, with three-jointed palps; the labium consists of two transversely elongate pieces bearing short two-jointed labial palps. In spite of its awkward shape and sluggish habits, the larva can make its way through soft earth with tolerable ease. It can rise to the surface in search of food, or descend to avoid frost. When laid on a hard surface, it rests on its side.

The pupa is to be found in cavities deep in the ground. It has the attitude and general structure of a Lepidopterous pupa,

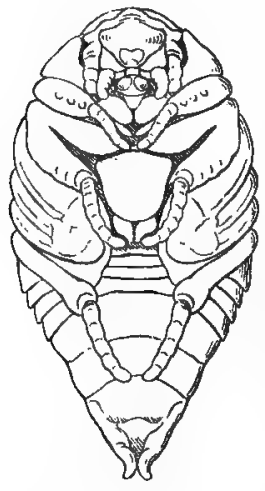

Fig. zz. but the appendages, though shrouded in a pupa-skin, are free, and not glued down. It is of a pale brown colour. The pupal stage lasts only a few weeks, and then the full-formed beetle casts its wrappings, not emerging from the ground, however, till the following spring.

The general course of the life-history is as follows:-The female beetle lays several batches of whitish eggs, some fifteen or more in a batch, a few inches beneath the surface of the ground. These hatch out in about three weeks, and the larvæ begin at once to feed upon the roots of grasses, trees, or fieldcrops. During the first warm season Fig. 22.
Pupa of cockchafer. $\times \frac{3}{2}$. their ravages are hardly noticed. At deep into the earth, and become torpid. Next spring they resume their activity, and feed voraciously. The second winter, like the first, is passed in a torpid state. Again the larva come up to feed, but after the third summer they are ready to pupate. In the following spring the beetles come forth. (In northern countries the life-history may extend over five years.) During the day, the full-grown cockchafer commonly hides under the leaves of trees, and flies abroad only at dusk. Like the dor-beetle, it flies heavily, though with tolerable speed, and does not avoid obstacles. It feeds upon foliage, stripping the trees, and especially the elm and the oak, of their leaves. It lives only three weeks or less after emergence, but the beetles appear in succession for about 
two months. The male quickly perishes, but the female enters the ground to lay her eggs. She prefers grass land, or well-manured, open soil.

Considering their numbers and their voracity, especially in the larval period, it is not surprising that in particular seasons the ravages of the cockchafers should be disastrous. A cold stormy spring sometimes acts as a powerful check. Genial weather in April or May may favour the production, after the usual interval, of great flights of migrating cockchafers. These, though not unknown, are rarely seen in the British Isles. The destruction that they cause is comparable only to that of the locust. As to remedies, the French farmers, whose experience is much more severe than ours, are almost in despair. Hand-picking after ploughing is a practicable, though costly, way of destroying vast numbers. Great poultry-cages, which can be transported from place to place on wheels, have been employed after ploughing with some success. Folding sheep on infested grass land, and feeding them on turnips, is effectual if persisted with long enough. When the cockchafers are resting on the trees, vigorous shaking of the boughs brings them down in great numbers, so that it is possible to collect them in sheets, and sweep them into sacks. None of these remedies, as at present practised, can do more than mitigate the evil, and the French farmer cries out for measures of thorough extermination, which have never been attempted on account of the crushing expense of any adequate remedy. Moles and the larger insectivorous birds, especially the rook, destroy the larvæ in great numbers, and there can be no doubt that the slaughter of such animals as these is a sure way of promoting the ravages of cockchafers and other insect-pests.

British insects of habits and appearance somewhat similar to those of the cockchafer are (I) the Midsummer cockchafer (Rhizotrogus solstitialis), which is only plentiful in the southern counties of England, and makes its appearance with great regularity at the end of June. The beetle is little more than half as long as the cockchafer, and the club of the feeler has only three leaves. (2) The garden chafer (Phyllopertha horticola) is more widely known as a pest in pastures and gardens. Its mode of life and method of feeding are very like those of the cockchafer. In the winged state, it devours 
the leaves and blossoms of roses and fruit-trees. The beetle is only half the length of the cockchafer. It has rusty wingcovers, and a dark green head and thorax.

\section{A CARNIVOROUS WATER-BEETIE (Dytiscus marginalis)}

The young naturalist, issuing forth with jam-pot and homemade net to capture the living creatures of the ponds and ditches, is likely to bring back insects of the Dytiscus-family, together with the minnows, caddis-worms, and water-snails with which he hopes to start his first aquarium. $\mathrm{He}$ will perhaps notice that the water-beetles of this family are excellent swimmers; that they are of a flattened shape, which enables them to glide without unnecessary resistance through the water, and to penetrate narrow recesses; that their outline is oval, head, thorax, and wing-covers being rounded off to an unbroken curve; that their colours are brown and black; and that they are of various sizes, from which he will probably draw the mistaken conclusion that the small ones are the young, and the big ones the full-grown beetles. A short experience of the behaviour of the beetles when tumbled into a bowl of water with fishes, snails, and miscellaneous water-insects will lead him to suspect, or to know for certain, that the Dytiscus-family is eminently carnivorous, attacking and often devouring their fellow-prisoners of all grades. A wider experience will teach our young collector that the water-beetles have wings and can use them. $\mathrm{He}$ will further come to know that an insect of any kind which has wings is always adult. Its growth has been completed in the larval and pupal stages, and the imago, or winged insect, neither grows nor changes its skin. The small beetles will never grow into big ones: their size, like their form and colour, are fixed characters of the species to which they belong.

The large species of Dytiscus, which is called Dytiscus marginalis, takes its name from the yellow stripe which runs round the whole body on its upper surface. Remark its firm and polished integument, the unbroken contour, and the angulation of the under side of the abdomen along the middle line. 
The mouth-parts of the adult are those of a predatory beetle, but the mandibles are not slender and piercing like those of a predatory land-beetle, but stout and double-toothed. The feelers are long and slender, and the compound eyes large.

The whole body is firmly knit together. The head is sunk in the thorax, the prothorax bears on its under side a backward-directed spine, which fits into a cavity in the mesothorax, and the basal joints of the hind legs are soldered to the underside of the abdomen, which therefore becomes particularly rigid.

The legs are of peculiar form. The hind legs are long, flattened, and fringed with hairs, and it is chiefly these which propel the body through the water ; they can be "feathered" like an oar, so as to diminish the resistance of the water during the return stroke. Since the basal joints are firmly attached to the abdomen, the movable part of the leg acts from the middle line of the body, and nearly from the middle of its length. I do not fully understand the advantage gained

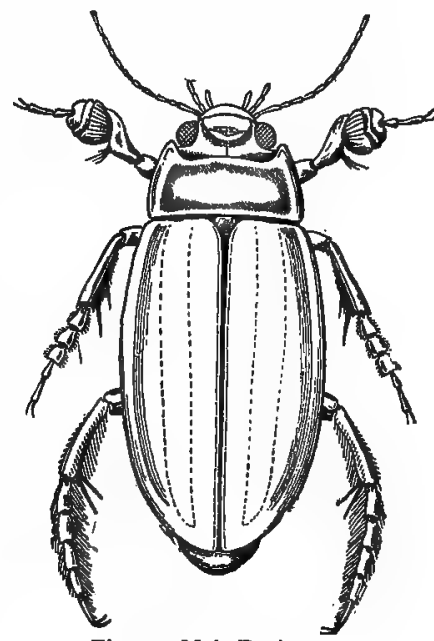

Fig 23--Male Dytiscus. thereby, but am inclined to attribute to this disposition the unusual power of changing its course, or the inclination of its body, which this insect exhibits. The usual pair of stout claws are insignificant in the hind legs, which are chiefly serviceable as paddles. The intermediate legs appear to be particularly useful in steering. For grasping the prey the beetle relies on its fore legs, which are of very peculiar form, especially in the male, where the first three joints of the tarsus are enlarged and form a circular sucker. The joints in question are studded with many cupules, or adhesive hairs, and two of the cupules on the first joint of the tarsus are enlarged to enormous dimensions. The adhesive power of 
the suckers is very great, and they will easily support the whole weight of the beetle in vacuo, which incidentally proves that they do not depend upon atmospheric pressure. It has been fully demonstrated that the cupules discharge a viscid secretion, as do the adhesive organs of a fly's foot. It is easy to see that a coagulable fluid is left behind when one of the suckers of a Dytiscus is pressed upon a clean slip of glass. The restriction of the suckers to the male beetle suggests that they are used to hold the female. 'They are also used to hold the struggling prey, but this cannot be their main function, since they are not found in the female at all. It is to be noted that the basal joints of the tarsus of the middle leg are enlarged and bear cupules, so that this leg also is serviceable in holding.

The elytra of the female are furrowed lengthwise, while those of the male are smooth. This has been interpreted as an additional provision for holding the female, but doubt is cast upon the conclusion by the following well-ascertained facts:-(r) Furrows on the elytra diminish instead of increasing the holding power of the suckers, which act best on smooth and polished surfaces; (2) the suckers of the male are not applied to the furrowed surface of the elytra; (3) females with smooth elytra are common in some districts, and the male can hold these just as well as the others.

The equilibrium of the body of the beetle (and we shall find that the same is true of the larva) is so adjusted that when the beetle rises through water without exerting itself, the tail-end comes up first. The largest pair of spiracles, upon which the insect mainly relies for replenishing its supply of air, are situated far back. This arrangement not only prevents needless exertion in assuming the attitude most convenient for breathing, but gives in particular emergencies an extra chance of life. Suppose that the insect is stunned, or in some other way temporarily disabled; it will rise by its own buoyancy to the surface in just that attitude which exposes the spiracles to the air. If it is still in a condition to breathe, it can do so without changing its position.

When the beetle dives, it takes down a considerable supply of air lodged beneath its wing-covers. The air clings to the felted hairs which cover the top of the abdomen, and 
forms a large flattened bubble. From this bubble air can be drawn into the body by a series of small spiracles which lie along the back.

The female of the Dytiscus marginalis lays her eggs in March or April upon aquatic plants, making a deep incision for each egg with her ovipositor. In about three weeks the larva hatches out. It grows fast, and attains its full size in four or five weeks, being then about two inches long.

The figure shows the shape of the larva. We remark its rather long, fringed legs, the fringed hinder segments, and the pair of fringed appendages borne by the last segment of all. The legs and tail are both effective in swimming, but the tail is less important for swimming than for breathing. The larva is lighter than water, and can only remain below by grasping solid objects. When it lets go, it rises to the surface, tail first. The water rolls off the hairy appendages in a moment, and then air can be sucked in by two spiracles, which open on the tip of the tail, and lead into the great longitudinal air-tubes. The action of the hairs can be explained by wellknown physical principles, but we must not stay to discuss the point here.

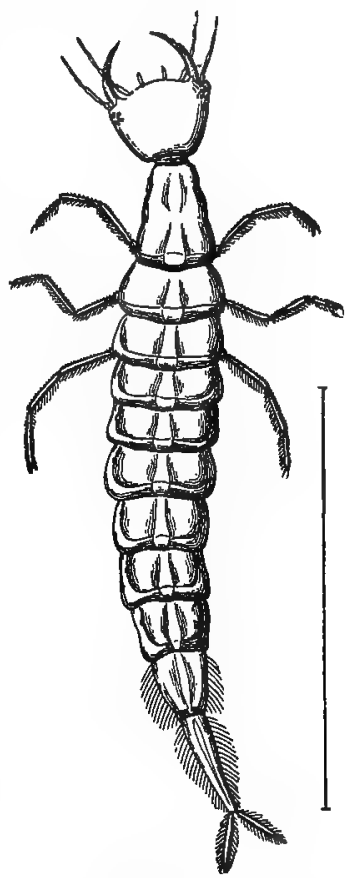

Fig. 24,-Larva of Dytiscus.

There is one curiosity of structure about the mouth-parts of the larva which we must not pass over. Whoever examines the larval head with a pocket-lens will be sure to notice the long, sickle-shaped mandibles. It was pointed out by Swammerdam, as long ago as the seventeenth century, that these cruel weapons are hollow, and that when the larva preys upon a red-blooded victim, the blood can be seen to flow 
through the mandible into the mouth. The inner orifice of the tube lies upon the expanded base of the mandible. In our own time an American naturalist, Burgess, has shown that the mouth of the Dytiscus-larva is capable of being absolutely closed by a "mouth-lock." When the mandibles are fixed in the prey and the mouth-lock closed, a completely watertight channel leads from the body of the victim into the stomach of the devourer. So completely is the ordinary outlet closed that when a larva preserved in alcohol is placed in boiling hot paraffin, the vapour escapes in the form of trains of bubbles by the tips of the mandibles, by the spiracles, and by every other opening, however minute; but none from the mouth. I find that the mouth-lock acts automatically, opening when the mandibles open, and closing when they close. Thus the larva can adapt its mouth, by a slight movement of the mandibles, either to sucking or to the gnawing of solid morsels.

When pupation is at hand the larva leaves the water and makes a cell in moist earth. The larval skin is cast, and the form of the body changes, becoming thicker and shorter than before. The new organs which are to serve the adult beetle, such as the wings and long legs, are bent towards the under side. Many of the segments now bear prominent spines, which are common in subterranean beetle-pupæ. They may be used in the limited movements of which such pupæ are generally capable. The pupal stage is brief, lasting only two or three weeks. But at the approach of winter any fullfed larvæ which survive creep into the earth, where it is probable they remain for months as resting larvæ, pupating only when spring is at hand. The subterranean life of Dytiscus is not yet well ascertained in all particulars.

The adult beetle is quite able to withstand the cold of winter, and can be seen swimming about beneath thick ice. How it manages to breathe under these conditions is a question of some interest, to which we have no answer ready.

The modifications of the adult beetle to aquatic life are far less profound than those of the larva. The same thing may be said of aquatic insects in general, to whatever order they may belong. The larva has only to feed and grow, but the adult female has to seek a mate, and to lay her eggs, occasionally at least, in a new site. To sacrifice the advantage of 
flying from pool to pool would be to lose all that can be gained by transformation. Accordingly we find that even insects so eminently aquatic as Dytiscus are capable in their adult state both of flight and aerial respiration. Many a young collector has been startled to find that water-beetles, which he left swimming about in a tank, have flown to a distance before morning.

\section{WIRE-WORMS AND CLICK-BEETLES (Various species of Agriotes, especially $A$. lineatus)}

Wire-worms are commonly reckoned as the worst pests of the farm. They feed chiefly on the roots of grass, cereals, hops, turnips, potatoes, and other crops, and abound on sandy or gravelly soils. The true wire-worms are the larvæ of beetles, which in their adult stage are called click-beetles, but millipedes and leather jackets, which are not beetles at all, are often included under the same name. Wire-worms devour roots and stalks, and as they travel about from plant to plant, they spoil a great deal more than they eat. They live three years or more as larvæ. It will be remembered that the larvæ of the chafers also go through more than one season. Burrowing larvæ, which feed on vegetable substances bulky in proportion to the nutriment contained, are commonly
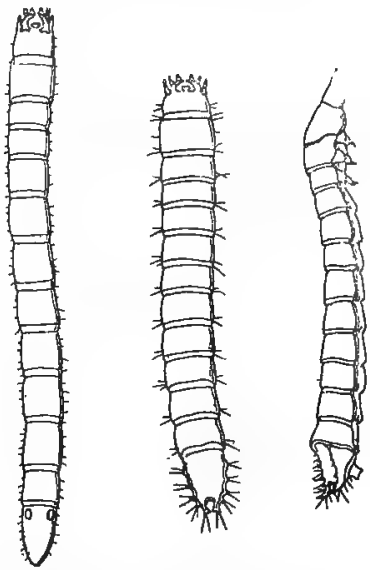

Fig. 25.-The left-hand figure shows the larva of Agriotes lineatus. To the right is shown, in two positions, another wire-worm (Corymbites aneus?). All magnified.

creatures of slow growth, the larval stage being prolonged by the circumstance that during part of the year they do not feed at all. It is quite otherwise with most leaf-eating larva. Here the food is both more nutritious and more readily accessible, but it can only be procured during the summer months. Leaf-eating larvæ accordingly complete 
their life-history within the year, and several broods may be produced in the course of a single summer. Wire-worms are

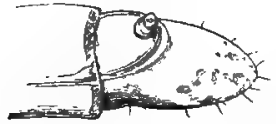

Hig. 26.-Last segments of wire-worm, showing the under surface and the anal foot.

long, narrow larvæ, with three pairs of thoracic legs. The end of the abdomen is bent downwards, and forms a support for the body, so that it has the appearance of a prop or foot. The segments are protected above and beneath by chitinous shields. When

the larva is full-grown it descends deep into the ground, and pupates within a small oval cocoon. This usually happens in July or August. The beetle emerges in two or three weeks, but often does not appear above ground until the following spring. The body of the beetle is elongate, rounded in front, and somewhat pointed behind; the feelers are serrate (saw-toothed) along the

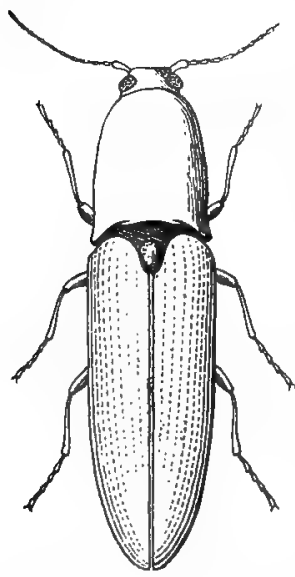

Fig. 28. - Click - beetle (Agriotes lineatus). $\times 7$. inner margin; the legs are rather short, and the tarsus five-jointed. The beetles climb upon plants, and escape notice by their dingy colours and sluggish

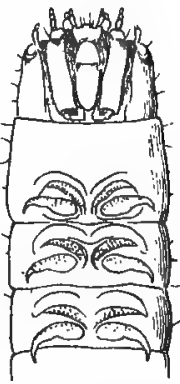

Fig. 27.-Head and thorax of wire-wormi, showing the under surface, with the jaws and legs. habits. When threatened, they let themselves drop to the ground. If they alight on the ground back downwards, and if no convenient objects can be grasped by the short legs, they are enabled to right themselves by a peculiar mechanism, to which they owe the name of click-beetles. The under side of the prothorax is drawn out into a strong spine, which locks into a cavity on the mesothorax. The sides of the groove offer' considerable resistance to the entrance of the spine, a resistance which can perhaps be increased by the muscular effort of the beetle. When the beetle puts forth its whole strength to force the spine into its socket, 
the resistance is suddenly overcome, the spine enters the socket with a clicking noise, the body is flexed, and the bases of the wing-covers strike the ground suddenly and sharply, so that the body is jerked into the air to a height of several inches. After one or two leaps the beetle generally regains its usual walking attitude. It is possible that this mechanism is not only used for righting the body, but also for escaping from enemies.

The destruction caused by wire-worms has stimulated many efforts to keep their numbers down. Gas lime has been ploughed into the soil; harrowing, rolling, and trampling by sheep have been recommended, especially in March and April, when the beetles are appearing. Slices of potato or mangold, and pieces of rape-cake have been successfully used as traps in hop-grounds; they should be plainly marked and frequently examined (not less than once a week). Rape is attractive to wire-worms, and a mixture of rape sown with wheat, etc., or rape-dust scattered broadcast, will often save the crop. The pest is, however, encouraged thereby.

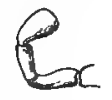

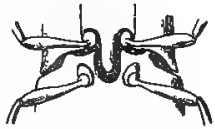

Fig. 29. - Upper figure, maxillary palp of click-beetle; lower figure, under surface of thorax, with spine on first segment.

Rooks, plovers, starlings, and various other birds devour great numbers of wire-worms.

\section{THE TURNIP-FLEA (Phyllotreta nemorum),}

The Turnip-Flea or Turnip Flea-beetle, which is one of two or three insects called turnip-fly, is a small active creature, which infests turnip-fields in vast multitudes, especially on dry soil and in times of dro:ight. It may be recognised by its leaping powers, which suffice to raise it a foot or more in the air. The faculty of leaping is associated, as in grasshoppers, with thickened muscular thighs on the hind legs. Thousands of flea-beetles descending upon the leaves make a sound like the patter of summer rain. Another mark of the turnip flea-beetle is the broad yellowish stripe which runs lengthwise upon each wing-cover. There are, apparently, only four joints in each tarsus, and the body is only $3 \mathrm{~mm}$. long. 
The four joints of the tarsus indicate a section of Coleoptera known as Tetramera, which are also called Phytophaga, from their taste for vegetable food. Close examina-

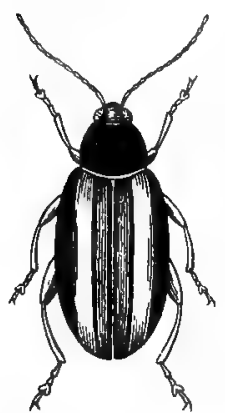

Fig. 30 . tion shows that there are really five joints in the tarsus, but that the fourth is reduced to a vestige of no practical use.

The phytophagous beetles are divisible into three families:- $x$ ) Seed-eaters (Bruchidx), often confused with weevils; the so-called pea-weevil is an example; (2) the Leaf-eaters (Chrysomelidæ), to which the flea-beetle belongs; and (3) the Longicorns or wood-eaters (Cerambycidæ), named Longicorns from their long feelers, which often exceed the body in length.

The flea-beetle feeds on all Cruciferous Turnip-flea. $\times 8$. plants, whether wild or cultivated, and is often found in places where turnips have never been grown. Large crops of turnips give it, of course, facilities for food and increase, which do not exist elsewhere. This beetle is active throughout the warm season, and produces several broods in close succession; in winter it seeks shelter, and is rarely seen.

The eggs are laid singly on the under side of leaves. The larva which issues from the egg is small and of pale yellow colour. It has a dark-coloured head, and three pairs of rather stumpy legs; the end of the abdomen bends down and forms a support. It is a leafminer, burrowing in the thickness of the leaf, eating up the green sub-

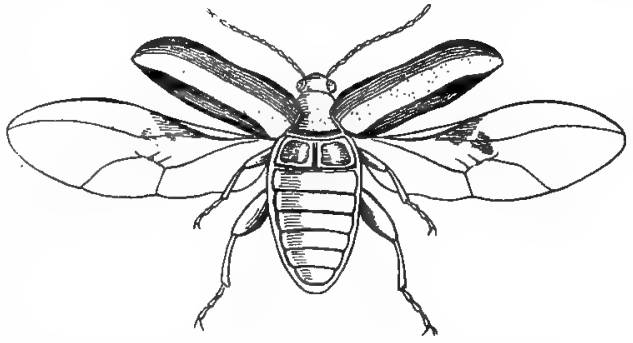

Fig. 31.-Turnip-flea, with wings expanded. $\times 8$. stance, and leaving a sinuous discoloured track or burrow, where only the dead cuticle is to be found. The habit of leaf-mining is by no means restricted to this particular insect. 


\section{THE TURNIP-FLEA}

Some weevils, some sawflies, many moths and two-winged flies do the same in their larval stage. The leaves of the oak, holly, bramble, and feverfew are often attacked in this way, as are a multitude of other plants. Each species of insect, as a rule, infests one particular plant only. The burrow usually begins as a scarcely visible line, and widens with the growth of the larva; at the broad end may often be seen an enlarged chamber in which the pupa rests.

The larva of the flea-beetle only feeds for about a week; it then descends two or three inches into the earth to pupate, and emerges after about another fortnight. In the height of summer a new generation is produced every month.

This beetle is one of those that

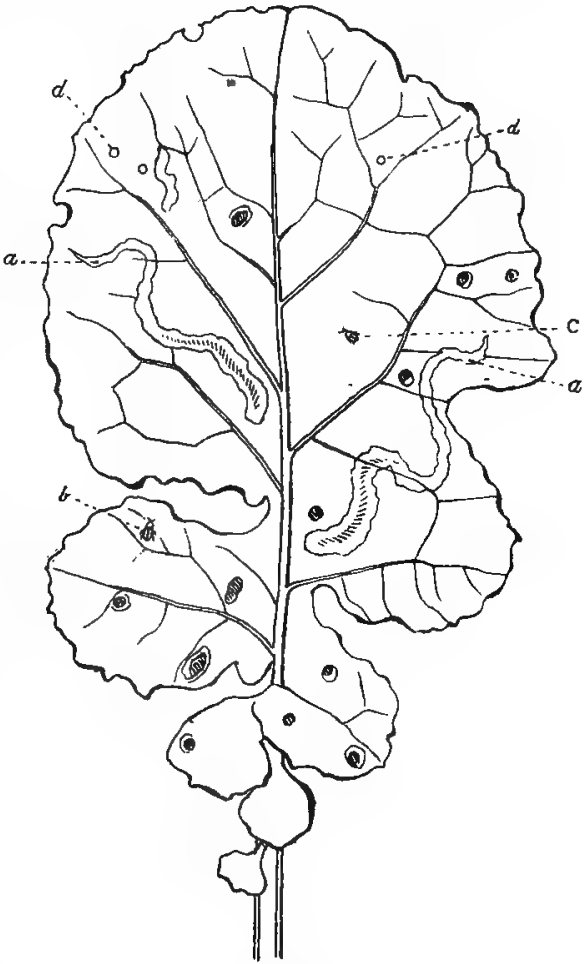

Fig. 32.-Turnip-leaf, mined by larva of turnip-flea. From Curtis" "Farm Insects." $a$, burrows of larva; $b$, male beetle ; $c$, female beetle; $d$, holes made by beetles.

are voracious in the final or winged stage. Whether an insect feeds busily after it has got its wings, feeds moderately and occasionally, or does not feed at all, is a question that depends very largely upon its manner of egg-laying. On a later page we shall attempt to guide the reader to a solution. 
How can this pest be got under? is the first and usually the only question that the farmer puts when he sees a horde of insects devouring his crop. It is easy to mention remedies which are

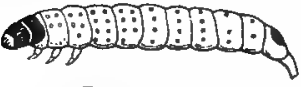
promising and worth trying; it is usually hard to mention one which is certain, rapid, and cheap. In the case

Fig. 33.-Larva and egg of turnip-flea, magnified. Frum Curtis" "Farm Insects." of the flea-beetle the best remedies

hitherto proposed seem to be:-(I) Clean farming. Get rid of weeds, and especially of Cruciferous weeds, from the borders of the fields. (2) Good feeding. Help the crop over the stage of attack by manuring and watering. (3) Poisoning the pest. This is no easy matter. It is hard to wet the beetles or the leaves with any poisonous solution, and impossible to reach the larva inside the leaf, or the pupæ underground. Soft soap and paraffin worked up in water and applied with a Strawsoniser seems a likely thing to try. Dressings of two parts of lime to one of soot have proved useful where the beetles abound. In America solutions of Paris green or some other arsenical compound are used freely in such cases, but the English farmer as yet shrinks from the risk of using large quantities of a poison which might destroy other life than that of insects (see Part IV.).

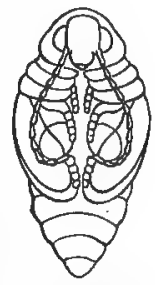

Fig. 34- - Pupa of turnip - flea, magnified. From Curtis' "Farm Insects."

\section{LADY-BIRDS (Coccínellidae)}

There are hardly any insects more familiar than these. Every child who plays in a garden knows the bright-coloured dumpy body of the lady-bird, and has seen it fly, crumpling up its large and gauzy wings beneath the hard, shiny wingcovers, when it alights again. But it is only with some trouble that all the stages of the life-history are discovered. The eggs are yellow, and laid in clusters upon plants infested by aphids or plant-lice. It is upon the aphids that the larvæ and full-grown beetles subsist, and they are born where 
their food is ready to hand. The larva does not look much like a predatory animal. Its body is flat, broad, tapering behind, and of soft texture. Its colour is grey, changing to yellow on the under side, and diversified with black and yellow warts, and pencils of black bristles. The head is small. Six rather long legs serve for locomotion, aided by the tip of the abdomen, which can be lengthened at pleasure, and used to shove the body along. The larva runs about on plants to seek aphids, and devours them in great numbers, for the aphids are absolutely fixed to the plant by their beaks, and have no effectual de-

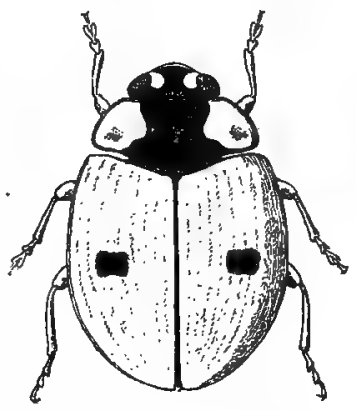

Fig. 35.-Two-spot lady-bird (Adalia bipunctata). $x$ ro. fences. The lady-bird larva grows fast, and changes its skin more than once. When it is full-fed, by the destruction of countless aphids, it settles upon a leaf, and

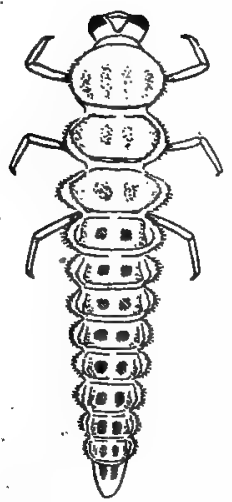

Fig. 36.-Lady-bird larva (Adalia bipunc. tata). Magnified. secretes a sticky fluid from the end of the abdomen, which glues it fast; the hairs are cast; the skin splits along the back, and by the wriggling movements of the body within, is worked towards the tail-end, where it sticks in a wrinkled mass like a stocking drawn off the leg. The pupa becomes visible as soon as the last larval skin is cast. It is very unlike the full-grown beetle, the small wing-covers concealing only a part of the body, which is very conspicuously segmented, and of an orange-yellow colour. It hangs by the tail, and, when disturbed, swings its body to and fro several times in rapid vibration.

The winged beetle has the shape of an egg cut lengthwise through the middle. The body is strongly arched above, and flattened beneath. The small head is partly sunk into the thorax. The tarsus is apparently three-jointed in all the legs; not truly three-jointed, however, for a minute extra joint can be discovered by close examination at the base 
of the terminal joint. The feelers are slightly clubbed. There are some forty species of lady-bird in this country, and, at least, two thousand in the world. One of our commonest species (Coccinella septempunctata) is red, with seven black spots upon the wing-covers. The beetle flies well, but creeps slowly. Like the larva, it feeds upon aphids, but is much less voracious than in its earlier state. When alarmed, the beetle withdraws its legs, and exudes from the joints a yellow

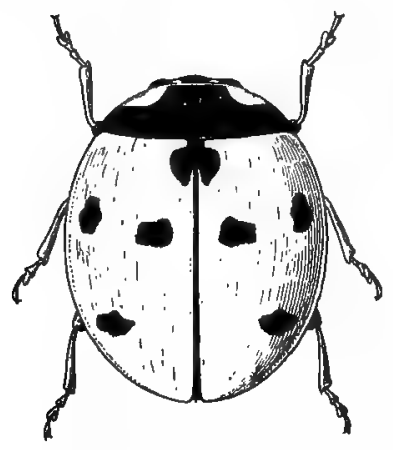

Fig. 37,-Seven-spot lady-bird (Coccinelia septempunctata). $\times 6$. fluid, which some naturalists describe as having an unpleasant smell and taste; the larva can emit a similar fluid from the warts upon its skin.

Lady-birds are of great service to man in keeping down aphids, scale-insects, mites, and other pests. Where the aphis abounds, lady-birds abound also; they are very prolific, and produce two or more broods in a single season; under favourable circumstances only one month is required to develop the beetle from the egg. Vast swarms of lady-birds have been seen to cover the ground in the neighbourhood of hop-grounds, in seasons when the hop-fly or aphis is unusually plentiful.

\section{THE GARDEN-WEEVIL (Otiorhynchus)}

The weevils and their near allies form a very numerous group of beetles, which are easily recognised, and not closely related to any other family. The head is drawn out into a long slender snout (rostrum) in front of the eyes, and upon the extremity of this snout the mouth-parts are placed. The feelers, which are attached a little further back on the sides of the snout, are elbowed, the long basal joint standing out from the head at a right angle, and the succeeding joints making a decided angle with the basal one. The tarsus in 
all the legs is apparently four-jointed, the proper fourth joint being reduced to a minute vestige.

Weevils often abound in grain, nuts, and stored fruits of seeds, but are by no means restricted to such food; they are insects of very varied tastes. It is to be remarked that the name weevil is applied to many small beetles which devour stores, irrespective of their structure. Thus the "weevil" that devours shipbiscuit has neither long snout nor elbowed feelers; it is a species of the

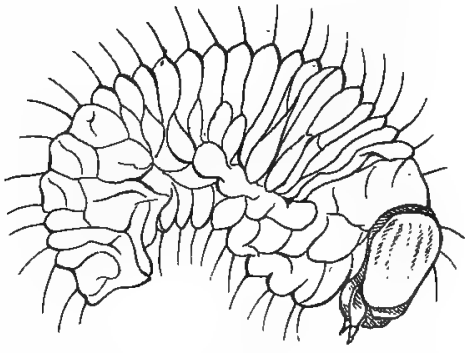

Fig. 38.-Larva of garden-weevil, $\times 4$. From Curtis" "Farm Insects." same family as those which drill small cylindrical holes in furniture, and is technically an Anobium.

A certain true weevil, which makes great havoc in greenhouses, is one of the

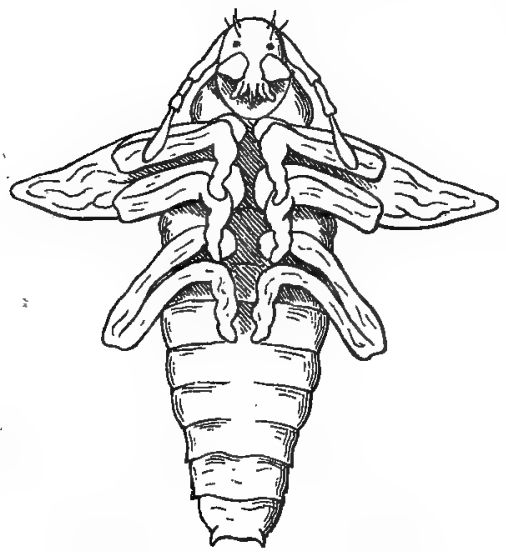

Fig. 39.-Pupa of garden-weevil, with the appendages extended. $\times 4$. easiest to procure for examination. Many nurserymen are plagued with it. This weevil inhabits flower-pots and frames, feeding on the roots when in its larval stage, and on the leaves or stems when it has gone through its transformations, and is a full-grown beetle: Though most common indoors, the garden weevil does not require protection, and is sometimes very mischievous in the open garden or field. A closely allied species ravages vineries.

The eggs are laid beneath the surface of the earth, and 
produce soft, white, footless grubs, with hard brown heads, which feed upon roots from August till the following April. Then they bury themselves deeper in the soil, and turn to pupæe, emerging as beetles about a fortnight later. The fullgrown beetle is about half-an-inch long, and of the colour of garden mould. The snout is rather short for a weevil, but quite evident. The wing-covers are united, and cannot be extended; there is no trace of wings, and the beetle is totally incapable of flight. The wing-covers are granulated, and roughened also by small

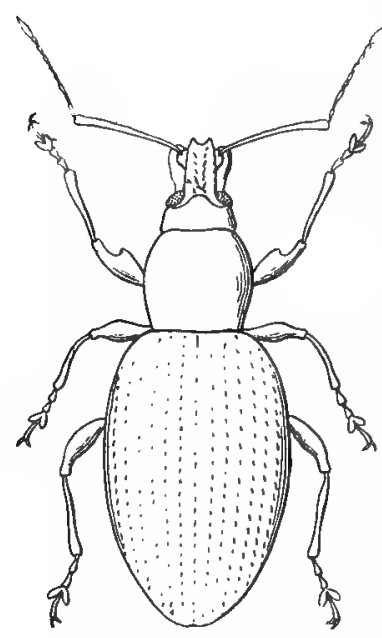

Fig 40.-Garden-weevil. $\times_{4}$. scales. The beetles only feed at night, and hide themselves by day.

The peculiarities of this beetle are very marked. We should be glad to know:-(I) why it has lost its wings ; (2) why its head is drawn out into a snout; (3) why its feelers are elbowed; (4) how the larva manages without legs. In reply to question $\mathbf{I}$, we may remark that insects which are indiscriminate feeders are often wingless, more particularly the females. One chief purpose of the winged state is to provide for the transport of the eggs to fresh localities; if the store of food is ample and close at hand, wings may often be dispensed with. 2. The long snout is particularly serviceable to weevils, which have to pass their jaws into small crevices or holes, such as holes made for the purpose in a hard fruit or seed. We might suspect that the object of drilling the hole was to feed upon the contents; it is much more common to pass an egg in, and thus make provision for the nourishment of the larva. 3. The bending of the feeler at an angle seems to facilitate the exploration by the sensitive tip of the surface to be bored. 4. The larva has its food ready to hand, and need not move from the place until it is ready to pupate. Under such circumstances feet are superfluous. Just in the 
same way the grub of the hive-bee, which lives upon a readymade store of honey, and the maggot of the blow-fly, which finds all the food it requires in the mass of putrid flesh selected by the parent, can manage perfectly well without organs of locomotion, and these larvæ are footless like those of weevils.

The garden-weevil is a most intractable pest. Perhaps. there is no better remedy known than sifting all the earth of the greenhouses, down to a depth of three to four inches, through fine sieves, thoroughly exploring at the same time all crevices, or stopping them up. When building or fitting up greenhouses, it will save much loss to avoid narrow chinks, and to arrange for sweeping out or lime-washing every part easily and completely. Repeated applications of soot and lime, worked up in water to the consistence of whitewash and used fresh, have proved useful in the field.

\section{THE ELM-BARK BEETLE (Scolytus destructor)}

If in our rambles we come across a felled elm-tree, which has lain some months on the ground, we shall be pretty sure to find that its bark is mined by a small beetle. Nearly all round the year the larvæ can be discovered in such a tree by stripping off a sheet of bark and searching the galleries thus exposed to view, or (in winter) by examining the young wood. Towards the end of May a vernal swarm of bark-beetles appears, and an autumnal swarm in the end of August, but the bark-beetles are so small (4-5 $\mathrm{mm}$. long) and show themselves so rarely, that they may abound in places where even the naturalist hardly ever remarks them. The elm-bark beetle is not found in Scotland nor Ireland, and it is more plentiful in the southern and midland counties of England than in the north.

To become acquainted with the mode of life of this beetle we must examine a sheet of infected elm-bark. The parts which have'been mined are indicated by small holes like shotholes, which are usually situated here and there in the bottom of deep cracks. In June, when the female beetle is at work, there may be a little heap of bark-dust close to the hole, but very often only the holes show where the bark has been mined.

On a sheet of bark detached from such a tree may be seen 
the galleries worked in the deep layers of the bark. The main galleries are longitudinal, i.e. running upwards and downwards in the erect tree; they may be 8 -10 centimetres long $(3-4$ in.), but hardly ever reach $12 \mathrm{~cm}$. (5 in.); sometimes they do not exceed $2 \frac{1}{2} \mathrm{~cm}$. ( $\mathrm{I}$ in.). From these main galleries pass off radiating passages, which are narrow at the place of origin, but widen gradually as they get further away from the main gallery. They are often sinuous, and now and then join other passages, either of the same or of another system. These two kinds of galleries are the work of the beetle in different stages of growth. The main galleries are wrought by female beetles, and may be called "mother-galleries"; the radiating passages are mined by larvæ, and may be called "maggot-galleries." The history of their construction is as follows :- The first beetles of the year emerge from their cells in the wood of the elm towards the end of June. The females soon set to work, and excavate a passage into the bark, generally beginning in the bottom of a deep crack. The males wander about the surface of the tree, and mate with females, which are not yet completely buried in the bark. The fertilised female continues her excavation along the trunk, and from time to time makes a rude cell, which is merely a slight enlargement of the gallery, now on this side and now on that. In each cell she lays an egg, and a hundred or more have been counted in one passage. The mother-gallery is finished in about three weeks; as soon as it is ready and stocked with eggs, the female dies, and her dried-up body will be found in some part of the mother-gallery. The larvæ quickly hatch out, and begin to mine. Each excavates its own maggot-gallery, which though at first narrow, widens as the larva gets bigger and stronger. In the widest and furthest recesses a few of the full-fed larvæ undergo their transformation, pupating towards the end of July, and emerging as beetles during the following month. The majority, however, prepare for wintering in the tree. Each excavates a little chamber half-an-inch or so deep in the wood, packs the entrance with wood-dust, and there lies concealed and motionless till spring. Then they pupate, and emerge as beetles in May. The advantage of the deep excavation is not hard to perceive. Winter rains and frosts are apt to loosen the bark of a dead or dying tree, and so might expose larvæ, resting in galleries excavated 
within the bark, to the weather or to the attacks of insecteating birds; the wintering larva avoid this danger by boring into the wood and resting there. Beetles which complete their transformation in August run less risk, and do not need to excavate beneath the bark.

There is reason to believe that the bark-beetles often begin their attack on the topmost boughs of an elm, which become dry and brittle in consequence, and gradually work their way down to the main trunk.*

The larva of the elm-bark beetle is a whitish, soft, and footless grub, much resembling weevil-larvæ in general appearance. It is thicker in front, and tapers behind. The back and sides are marked by deep wrinkles. The head is hard, and armed with powerful jaws. The pupa is very similar to that of many other beetles, and no remarkable details have been recorded concerning it. The perfect insect is $4-5 \mathrm{~mm}$. long, black, with obscure markings of red or brown on the elytra and legs. The

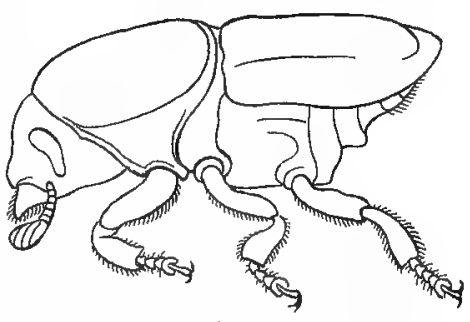

Fig. $4 \mathrm{I}$.

Elm-bark beetle. $x$ ro. After Ritzena Bos. feelers are rather short, bent, and clubbed. The rostrum, which carries the mouth-parts, and which is long and slender in many weevils, is here very short. The thorax is enormous in proportion to the abdomen, and extends so far back on the under side of the body that the hind legs are attached beneath the middle of the elytra. The tarsi, until minutely examined, appear to be four-jointed. The under surface of the particularly short abdomen slants upwards towards the end of the body, and looks as if a great piece had been cut away by an oblique incision. The elytra are marked by 6-7 longitudinal streaks, which are resolved by a lens into rows of dots.

The bent and clubbed feelers, the apparently 4 -jointed tarsus, the striate elytra, and the footless larva indicate that the elmbark beetle is allied to the weevils, though the rostrum, which is greatly prolonged in most weevils, is here short and inconspicuous.

* Oberförster Brecher, in Altum's "Forstzoologie," III., Insecten, Abth. i. p. 244 (2nd ed. I88r). 
This beetle is beset by many insect-parasites. Ichneumons and allied Hymenoptera lay their eggs in the larva, and Taschenberg enumerates thirteen different insects which have been bred from it.

Various remedies have been proposed for the extermination of the elm-bark beetle, such as bands of coal-tar, to prevent the beetles from climbing the trunks, vigorous paring of the outer bark, and the felling and burning of all infected elms. It is to be noted that for upwards of sixty years entomologists have called attention in the most emphatic language that they can command to the danger of leaving felled elm-trees long on the ground. The trunks of such trees nearly always become infested by bark-beetles, and furnish a perpetual supply for the infection of sound trees. The plague has become so widespread that very drastic measures are called for, if it is to be effectively checked. Under present circumstances single plantations of elms can hardly be protected without the most vigilant attention.

Another and smaller species of Scolytus (S. multistriatus) is sometimes found on the elm; its maggot-galleries radiate much more regularly than those of $\mathrm{S}$. destructor. Other species attack the birch, the oak, and the plum. Pines are attacked by allied species of bark-beetles, such as the Tomicus typographus, which has caused great loss in the forests of Germany. The forestry departments have now learned how to keep its devastations within bounds. Either trees already infected or sound trees are felled at the time when the beetles are expected shortly to appear. Sometimes they are only ringed at first, being felled some weeks later. These trees are selected in preference to uninjured standing trees by the beetles, and when they are well-stocked with larvæ, the bark with all its population is stripped off, and scrupulously destroyed. The German foresters call the felled trees Fangbäume or beetle-traps. The successful treatment of what was locally known as the "barkbeetle calamity" of Bohemia in I87x-5 is a model for all foresters, who may be called upon to contend with similar plagues. ${ }^{*}$

There are many true weevils (p. 44) whose larvæ burrow beneath the bark of trees. These beetles lay their eggs outside the tree, in surface-cracks, and make no mother-galleries (see p. 48).

* The story is related by Altum, loc: cit., p. 295. 


\section{B. MOTHS AND BUTTERFLIES (LEPIDOPTERA)}

\section{2. (PRACTICAL.) DISSECTION OF A CATERPILLAR}

TAKE any large caterpillar, and kill it by placing it in a box with a few drops of ether. Observe the following external characters :-

The head is small, hard and polished. As seen from the front, it consists of two lateral (epicranial) plates, and a median plate (clypeus) between them. Six simple eyes can be discovered on the epicranial plates by examination with a lens; some are in front, the rest on the sides or behind. The epicranial plates also bear the small, three-jointed feelers. When the back of the head is examined, the mouth-parts come into view. In front is a pair of short and stout mandibles, whose edges are divided into a number of teeth. Behind and in the middle line is a conical prominence, the spinneret, from which in silk-spinning caterpillars a thread is often seen to issue; it represents the labium, or fused second maxillæ. Outside the

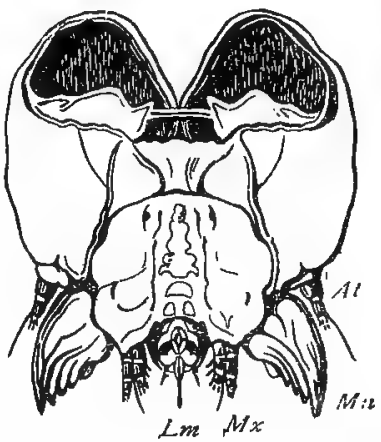

Fig. 42. - Head of larva of goatmoth, seen from behind. Copied from Lyonet. spinneret appear the maxillæ.

The next three segments constitute the thorax. Each bears a five-jointed leg, ending in a point. The first thoracic segment possesses a spiracle, but the two succeeding segments, which ultimately carry wings, have no spiracles.

The abdomen consists of ten segments, of which one (the ninth) is not easy to see in most caterpillars.* The number

* Occasionally, as in Notodonta, the ninth segment is easily seen without dissection. 
is accordingly reckoned in books as nine. Of these the first two bear no appendages, the third, fourth, fifth and sixth bear each a pair of feet known as prolegs, which are different in form from the thoracic legs, and are not succeeded by legs in the pupa or imago. The remaining segments bear no appendages till we come to the last of all, which carries a pair of unusually large anal feet. Deviations from this arrangement are not uncommon. The last pair of abdominal legs may cease to act as feet, and become transformed into a pair of protrusible filaments, as in the larva of the puss-moth and some others. Two or three of the fore pairs of abdominal legs disappear or become shorter than the rest in some larvæ, while in the numerous family of geometers, only the legs of the sixth abdominal segment and the anal feet remain. These larvæ are distinguished by their peculiar looping movements, and by their habit of extending the body in a straight line from the twig to which they attach themselves, which they often resemble so closely that they completely escape observation. The abdominal feet of a caterpillar are usually short, and end in a double crown of hooks. The eight foremost abdominal segments bear spiracles, and these are often very conspicuous, being unlike in colour to the surrounding skin. The anus opens on the last segment, and is usually concealed by a triangular valve.

When these points have been observed, and also the characters peculiar to the particular species under observation, the caterpillar should be opened along the back with a pair of fine scissors. The skin must be carefully separated from the underlying parts, and laid out with pins on each side. A shallow dissecting dish lined with paraffin or cork* should be used, and when the skin has been reflected and secured, water enough to cover the insect should be added. The muscles of the body-wall and the heart need not be separated from the skin. $\uparrow$ The head should be secured by two crossed pins, but not injured in any way.

* A small tin tray, such as pastrycooks use, makes a capital dissecting tray for insects. Mix hot paraffin wax and asphalt, and pour a little on the bottom.

† To make a satisfactory dissection of the heart it must first be hardened with suitable reagents, then removed from the body, together with the uninjured dorsal integument, and last of all dissected away from the adjacent parts. Beginners are not recommended to attempt this. 
When the skin with its attached muscles has been reflected two whitish and crumpled sheets are brought into view. These conceal to a great extent the parts beneath. They are loaded with fat, and are hence called the fat-bodies. The fat which they contain is often used up to a great extent during the pupal stage. It will be found that the fat-bodies are held in place by a multitude of branching air-tubes or tracheæ. Displace the fat-bodies so as to expose the alimentary canal beneath. In this and similar cases it is very desirable to avoid breaking up the tissue which has to be removed. When a dissection gets encumbered with fragments which intercept the view, the parts beneath are often accidentally injured. Raise the fat-body with a needle or forceps, and carefully cut through its attachments with fine scissors or a sharp scalpel. The alimentary canal will thus be exposed, and on either side the longitudinal tracheæ or main air-tubes of the body will be found.

The alimentary canal or digestive tube takes a straight course from mouth to anus. It consists of three primary sections:-(I) the osophagus or fore-gut, (2) the stomach or mid-gut, and (3) the intestine or hind-gut. The appendages of the alimentary canal are the salivary glands, the silk-glands, and the Malpighian tubules. The first and third sections are lined by a thin chitinous cuticle. The œsophagus and intestine are short, compared with the stomach, which in most caterpillars occupies more than half the length of the alimentary canal. The esophagus is narrow near the mouth, from which it takes its origin. It dilates behind to form a pear-shaped sac, the crop, which is often distended with food. In some caterpillars, such as the wood-eating larva of the goat-moth, the hinder part of the œsophagus may have its muscular wall thickened, and form a kind of simple gizzard, which has not, however, the chitinous armature found in the cockroach and many other insects. The stomach or mid-gut is long, cylindrical, and of simple form, wanting the circles of radiating tubules which in some insects act as digestive glands. In a caterpillar which has recently fed, the stomach often bulges outwards at a number of places, and appears to be beaded. The intestine or hind-gut is short. It begins in many caterpillars with a narrow portion, which dilates and forms a short colon, usually distended with the refuse of the food. This 


\section{INJURIOUS AND USEFUL INSECTS}

leads to a rectum which when full has a considerable capacity, but contracts when empty. On each side of the alimentary canal may be seen the long, winding silk-glands. These are usually much longer than the body, and are therefore repeatedly folded. They are of unequal thickness ; and consist of a long, very slender, tubular thread, a wider reservoir, and a narrow outlet or duct. The ducts cannot be completely followed at present, but the glands should be unravelled and laid out with pins. The salivary glands, which are of minute size, open directly into the mouth. They resemble in structure the corresponding glands of the cockroach, but consist of a single pair only. Observe the fine, convoluted Malpighian tubules, which overlie the intestine, and the hinder end of the stomach. When unravelled, they are found to consist of three pairs of delicate tubes, which open into the beginning of the intestine by a pair of common ducts. The Malpighian tubules act as kidneys, separating waste nitrogenous matter from the blood, and discharging it into the intestine.

Draw the dissection, after displaying the various parts.

Cut through the intestine near the anus, and turn it forwards, cutting through the tracheal tubes which hold it in place. Look for the ducts and the silk-glands on the under side of the crop and cesophagus, and find the common duct in which they terminate. Follow this towards the head. A pair of very minute branched glands are often seen on the common duct or its branches near the junction. The fluid contained in each silk-gland is drawn out into a thread as required, and the two threads so formed may possibly be bound together by a cementing substance derived from the small glands.

By neatly halving a larva lengthwise, removing the alimentary canal, soaking the halves in dilute potash solution for a day or two, and then mounting in balsam, beautiful preparations of the respiratory system can be made; some experience in microscopic mounting is of course requisite.

Clear the nerve-cord, which lies in the middle line on the ventral surface. Besides the brain and the sub-œsophageal ganglion which occupy the head, there are three thoracic ganglia, and seven abdominal ganglia, united by double connectives. In the thoracic region the connectives are more widely separated than elsewhere.

Separate the silk-glands as completely as possible from the 
alimentary canal, but without cutting the common duct. Draw them and make a diagram of the nerve-cord, showing the segments in which each ganglion lies.

Examine the tracheal system more fully. Observe the longitudinal trunks, the short and rather wide branches which lead into it from the spiracles, and the branches of distribution, segmentally arranged. Cut out a piece of a large trachea, and examine it under the rnicroscope. Observe the spiral thickening and the mode of branching.

\section{3. (PRACTICAL.) HOW TO INFLATE A CATERPILLAR, AND SET A MOTH}

Dried caterpillars inflated with air, so as to retain something like their natural shape, are very useful additions to the cabinet of Lepidoptera, and everyone who intends to study and compare the various stages of injurious insects should know how to make such preparations.

The rough idea of the process is this. The empty skin of a fresh caterpillar, when distended with air, takes the shape of the living caterpillar. If it can be dried in this condition it will form a tolerable model of the natural object, nearly perfect in colour (unless the caterpillar is green) and surfacemarking.

It is necessary first of all to empty the skin very completely, and this can easily be managed after one or two attempts. Kill the larva by placing it in a box with a few drops of ether. Then lay it in the natural position on a sheet of blottingpaper. Double the paper over the larva, and press gently through the paper on the back, beginning at the head and proceeding towards the tail. Before pressure is actually applied clear the anus with a pin, so as to make sure that the remains of the food can pass out. The pressure should be applied steadily and continuously, and nothing answers so well as the thumb. Begin by pressing the head of the larva with the middle part of the thumb, and end by pressing its tail with the tip of the thumb. The paper is kept between the thumb and the larva all the time. A steady pressure, brought to bear on every part of the body in succession, forces out nearly all the contents through the anus. If the 
operation is not perfectly effected at first, repeat it. Some people use a ruler instead of the thumb, but this is a rougher method, and more liable to injure the skin.

The skin, when successfully emptied, is flat and much contracted. The muscles of the body-wall are still in place, and cause shrinking of the skin. A glass-pipe of suitable size passed into the anus might now be used as a blow-pipe to inflate the skin, but some special arrangements are necessary to prevent the skin from collapsing as soon as the pipe is removed. Various methods have been proposed, but nothing answers better than the following:-Take a glass pipe, drawn out at one end to a moderately fine point. To this fasten two pieces of watch-spring in the following way. Cut the watch-spring by striking it with a steel point and a hammer. This will give a notched edge on each side of the fracture, and such edges are excellent for holding. The spring must further be softened by heating in a flame and slow cooling, so that it will take any required position. Then arch both upper and lower springs in opposite directions and tie them into the required position with thread. The free ends of the springs must press against the glass pipe, and one must be longer than the other by about a quarter of an inch. The springs should not be attached directly to the glass tube, but to an outer tube which slides easily upon it. A split metal tube of suitable size to slide upon the glass tube can be got from a penholder or some kinds of pocket-pencil.

When all is ready draw the sliding tube away from the point of the glass tube, insert the tip of the glass tube into the anus, then, holding the springs apart, slide the split tube forwards. Bring the end of the longer spring, which is to be held downwards, against the under side of the larva, just in front of the anal feet, while the shorter spring is made to hold the skin of the dorsal surface. The larva hangs down quite limp, but stands out straight when air is forced into it by the pipe. See whether the air escapes too rapidly, and if any considerable leak is discovered, readjust the springs.

Air-pressure may be got by blowing with the mouth, by a hand-syringe, or even by the gentle contraction of an indiarubber toy balloon. A wire clip on an india-rubber connection will prevent the escape of the air when the skin is inflated. 
Rapid drying can only be effected by artificial heat. A small tin canister with a hole an inch in diameter cut out of the lid and heated by a Bunsen flame is convenient.* If the canister gets too hot the larva will scorch; if it is not hot enough the operation will be protracted for an unnecessary length of time. Pass the distended larva well into the canister. On withdrawing it, ascertain by a slight touch of the finger whether the skin is rigid or gives way. The heating should not be discontinued until the skin is quite rigid. It is best and safest to do the drying by heat rather slowly and to break off two or three times to find out how things are going on. When you think the skin is quite dry repeat the heating once more. It is not uncommon for a skin which is supposed to be sufficiently dry to collapse a few minutes afterwards. When the skin has become quite cool, release the springs. The dry skin is apt to cling to the glass tube, from which it should be cautiously detached with a pin-point. Make a coil of fine silk-covered wire by winding it round a pin. Straighten the free end of the wire for an inch or more according to circumstances, and make this adhere to the under side of the dry skin with gum or coaguline. The wire should pass between the abdominal feet. When the gum is dry the preparation is complete. The caterpillar can be attached by the wire to a twig, if a more natural appearance is desired.

A good deal of practice is desirable, and a demonstration by an experienced hand will save many mistakes. The commonest mistakes are:-(I) imperfect emptying of the skin, causing distortion or partial inflation; (2) collapse from insufficient drying; (3) leakage from bad fitting of the ends of the springs; (4) over-distension, causing the larva to appear much larger than life-size; (5) scorching; (6) injury during detachment from the glass pipe. The anal feet are sometimes broken off in this operation.

The best and almost the only way of learning how to set moths neatly is to see a skilled hand at work. There are many little details which cannot be described in print, but which are essential to complete success. The necessary implements are grooved setting-boards and entomological time.

* Some hold the skin over a hot iron plate, and keep it in view all the 
pins of different sizes. The moth must be pinned as soon as possible after death, the pin being passed exactly through the centre of the thorax. A specimen which has been allowed to dry can only be set after relaxing. This is done by keeping it in a box or bottle with some wet blotting-paper; it should be examined daily, and removed as soon as the wings and legs become soft enough to be bent readily. The object is to restore them to the condition of a fresh-killed insect. If relaxing is too much prolonged, the moth will become mouldy or putrid.

When the moth is pinned into the groove of the settingboard, the body, feelers, and legs should be arranged in natural attitudes, and secured by pins. The wings are to be expanded, and held down by strips of paper or card (braces). A needle or fine forceps is convenient for extending the wing, and it is a general practice to extend the fore wings until a line drawn from tip to tip just clears the head. After this the specimens are left to dry in a safe place, free from dust or damp. The moths must be so set that they do not touch any surrounding object, and care must be taken to prevent the access of mites or other museum pests. A little dry naphthalene in each tray is a sufficient precaution. The collection must not be exposed constantly to light as the colours will fade.

\section{THE TIGER-MOTH (Arctía caja)}

We shall take as our first example of a Lepidopterous insect the tiger-moth, a common and hardy species, which is easily reared, and conspicuous by its size and bright coloration. Many schoolboys have kept the larvæ in paper cages, feeding them on nettle or dock-leaves. In such cages the leaves soon dry up, and a daily supply must be procured. It is, therefore, better to stick a cut branch of the food-plant in a small bottle of wet sand. Then we want a case to prevent the larvæ from escaping. Make a tall upright frame without bottom (20 in. $\times 8$ in. $\times 5$ in. are convenient dimensions). Fit panes of glass to the sides, and a piece of perforated zinc to the top; all the sides but the one in front can be made of perforated zinc, if desired. The larvæ, bought from a dealer, 
or collected in early summer, can be put upon the food-plant, and covered by the frame. They feed almost incessantly, grow fast, and change their skins from time to time. The full-fed larva of the tiger-moth is about two inches long, of a beautiful velvety black varied with brilliant white warts, from which spring bunches of long and close-set hairs, which are foxy-red on the sides of the body and towards the head, but black, tipped with greyish white, along the back. When alarmed, the larva (which is called "woolly-bear" from its hairy covering) rolls itself up into a ball, and lets itself drop. The long, elastic hairs break the fall, and after lying quiet for a minute or so, the caterpillar begins to creep about again. Hedgehogs use the same artifice when they wish to let themselves down from a height. Woolly-bears are active in their habits, and creep pretty fast. About the end of June they begin to spin the cocoon. Seeking a sheltered corner, they secure their bodies with a few outer threads, and then spin a dense cocoon, into which they weave most of their own hair. At last the larval skin, thus denuded, splits and is cast off. A shining black pupa is now revealed, which lies motionless within the cocoon for four or five weeks, until the parts within are perfected, when the pupa-skin cracks, and a handsome moth with thick reddish body, fore wings of umber mottled with cream colour, and hind wings of red, spotted with brown and black, makes its appearance. The moths when living at large, copulate and lay their eggs, which soon hatch out, and produce a brood of small hairy caterpillars. These feed awhile, but before they have grown to any considerable size, winter forces them to crawl into biding-places, where they lie dormant till the following spring.

Such are the most obvious features of a Lepidopterous lifehistory, and without knowledge or skill beyond those of the schoolboy we may observe them for ourselves.

When a number of moths are reared in captivity, we may now and then be lucky enough to observe what takes place at the time of pupation. The larval skin splits, and the insect within wriggles out. It is pale and flabby, altogether unlike the larva in form, but resembling, except in colour, the imago or winged insect. It possesses two pairs of wings of simple form, and much smaller than those of the moth, six long legs, feelers, and a proboscis like those of the moth, and 
quite unlike anything that has been seen in the larva. All these appendages are movable, though enclosed in a transparent envelope, or pupa-skin, and for a short time the pupa is a free-limbed pupa. In the act of extrication or immediately after, the appendages bend forwards, and are arranged with perfect symmetry upon the sides and ventral surface. Then a fluid, which is probably chitinous, though it resembles varnish, exudes from the body, and glues down all the appendages. The pupa becomes agglutinate, and until the moth escapes from its close-fitting and rigid envelope, only the most limited movement is possible. It is not true, therefore, though many books and teachers continue to repeat the statement, that the body of the moth forms during the pupal stage. Externally, at least, it is complete when the pupal stage begins. But the muscles which actuate the new organs are still very imperfect, and many other details of structure have to be acquired before the winged imago is fit for its brief but active career. Sections through an early pupa show that much of the interior is occupied by a nearly fluid, cellular pulp, in which the rudiments of many essential organs can only be made out by microscopic study.

Even before the pupa frees itself from the larval skin the most characteristic organs of the moth can be distinguished. 'Take a full-fed larva, kill and harden it by dipping it for a moment in boiling water, and then strip off the outer skin. There will be found beneath it the wings and legs, the feelers and mouth-organs of the fly. The change of the crawling caterpillar into a flying moth is prepared long in advance, and the minute rudiments of the new organs can be detected by refined methods of inquiry long before the feeding-stage comes to an end.

With the larva, pupa, and imago of the tiger-moth before us, we can remark the points of external structure which distinguish each stage of a Lepidopterous insect. The larva has been described in Lesson $x_{2}$ (p. $5 \mathrm{r}$ ). In the pupa we can make out with some attention the head, which is bent down along the ventral side of the body. The proboscis is stretched out along the middle line, and can be seen to be composed of lateral halves; a pair of pointed projections, touching one another along the middle line, are the labial palps. On either side of the proboscis two legs appear; then comes the feeler; the hind 
legs are concealed by the wings. The legs are bent, and only the tibia and tarsus are visible. Just within the base of the feeler a prominence marks the position of the compound eye. On the sides of the body are the wings, the hind pair being almost altogether hidden by the fore pair. The ten segments of the abdomen are visible on the back of the pupa: the first and last but one are of small size, while the last is conspicuous, and bears a spinelike projection.

The moth shows two pairs of broad wings and three pairs of long legs. The wings of the male are connected at the base by a stout bristle which projects from the hind wing, and is held by a hook-like tuft on the fore wing; in the female the bristle is divided into three or four, and is shorter than in the male. When at rest the wings slope, and are somewhat folded. On the head we distinguish the large, black, compound eyes, the feelers, slender and hairlike in the female, pectinate (comb-like) in the male. The proboscis is rather short, rolled twice round, and so

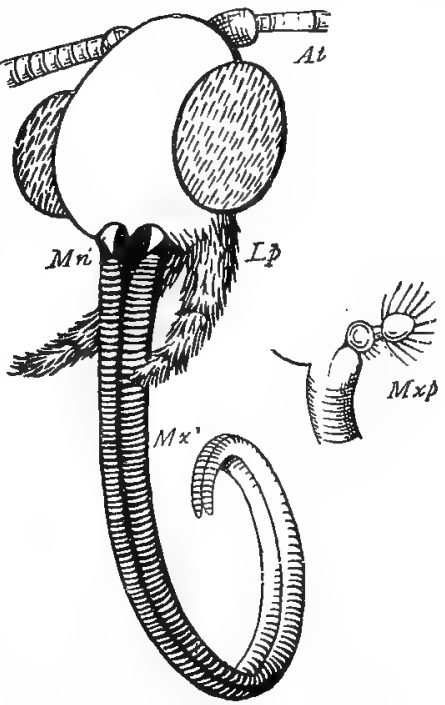

Fig. 43--Mouth.parts of lurnet moth. The identity of the parts marked .1/ with true mandibles has been questioned. kept out of harm's way; it consists of two flexible, grooved, many-jointed rods (the maxillæ), which can be closely applied to one another, and held in place by innumerable hooks, when the two grooves unite to form a tube, along which the sweet juices of flowers can be sucked up. The labial palps stand out like tusks on each side of the proboscis. The hairy body does not show its true form until it is wetted with alcohol, or divested of its covering by careful brushing; the thorax will then be seen to consist mainly of a large mesothorax, which bears the fore wings; the prothorax is reduced to a narrow 
"collar," and the metathorax is also much reduced. A narrowed waist connects the abdomen with the thorax.

Lay one of the wings in a watch-glass with a little alcohol, and brush it with a camel-hair pencil cut short. Brush until the wing is bare, and the veins appear. Examine a! few loose scales with the microscope, and also study a bit of wing from part of which the scales have been removed, while another part is undisturbed. The scales are set in rows, and each is attached by its slender tip to a hole in the wing. The pattern of the veins is often employed as an aid to the classification of Lepidoptera.

\section{CABBAGE WHITE BUTTERFLIES (Pieris)}

Three species of these mischievous insects are commonly

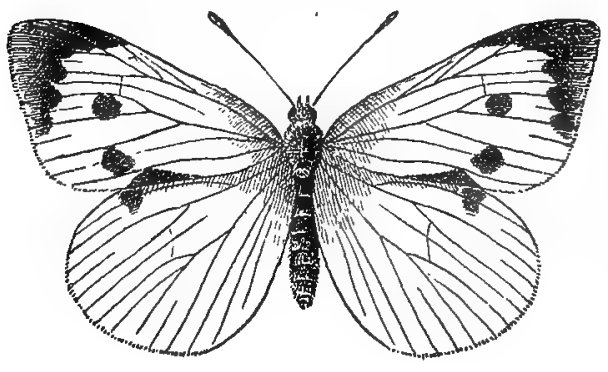
met with in this country, their caterpillars feeding upon cabbages and allied plants, such as mustard and turnips. They are distinguished as the large, the small, and the green-veined cabbage whites. The butterfly of the large species mea-

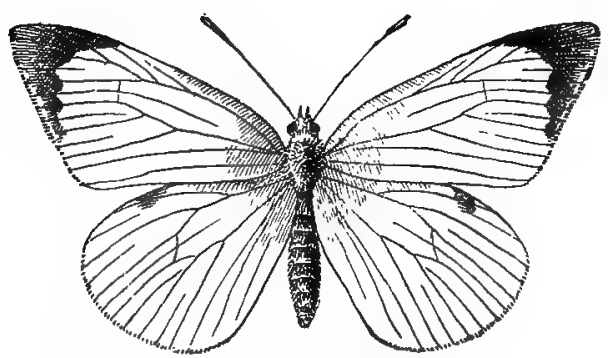
sures $60 \mathrm{~mm}$. or more across the expanded wings, that of the smaller species is only about $50 \mathrm{~mm}$., while the greenveined butterfiy is about as big as the second, or a little smaller. The

Fig. 44. - Large cabbage white. The upper figure represents the female. markings on the 
wings are very similar in the first two, but the green-veined species has greenish veins on the under side of the hind wings. The larvæ can be distinguished without much difficulty. That of the large species is yellow, spotted with black; that of the small cabbage white is green, spotted with black and yellow; while the larva of the green-veined species is green all over, except for the reddish spiracles, and a yellow border which surrounds each one. The eggs of the first species are laid in clusters on the under side of a leaf, while those of the other two are laid singly.

Wintering as pupæ, the insects emerge in spring as butterflies, and commonly produce two broods in the course of the summer. There is, therefore, no time between April and October when we may not

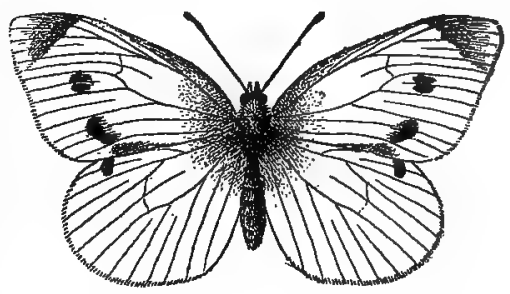
see the butterflies flitting over the fields, while the larvæ often feed till near Christmas. When full-fed they quit the food-plant, and betake themselves to the nearest dry and sheltered refuge that they can find. There they proceed to hang themselves up and pupate. The larva creeps up a paling or wall, chooses

a convenient spot, and covers it with a little hillock of silk, to which the tail-end of the body, which bears hooks, is soon attached. But since the pupæ of the cabbage whites do not hang downwards, like many other Lepidopterous pupæ, but rest upright, a second attachment is provided. This takes the form of a girdle. Silken threads, issuing from the mouth of the larva, are passed backwards and forwards from one point of the supporting surface to another, and attached at both ends. When enough threads have been spun to give due strength to the girdle, the larval skin 
is shuffled off downwards, like a stocking stripped off the leg, the loose skin of the upper part of the body being passed through the girdle. In order to provide room enough for this, the spinning larva doubles up its body, throwing the head far back, so as to give it a wide sweep. When once the larval skin is cast, the pupa has only to lean back a little, in order to get a comfortable support from its girdle.

The cabbage whites illustrate the points of difference

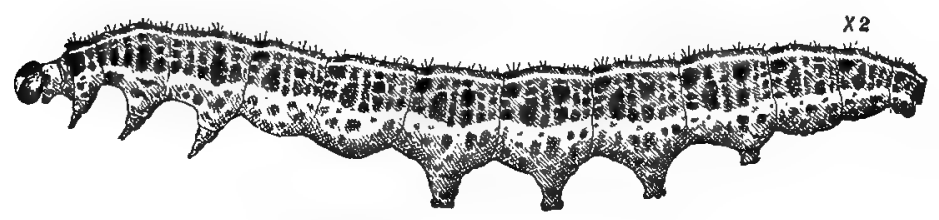

Fig. 46.-Larva of large cabbage white. $\times 2$.

between a butterfly and a moth. In them, as in all butterflies, the wings are broad, erected over the back when at rest, or fully expanded, but never folded fanwise, as often happens in moths. The fore and hind wings are never secured by a bristle and catch, as is the case with most moths. The body is slender. The feelers are long, and thickened or knobbed at the tip. Like other butterflies, the cabbage whites fly by day, and usually only in sunshine. The pupa is fixed by the

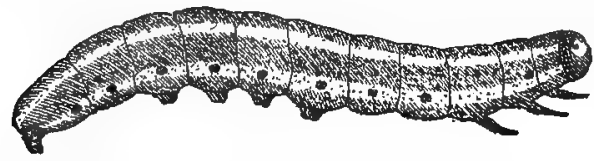

Fig. 47.-Larva of small cabbagre white. $\times 2$. tail, and, as in some other butterflies, is further secured by a silken girth.

It is hard to find a simple and effective remedy against the larvæ of the cabbage whites. Washes and sprays produce little effect, for the larvæ conceal themselves on the under side of the leaves, or in the heart of the cabbage; and, besides, there is a waxy bloom on a cabbage-leaf, which throws off the liquid. It is possible, by patient search, to remove the egg-clusters of the large cabbage white, but the process is slow and troublesome; no one would dream of hunting for the single eggs of the other two species. A frequent change of crop will keep down the numbers of 
this or any other insect-pest, if there are no other breedinggrounds close at hand. It is possible to find and destroy the pupæ, which lie up on palings, walls, and similar objects. A quick eye is needed to distinguish them, and unless their places of shelter are scrupulously searched at frequent intervals they become safe retreats instead of traps, and should be abolished as far as possible. No means of extermination that man can devise is nearly so effectual as the ichneumons, an account of which is given in Lesson 22 . In certain years so large a proportion of the larvæ are ichneumoned that for some years afterwards the cabbage whites are comparatively few. In this, as in other cases of insect attacks, liberal feeding may help the crop over the time when it is most liable to serious injury.

\section{THE GOAT-MOTH (Cossus ligniperda)}

The caterpillars of the goat-moth are very destructive to standing timber, devouring the wood of healthy trees of

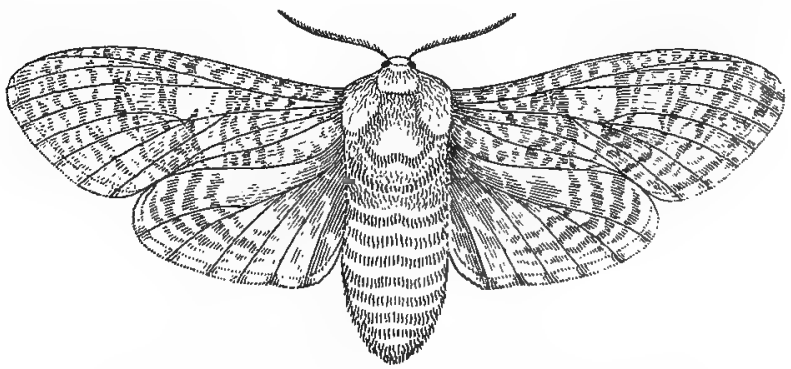

Fig. 48.-Goat-moth (female). After Roesel von Rosenhof.

many sorts. They are most commonly met with on the willow and poplar, but the damage which they do to oaks causes the most serious loss.

The female is a large, thick-bodied moth of brown and grey colours, from 70 to $90 \mathrm{~mm}$. across the expanded wings; the male is decidedly smaller. The fore wings are long, and marbled or mottled with black and white; the hind wings are short, rounded, and nearly uniform in colour. The 
feelers are pectinate (comb-like) in the male, serrate in the female; the proboscis is reduced to a vestige. The moths are sluggish, and remain notionless throughout the day on the trunks of trees, escaping notice by their resemblance to the silvery bark on which they rest. They appear in July. The female lays her eggs in the cracks of the bark, near the ground, and sometimes on the roots of the tree.

The fresh-hatched larvæ at first gnaw only the bark and young wood; but after the first winter they bore deep, and run long galleries through the wood in a more or less vertical direction. Though the young larvæ are always low on the tree, the older ones may be found up to the height of a man above the ground. The larger galleries are wide enough to admit a lead-pencil, or even a finger. The caterpillars feed only on sound wood, and usually attack trunks of good size, at least as thick as a man's arm. Exposed and solitary

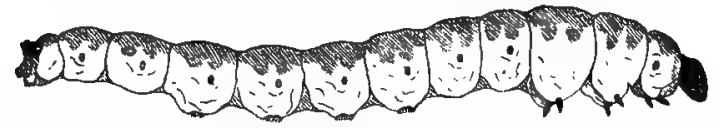

Fig. 49.-Larva of goat-moth.

trees are more often infested than trees growing together in a wood or plantation, and the outermost trees of a wood are selected in preference to the rest. The larvæ do not feed in winter, but lay themselves up near the bark. They feed for two years before pupating, resembling wire-worms and cockchafers in their prolonged larval stage. It has often been remarked that complete protection and a sure supply of food tend to protract the duration of the larva. $A$ diet of fresh leaves, and more than all, of animal food, tends to abbreviate the larval stage. Full-fed larvæ are about $80 \mathrm{~mm}$. long ( 3 inches); the males, however, being shorter. There is a black head, a pair of dark shields on the segment next behind the head, and a single large shield on each of the following segments. The body narrows behind, and is almost free from hair. Young larvæ are pink, like boiled shrimps; but the colour darkens with age to a reddish brown, and the shields at length turn almost black. The presence of these caterpillars in a tree is indicated by 
the sawdust which falls from their workings, by the holes in the trunk and the sap which oozes from them, by the empty pupa-skins sticking out from the trunk, or, in some cases, by the disagreeable sour odour, rather like that of crude acetic acid, which is given off by the larvæ. It is on account of its peculiar smell that the insect has received the name of goat-moth. The full-fed larva makes its way to the surface of the tree-trunk, and there pupates about midsummer, within a cocoon of sawdust lightly spun together. The cocoon is placed close to the outlet of the gallery, so as to facilitate the escape of the moth. The pupa is of a reddish brown colour ; the fore part of its body is compressed to the shape of a wedge; on each of the abdominal segments is a single or double transverse row of pointed projections, and the end of the body bears short spines. Such roughening of the skin is common in larvæ or pupæ, which have to travel along narrow spaces. The pupal stage lasts only two or three weeks. When the time for emergence comes the pupa cleaves its cocoon by pressing its wedge-shaped body against it, and moves onwards till the wing-sheaths are completely protruded from the hole. The fore part of the pupa-skin then splits into two, and the winged moth becomes free, the empty pupa-skin being left sticking out of the hole. Sometimes the larva pupates underground in an earthen cocoon.

The damage done by the larvæ of the goat-

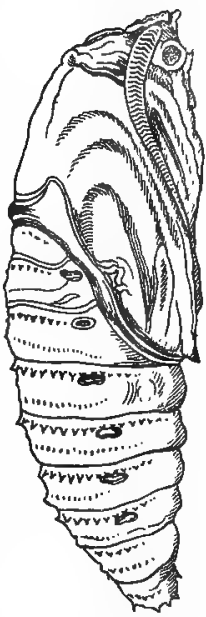

Fig. 5o.-Pupa of goat - moth, after Lyonet. moth is often not discovered until the trees are seriously injured. It is easy to draw out, or at least to destroy, the caterpillars by passing a wire into their holes; or a wash of soft soap and petroleum may be injected with a syringe. Since the eggs are always laid near the ground, it is possible to hinder the moth from visiting the tree by smearing the base of the trunk with a repulsive substance. A mixture of cow-dung, clay, and lime, worked up with tobacco-water to the consistence of oil-paint, may be laid on with a brush in the end of June, and allowed to dry hard. The trunk should 
be painted to a height of four or five feet, and petroleumemulsion poured upon the earth about the base of the trunk. Badly infested trees should be felled and split, all caterpillars lurking in the wood being destroyed at the same time with wires. The green woodpecker is useful in keeping down the numbers of the goat-moth, and its stomach is sometimes filled with the larvæ.

\section{THE SILKWORM (BOmbyx mori)}

Though the silkworm is not native to Britain nor to any part of Europe, and though all attempts to acclimatise it in England have failed, it is an insect so important to industry that we feel bound to give some account of it. The insects which are directly serviceable to man are few, and not a single one is indigenous to our northern countries. First in importance come the hive-bee, and the silkworm. Next, but distinctly inferior to the first class in usefulness, we should place the cochineal-insect, and the lac-insect. After these there seems at first sight nothing worth mention, except perhaps the blister-beetles, the few insects which are used as food, mostly by savage races, and the insects used as bait by the angler. But we are overlooking infinitely greater benefits received from insects than any which we derive from their bodies or their secretions. A large proportion of our flowers depend upon the visits of insects for the setting of their seeds, and among these flowers are many of great practical importance, fruit-trees, forage-plants, and vegetables. Insects constitute the sole food of large tribes of birds, and some part of the food of nearly all. Were it possible to exterminate all insects except such as are known to be directly profitable to man, we should lose many an agreeable fruit, many a beautiful flower, and most of our song-birds. The daily life of the artisan and the labourer would be impoverished, as well as the studies of the biologist.

The silkworm is now known only as a domestic species. It is native to China, and probably as a wild species inhabited the mountainous regions of Northern China. Though introduced long ago to Japan, India, and other countries bordering on China, we have no proof that it was indigenous in any of 
them. The natural food of the silkworm was no doubt the leaves of the white mulberry, on which it thrives best. The black mulberry of Persia and other northern countries, which bears the well-known fruit, may also be used as the food-plant, but the quality of the silk is impaired thereby. Long domestication has made the silkworms dependent on the protection of man. They have lived so long under shelter that the caterpillars cannot keep their hold when exposed to wind; they do not know how to screen their bodies from sun or rain, nor how to escape insect and bird enemies. They will often bite through the base of the leaf upon which they are feeding, and so fall to the ground; some are incapable of remounting the tree from which they have fallen, or even of passing from leaf to leaf. The wings of the female moth are imperfectly expanded, and she does not attempt to fly. This is common in wild Bombycidæ, and is no mark of artificially induced degeneration. But the males are almost as incapable of flight as the females; at most they are able to flutter downwards, never upwards. In a wild species such inactivity in both sexes would soon lead to total extinction. Attempts have been made to accustom silkworms to live in the open air, and there are some indications that persistent experiment and selection might restore the hardiness and vigour which this insect no doubt enjoyed when leading a free life. Where silkworms are reared for curiosity, the quality of the silk being neglected, lettuce-leaves are commonly used for food. They will also eat nettle and oak, but do not thrive on them. Silkworms require either a warm climate or artificial heat. Even in Italy and southern France they require protection from the cold, and the eggs do not hatch spontaneously in spring. Many attempts have been made to introduce silkgrowing into new countries. England, Ireland, Denmark, Sweden, Virginia, Pennsylvania, California, Mexico, all in their time entered upon this industry with great hopes, which were doomed to utter disappointment. Cheap labour is as necessary as a genial climate and a suitable food-plant. So far the only countries which meet all the conditions of silk-growing are China, Japan, Bengal, France, Italy, and Asia Minor.

In southern France the silkworms are reared in special buildings (magnaneries) which are well-ventilated and carefully warmed, the air being frequently tested by thermometers 
and hygrometers. Separate rooms are provided for hatching the eggs, rearing the larvæ, and storing the mulberry-leaves, which are carefully stripped from the trees, and half-dried. A single annual brood is considered to answer best. It is possible to raise more than one, and there are races of silkworms which regularly produce two or three generations in the year, but the difficulty of procuring a sufficient supply of food late in the summer is an effective check to the multiplication of annual broods. The eggs are laid upon pieces of cloth or stout paper, to which they adhere. A gramme of graine (eggs) contains I 500-I600 eggs, of which one moth will lay from 400 to $55^{\circ}$. The eggs are kept from hatching prematurely by storing in icehouses or other cool places, and are hatched out by artificial heat when the mulberry-leaves are ready to be gathered. The grub forms in the egg not long after laying( in summer), and can be artificially hatched at any later time if required. It bites its way through the firm egg-shell, but sometimes finds a difficulty in freeing its body from the fragments. Pieces of paper with small holes pierced in them are put over the hatching-trays, the larvæ creep through the holes to the light, and in doing so, scrape off any bits of the envelope that still adhere. As a rule, the larval period is interrupted by four moults (there may be only three), and is therefore naturally divisible into five stages. Great pains are taken to cause all the larvæ of one magnanerie to go through these stages simultaneously. A batch of larvæ which lag behind the rest may give much trouble in such matters as food-supply, or the regulation of the temperature of the rearing-chamber. At times of moult the larva becomes motionless, and ceases to feed for a day or more. The old skin becomes loose and wrinkled, and is fixed to the support by a few silken threads paid out from the mouth. At length it splits along the fore part of the back, and the larva disengages itself. The following points characterise the various stages:-

Stage 1. (From hatching to the Ist moult, 5 days.) The freshhatched larva is only I $\mathrm{mm}$. long, but immediately lengthens to $2 \mathrm{~mm}$. It is dark, almost black, and covered with hair. The head is relatively larger than in succeeding stages.

Stage 2. (Between ist and and moults, 4 days.) The larva is $9 \mathrm{~mm}$. long at the beginning of this stage. The hair is scanty, and the colour grey. 
Stage 3. (6 days.) The larva is $14 \mathrm{~mm}$. long at the beginning of this stage, smooth, and of yellowish-white colour, showing crescentic markings on the and and 5 th abdominal segments, as was the case also in the latter part of stage 2. The head is red, sometimes black.

Stage 4. ( 7 days.) The larva is $27 \mathrm{~mm}$. long at the beginning of this stage. The space allowed to the larvæ has now to be increased, and a number of them are removed to fresh trays.

Stage 5. (Io days.) The larva is $40 \mathrm{~mm}$. long at the beginning of this stage. Its voracity is now marvellous. Where many are kept in one room, the sound of their jaws resembles the patter of heavy rain. At length, when they have attained a length of about $9 \circ \mathrm{mm}$., they pause, and show an inclination to leave their food. During this 5 th and last stage diseases, sometimes contracted long before, it may be before the larva was hatched, often show themselves for the first time, and the larvæ are watched with much anxiety.

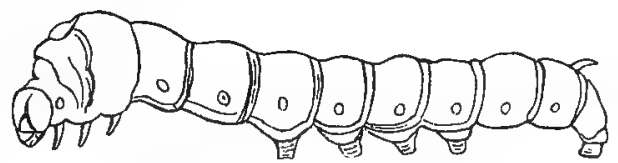

Fig. 5r.-Silkworm. After Westwood.

They require a somewhat higher temperature than before, and the air of the room is kept at $23^{\circ}-25^{\circ} \mathrm{C} .\left(73^{\circ}-77^{\circ} \mathrm{F}\right.$.). Sudden changes of weather, foul air, or vitiated food produce heavy mortality at this time in ill-kept establishments.

We will interrupt the life-history in order to describe the larva at the time of its maturity. When full-fed and of large size, it may attain a length of $90 \mathrm{~mm}$. (upwards of $3 \frac{1}{2}$ inches), but the different breeds vary a good deal in this respect, and $75 \mathrm{~mm}$. ( 3 in.) is a maximum with some of them. The body is slender in comparison with most Bombycidæ. The colour, which was dark, approaching to black, in the fresh-hatched larva, grows paler at each moult, and at last becomes a translucent greenish or yellowish white, like that of a muscatel grape. The head is small, hard, and red or blackish. Behind it come twelve segments to outward appearance, but really thirteen, of which the last but one is only obscurely indicated; its distinctness is established by comparison with the imago, 
where the corresponding segment is particularly large. These thirteen segments are divisible into three thoracic and ten abdominal. The last but one bears a short dorsal horn, resembling that of a Sphinx-larva, though of smaller size. The first segment behind the head (prothorax) is small, and looks like a mere neck, the meso- and metathorax are large, not clearly separated, and make a prominent hump. As usual in Lepidopterous larvæ, each thoracic segment bears pointed, five-jointed legs, while pseudopods or false feet, unjointed and ending in coronets of hooks, are borne upon the $3 \mathrm{rd}, 4^{\text {th }}$,

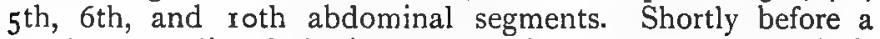
moult a peculiar dark ring appears in the prothorax; this is the new larval head, which forms, not within the old one as in most insects, but behind it. The soft structures are gradually withdrawn into it, and before the skin is cast, the old head is nothing but an empty shell. The same thing happens in some other insects, with a relatively small larval head; it is to be explained by the lack of space within the old head, and is a simple case of a method of development which in certain Diptera becomes very complex and peculiar.

The internal structure of the larva is much the same as in other caterpillars. The silk-forming organs have naturally received much attention from insect-anatomists, and call for some special notice here. In insect-larvæ there may be several successive pairs of salivary glands, which take different forms, and pour out different secretions. In the silkworm one pair of these glands are large and easily demonstrated by opening the body from beneath. We then see the long, coiled, and rather voluminous glands extending through a great part of the length of the caterpillar; they are so long that one of them, when uncoiled, is nearly five times the length of the larva (14-15 in.). The extremity of the gland is very long, slender, and tortuous, forming a tangled mass, which overlies the intestine. This opens into a wider portion, of about twice the diameter of the preceding, which is bent twice upon itself, and when thus bent occupies about half the length of the body-i.e. the two middle fourths. In front it gradually narrows to form the salivary duct. Careful dissection with a good lens brings to light further details. Where the two ducts fuse together there is a muscular enlargement, the 
press, and just behind it a pair of small, much divided glands open into the common tube. The common duct can be traced forwards to the spinneret, which opens on the labium, beneath the head (see p. $5 \mathrm{I}$ ). There is yet another pair of salivary glands, which open independently into the mouth, and probably form the only part of the apparatus which has any digestive function, but these can only be made out by a practised dissector. The large convoluted glands already described, whatever may have been their original function, are now solely employed in the elaboration of silk, and may conveniently be called the silk-glands. The walls of the glands are lined by a regular layer of cells, which secrete fluid silk, and store it up till it is wanted. When exposed to air, this fluid silk solidifies, and forms a tough substance, about as firm as horn, which, drawn out into fine threads, constitutes the silk fibre. If we magnify a thread cut from a silkworm's cocoon, we soon discover that it is double, each thread consisting of two flattened, ribbon-like filaments, and that the component filaments are glued together. Hot water dissolves the glue, and sets the filaments free. Some notion of the tenacity of silk may be got by remarking that the secretion when drawn out from the body of a fresh-killed silkworm, stretched between pins, and dried, forms the gut so highly esteemed by anglers. The silkworm draws out its silk so fine that the thread used in a single cocoon is about 4000 feet long, say $\frac{4}{5}$ of a mile ; nevertheless, it is amply sufficient to bear the weight of the full-fed larva. The tenacity of a silk thread is only exceeded by steel wire, drawn copper wire, and aluminium bronze; platinum wire is inferior to it. The two threads are formed independently in the two salivary ducts, and apparently emerge ready-coated with the glue (this has been both affirmed and contradicted). They are then passed through the press and consolidated. Whether they receive at this point the secretion of the glands which open just behind the press, and what the nature of that secretion may be, are questions on which no certain information is to be had. Finally the thread, fully formed and consolidated, is emitted by the spinneret. We do not know how and where the coagulation of the fluid silk takes place, except that the process is complete before the thread leaves the spinneret. For a considerable part of the three days spent in forming the 
cocoon, the thread is delivered at a greater rate than a foot per minute, and the coagulation must therefore be very rapid.

When the larva has done feeding it rests for a short time. The body shortens, the skin of the neck becomes wrinkled, and a long silken thread may usually be seen trailing from the spinneret. Provision has been made long before by the silkworm breeders for the next event, which is the ascent of the larvæ to the places where they will form their cocoons. These are arranged above the feeding-trays. In old days mulberry branches were set up to receive the climbing larva. Then it was observed that any other twigs would do as well, for after this the larvæ feed no more. It was long the practice to leave each silk-worm to choose its own retreat, but this plan had serious inconveniences. They often begin to spin so near together, that the spiral turns of the threads become crossed, and then double cocoons are formed, which cannot be unwound. To render this difficult or impossible, special cells of wood or paper have been devised, in which two silk-worms cannot find room to spin. When the larva has established itself in a dark recess, it begins to spin, first securing its body by threads attached to different fixed points. At length the head begins to revolve steadily round the body, which is first veiled and then completely hidden. In three days the cocoon of golden or silver threads is complete, and the larva rests from its labours. The withdrawal of so much silk has materially reduced the size of the body, and this facilitates the casting of the last larval skin. The silk-glands shrivel and disappear. If the cocoon is carefully examined, it will appear that the first and last portions of the silk-thread differ from the intermediate portion, which greatly exceeds them in length. The first spinning forms loose flaky masses, which can only be utilised as silk-waste; then comes the chief bulk of the fibre, which is readily unwound; last of all, and next to the body of the silkworm, is an inner, felted tissue, which gradually becomes too close for unwinding.

Ever since the beginning of the fifth stage the growth of the moth within the larval skin has been steadily advancing. Special nests of epidermic cells, at first quite superficial, form the first rudiments of the future head, legs, wings, and external reproductive organs. These grow dense, take more and more definite shape, and then, finding no room to expand between 
the body and the chitinous cuticle, become telescoped inwards. In the resting larva within the cocoon, all the characteristic organs of the moth are pretty near completion. The muscles and nerves, it is true, are still rudimentary, and the new parts are soft and white, but they are taking their final shape, and having now gained additional space owing to the emptying of the silk-glands and the relaxation of the dead larval skin, they project from the external surface much as they do in the moth. An old experiment of Swammerdam is instructive on this point. Take a resting silkworm, dip it for a few seconds into boiling water, and then strip off the larval skin. The new head, with its compound eyes and feelers, the wings, and the long, slender, many-jointed legs will be found within, either more or less sunk into the body, or completely protruded, according to the age of the larva. At length, in the natural course of events, the larval skin bursts, the moth, clad in a temporary, transparent, and close-fitting pupal skin, emerges, folds its long appendages slowly into a symmetrical position, so that they may be supported without crowding or overlaying, and then exudes a sticky fluid, which hardens rapidly and binds all together. In a few hours the pupa is covered with a firm brown varnish, which protects it from injury, and, at the same time, renders it incapable of any but the most limited movements.

Internal growth still proceeds, the last details of the tissues are elaborated, the surface of the imprisoned body acquires its appropriate ornaments, and then one last moult sets the moth free. It generally makes its escape early in the day, from a fortnight to three weeks after spinning up. As soon as the head finds itself impeded by the interwoven silk, a fluid (probably secreted by the salivary glands) is projected from the mouth. This softens the fibres, which are then easily displaced. The moths shun the light; their mouths close, and there is no more solicitude about food. Mating and egglaying are the sole business of the few days which remain to be spent.

In the ordinary course of business the breeder now proceeds to select the best cocoons for egg-production. The rest are sorted; those containing dead worms, besides doubles and other malformations, are put aside; cocoons not required for breeding are killed by heat, and the winding of the silk 
begins, a process which we shall not describe here. The cocoons selected for breeding are divided into males and females. The male cocoons are lighter, less regularly rounded at the ends, and narrowed in the middle. The sexes are kept apart, so that the males may not be excited by the odour of the female, which sets up violent struggles for liberty, A yellow fluid is discharged from the intestine before the moths are considered ripe. Then mating is permitted, and shortly afterwards the female begins to lay. The male moths perish early, but the females live several days, longer in cool weather than in hot. For at least three centuries it has been known that unfertilised females, occasionally though rarely, lay eggs, from which normal larvæ proceed.

The body of the moth is thick (especially in the female) and

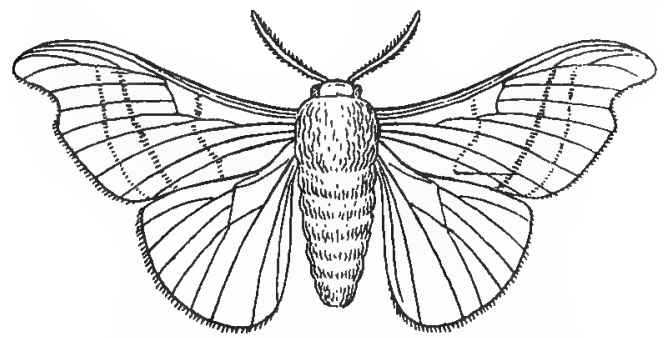

Fig. 52.-Male silkworm moth. After Westwood.

hairy. The feelers are pectinate (with comb-like projections), especially in the male. The fore wings are falcate (with a concave incision behind the tip). Both wings are creamcoloured, with faint transverse streaks of darker colour, and are extended when at rest ; the legs are densely clothed with hair. The length of the female is about $21 \mathrm{~mm}$., and the expanse of wings $43 \mathrm{~mm}$. The moths occasionally utter a faint sound.

Silkworms are subject to several infectious diseases, which have caused ruinous losses in the crowded rearing-houses. The story has often been told how, when the prosperity of large districts in the south of France was destroyed by pebrine and flacherie, Pasteur, who had never treated any animal for any disease, was called in as adviser, how he learned the 
marks of the disorders which afficted the silkworms, traced the modes of infection, and at length discovered how to separate sound from infected eggs, and how to maintain a race of silkworms free from disease. While we learn from this memorable story what great and beneficent results may be accomplished by the genius and unflinching labour of one man, we learn also lessons more applicable to the ordinary affairs of mankind, where neither genius nor heroic sacrifices can be counted on. We learn that the experimental habit of mind may be more productive, even in the biological sciences, than much professional learning, and that true science can win for any nation rewards for which no price is too high.

\section{THE VAPOURER MOTH (Orgyia antiqua)}

Caterpillars of this common species are now and then found in gardens in great abundance, devouring the leaves of many different trees and shrubs. When the vapourer has swarmed to such a degree as to cause much damage, it often falls off in numbers, and escapes notice for years together. This occasional abundance is a common thing with insects. Sometimes it is due to temporary freedom from the attacks of ichneumons and other parasites (see gooseberry saw-fly, p. 94), but this explanation will not meet every case. Vapourer caterpillars usually appear for the first time in the year towards the end of June, and are perhaps more often discovered on roses than other plants; a second brood is often hatched out in September. They are of active habits, running about with considerable agility upon occasion, and making their way without difficulty to distant trees and shrubs. Owing to their accommodating tastes in the matter of food, they are very easily reared in captivity, if simple precautions are taken to prevent them from straying, and few of our insects are better worth close observation.

The caterpillar is often about $50 \mathrm{~mm}$. ( 2 in.) long when fullfed, but a certain proportion never attain these dimensions, pupating when only about $30 \mathrm{~mm}$. long. These smaller caterpillars produce male moths, the larger ones female. The caterpillar is easily recognised by its conspicuous coloration. 
The ground-colour is usually a dark grey, diversified by reddish warts, as well as by longitudinal streaks of white and black. Brushes of variously coloured hairs stand out from the body. A little behind the head is a pair of long black pencils, which point forwards. Four segments near the middle of the body bear shorter tufts of white hairs, standing erect on the middle of the back; from the sides of the two foremost of these four segments lateral pencils project, the first pair being tawny, the second black. A long black pencil points backwards from the end of the body, and forms a kind of tail. Professor Poulton tells us that "a caterpillar of the common vapourer moth (Orgyia antiqua) was introduced into a lizard's cage, and when attacked, instantly assumed the defensive attitude, with the head tucked in and the 'tussocks' separated and rendered as prominent as possible. An unwary lizard seized the apparently convenient projection; most of the 'tussock' came out in its mouth, and the caterpillar was not troubled further. The lizard spent a long and evidently most uncomfortable time in trying to get rid of its mouthful of hairs." *

When full-fed, the larvæ spin whitish cocoons, interwoven with many of their own cast hairs, and change to pupæ. In a few days the moths emerge, and then a striking difference in the outward form of the sexes is remarked. The male moth has rather broad, tawny wings, each marked with a conspicuous whitish spot. His feelers are comb-like, with a double row of fine and close-set projections. Their large size and complex structure indicate that they are the seat of a well developed organ of special sense. The male moth flies fast, hovering in the sunshine, and describing a series of loops as he makes his way from garden to garden. $\mathrm{He}$ may often be seen in the squares, and even in the streets of London, where the caterpillars abound in the shrubberies. This mode of flight our forefathers seem to have called vapouring: hence the name which they gave to the moth. The female is so different that no one could have guessed that she was of the same species. Her body is covered with tawny hairs, the abdomen egg-shaped, and far too heavy for the short and weak legs. She has no wings that appear, and it is only by close examination that we discover their useless " "The Colours of Animals," pp. 197-8. 
vestiges. Her feelers are smaller and simpler than those of the male. She sits still for the short remnant of her days, close to or actually resting upon the cocoon from which she emerged, and gives no other sign of life than an in and out movement of the end of the abdomen, such as everyone has observed in bees and wasps. This is her way of filling and emptying her air-tubes.

The male is quick to detect the presence of a female. He can find her out, not only in a sheltered corner, but in the dark, or when she is imprisoned in a box. Since the female utters no sound, we conclude that he is guided by his sense of smell, which, as in not a few other insects, is probably lodged in the large and elaborate feelers. The eggs are laid upon or close to the cocoon, and the female dies soon after laying, having never flown, nor crept more than the length of her own body, nor taken a particle of food. Both male and female are incapable of feeding, for the mouth is closed up, and there is but a vestige of a proboscis.

We must now put a question: Why has the female vapourer no wings, or wings so minute that she cannot fly? Before we attempt an answer, let us consider why moths and other insects fly at all. It is not merely that they may seek their food, for they are full-grown when they get their wings, and many of them never feed afterwards. The life of an insect is often divided into two active stages, with a resting-stage between. There is a feeding-and-growing stage, when they creep, burrow, or swim; and afterwards a pairing-and-egglaying stage, in which they are often equipped for flying. The power of flight enables the female to lay her eggs far from the spot where she was herself reared, and if need be, to lay some here and some there over a wide tract of land. Then the larvæ which issue from the eggs will not be too crowded. Wings are to insects what spores are to ferns, plumed seeds to dandelions, and hooked seeds to burrs-a ready means of dispersal.

Some insects, though wingless, can make up for their inability to fly by running or leaping. Cockroaches, springtails, and flightless beetles find no more difficulty in dispersing their eggs than spiders or centipedes, which are equally wingless. But the female vapourer can neither fly nor run. All her eggs, perhaps a couple of hundred in number, are 
laid and hatched in one place. What will happen to the larva? Will they become crowded and starved? Any one who has kept vapourer-larvæ in captivity knows perfectly well that they will be in no sort of difficulty. They run boldly and pretty fast; it is easy for them to leave one tree and climb the next. And the next tree is pretty sure to yield them agreeable food. Though they may have been hatched on a rose-tree, they can feed perfectly well on hawthorn, apple-tree, laburnum, acacia, sallow, or oak. Such larvæ cannot well be crowded, nor will they starve for want of food. It would be very different if the larvæ fed only on one plant, particularly if that one plant grew singly, or a few together. The mullein moth larva, for instance, feeds upon plants which grow only a few together, and is restricted to a single kind of plant, or nearly so. Here the eggs must not be clustered, but scattered. The female must be able to fly from plant to plant, or from one clump to a distant one. This takes time, and the female must accordingly be supported by feeding. Hence she has a well-developed tongue, and can nourish herself upon the nectar of flowers. If we make a list of the moths which have no wings, or only imperfect wings, unable to support the body in the air, and then note the food of their larva, we shall find that they are either supported during the feeding stage upon the leaves of trees and shrubs, where the supply is practically inexhaustible, or else they feed upon social plants, like grass and heather, or else they are not dainty about their food, and will like what they can get, if they cannot get what they like. The winter moth, the March moth, the umber moth, and others which have no English names, are well-known examples. Where a promiscuous diet, or the great abundance of the food-plant, relieves the female moth from the labour of dispersing her eggs widely, it may be a positive advantage that she should lose her wings. She can then produce more eggs, and her abdomen may swell into a nearly globular egg-bag (as in the vapourer), which no flying insect could carry. The disuse of wings adds also to her safety. She can remain motionless in some hidden corner, safe from all enemies, and only to be discovered by the quick scent of the male moth. No male moth or butterfly is wingless. If the female flies well, the male must fly after her; if she is sedentary, he must seek her out. But in those orders of 
insects where the females habitually walk or run, both sexes are often incapable of flight. If the female can do no morethan walk, walking will suffice for the male too. Whether the parent disperses the eggs, so that the larvæ may not be crowded, or whether the young larvæ disperse as circumstances require, is a matter of no great consequence. One insect adopts one method, and another another. The responsibility for dispersal may be undertaken by the parent, or by the young, or shared between them. Whatever the larva can do for itself, the female can safely leave undone; but what the larva cannot do, by reason of sluggishness or restricted diet, the parent must provide for. Hence activity and intelligence in the one tend to degeneration in the other. A sluggish maggot, buried in its food, requires a nimble and quickwitted mother, but an active larva, able to shift for itself under a variety of circumstances, may do well enough, even if the mother is stationary.*

* Weismann has clearly pointed out the relation between a plentiful supply of food for the larva and the disuse of flight by the parent. See his essay on "Duration of Life." 


\section{BEE-LIKE INSECTS (HYMENOPTERA)}

\section{THE HIVE-BEE (Apís mellifica)}

MORE is known of the hive-bee than of any other insect. Its great industrial importance has led many observant persons in every country to attend to its mode of life; professional advisers, the "bee-masters" of former generations, have collected and transmitted the teachings of practical experience; while the talents of the minute anatomist and draughtsman have been employed to delineate every detail of structure. If there are still problems to be solved, it is because the life-history and economy of the hive-bee are of unparalleled complexity. We shall first relate the lifehistory of the hive-hee, and then give a short account of the orderly life of the bee-community. The practical details of bee-management must be left to special teachers.

The eggs are laid by the queen-bee in the honeycomb, each at the bottom of a separate cell. They are of longoval shape, and covered with a microscopic netted pattern. From the eggs are hatched larvæ, which are fed by the workers with a mixture of honey and pollen, supplied so profusely that they are bathed in the pap. They grow fast, change their skins several times, and after five or six days, as a rule, are full-fed and nearly fill the cell, which is then closed by the attendant workers with a convex, porous cap, suitable for the admission of fresh air. The larvæ, thus imprisoned, spin their cocoons, and await the change which converts them into pupæ.

The larva has a head followed by thirteen body-segments. It has no appendages, though before it left the egg every segment bore legs, or leg-like prominences. The small head is furnished with a pair of simple eyes, mandibles, maxillary palps, besides a labium, which bears the spinneret and the labial palps. Spiracles open on the sides of nearly 
every segment. A great part of the interior of the body is occupied by the stomach, which has no outlet behind.

The new structures which are required by the winged imago develop within the larva, and when the larval skin is cast, there lies within the cell, shrouded in a temporary pupa-skin, an insect which, but for its pale colour and soft texture, perfectly resembles a bee. In twelve days or so the pupal skin is cast; then the imprisoned bee bites a curved slit in the waxen cap of its cell, and pushes its way out. Though it is still soft and pale-coloured, it will in a few hours be ready to enter upon active life.

The bee-commonwealth is composed of three kinds of winged insects-(I) males or drones, (2) females or queens, and (3) imperfect females or workers. These differ so decidedly from each other that they can be distinguished at a glance by an experienced eye. The drone has a stout body and very large compound eyes, which meet on the top of the head; he is larger every way than the worker, but shorter than the queen; his abdomen is short and blunt. The queen has a particularly long body, the abdomen extending considerably beyond the closed wings. The worker is the smallest of the three. Only the queens and workers possess a sting. The legs of the workers are formed for collecting pollen; but in the drones

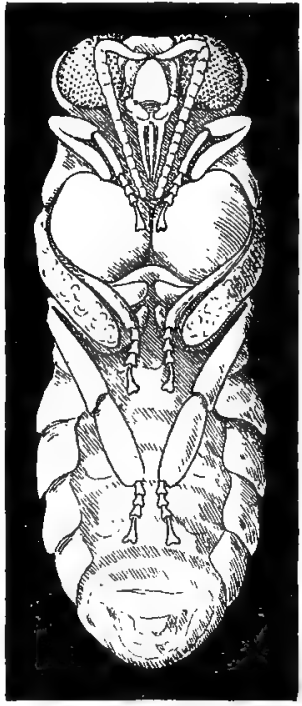

Fig. 53.-Pupa of hive-bee. and queens, though the same general proportions are kept, the details differ, and the legs are ineffectual for collection.

The head of a worker is flattened from before backwards, and almost circular in front view, except for the mouth-parts which hang down from it. On each side are the compound eyes, while on the top of the head are found three simple eyes, arranged in a triangle. The feelers spring, near together, from the middle of the face; each consists of a long basal joint, succeeded by eleven smaller ones. The 
lower part of the face is defended by the triangular plate

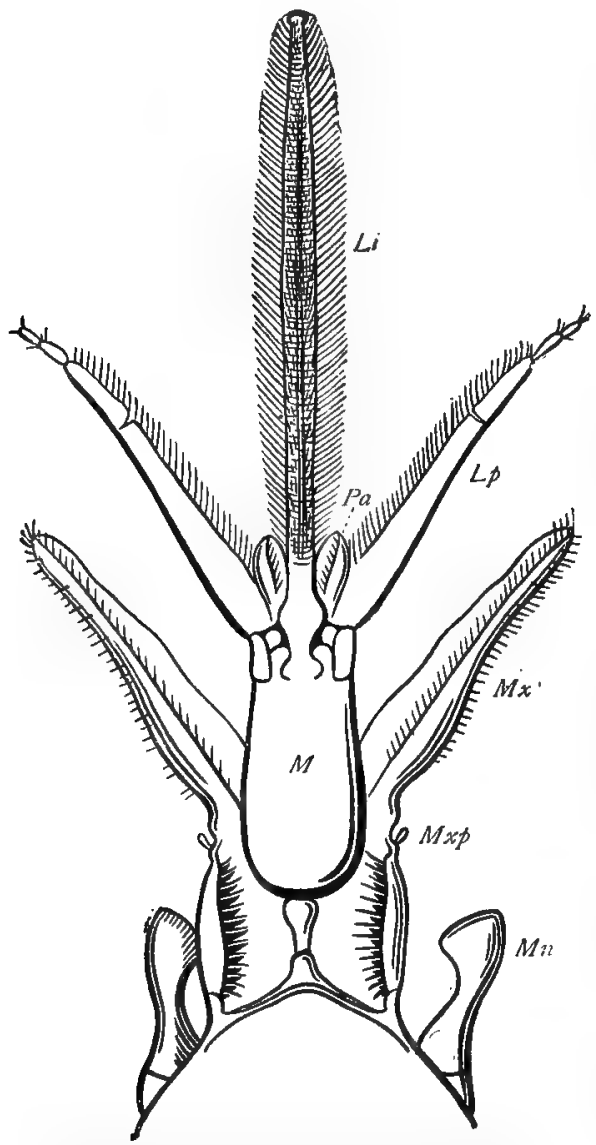

Fig. 54.-Mouth-parts of hive-bee, $M n$, mandible ; $M x p$, maxillary palp; $M x$, maxilla; $M$, mentum (base labial palp; $L i$, lingua (?), enclosed at its base in the mentum (labium). of labium); $P a$, paraglossa or galea of labium; $L p$,

called clypeus, from whose lower border a transverse labrum hangs. The mandibles are devoid of teeth, the straight inner edge being used in biting. Only one of the usual maxillary lobes can be traced (the lacinia), which forms a broad and flexible blade; a vestige of the maxillary palp can be discovered at its base. In the labium (second pair of maxilla) the labial palps are conspicuous ; they form thin, four-jointed appendages, whose tips are adapted for use as organs of touch. At the base of the labial palps, small appendages are visible which seem to answer to the galeæ of the ordinary insect - maxilla. Enclosed within the labium is the long, hairy tongue, which forms a split tube useful in sucking; its tip is a spoonshaped lobe, not unlike the "finger" of an elephant's 
trunk.* When the bee explores a deep flower-tube, the proboscis is fully extended. Supported at its base by the maxillæ and labial palps, it is firm enough for penetration into a narrow space, while its split tube, completed by the sheathing parts, renders it effective in sucking. When no longer in action, the proboscis can be retracted and folded like a carriage-step. Thus folded, it is completely hidden from view in a cavity behind the head.

The thorax consists of the usual three segments, but to these the first abdominal is firmly attached. The greatly contracted second abdominal segment forms the narrow waist, the articulation between it and the complex thorax being extremely mobile. In some wasps, ichneumons, and other Hymenoptera the waist is long; in bees it is so short that the abdomen seems at first sight to be attached by its whole breadth to the thorax, and the real state of matters is only discovered by bending down the abdomen. The prothorax, or first thoracic segment, has a . peculiar structure, the side-pieces being prolonged upwards and downwards so

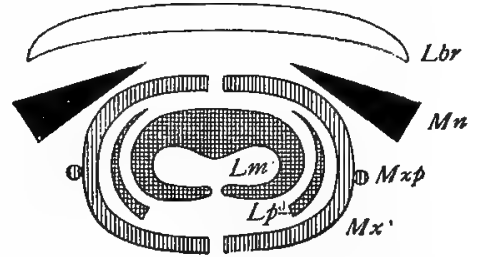

Fig. 55.

Diagram of mouth-parts of hive-bee. as to form a ring-like piece, which articulates with the head and carries the fore legs. The proper ventral half of the prothorax (prosternum) is firmly attached to the great central mass of the mesothorax. The tergum of the prothorax (pronotum) is developed in the form of the "collar," which looks like a distinct segment, and has often been so interpreted. The head and fore legs acquire, in consequence of the detachment of the prothoracic ring, an unusual power of rotation upon the hinder part of the thorax. The arrangement is quite similar in principle to what we find in the first and second vertebræ of man and quadrupeds, where part of

* The "tongue" of the bee is often identified with a projection of the floor of the mouth, technically called the lingua, but comparison with the simpler mouth-parts of certain wild bees and wasps renders it probable that it is originally two-lobed, and is an expansion of the lacinize of the second maxilla. The matter is not, however, free from doubt. 
the first vertebra, completed into a ring, rotates upon its own centrum, which has been incorporated with the second vertebra. The mesothorax, which bears the first and principal pair of wings, is of enormous relative size in Hymenoptera, as well as in Diptera and Lepidoptera. The metathorax is reduced to a narrow strip, crowded in between the mesothorax and the first abdominal segment, which, as we have seen, is in Hymenoptera fused with the thorax, and lies in front of the narrow waist. The thorax bears two pairs of spiracles, a mesothoracic pair, which is partly concealed by the movable portion of the prothorax, and a metathoracic, which lies just beneath the root of the fore wing, in the extreme front of the metathorax; it is not easily seen without breaking up the thorax. Another spiracle, which is the first abdominal, is plainly visible on the side of the first abdominal segment, which forms part of the same mass with the thorax.

The fore pair of wings are both longer and wider than the hind pair. A peculiar arrangement exists which has the effect of making the two wings of the same side into one, when the bee flies. Examine the fore edge of the hind wing with a lens. It will be observed that in the inner (proximal) half the stout rib which supports the margin of the wing bears a row of bristles, but where the outer (distal) half begins, these bristles are curved upwards and form hooks, which are arranged in a row, and cease where the wing begins to be rounded off. Next examine the hinder margin of the fore wing. The part which corresponds in position to the row of hooks on the hind wing is folded underneath as a sharp plait. When the wings are at rest the fore wing overlaps the other; when they are spread for flight, the fore wing glides outwards over the hind one, meeting no resistance until the row of hooks catches the plait; then the two wings become locked together, and act as one, being, however, automatically released whenever they are brought to the resting position.

The legs of the worker-bee, but not those of the queen or drone, possess a complex adaptation for the collection of pollen.* The first joint of the tarsus of the hind leg is greatly enlarged, and its inner face (i.e. the face which is ordinarily

* The best account of the bee's legs that I know is given by Cheshire in "Bees and Bee-keeping." 
turned towards the body) is set with many stiff spines in nine or ten transverse rows. By these rows of spines the bee combs out the pollen grains, which cling to the long weak and branched hairs of the body and legs. The tarsal combs are cleared out from time to time by means of another contrivance, which consists of regular and rather long spines set in rows along the borders of the tibia of the same leg. One row bends over the lower part of the large concave outer surface of the tibia, and thus closes in what has been called the bee's bread-basket. The legs are crossed during the transference of the pollen, so that the right bread-basket is charged from the left tarsus, and vice-versa. The intermediate leg bears a spike on the lower end of the tibia, which is used to dislodge the pellet of pollen when the bee returns to the hive. The fore leg has also a contrivance of its own. Here there is between the tibia and the first joint of the tarsus a notch which is nicely adapted to receive the feeler. The rounded concavity of the notch is roughened by a comb. When the bee has visited a number of flowers and dusted every part of its body with pollen, it combs out the pollen from its legs and body with the tarsal comb of its hind legs, but for the sensitive feeler a more delicate means is employed. The fore leg is raised, the feeler grasped by the notch, and by the closing of the joint secured as tightly as is requisite, the notch being completed into a ring by a small piece which hangs from the tibia. Then the feeler is gently drawn through the ring and combed clean. Some beetles have a similar comb. Between the tibia and tarsus of the hind leg, and just beneath the bread-basket, is a notch with prominent edges, which can be used like a pair of nippers, to draw out the plates of wax secreted between the joints of the abdomen. The last joint of the tarsus bears a pair of stout, double-pronged claws, between which is a pad. In walking over a rough surface, the bee uses its claws to get a firm hold, but on a smooth surface, such as a glass window-pane, the pad is relied on. When the claws are bent the pad is kept from contact with the ground, but by merely straightening the claws, the pad comes automatically into action. It exudes a viscid fluid, which produces adhesion, and a bee walking on a polished surface leaves tracks which can be detected by the microscope. House-flies and many other insects can employ the pads of their feet in the same manner. 
If a pane of glass is wetted with the breath, or dusted with fine flour, no insect can climb up it.

The sting of the bee is too remarkable to be passed over, but its structure is complex, and cannot be understood except by those who will take some trouble. If we remove the integument from the under side of the last exposed segment of a worker-bee, we see a whitish, conical mass, enlarged in fronti.e. towards the head of the insect, and tapering behind. This is the sting. The hard, piercing parts, which are dark-coloured, are enclosed between a pair of fleshy prominences (right and left) which form the sting-palps. The base of the sting consists of two rounded masses of muscles, in each of which we can discover, with the aid of a lens, two curved, darkcoloured, chitinous bands. With the point of a needle the central part, or sting proper, can be separated from the sheath, and parted into three. The central part may be called the guide, for reasons which will shortly be given, and the pair of slender pieces, one on either side, the darts; all three are hard, finely pointed, and barbed towards the tip; the guide being barbed on both sides, but the darts only on the outer sides. By cutting a section through the whole, which is by no means an easy thing to do, owing to the hardness of the guides and darts, their disposition can be better understood. It will then appear that the guide is three-cornered, with two convex and one concave side. The concave side is turned downwards. Running along it, and near its edges, are two parallel beadings, upon which slide corresponding grooves sunk in the darts. Each dart has its own groove, which glides smoothly upon the beading. Between the guide and the two darts a channel is enclosed, along which fluid poison, drawn from a poison-bag at the base of the sting, can be forced. Beyond the guide, the poison is enclosed by the darts alone. Though the wall of the channel is formed of sliding parts, the fitting is so true that no fluid escapes except at the further end, where it passes out by several pores close to the bases of the barbs. It may next be pointed out that the guide branches towards its base into two slender, curved arms; each dart is also prolonged at its base into a curved, slender arm, and these four arms are the dark-coloured chitinous bands already seen at the root of the sting, where the muscles which actuate them are collected. 
When the sting is protruded from the body, the darts slide upon the guide, and so lengthen the sting. By the same act the poison is injected into the wound, for each dart has a large prominence at one part of its inner side, and these prominences, bulging into the channel, sweep the fluid poison along. The sting is withdrawn from the wound with difficulty, and is often torn from the body, so that the bee is fatally mutilated by the act of stinging.

By the anatomical study of late bee-larvæ it can be shown that the darts arise as paired outgrowths from the under side of the last segment but two. On the last segment but one there are also paired outgrowths, which in an early stage of development become divided into four, two inner and two outer.* The guide is formed by the fusion of the ends of the inner pair; while the outer pair form the sting-palps. The same segments as those which carry the sting in the bee, are in certain other insects (cockroach, cricket, etc.) furnished with six projections arranged in the very same way-viz. four on the last but one (ninth abdominal), and two on the last but two (eighth abdominal). In many insects, the projections are not transformed into a sting, but form a kind of forceps, known by the name of ovipositor, because it is used to hold the eggs and pass them into recesses in wood, earth, etc. Not unfrequently the ovipositor can be used to make the hole as well as to pass the eggs into it, and then the tips of the component parts, or some of them, may be armed with teeth. The sting of the bee is therefore, we have reason to suppose, only a special modification of an instrument whose primary function is the deposit of the eggs in safe places. It is a natural consequence of derivation from an organ possessed only by female insects that none but females ever possess a sting at the end of the abdomen. In the bee-larva the last segments of the body are completely exposed, but in the pupa and imago they are telescoped into the body, so that the sting becomes concealed, and is only protruded at the instant of striking.

The food of bees consists of the nectar and pollen of flowers. When pollen cannot be had in sufficient quantity, as in early spring, they are glad of farinaceous substances, which in a state of nature they obtain from the seeds of * See fig. 6r, p. roo. 
grasses and leguminous plants. Honey is made from the natural juices of flower-glands by a partial digestion in the crop of the bee; it is then disgorged and collected in the cells of the comb. Honey-cells are sealed up with caps of wax. Pollen is stored in separate cells, which are left unsealed. It is most largely consumed during the time when larvæ are being reared, and is the chief ingredient of bee-bread. It is well known that bees can make honey out of ordinary sugar. Such honey wants the aroma which natural honey derives from the essential oils of flowers.

Next in importance to honey in the life of the bee is the wax of which the combs are made. It was formerly thought that beeswax was merely collected by the bees from the waxy bloom of fruits and leaves, but this has been disproved by careful experiments. Captive bees, fed on honey alone, form wax in tolerable quantity; if fed on sugar alone, rather less wax is produced; if fed on pollen alone little or no wax is yielded. Between the segments on the under side of the abdomen of a worker-bee are four pairs of pockets, a pair to a segment. The glandular wall of each pocket secretes wax from the blood. When the plates of wax have grown to their full size, the bee removes them with the nippers of her hind legs, and kneads them with her mandibles, afterwards working them into combs. Sometimes the bees relieve one another of their wax. Bees caught during the warm season generally bear plates of wax, and the secretion is promoted by warmth, quiet, and abundance of food. These conditions are secured by the workers gorging themselves with honey, and then hanging in dense masses in the hive. The temperature of the crowd of bees is observed to rise considerably above that of the outer. air.

Before constructing their combs, the bees block up any clefts in the wall of the hive with a sort of varnish, which they obtain from the buds of poplars and other trees. The same substance, called propolis, may also be used as a foundation for the combs, and as a means of covering up objects which would prove awkward or offensive. Snails which have penetrated a hive are stung to death, and then varnished over with propolis. *

The comb is started by a single bee, who attaches to the * Maraldi ; Réaumur, V. p. 442. 
roof of the hive, or to the upper bar of the frame supplied by the bee-keeper, little pellets of wax. Other workers come in to help, and the comb grows fast, the new cells being gradually added below. They are placed horizontally in a double layer, the open mouth facing outwards. The work is roughly done in the first instance, and its regularity, lightness, and economy of material, which have been the wonder of mankind in all ages, are the result of much subsequent trimming and moulding. Every ordinary cell takes the form of a six-sided prism, closed at one end by a pyramid of three rhombical sides. Pins passed through each rhomb in turn will be found to penetrate three different cells of the opposite layer. Thus every cell abuts by its closed end upon three others, an arrangement which greatly favours the strength of the comb. The walls are extremely thin, and on an average the weight of seventy-seven cells is only one gram. The cells vary in size and character according to the uses to which they are put. Pollen is stored in open cells, honey in sealed cells. Honey-cells are deeper than brood cells, sometimes much deeper, and inclined upwards, so as to lessen the tendency of the honey to flow out. The cells in which larvæ are reared are sealed just before pupation. Drone-cells are of larger than ordinary size, queen-cells very large and clumsy, built upon a number of cut-down ordinary cells at the margin of the comb, and only showing economy of material in the pitting of the walls. Combs are used repeatedly until they grow black with age, and the material of a disused comb is often worked into new constructions.

Swammerdam, more than two hundred years ago, proved by dissection that the queen-bee is the fertile female, the workers incompletely developed females, and the drones males. It is needless to say that the queen exercises no command; she is timid, averse to the light of day, and on the slightest appearance of danger takes refuge in the innermost recesses of the hive. The workers, who really govern the bee-republic, are aware of the great value of the queen, but allow her, except on rare occasions, neither liberty nor choice. Two emergencies only rouse the queen to unaccustomed activity. When she first emerges from the pupa-skin in early summer, she remains for six days quiet within the hive. After that interval she chooses a fine afternoon when the drones are 
humming in the air, and flies abroad. Nearly always she returns in a fertilised state, and then goes out no more, except to accompany a swarm, if such should be sent forth. The presence of a second queen rouses her to a desperate encounter, in which one of the two perishes. If the workers should rear supplementary queens, as they find it necessary to do at times, they have to restrain the old queen by force from destroying them.

Once fertilised, the queen can produce fertile eggs during her whole life. It is probable that the sperms received from the male and stored in a special pouch (spermatheca) can be allowed access to the eggs or not at the pleasure of the queen. Fertilised eggs produce females (workers or queens), unfertilised eggs drones. When workers lay eggs, as they sometimes do, these eggs are always unfertilised and yield drones. The queen begins to lay about two days after fertilisation, and continues to lay, with greater or less frequency, according to the needs of the swarm. The eggs are produced most rapidly in early summer, fall off in July and August, and cease altogether at the approach of winter. A queen is prolific for the first two or three years of her life; in the fourth and fifth years, if she survives so long, her fertility greatly abates. Under favourable conditions a queen can produce 3000 eggs a day, 60,000 in a month, 250,000 to 300,000 in a season, and perhaps a million in her lifetime (Dzierzon).

The time required for rearing a larva from the egg is not always the same. A new generation of workers can be produced in three weeks; drones require about three days more; a queen can be reared in little more than a fortnight. The remarkable fact that queens or workers can be developed at pleasure from the same fertilised eggs is now established beyond question. The question is decided by the quantity and quality of the food supplied to the larva by the workers. When queens are called for, special and unusually large cells of irregular form are built, and the larvæ are fed unusually Iong upon a partially digested nutritive jelly, rich in albuminoids and relatively deficient in sugar.

The duration of life is far less in workers and drones than in queens. During one summer the workers are renewed two or three times, but those which enter the dead season often last till the following summer. The drones are suffered 
to live as long as there may be occasion to produce new fertile queens. During this time they fly abroad, or dwell in the hive at pleasure, feeding, but doing no work. There may be two or three thousand in a strong swarm. After midsummer the workers commonly drive the drones forth to perish of cold and hunger, or bite off their wings. Now and then, when the supply of fertile queens has failed, the drones are allowed to live until they die naturally in September. If food should run short at any time, even in early summer, the drones are always sacrificed.

The swarming of bees is the sending out of new colonies. In spring, when food is plentiful, breeding proceeds rapidly, and the hive, which during winter was thinly populated and devoid of drones, becomes crowded. Then preparations are made for swarming. Several queen-cells are built, and a fertilised egg laid in each. Before leaving the hive, the workers begin to secrete wax, or at least fill their crops with honey, so as to be ready to make new combs without loss of time. When the new queen-cells are sealed, and the larvæ in them are about to pupate, the bees are ready to leave. A fine, warm day is chosen, and the bees pour out of the hive in a tumultuous crowd, until nearly all are hovering in the air. The old queen usually goes too; if she is not found by the bees, the swarm soon returns to the hive. In a short time the bees choose a settling-place and form a cluster, hanging in a mass which resembles a bunch of grapes. If they are now gathered into a hive, they will probably accept it as their new home, and return to it from their journeys, apparently taking no more notice of their old quarters. Meanwhile, in the old and nearly empty hive, the brood-combs, previously stocked by the queen-bee, soon begin to supply a new population. Eight or ten days after the departure of the first swarm the first of the new queens is ready to emerge. She seeks to destroy the inmates of the other queen-cells, but is only permitted to do so if bad weather or deficiency of food renders fresh swarms undesirable. When restrained from attacking the sister-queens in their cells, the queen-bee makes a croaking sound, called "piping," which can be distinctly heard when the ear is brought close to the hive; it is an almost certain indication of a second swarm. The issue of the second swarm is less affected by weather than that of the 
first; two or three young queens may now be allowed to accompany the other bees. As the brood-cells continue to yield new bees, a third, fourth, and even a fifth swarm may be sent off within a day or two of the second. When about three weeks have passed since the departure of the old queen, the eggs laid by her will probably be exhausted, and as the new queen will hardly have begun to lay, the hive may be for a time almost unprovided with brood. When swarming is over, the eldest of the remaining queens is allowed to leave her cell and destroy the others. It is only the first swarm which possesses a fertile queen. The later "casts," as they are called, have only virgin queens, and are not ready to rear brood until she has sought the drone. She has to leave the hive for this purpose, and runs risk of being lost or destroyed. If this should happen, the swarm is ruined, and will slowly dwindle away. A virgin queen is less valued than a fertile queen, and receives much less attention from the workers.

Since all the bees of a hive are usually the progeny of a single queen, they may be considered as one family, numbering as many, perhaps, as 40,000 , or even more. Occasionally a new strain of blood is introduced by means of a drone from another hive, or by the introduction of a new queen. The queen can only be introduced with great precautions. She is brought in by means of a perforated box, and allowed to acquire what is called the smell of the swarm, before the bees are allowed access to her.

\section{THE GOOSEBERRY SAW-FLY (Nematus ríbesii)}

The eggs are laid along the veins of gooseberry or currant leaves. They seem to absorb moisture from the leaf, for if a leaf is cut off and allowed to dry, the embryos in the egg perish. About six days after egg-laying the larvæe appear, and begin to creep upon the leaf; they are at first $2 \mathrm{~mm}$. long. Very young larvæ bite circular holes in the leaf; but before long they eat along the edges, leaving nothing but the midrib and large veins. The feeding larva is active for about four weeks, and moults four times. It then enters the earth and becomes a resting larva. A full-fed larva is 
I6-I $8 \mathrm{~mm}$. long. It consists of a head and twelve segments, which are indicated by the appendages, the spiracles, and the repeated pattern of

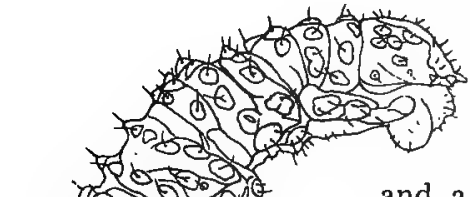
black dots on the skin. The head is shining black, with many short hairs, and is flattened in front and behind. There is a small simple eye on each side, and a minute three-jointed feeler. The mandibles are strong and toothed. The first pair of maxillæ are represented chiefly by a pair of six-jointed palps. The labium

फ0

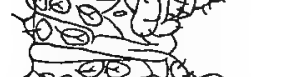

$400 \div$

10003

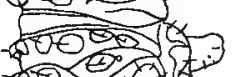

梠里

$-$

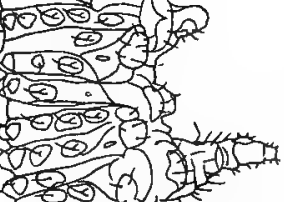

Stent?

He

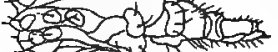

I5

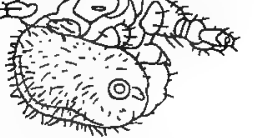
carries the spinneret and a pair of three-jointed palps. The skin of the body is nearly transparent, and shows the colour of the parts within; thus it appears green over the digestive tube, which is loaded with green food; but is yellow close to the head and hinder end, where the fat-body comes to the surface. Many black spots diversify the skin; these are hard and shining, and bear short bristles or groups of bristles. Most of the segments are sub-divided into three annuli, which are marked out by constrictions, and bear each a row of spots extending across the back. The thoracic segments bear pointed, three-jointed legs. The abdominal segments $2,3,4,5,6,7$, and 9 (the last) are provided with pseudopods or prolegs, resembling those of caterpillars, but without the crown of hooks. The pseudopods seem to act as suckers, for the larva can creep up a plate of glass. The last pair are slightly united at the base, and form claspers, which are not much 
used in holding on. A pair of small cerci (tail-like projections) stand out backwards from the last segment.

It will be seen that the larva of the gooseberry saw-fly is not unlike a Lepidopterous caterpillar, and that its appendages particularly resemble those of a caterpillar. There is a difference, however, in the position of the abdominal pseudopods, as will be seen by comparing these two formulæ:

\begin{tabular}{|c|c|c|}
\hline & Thorax & Abdomen \\
\hline $\begin{array}{l}\text { Caterpillar } \\
\text { Gooseberry saw-fly }\end{array}$ & I 23 & $\cdots 3$ \\
\hline
\end{tabular}

In saw-flies which have abdominal pseudopods, and these are the great majority, the number varies, but is never so low as five pairs, the usual number in Lepidoptera; moreover, the second abdominal segment always bears pseudopods in a saw-fly larva, if any are present at all-hardly ever in a Lepidopterous caterpillar.

We have said that after the fourth moult the larva ceases to feed, enters the earth, and becomes a resting larva. At

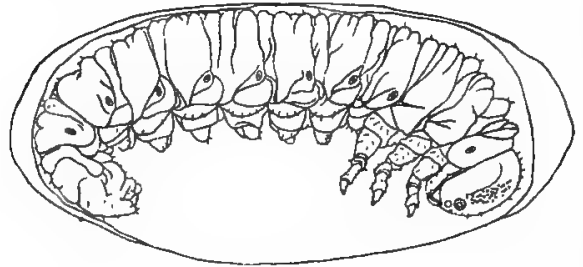

Fig. 57--Resting larva of gooseberry saw-fly. $\times 5$ this time the black spots disappear, or become much reduced, and the colour changes from variegated green to yellow, in consequence of the emptying of the alimentary loses its dark colour, and becomes pale, showing up the red mandibles and the black eye-spots. The mandibles change their shape, becoming more pointed. In a few hours the larva falls from the bush, enters the earth, and there spins its cocoon in any suitable cavity. Occasionally it spins upon the leaves of the bush. During the feeding stage the salivary reservoirs become distended with fluid silk, which is used up in spinning the cocoon. It is probably a consequence of the loss of silk that the resting larva contracts and becomes distinctly shorter. It rests in its 
cocoon in a curved position, the head and tail being bent round to the ventral side. If disturbed, it is capable of sluggish movement. In Lepidoptera the resting larva is a brief and unimportant stage, while the pupal stage is often prolonged. In sawflies the resting-stage is often prolonged, and the pupal stage shortened in proportion.

Within the body of the resting larva the destruction of old parts and the development of new go on with great rapidity. When the imaginal organs are well advanced the last larval skin is cast, and the pupa appears. It bears a general resemblance to a Lepidopterous pupa, but the appendages are not glued down, there is no proboscis (for the imago has a biting mouth), and peculiar organs, the saws, appear on the ventral surface of the last abdominal segments of the female. As in all pupæ, the

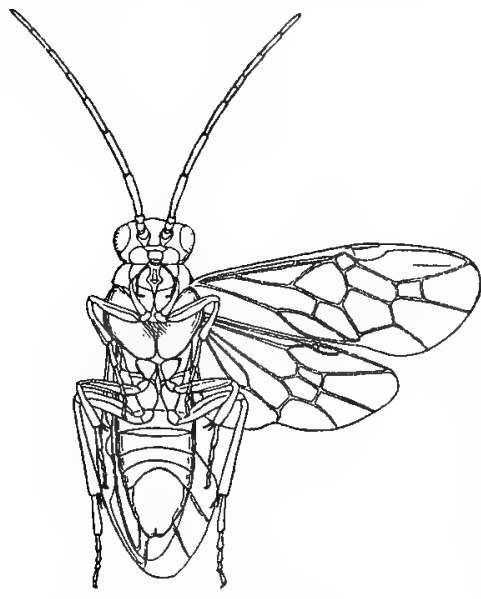

Fig. 59.-Gooseberry saw-fly, ventral surface, $\times 5$. body is completely in-

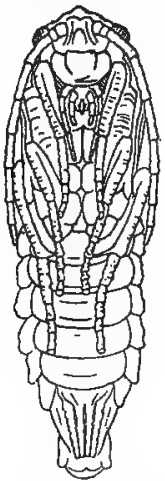

Fig. 58. - Pupa of gooseberry saw-fly. $\times 5$. vested by a special pupaskin.

When the fly is ready for active life it creeps out of the ground, and hovers round the bushes on which it was reared. It is sluggish, and does not usually fly far. Hence one garden may be devastated with saw-flies, while another, at no great distance, is free. The fertilised female lays her eggs on several different leaves, and then dies. The fly has four large membranous wings and biting mouth-parts, as in other Hymenoptera. The long feelers are nine-jointed. The narrow waist, distinctive of such Hymenopterous flies as sting or 
bore, is not found in any saw-fly, where the abdomen is always broad at its base. Saw-flies take their name from a pair of remarkable appendages, carried by the female on the under side of the extremity of the abdomen. These answer to the ovipositor of the cockroach or the sting of the bee; but they are true saws in mechanical design, and employed in cutting incisions upon twigs or leaves, in which the eggs are afterwards laid. In the gooseberry saw-fly the saws are not really such; no cut is made in the leaf, and the blades are only used to grasp the eggs. The common saw-fly of the rose-tree may be watched by anyone who desires to see the saws in action.

There are usually three broods of gooseberry saw-flies in the course of one summer. Eggs laid in autumn produce larva which do not proceed at once to pupate, but remain for weeks or months underground as resting larvæ, coming up as flies only in the following spring. In the spring-brood the numbers of the sexes are about equal, but in the autumn brood the females greatly predominate. An unfertilised female lays eggs readily, but these eggs always produce males. This observation can be readily confirmed by hatching out a female pupa, and then keeping the fly under a bell glass. The numbers of this destructive insect are subject to one very important natural check; they are greatly infested by ichneumons. After a series of years, during which the bushes have been regularly stripped of their leaves, it will be found by a close observer that the larva produce in ever-increasing numbers ichneumons instead of saw-flies. Then the sawflies fall off to such an extent that none can be found in a wide district which was a few years before completely devastated by them.

Various remedies for the attacks of this insect have been proposed. I have found nothing so effectual (except the ichneumons) as searching the bushes about once a month in summer, and removing every leaf which has eggs on it. The operation is not too laborious, and it produces a marked effect. A garden once cleared is not quickly overrun again, as the flies change their quarters with difficulty. Some bave found it a good plan to remove the surface soil during winter, and bury it in a deep hole. The resting larvæ are thus destroyed. The fresh soil from the hole is spread beneath the trees. 


\section{THE WOOD-WASP (Sirex)}

The wood-wasp of fir-trees, though very common in northern Continental countries, is only met with now and then in England. A large wasp-like fly, an inch-and-a-half long, which hums as it flies, and is armed with what looks like a terrible sting, is perhaps discovered in some house or shop, captured by the boldest man about, and sent to the local naturalist for examination. Some disappointment follows upon his report that the insect is not a hornet, that it has no sting, and that, though capable enough of mischief, it never wounds man or any other animal. In its early stages it dwells in fir-trees. The egg is laid in timber, standing or felled. The larval Sirex devours the wood, running long, winding galleries along the trunk; it pupates within the tree, and finally emerges in the winged form, to per-

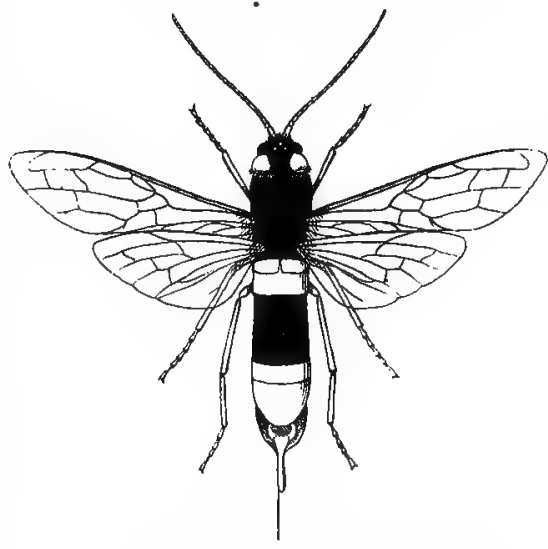

Fig. 60.-Female wood-wasp (S. gigas). Natural size. petuate the race. Sirex only shows itself in England casually, but it often appears many at a time, and does much harm. It is not unlikely that our attacks are due to recent importations of live insects from the Continent. Wood containing larvæ may be stored and even cut up without hindering the development of one or more wood-wasps, which may, perhaps, give rise to a local infestation.

The fly wears the colours of a wasp, black and gold, but has not the narrow waist, nor yet the sting of a true wasp. It has four membranous wings, and biting mouth-parts. Since it undergoes complete transformation, and does not exhibit 
the complex network of wing-veins with a multitude of small cells, which is characteristic of Neuroptera, we may safely refer it to the Hymenoptera. The abdomen is sessile, nearly cylindrical in the female, a little flattened from above downwards in the male, and ends in a stiff, pointed horn, which continues the line of the body. The trochanter (2nd joint of the leg) is double, a feature which reappears in the parasitic Hymenoptera. The long weapon, which is naturally taken at first sight for a sting, is found only in the female
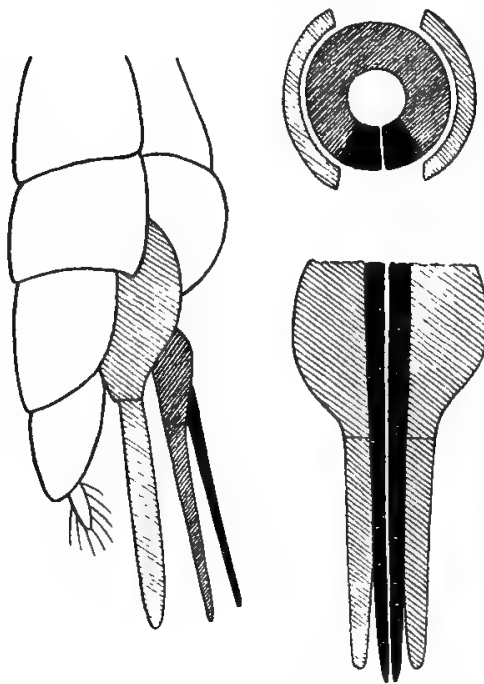

Fig. 6r.-Borer or ovipositor of Sirex (diagram. matic) in side-view, transverse section and longitudinal section. The valves are lightly shaded, the guide is darker, and the darts are black. darts. We have already seen that valves, * guide, and darts are all present in the sting of a bee, and we find answering parts in the saws of a saw-fly, and in the eggdart of an ichneumon. These various organs, so different in form and mode of application, are all constructed on a positor, or egg-laying implement. On closer examination we shall notice that it springs far forward, from the under side of the middle of the abdomen. If we are able to handle a fresh insect, or a dead one that has been soaked for a few hours in dilute potash solution, we can make out that there is an outer sheath and a central core in the ovipositor. Outside is a pair of long, slender, twojointed valves, one on either side; within these comes the actual boring tool or core, a fine tube, which can be separated without injury into an upper half, the guide, and

Sirex; it is the ovi- 
common plan; moreover, they are found only in female insects. We conclude that they are homologous, or equivalent structures; at first, in all probability, framed as egg-forceps for depositing the eggs in narrow crevices, but afterwards taking on highly special functions, and becoming fit for boring, cutting, or stinging. In all Hymenoptera the implement, whatever its functions, is developed from three pairs of prominences, which in the embryo stand out from the under surface of the hinder segments.

When the female Sirex is ready to lay, she chooses a firtree, by preference one that is felled, uprooted, or sickly, bores a hole through the bark into the young sapwood, and deposits in it a single egg. The operation has rarely been witnessed, and we know few of the details. Since the larvæ are usually found several or many together in one trunk, it is probable that the female lays egg after egg in the same tree. In boring, the valves are parted, and only the central part of the ovipositor enters the hole. A fresh-hatched female contains about a hundred eggs. After the majority are safely lodged in trees, she grows faint and weary, and often dies with her ovipositor inserted in the wood. Insects found dead in this attitude are nearly always spent females, which have died from exhaustion, sometimes, perhaps, because the borer got jammed in the wood.

The larva of the wood-wasp is long, cylindrical, pale and fleshy, the head small and hard. Living always in the dark, it has no eyes. It crushes its food with a pair of strong, toothed mandibles, which do not form a symmetrical pair, but differ in shape. Sedentary life has reduced the legs to vestiges; the thoracic legs are represented by small, unjointed prominences, while there is hardly a trace of the pseudopods, or false feet, which are so conspicuous in the caterpillar of the saw-fly. The body ends in a hard and pointed tip, as in the fly. Eating is the same thing as working to this larva, for it mines by eating the wood, which is its only food. It works lengthwise along the trunk, keeping at first to the sapwood. Old larvæ penetrate to a greater depth, but as the time of pupation approaches, they take care to lie near the bark. In May or June the sound of their jaws can be heard if the observer places his ear close to the trunk of an infected tree. Larvæ which begin to feed late in summer resume their 
activity in spring; those that are hatched in early summer complete their feeding before autumn. It is probable that, as in many other Hymenoptera, there is a resting larva stage, of uncertain duration, for the flies sometimes emerge from wood which has been long stored. The pupal stage is passed in a slightly enlarged gallery near the outside of the trunk, and there is no cocoon. When the wasp emerges, it has still to make its way to the outer air. The long winding larval gallery, narrowing at length to a fine egg-hole, could not possibly give passage to a large fly. There is nothing left but to gnaw a fresh hole, leading straight to the air. Guided, we may suppose, by the grain of the wood, perhaps, also, by the curvature of the rings and their different degrees of hardness, the wasp takes a short, straight course through the wood, and soon becomes free. It leaves the trunk riddled for many feet together by winding cylindrical passages. If many larvæ have lived in the same tree, it is probably only fit for firewood. The short, wide passages by which the wasps escape, are sometimes plainly seen on standing or felled trees. An experienced eye can sometimes detect the attack of the woodwasp in an early stage by means of the pin-holes from which resin distils, and which mark the places where the borer of the female has been at work.

Two species of Sirex are found in Britain-(I) Sirex gigas, which is yellow and black; (2) Sirex juvencus, which is rather smaller, and has a shorter ovipositor. The female of Sirex juvencus is steel-blue, with reddish legs; the male has some of the abdominal segments coloured red. When pine or firtrees are attacked, the only remedy known is prompt destruction of infected trees. Felled trees must not be allowed to lie on the ground, and all mined trunks should be burnt as soon as possible.

\section{IOHNEUMONS AND THEIR ALLIES}

The great majority of insects, as of animals in general, are vegetable feeders. A glance at the common plants of our fields, woods, and hedges, in summer. or autumn, shows how many of them provide subsistence to insects. Some insects gnaw the roots, others run their galleries through the wood, 
consume the leaves, or drill holes in the seed. Hence there is no large class of animals which is so much affected by the annual cycle of vegetative changes. While many other animals feed throughout the year, it is only such insects as dwell in earth, water, or the trunks of trees that are active in winter. The rest are usually obliged to complete the feeding stage, as well as the mating and egg-laying stage, within the summer. Then they may feed with hardly a break, and multiply viviparousiy, while still immature, as if to take the fullest advantage of a time of plenty. The visits of insects are not pure loss to the plants. Some flowers have come to depend upon winged insects for the setting of their seeds. But the balance of gain and loss is probably unfavourable to the plants. They give up much valuable food-substance, and undergo mutilations which are often serious and sometimes fatal. The ravages of plant-eating insects are multipled when man, for his own purposes, raises vegetables and trees by the acre. Indeed, cultivation would often become impossible, if nature had not provided remedies more effective than any that we can contrive for ourselves. As the plant-eating insects increase in number, insect-eating animals increase too. Natural contrivance is impartially put forth for the advantage of the plant, the herbivorous animal, and the carnivorous animal alike. The plant multiplies its defences, the plant-eating insect its weapons of attack, while the instincts of the predatory bird or insect are sharpened. But the most effectual check upon plant-eating insects is not the open warfare of predatory species; it is the insidious attacks of small and artful creatures, themselves insects, which, betraying their natural allies, rear their young at the cost of others. The egg is laid in, upon, or near a feeding larva, and the grub which issues from the egg is adapted by every refinement of organisation and instinct to devour the flesh and blood of a living victim. Even the minute eggs of insects give opportunity to still smaller parasites. There is a very numerous tribe of eggparasites, which lay their own eggs in the eggs of larger species. The parasitic larva devours the yolk, and at length emerges as a fly totally different from the one which provided the yolk. So far is living at another's cost carried that there are among insects many examples of parasites upon parasites. One such case will be mentioned in this lesson. Parasitism upon living 
insects is not restricted to the Hymenoptera. There is a large family of Dipterous flies, the Tachinidæ, which are reared within caterpillars and other larve. 'The Tachinid flies are unable to pierce the skin of a larva; they can only glue their eggs to the victim, and leave the issuing grubs to force a passage for themselves.

It is the parasitic Hymenoptera which do most to keep down the numbers of plant-eating insects. The name Ichneumon calls for explanation. Greek naturalists knew of a weasel-like quadruped which they called ichneumon, the mongoose of India. Different species abound in parts of Africa and tropical Asia, feeding on small quadrupeds, snakes, insects, and eggs of several kinds. It was anciently believed that the ichneumon of Egypt was serviceable in devouring the eggs of the crocodile, and it was reputed bold enough to enter the crocodile's throat, and feast upon its entrails. Coming to know of wasp-like insects, which preyed upon spiders and their eggs, the Greeks likened them to ichneumons, and called them by the same name.

The parasitic Hymenoptera (or Ichneumons and their allies) may be recognised by the following marks:-The waist is usually narrowed, sometimes to such a degree that the abdomen looks like a mere $\mathrm{knob}$ on the end of a long tail. The leg has a double trochanter, the joint so named being divided into nearly equal parts by an articulation. This peculiarity occurs in some other Hymenoptera-e.g. in Sirex. There is no sting, but the same parts which compose the sting of the bee are here converted into a borer or egg-laying tube, like that of Sirex. In most ichneumons, but not quite in all, the feelers execute rapid quivering movements, which seem to be connected with the search for hidden victims. The larvæ are footless grubs, the pupæ are commonly protected by a cocoon, which may be spun either inside or outside the dead body of the host. Dr Sharp * thinks that there may be 200,000 species of parasitic Hymenoptera, and far higher estimates of the number have been made. Some of the families include gallmakers and plant-eaters, as well as insect-parasites.

The narrowed waist is not universal in Hymenoptera. Sawflies and wood-wasps, as we have seen, have a sessile abdomen, as broad at its base, or nearly so, as in any other part. But it * "Cambridge Natural History," vol. v. p. 520. 
is usual for Hymenoptera which sting or bore to have a slender waist. This increases the mobility of the abdomen, which is sometimes extreme. Some ichneumons, when they lay their eggs, bend the abdomen forwards over the back and then vertically downwards; others bend it so far under the thorax that the borer reaches beyond the head. The borer can be directed to almost any point ; if it is long, it may be worked up and down at right angles to the body; and there is often a certain amount of side-to-side action, or a twisting motion as well. Though the sting or borer is generally associated with a slender waist, the slender waist does not imply a sting or borer. To say nothing of narrow-waisted Hymenoptera, which have lost the apparatus once possessed by their progenitors, most male Hymenoptera have the slender waist, but never possess either sting or borer.

We shall next describe the general structure and mode of life of a few well-known ichneumons. One of the commonest of our native species is a large orange-coloured insect (Ophion luteus), which has its abdomen flattened from side to side, and curved in a vertical arch to the shape of a sickle-blade. The borer is short and concealed. The feelers are long and slender, and do not quiver. Ophions are often yellow, sometimes yellow and black, or red; they are never marked with white. Ophion luteus is I $2 \mathrm{~mm}$. long; some other species are longer. The female Ophion seeks out leaf-eating caterpillars, which are not hidden in earth or wood. She does not pierce the body, but applies a sticky egg to it, and then, withdrawing her abdomen, leaves the egg fastened by a long thread which immediately sets hard. When the larva is hatched from the egg, it bites, enters, and in the end devours its host, pupating outside the dead body within a long, parchment-like cocoon. Noctuid and Bombycine larvæ, and most commonly perhaps, the larva of the puss-moth, are attacked by Ophion luteus. Several eggs are generally laid upon one larva.

Very different are the structure and habits of the ichneumons which prey upon wood-boring larvæ. Pimpla manifestator, for instance, attacks the larvæ of longicorn beetles and wasps in the wood of trees. Its length, not including the ovipositor, is $30 \mathrm{~mm}$. The general colour is black, but the legs are orange. The abdomen is long, slender and flexible, but not distinctly stalked; the borer equals in length the rest of the body. 
This formidable weapon consists of an outer pair of valves, and within them of a guide and a pair of darts, which can be separated into three, or combined into one. Here we have evidently the same parts as in the borer of Sirex (p. 100); in the bee also (p. 88) we make out with no great difficulty the same valves, ${ }^{*}$ guide and darts. Even the saws of a saw-fly, though very different at first sight, can be referred to the same common plan; all are homologous, or answerable organs. The darts of Pimpla are roughened by teeth, which enlarge the hole, and diminish the risk of the borer becoming jammed, an accident which happens now and then to wood-borers. Thus furnished, the female Pimpla sets out to discover a woodeating longicorn larva, or the larva of a solitary wasp. By what exercise of her long, vibrating antenna she discovers the larva deep in the solid wood we cannot tell, except that the antennæ (feelers) are brought as close to the spot as possible, and passed down into the hole wherever that is discoverable. Then she raises her abdomen into the air, pointing the separated valves almost vertically upwards, and passes the inner tube of the borer into the wood. To judge from the movements of the abdomen, the darts, in drilling a hole through solid wood, are worked in and out, up and down, and also screw-wise, being steadied all the time by the hind legs. At last, with a throb of the abdomen, an egg is sent down the long tube, and the task of the Pimpla-fly is accomplished. It seems to be left to the larva which issues from the egg to make the actual attack upon the owner of the gallery. Another Pimpla reaches the grub of the goat-moth in its tree; a third attacks the Sirex-larva. There are also Pimplas with short borers, which lay their eggs upon the external feeding larvæ or the pupæ of Lepidoptera.

Réaumur, in one of his graphic chapters on the history of insects, $\uparrow$ tells us how he saw in August a small four-winged fly settle upon a caterpillar of the cabbage white. The fly chose her point of attack, pushed out a slender borer, nearly as long as her body, and buried it almost to its base in the caterpillar. The victim bore the wound patiently, making only slight movements, to which the fly paid no attention. The borer was withdrawn, and inserted again and again, always at the junction of two of the hinder segments. Sus-

* Called sting-palps in the bee.

t Vol. II. Mem. xi. (1736). 
pecting that an egg had been introduced at every prick, Réaumur fed the caterpillar, and waited to see the issue. After ten or twelve days the caterpillar pupated, but immediately afterwards began to waste visibly. In four days it was evident that all its internal organs had been devoured by the parasites, which did not, it would seem, find enough food to support themselves, for none of them were able to complete their transformation. He subsequently learned that in the ordinary course all the parasites quit their host after a certain length of residence, and that they emerge before or after it pupates, according as they were introduced early or late. In December Réaumur found a number of cabbage-white caterpillars, and put thirty of them into a glass dish. More than five-sixths proved to harbour parasites. When they were ready to emerge, he observed a small, whitish prominence on the flank of a caterpillar, which projected at right angles. Now and then the prominence was withdrawn a little, and then pushed out farther than ever. Soon a second prominence began to form, and this went on until, in less than half-an-hour, fourteen or fifteen larvæ had protruded themselves from one side of the caterpillar, and about as many from the other. When they had set themselves free, they did not travel far, but remained close to the caterpillar from which they had issued. During this painful operation, the caterpillar remained motionless, as if dead. When it was finally rid of its cruel enemies, it moved about a little, but died within four days. Sometimes the parasites did not emerge until the caterpillar had either suspended itself for pupation, or actually pupated. No caterpillar which had contained parasites produced a butterfly. Réaumur estimated that not more than a tenth of the various caterpillars which he kept under observation completed their life-history. It is, however, quite possible that in another year the proportion might have been much more favourable to the butterfly. (See saw-fly, p. 98.) These parasitic larvæ are white, with smooth skins and no legs; the head is retractile. The digestive tube has no outlet, for the food consists only of the blood and tissues of the caterpillar, and contains no indigestible residue. Were any refuse to be discharged into the body-cavity of the caterpillar, its torments and the lives of the parasites would be speedily cut short. All ichneumon-larvæ are alike in this point of structure. 
As soon as Réaumur's parasitic larvæ became free, they began to spin themselves cocoons of silk, very similar to small-scale copies of a silkworm's cocoon, and of the same golden colour. Within these cocoons the insects remained long unchanged. Thus larvæ which span up in December were still larvæ on April 23 rd. Very soon afterwards they turned to white pupæ, and the flies emerged before the end of the month. Hymenoptera often prolong the resting stage at the expense of the pupa-stage (see saw-fly, p. 97), whereas in Lepidoptera the resting larva quickly changes to a pupa.

Such is the history of the ichneumon of the cabbage white, as condensed from Réaumur. The fly is technically named Microgaster (or Apanteles) glomeratus; it is $3 \mathrm{~mm}$. long. The abdomen is short, of few segments, and sessile, or apparently so. The pattern of the wing is materially different from that of a Pimpla or an Ophion. Many ichneumons resemble Microgaster in the venation of the wing, and are grouped as the family Braconidæ. The Braconidæ are usually, but not quite always, social, many being reared within one host. Microgaster pupæ are often found sticking in clusters to palings or similar objects close to a cabbage-plot. They are preyed upon (one might call it a just retribution!) by secondary parasites, minute Hymenoptera of the family Chalcididæ.

Among the Braconidæ is an ichneumon which attacks aphids. This is Aphidius rosarum, which is often to be met with on rose-bushes. The fly is yellow and black, $2 \mathrm{~mm}$. long, with stalked abdomen, and short, few-jointed feelers. The female Aphidius sends its borer forwards between its legs till it projects beyond the head. In this singular attitude it pierces a wingless aphid, which soon ceases to move, turns yellow, and becomes unnaturally inflated. The parasitic larva devours all the contents of the body, forms no cocoon, but pupates within the inflated abdomen in a doubled-up posture. The fly bites a circular lid out of the abdomen of the dried aphis, and emerges through the hole.

There is also a numerous family of egg-boring ichneumons, which draw their whole substance from single eggs of spiders or insects. One egg bas been known to maintain several parasites. The minute egg of the Hessian fly provides both space and food for a parasite called Platygaster, which is remarkable for its complicated transformations. In certain stages it 
hardly looks like an insect at all, yet the fly is unmistakably Hymenopterous.

The various families of parasitic Hymenoptera differ materially in structure, being sometimes more closely allied to a nonparasitic group than to any other parasitic one. Only a few families are altogether parasitic upon other insects; the rest include gall-flies or vegetable-feeders. These facts suggest that the parasitic habit may have been independently acquired, and that more than once or twice.

Encyrtus fuscicollis, a Chalcidid, infests the larva of the small ermine-moth. From 50 to roo eggs or larvæ may be found within a single caterpillar. They are at first invested by a common branching envelope with a cellular lining. The air-tubes of the caterpillar ramify upon the envelope, and supply the parasites with air. All the larvæ inhabiting one caterpillar are of the same sex. This is wonderful enough, but a still more curious fact has lately come to light.* The branched sac with its many embryos proceeds from a single egg, introduced by the female Encyrtus. The embryo buds, like a polyp or a plant. This process of embryonic fission, as it is called, is probably not uncommon in Chalcididæ. It is not peculiar to insects, but occurs in animals of several different classes. Even a mammal (Praopus, an armadillo) is known regularly to produce several embryos from one ovum, and here, too, all the brood are of the same sex.

* Maréchal, Comptes Rendus, 1898, p. 662. 


\section{TWO-WINGED FLIES (DIPTERA)}

\section{THE HARLEQUIN-FLY (Chironomus)}

THERE are few commoner insects than this. The larva, which from its deep red colour is popularly called the bloodworm, abounds in slow streams, particularly in the foul streams which flow near towns and cities. The pupa is aquatic too, but the fly is a delicate, gauzy creature, gnatlike in appearance, which is often seen upon the windowpane in summer. It belongs to the same order as the gnat - the Diptera, or two-winged flies. The larva is not large enough for ordinary dissection, being only an inch long at most, and very slender. It has, however, the great advantage of transparency. Any student who can command a microscope will be able to see more internal structure in this small larva than he is at all likely to discover in the largest caterpillar. A second reason for selecting this particular type for examination is that it is reared with great facility. A few dead leaves in a saucer of water suffice for all its wants, and the life-history can be followed throughout on the easiest possible terms.

Having found a stream, a water-butt or a garden-tank which harbours the larva, pick up a few, either with a dipping tube, or a spoon tied to a walking-stick, as may best suit the place of abode, and bring them home. Observe the looping movement by which they swim about, and the anxiety which they show to conceal their bodies. They weave together bits of leaves, or any other particles which lie about, with viscid threads. Where circumstances allow, they make burrows or tubes in mud. A very small larva is best for microscopic study. Place one in water on a glass slip, and cover it with a glass circle. A little cotton-wool may be teased out in the water beforehand, so as to imprison the larva and take off the weight of the cover-glass. Be careful not to introduce so 
much wool as to hide the larva. A low power will be best for examination.

The body consists of a very small head, and twelve segments. On the head will be found a pair of short feelers, two pairs of eye-spots, which are mere blotches of pigment without lenses, a labrum, and a pair of stout, toothed mandibles. The maxillæ are reduced to minute vestiges. The labium is represented by a flat plate, with toothed margin, which lies behind the mouth and aids the action of the mandibles. On the first thoracic segment is a pair of feet, armed with numerous hooks, which are used for locomotion within the burrow. A pair of rather similar, but less mobile appendages (the anal feet) project from the last segment. These, like the anal feet of a caddis-worm, are often used for holding on to the burrow. On the last segment but one, four slender and hollow tubules

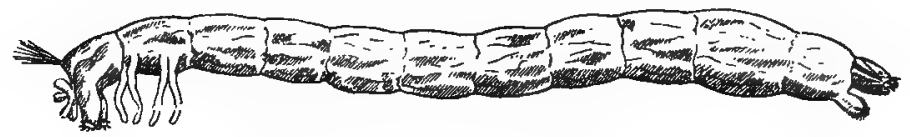

Fig 62.-Larva of Chironomus dorsalis. $\times 3$.

will be seen to stand out from the ventral surface. Four short, hollow outgrowths can also be seen on the last segment, close to the outlet of the intestine (see fig. 62). On the dorsal surface of the last segment a pair of small brushes will be found, which are probably sensory. The heart can readily be seen pulsating beneath the transparent skin. It lies on the dorsal surface near the tail-end, and gives off a long dorsal vessel, which passes along the back to the head. Two pairs of lateral inlets admit the blood to the heart from the bodycavity. The alimentary canal is traced without difficulty. A long and narrow gullet proceeds backwards from the head. In the metathorax it suddenly expands into an enlarged and muscular cardiac chamber. This has a very uneven appearance; a number of prominences stand out from its outer surface, which look like tubular outgrowths. They are, however, solid and not hollow. Beyond the cardiac chamber comes the stomach, which is unusually long, and narrows irregularly behind. Four long and winding Malpighian tubules mark the beginning of the intestine, which is at first narrow, but 
afterwards enlarges, and then tapers to the anus. A pair of salivary glands lie one on each side of the gullet, and communicate with the mouth by long and slender ducts, which unite into a common duct, and finally discharge into the mouth. The nervous system can also be made out in the living larva. There are no ganglia in the small head, the brain and sub-esophageal ganglia being retracted into the prothorax. Behind them comes the usual gangliated chain, with somewhat short and thick connectives. The last ganglion lies in the seventh abdominal segment, the tenth from the head. The tracheal tubes, which in most insects supply every organ of the body with a copious network, are reduced almost to nothing in the larva of Chironomus. By attentive examination of the thorax in side-view, a few delicate and branching tubes can be seen, which constitute almost the only vestige of a tracheal system. It is completely closed, but on each side of the body branches lead to two sealed spiracles. The vestigial system of air-tubes and spiracles is some proof that remote progenitors of the blood-worm lived in air, and breathed after the fashion of ordinary insects. But the airtubes are now completely closed, and some other means of aerating the blood must be looked for. The blood-worm, having become completely adapted to a submerged life, breathes by gills, thin-walled, hollow filaments, which stand out into the water, and allow the carbonic acid formed in the body to pass out, while oxygen is passed in. The gills of the blood-worm are the two pairs of long tubules on the last segment but one, and the two pairs of short prominences on the last segment of all. All these gills are distended with blood, which is pumped in and out by the action of the heart, and they have thin, transparent walls to facilitate the exchange of gases.

The blood-worm, in order to avoid its enemies, keeps to the mud at the bottom of the stream, and there constructs a tube or sheath in which it lies hid. Now the bottom-water of a slow stream contains very little oxygen, particularly when decaying organic matter, such as forms the food of the bloodworm, is plentiful. How then does it manage to aerate its blood? The difficulty, though serious, is not insurmountable. By day, when fishes and predatory insects are active, the blood-worm stays at the bottom, but at night it comes to the 
surface, and disports itself in the well-aerated water. Having got its supply of oxygen, it descends again, finds its old tube or else makes another, and can then hold out till darkness makes it safe to venture once more to the surface. The habit of coming to the surface only by night implies that the bloodworm is furnished with some means of storing up oxygen. The oxygen taken in during one night has to last till the following night at least. Where and how is the oxygen stored? An answer to this question is suggested by the fact that the blood-worm is of a red colour; it shows the bright crimson of arterial blood. In a fish or in ourselves this colour indicates the presence of a peculiar substance named hæmoglobin. The hæmoglobin of the blood picks up oxygen in the gill or lung, carries it to every part of the body, and gives it out to all the tissues which require a fresh supply. Now if hæmoglobin can carry oxygen, it can also store it up for a time. The oxygen taken up by the blood-worm during the hours of darkness is combined with the hæmoglobin, or red colouring matter of the blood, and doled out as required. The proof that the red colour of the blood-worm is really due to hæmoglobin is got by spectroscopic examination of the blood, which yields absorption-bands precisely similar to those of human blood.

The tube in which the blood-worm conceals itself is easily and quickly made out of bits of dead leaves, earth, sand, anything in short which is lying about. The particles are woven together by threads of a viscid substance, a kind of silk, which is formed in the salivary glands and paid out from the mouth as required. By means of the salivary secretion the bloodworm forms a coherent wall for its tube. If no suitable materials are at hand; if, for instance, the larva is placed in a saucer with nothing but clean water, it will at length begin to make its tube of silk only, a transparent cylindrical case, through which all the movements and actions of the larva can be observed. By this means we can see that the bloodworm, when concealed within its tube, is hardly ever at rest. It holds on to the walls by its hooked feet (p. I II), and then performs an undulatory movement, the effect of which is to set up a current of water which flows through the case. This is one method of extracting from the water any free oxygen which may be present. At other times the blood-worm sticks 
the hinder end of its body out of the tube, and the thin-walled gills, which are all placed near the hinder end, are thus brought into action.

The pupæ of Chironomus can be fished up from the same streams as those in which the larvæ dwell, or they may be reared in captivity by placing full-grown larvæ in a suitable vessel, and waiting for the time of transformation. The pupa

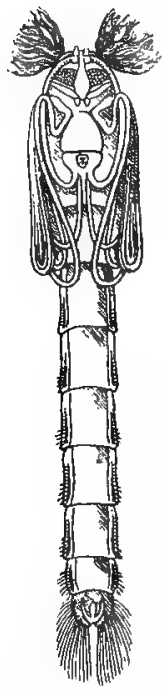

Fig. 63.-Pupa I of Chironomusdor. salis. $\times 8$. usually lies half in and half out of the mud, and sways the fore part of its body to and fro for respiratory purposes. After two or three days it becomes buoyant, and floats at the surface. The pupa consists of the body of the future fly, enclosed within a transparent pupal skin. It is provided with certain peculiar temporary organs-viz. a broad, fringed tail-fin, and two bunches of branching filaments, given off just behind the head. These filaments are the pupal respiratory organs. They wave to and fro in the water, and by some process, which cannot be satisfactorily explained in the present state of our knowledge, extract air, or rather oxygen, from the water. The head, legs, wings, and all other parts of the future fly are shrouded within the close-fitting pupa-skin. Not only are they externally complete, but they are fully developed in almost every microscopic detail. The pupal stage of Chironomus is not so much a time of growth, as a brief period of adaptation to a new and very different set of external conditions. The many complex organs of the fly, such as the elaborate and beautiful antennæ, the compound eyes, each of many facets, the slender and many-jointed legs, and the gauzy wings, cannot be extemporised. A long time is necessary for their development. The whole pupal stage is brief, lasting only two or three days, and even before it sets in, the parts of the fly are already formed. It is clear, therefore, that the development of the new organs must have been long in progress at the time of pupation. On careful examination of a fullgrown larva this conclusion is confirmed. The thoracic segments shortly before pupation become visibly enlarged, and 
through the transparent skin can be seen the folded-up wings and legs, which only become functional in the fly. The head of the fly is already far advanced, but as it is a good deal broader than the small larval head, it becomes folded backwards into the thorax, and is actually for some days, or even weeks, turned inside out and directed backwards. It is only at the time of pupation that the new head assumes the position for which it is destined. Singular as this inverted development may appear, it is not the most complicated case of its kind which occurs among insects. The growth of the blow-fly or house-fly is still more remarkable, though less easily understood.

The following points may be observed by careful observation of larvæ about to change to pupæ. A number of larvæ, which show by their thickened thorax that they are nearly ready to change, should be placed in a shallow vessel of water, and watched continuously for an hour or more. The fore feet will suddenly be withdrawn into the body. About a minute later the anal feet and other projections at the tail-end will also be retracted. These movements of contraction appear to set up a blood-pressure, which causes the head of the fly, as yet inverted and turned backwards into the thorax, to bulge forwards and assume its final position. The larval head is suddenly emptied of its contents, and slips round to the ventral surface. In a minute or two the appearance of the insect is completely changed. The external organs of the larva shrink, and are cast off, while new organs, which have been slowly forming within, are for the first time protruded. The old larval skin becomes wrinkled and torn into shreds, and is gradually rubbed off by the movements of the pupa. As yet, the new organs are not completely exposed, but enveloped in a temporary skin, the pupa-skin, which prevents their full expansion, though it allows them to be seen with tolerable distinctness.

After three or four days of pupal life the fly is ready to emerge. The respiratory filaments have by this time removed so much oxygen from the water as to distend the tracheal system ; the pupa becomes buoyant and floats at the surface. Suddenly the skin cracks along the back of the thorax, the fly extricates itself, and often resting for a moment on the floating pupa-skin, takes wing. The operation is so rapid as to startle an inex- 


\section{6 INJURIOUS AND USEFUL INSECTS}

perienced observer. While studying the floating pupa with a lens he will see a commotion in the object, and before he has had time to realise what is going on, the fly is off and away. Examination of the cast skin teaches us that the pupal skin cracks lengthwise along the thorax, and that the fly emerges

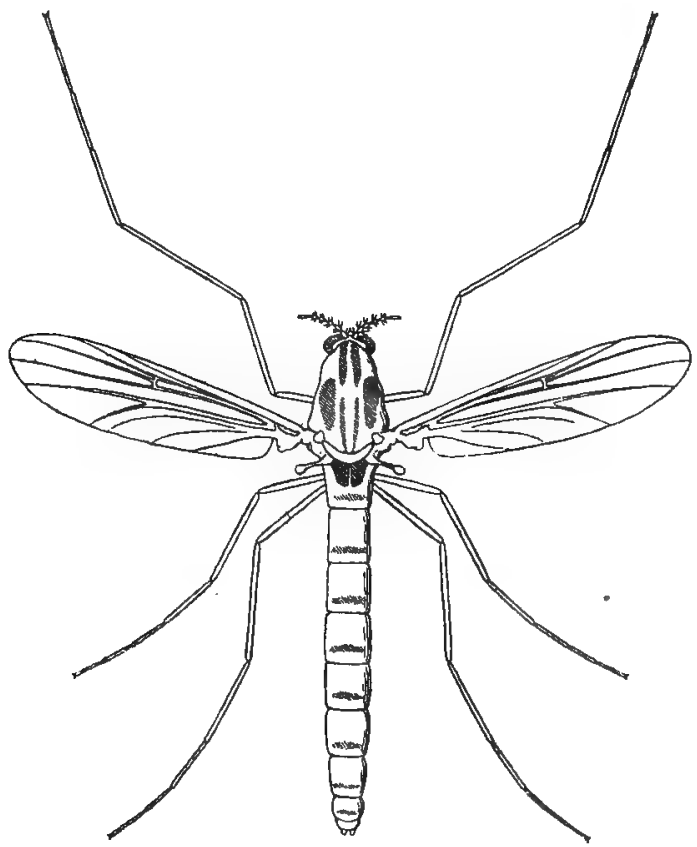

Fig. 64, -Female fly of Chironomus dursalis. $\times 8$.

here, drawing its head backwards, its legs upwards, and its abdomen forwards to this one slit. The cast skin fills with air as the body is withdrawn, and forms a float upon which the fly can rest for a time if so disposed. By attentive examination the top of the back of the fly can be seen to protrude for a minute or two just before the insect escapes, and I imagine that at this time the legs, feelers, and other tight-fitting parts are loosened from their sheaths. It is curious to see the fly, 
without education or example, at once execute so difficult a manœuvre as that of flight, for it flies as swiftly, and steers its course as certainly, as the most practised insect.

The fly of Chironomus is a delicate insect with long legs and gauzy wings. It may easily be recognised as Dipterous, by its single pair of functional wings, and by the rudimentary hind-wings or halteres, which project from the third thoracic segment. On the head may be seen the great compound eyes, nearly meeting above in the male, but somewhat smaller in the female. The antennæ spring from the face. In the male they are plumose, and of relatively large size; in the female they are smaller and of simpler structure. The second joint, especially in the male fly, is enlarged, and forms a spherical chamber, which is believed to lodge the organ of hearing. The antennæ of the male fly are thirteen - jointed; the simpler and smaller antennæ of the female are eight-jointed. The antenna of numerous joints characterises a primary division of Diptera known as Nemocera. The rest of

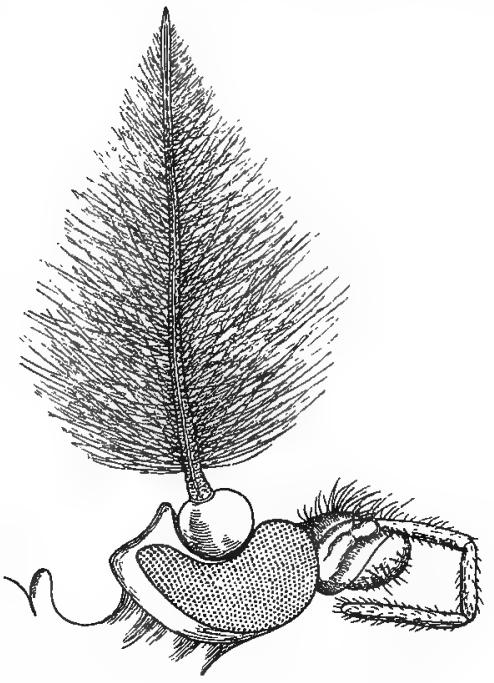

Fig. 65.-Head of male Chironomus fly, in side-view, showing antenna, compound eye, and mouth-parts.

the Diptera have, like the blow-fly, antennæ of the plate and bristle type, with three rather large joints and a bristle projecting on one side (see p. 209). From the rostrum, which forms the lower part of the head, project the mouth-parts, of which the long, four-jointed maxillary palps are the most conspicuous. The digestive apparatus is taken over from the larva and pupa to the body of the fly. During the pupal stage it shrinks and collapses, and is never used again. The fly does not feed at all, and there is not even a passage from its mouth to its 


\section{8 INJURIOUS AND USEFUL INSECTS}

stomach. An experienced observer of insects might have predicted that the fly would not feed, from the mere fact that all the eggs are laid in a single mass. Where the eggs are laid one by one, the female must fly from place to place, and select the best sites for the future larva. This may occupy days or weeks, during which time she must be supported by food. But where all the eggs are laid together, the business can be transacted in a very short time, and then the fly commonly does not feed at all. Nature cares nothing about the spent fly, which perishes speedily. The nervous system is taken over from the larva with no very important change. One thing, however, is noteworthy. In the fresh-hatched larva the brain lies where we naturally expect to find it - that is, in the head, close to the feelers, eyes, and mouth. After a few days it is withdrawn into the thorax, where it is to be found during the rest of the larval stage. Why should the brain be thus retracted into the thorax? I think it may be because the future head of the fly is to be formed there. The head, when completed and duly expanded, will again enclose the brain. For this purpose the brain must be behind and not in front of the rudiments of the head, which have to extend backwards as they open out. But why is the head of the fly formed in the thorax, and not, as usual, within the larval head? Perhaps because there is much more room in the capacious thorax for the deep folds which give rise to the head. When once this plan is adopted, and the head of the fly is made to develop within the thorax of the larva, it is plain that the head of the larva may be still further reduced in size, for a chief part of its contents has been removed elsewhere. In the thorax of the fly the predominance of the middle segment, or mesothorax, is to be remarked. The prothorax and mesothorax are insignificant in comparison. Here, as in the blow-fly (p. I 42), the functional wings and the muscles attached thereto call for an enormous enlargement of the corresponding segment.

One peculiarity of the fly of Chironomus enables us to distinguish it at a glance from other Diptera of the same size and general appearance. It does not bring its fore legs to the ground when resting, but keeps them stretched out in front. Some may-flies (Ephemeræ) have the same habit. Gnats extend their hind legs, and wave them about. This peculiar poising of the fore legs, like the arms of a tight-rope dancer, 
suggested the name Chironomus, which may be translated Harlequin-fly.

On summer evenings the male flies gather in great swarms, often containing several thousands of individuals, in the neighbourhood of the streams or pools in which the larval stage is passed. Here they perform an aerial dance, rising continually to the top of the swarm, and then slowly subsiding.
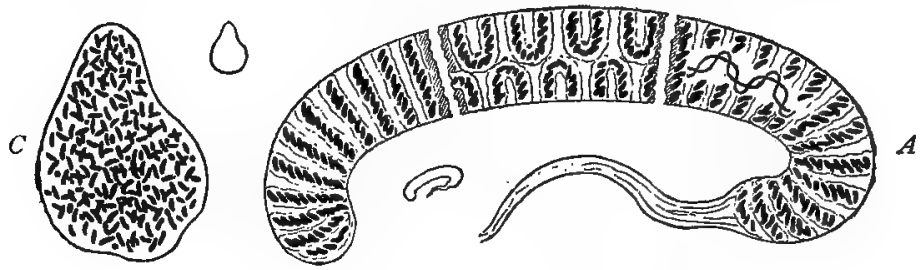

$B$
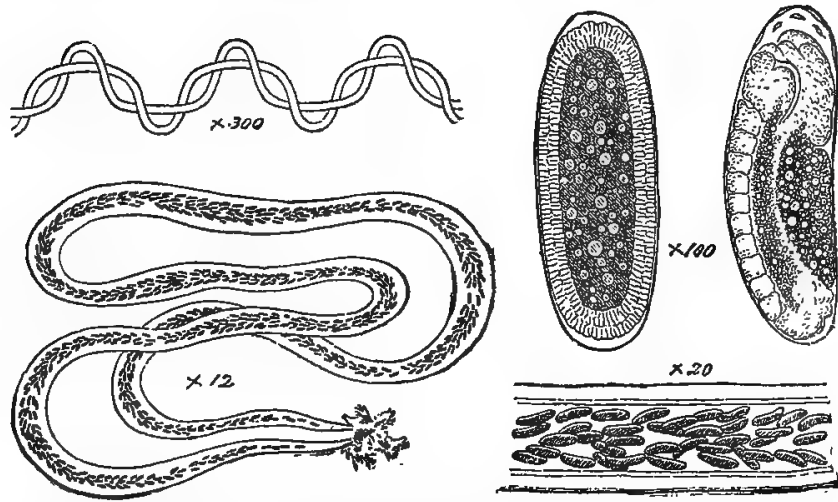

Fig. 66.-Egg-masses of Chironomus. $A$, egg-rope of $\mathbf{C}$. dorsalis, divided into sections, to show both sides; $B$, twisted fibres, which traverse the egg-rope; $C$, eggmass of another species of Chironomus; $D$, egg-mass of a third species ; $E$, part of eggmass, more higbly magnified; $F$, developing eggs, two stages.

Females are rarely seen in the swarms, and the purpose of these singular gyrations was long obscure. But it has been recently observed by $\mathrm{Mr} \mathrm{T}$. $\mathrm{H}$. Taylor that on windy evenings, when the swarm is blown hither and thither, a certain proportion of females may be found among the males. A female fly, immediately after emerging from the water, joins the nearest swarm, and in still weather is mated at once. Then she flies 
off to lay her eggs, while the male rejoins his comrades. Since the females remain so short a time in the swarm, it is not surprising that a sweep of the net, which captures hundreds of males, should often contain not a single female. But when the swarm is much agitated by wind, pairing becomes difficult, and a number of females may be forced to remain unmated.

The conditions of egg-laying are peculiar, and call for many special provisions. The eggs must be numerous, as the larva runs many risks; they must be laid in water, although the fly cannot enter the water without being drowned; they must float at the surface, lest they should be overwhelmed by the refuse of a foul stream; they must be made fast, so that they do not drift into some quite unsuitable part of the stream, or even into the sea. Floating eggs are exposed to the attacks of hungry creatures of various kinds, such as birds, predatory water-insects, and fishes. These difficulties, which are many and real, have been surmounted in a singularly interesting way. The eggs are coated with a gelatinous envelope, which swells out the moment it reaches the water, into an abundant transparent mucilage. This mucilage answers more than one purpose. In the first place it makes the eggs so slippery that birds or insects cannot grasp them. It also spaces the eggs, and enables each to get its fair share of air and sunlight. The gelatinous substance appears to possess some antiseptic property, which prevents water-moulds from attacking the eggs, for, long after the eggs have hatched out, the transparent envtlope remains unchanged. The egg-mass of a harlequin-fly forms a transparent cylindrical rope, nearly an inch long, which floats at the surface of the water. The eggs are arranged just below the surface of the egg-mass in loops, which wind to right and left alternately. The whole egg-rope is moored to the bank by a thread, which passes along the middle in a series of loops; and returns in as many reversed loops, so as to give the appearance of a lock-stitch. The threads are tough, and perfectly invisible in the natural state, owing to their transparency, but they can be made apparent by dipping the eggrope into boiling water, when they turn white. Thus the whole mass, containing nearly a thousand eggs, is firmly moored, yet so moored that it rises and falls with the stream. The eggs get all the sun and air which they require, and 
neither insects, nor birds, nor water-moulds, nor sudden rushes of water can injure them.

The eggs of the harlequin-fly are beautifully suited to the wants of the student of development. They are so transparent that they can be studied alive under the microscope. When you have examined them, and noted what progress has been made, you can put them back into the water to develop for another three hours, and three hours is enough to produce a visible change. The whole course of the development is completed in five or six days, so that it is not difficult to observe every important step.

The egg is long, narrow, and rounded at each end like a bird's egg. It has a tough shell and a thin shell-membrane. Not long after the egg is laid, the cells, out of which the body is to be formed, appear. They creep out of the oily yolk which occupies the interior, and arrange themselves in a regular sheet just within the shell-membrane. The outside of the body forms first, as it does in most animals, and there is an early stage when the body of the future bloodworm is nothing but a hollow bladder, composed of transparent cells and filled with yolk. In this stage there are no organs, and you cannot distinguish head from tail. Very early, however, the layer of cells becomes folded inwards at one place; the cells infolded soon cease to grow, while the rest grow rapidly. This fold marks the place of separation of the head and tail of the future larva, and for a time there is nothing else to distinguish them. The original single layer of cells has now thickened, and become divided into numerous layers. Then cross-folds appear, and the body becomes ringed. The jaws and legs are next developed. The nervous system appears early, the digestive tube rather late. At last the body lengthens so much that it becomes too long for the egg-shell, and has to be coiled. Then it begins to move about, and on the fifth or sixth day escapes from the egg as a minute larva with colourless blood and no gills, but otherwise like a blood-worm.

Further details respecting the development of the larva within the egg are given in the next chapter. 


\section{4. (PRACTICAL.) THE DEVELOPMENT OF AN INSECT (Chíronomus)}

Procure two or three of the egg-masses described on p. I 20. They are transparent, float at the margin of still water, and adhere to the bank by a fine double-thread. Horse-troughs or fountains in gardens are often the most convenient places to search. A small spatula or penknife is useful for detaching the egg-mass.

Examine an entire egg-mass, and compare it with the description already given (p. I 20). Dip it into boiling water, and then study the arrangement of the interlacing threads which traverse the cylinder, and moor it to the bank. Heat renders them sufficiently opaque to be distinguished from the transparent jelly in which they are imbedded. Determine the stage of development according to the table which follows. Having made out the chief features of any stage, replace the egg-chain in water, and re-examine at intervals of three hours.

For many purposes it is convenient merely to place the egg-mass in a watch-glass with a little water, and examine it with a good lens. The details require the compound microscope. A small piece of an egg-chain may be snipped off, placed on a sunk slip and secured by a cover. A quarterinch objective is high enough for most purposes. If sections are desired, the egg in the cylinder must be killed with hot 30 per cent. alcohol, half-saturated with corrosive sublimate. They can then be gradually transferred to absolute alcohol, chloroform, and melted paraffin. The sections are cut by a microtome, and stained on the slide by Heidenhain's hæmatoxylin process. It is not possible to arrange the eggs in any particular position, and many of the sections are therefore useless. The method is too difficult for unpractised hands, and elementary students are recommended to observe only the living embryo. Owing to interruption for sleep and occupations, and the difficulty of obtaining egg-masses of the precise age desired, several will have to be procured in order to complete the history. If a good site is discovered near at hand, this is not a serious difficulty. The inquiry can be carried on most easily in June, July, 
August, and September. Draw everything that can be clearly seen.

It is not possible to give precise information as to the age of the various stages. Development proceeds at very different rates in warm and cold weather. The whole time required is about six days, but varies from four to seven.

stage 1. (The undeveloped egg). It is not easy to get eggs immediately after laying. I have found it necessary to capture a female in the act of fertilisation, and imprison her in a bell-glass with a cup of water. At this time, and more or less for some hours after, the following details are visible. The egg is contained in a transparent oval egg-shell, which is flattened along one side. Within the egg-shell is a transparent vitelline membrane, hardly to be distinguished at present, but becoming plainer in the course of development. A mass of yellow, granular yolk occupies the centre of the egg, while the outermost part is clear, and shows no structure. The formation of polar bodies and pronuclei can be studied by those who have experience of embryological methods.

Stage 2. About two hours after egg-laying, segmentation begins at the hinder pole. A few large nuclei appear in successive pairs at the surface of the egg, the protoplasm gathers round each, and forms constricted masses, which afterwards bud off, complete themselves, and divide into four and eight. After this, the nuclei divide without separating, and form eight large cells, with four nuclei apiece. These are the sexual germ-cells. At this time the yolk contains several scattered nuclei, which can only be demonstrated by refined methods. They multiply with great rapidity, travel towards the surface of the egg, and arrange themselves side by side in a transparent layer, which completely lines the egg-shell. This layer is the blastoderm; it gives rise to the whole body, and also to certain temporary structures, which are afterwards cast off. The blastoderm appears very suddenly, and the act of formation is hard to observe. Within the blastoderm a clear zone appears, and a regular layer of nuclei forms in it, so that the blastoderm soon becomes two-layered.

Stage 3. It is only by much attention that the events already described can be actually observed, but the subsequent stages present far less difficulty. Only the most essential features are described here. The cellular layer, or blastoderm, 
becomes infolded and thins away at one place, so as to allow the yolk to reach the surface. The body has henceforth two ends, a head-end and a tail-end, though they are at first not very unlike each other. The embryo is, during this and the next three stages, curled round the yolk, with what will ultimately be its ventral surface outwards. The cells of the blastoderm divide rapidly along the under side, forming the ventral plate, while the dorsal part of the blastoderm thins out. The cavity is still occupied by granular yolk. About this time the sexual germ-cells re-enter the egg, apparently by forcing a passage through the blastoderm. The ventral plate at first lay along the convex side of the egg, while the future head and tail were on the flat side. Now the embryo rotates on its principal axis, so that the ventral plate lies along the flat side of the egg. The rotation occupies about a quarter of an hour. The first day of development is thus completed.

Stage 4. Early in the second day the ventral plate becomes transversely constricted. The segments which form first are those which enter into the future head. Others are rapidly added behind these. The body contracts, and the head and tail become more and more widely separated. Towards the middle of the second day the embryo rotates a second time on its axis, and the ventral plate comes to lie once more on the convex side of the egg.

Stage 5. The body is now segmented throughout. Sixteen segments can be counted, and some of these are beginning to push out paired appendages, the rudiments of jaws or legs. The body has now contracted and straightened itself to such an extent that the head is at one pole of the egg and the tail at the other. The nerve-cord has made great progress. Its first rudiment appeared on the ventral side of the body, towards the fore end, and rapidly grew till a gangliated chain, extending the whole length of the body, was formed. Owing to its transparency, the nerve-cord can hardly be made out till a later stage unless stained sections are employed. At first the ganglia are relatively large, and occupy almost the whole cord.

Stage 6. A pit is formed by pushing the skin of the under side of the head inwards. A second pit forms by the pushing of the skin inwards at the tail-end. These two pits lengthen, and ultimately form the fore-gut (gullet, etc.) and hind-gut 
(intestine). The mid.gut, or stomach, is formed differently, by the completion into a tube of a pair of cellular bands which immediately enclose the yolk. The fore-gut and hindgut, being formed by the pushing inwards of the outer skin, possess a chitinous cuticle, internal to its generating layer. The stomach, which has never formed part of the outer integument, has no cuticle of its own. The sexual germ-cells are by this time enclosed within the hinder end of the body, where they appear as a pair of cellular masses; in a later stage they give rise to the ovaries or testes. It is remarkable that these are the very first parts of the body to be differentiated.

Stage 7. During the third day the jaws begin to take their ultimate form. The dorsal wall of the body is completed by the growing upwards of the edges of the ventral plate.

Stage 8. During the fourth day the wall of the stomach is completed. Eye-spots appear, and the dorsal vessel forms.

Stage 9. The body is by this time (fifth day) longer than the egg, and becomes coiled in consequence. On the sixth day the coiling increases, and the larva begins to move about within the egg. The egg-shell is burst open, and the larva becomes free. It is now half a millimetre long, and differs from the full-grown blood-worm in several particulars. The blood has no red tinge; there are no ventral blood-gills; the head is very large, and as yet encloses the brain. These peculiarities are lost after the first moult.

\section{GNATS (Culex)}

The early stages of gnats are passed in water. They require still water, such as is found in ponds, ditches, and cisterns, and thrive best when it contains much microscopic life. Hence foul water, or water containing abundance of dead leaves, yields a suitable breeding-place for gnats of several kinds.

The larva floats at the surface of a pool in a nearly upright position, the head downwards, and the tail-end in communication with the air. If we examine it closely with a lens in a good light, we see a gleaming band around the 


\section{I26 INJURIOUS AND USEFUL INSECTS}

head, which is due to the play of light upon a multitude of hairs, all busily sweeping into the mouth the microscopic particles upon which the larva subsists. There are no limbs, but the last segment bears a simple fin formed of a row of bristles, and the last but one sends out a breathing-tube, by which air is taken into the body. In swimming, the regular tufts of bristles which stand out from the sides of the body are, no doubt, of use. The larva propels itself by striking the water suddenly with the hinder part of its body, and can travel pretty fast with a jerking movement. It can remain floating at the surface as long as it pleases, feeding with its fringed mouth, and breathing through its air-tube. This is a little singular, for the body is heavier than water. When a larva, detached from the surface, ceases to struggle, it sinks slowly. It maintains itself at the top of the water by taking advantage of the surface-film which overspreads every free surface of a liquid. By means of this same surfacefilm a steel needle can be made to swim on water, and the gnat-larva is supported without effort by the pull of the surface-film upon the pointed valves which open and close its air-tube.

The larva, when full-grown, is about half-an-inch long in certain common species. The various parts of the fly are already in an advanced stage of development. As soon as the last larval skin is cast, the new organs rapidly take something like their ultimate form and place, and in a minute or so the creature is transformed into a pupa, strikingly unlike the larva, both in form and habits. As in the harlequinfly, the pupa is practically a fully formed fly, shrouded for a time in a close-fitting, transparent skin, the pupa-skin. Every limb and appendage of the fly has its own pupal sheath. At the hinder end of the body is a broad tail-fin, formed of a pair of flaps, and this constitutes a very effective paddle. The pupa is buoyant, its air-tubes being distended with air; when at rest it floats at the surface of the water, sinking only when alarmed, and with considerable effort. A pair of trumpets behind the head, shaped like cows' horns, but attached by their points instead of by their broad ends, now serve for taking in air ; their position is so accurately adjusted, that whenever the pupa comes to rest, the broad open ends of the trumpet lie flush with the surface of the water. After 
a short interval (three or four days in summer) the pupal skin cracks along the back of the thorax, and the fly escapes into the air, sometimes resting for a few minutes on the cast skin until its wings are dry.

The fly is not unlike the harlequin-fly in general appearance. The male is distinguished from the female, as in the harlequin-fly, by its bushy feelers. Harlequin flies raise their fore legs from the ground when resting, and stretch them out in front; gnats often raise their hind legs and stretch them out behind. When the female is ready to lay her eggs, she chooses a suitable pool, and after gliding to and fro over the surface for some time, settles on the water, or on some floating object. The hind legs are extended and crossed. Into

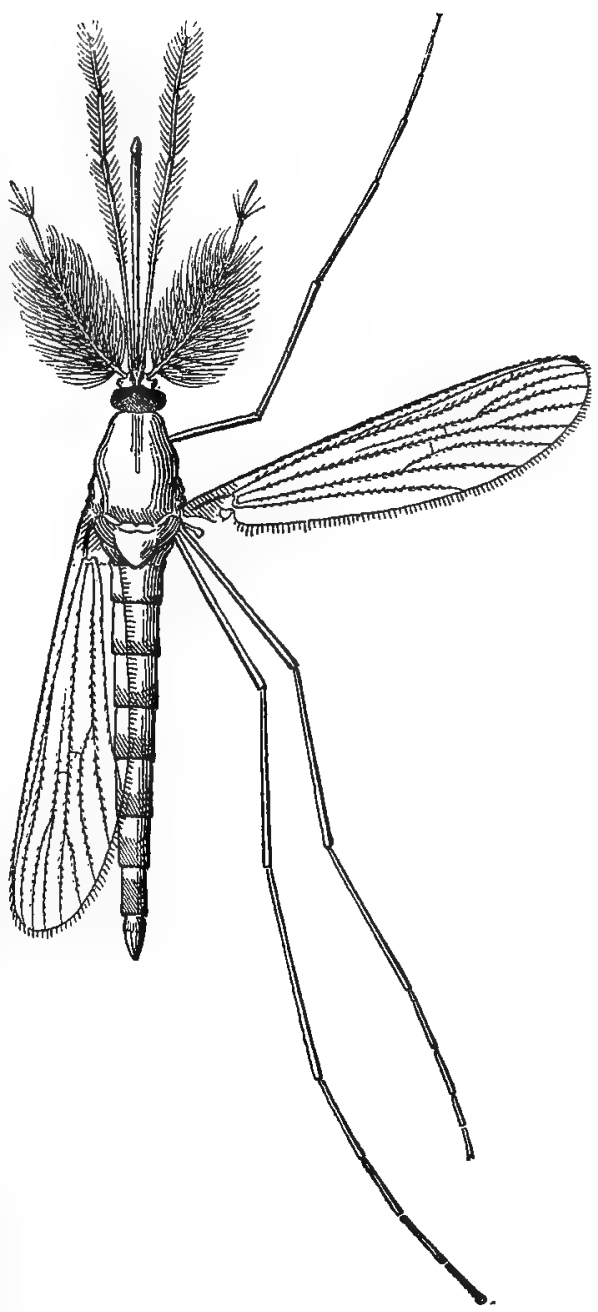

Fig. 67*-Male gnat, magnified. 
the angle between them the eggs are received as they pass out from the body, and, being sticky, they adhere and form a packet, or egg-raft. When 200 to 300 are collected and glued together, they are set floating on the water. Each egg is of elongate form, and its lower end is furnished with a circular lid, which opens when the larva within is completely developed,
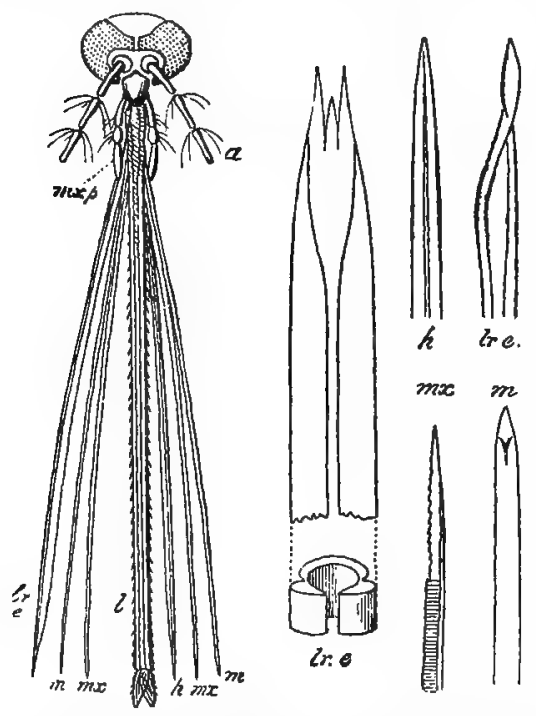

Fig. 68.-Mouth-parts of female gnat. $a$, base of antenna; $\Re x p$, maxillary palp; lre, labrum-epipharynx; $l$, labium ; $m$, mandible ; $m x$, maxilla ; $h$, hypopharynx. The separated mouth-parts are copied from Dimmock. fruits, such as bananas. One particular sort of gnat (called Anopheles by entomologists) has recently been convicted of communicating to human beings dangerous malarial fevers of more than one kind. As long ago as I 880, a French surgeon named Laveran observed minute specks in the red blood-corpuscles of malarious patients, and showed that these ultimately enlarged, devoured the corpuscles, and formed rosettes, rounded bodies with minute spheres on their surface. The connection of these bodies with various in- 
termittent fevers was established, and it was discovered that each recurring attack of the fever corresponds to the liberation of a fresh crop of spores or malaria-germs. Quinine destroys the parasite without injuring the patient, and is therefore a powerful remedy against malaria. The next step in the inquiry was to discover how the malarial parasites entered the blood. Dr Manson suggested, and Major Ross in 1897 proved, that mosquitoes (which are only gnats under another name) are the agents. The gnat draws blood, and in the very act infects the patient with the malaria-germ. An uninfected gnat becomes infected by drawing blood which contains malaria-germs. They multiply in the body of the insect, and, after completing their own life-cycle, produce and set free vast numbers of rod-like bodies, which accumulate in the poison-glands and their ducts, to be introduced at the first opportunity into another human victim. Now that the cause of malarial fevers is ascertained to be intimately connected with the bites of particular gnats, the search for means of prevention becomes hopeful, and it may not be very long before the malarial districts of the tropics are rendered perfectly safe to Europeans.

\section{THE CRANE-FLY (Tipula oleracea and allied species)}

This very common insect is known as a larva by the name of leather-jacket, and in the winged state as the crane-fly, or daddy-longlegs. The larva is subterranean, and is hardly ever seen except when a sod is lifted. The toughness of its skin suggested the popular name of leather-jacket. It attains a length of nearly an inch and a half, is of a dull brown or dark grey colour, and is not unlike a fragment of a small twig. On examining it closely, the head can be distinguished. It is rather small, hard, and retracted within the prothorax for two-thirds or more of its length. As is usual with retractile heads, the chitinous wall is imperfect, and shows large gaps or incisions. There are no limbs; the feelers are rather short and three-jointed; the mandibles strong and toothed, the maxillæ reduced to mere vestiges. The labium is represented by two plates, one in front of the other, with their fore-edges toothed. Against these teeth the mandibles play 
in the act of dividing the food. At the hinder end of the body are six short conical projections, and in the centre of the space enclosed by them are two large spiracles, the only efficient spiracles in the body. By microscopical examination,

a row of minute closed

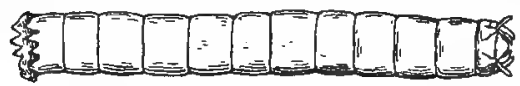

Fig. 69.-Larva of crane-fly. $\times \frac{4}{3}$. spiracles can be made out extending along each side of the body. The larva devours dead vegetable matter, as the contents of itsalimentary canal show. It is likely that it also gnaws the roots of grass, as it is well known that grass and corn are seriously injured by the presence of a number of leather-jackets in the soil.

When the larva has attained its full size, it casts the last larval skin, and is converted into a pupa. The pupa, as soon as it becomes free, takes a vertical position, and forces its body through the soil to the surface, where it sticks out about half of its body. In making its way to the surface, it relies mainly upon a number of short hooks, which project from all the segments of the abdomen, and are particularly numerous towards its extremity. The wings and legs of the fly, as well as the head with its compound eyes, can now be easily distinguished, though all these parts are still enclosed within the pupal skin. The legs and wings are much crumpled, and arranged upon the ventral side of the body; each is enclosed in its own sheath. Just behind the head there stand out from the dorsal surface of the prothorax a pair of curved horns which lead into the tracheal system, and constitute the respiratory trumpets of the pupa. The position adopted by the insect in this stage renders it an easy matter to take in a fresh supply of air through the respiratory trumpets. After a few days the pupal skin cracks along the exact middle of the dorsal surface of the thorax, and through the fissure

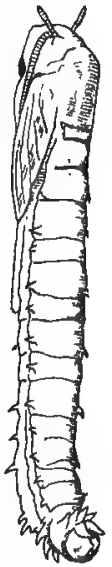

Fig. 70. Pupa of cranefly, enlarged. the fly escapes, leaving the empty pupa-case sticking out of the earth.

The crane-fly in its final stage is at once distinguished 
as Dipterous, having a single pair of functional wings and in the place of hind wings a small pair of halteres. The head is small; in the hinder part, which is more or less globular, the compound eyes are conspicuous. In front of these the head is drawn out into a kind of snout which bears the feelers and mouth-parts. The feelers are 13 -jointed, and at the base of each joint is a regular whorl of bristles. A pair of 4 - jointed palps are conspicuous among the mouth-parts. The crane-fly is remarkable, as everyone knows, for the extreme length and slenderness of its legs, suitable to an insect which has to make its way among the blades of grass, and particularly at the time of egg-laying. The male fly can be

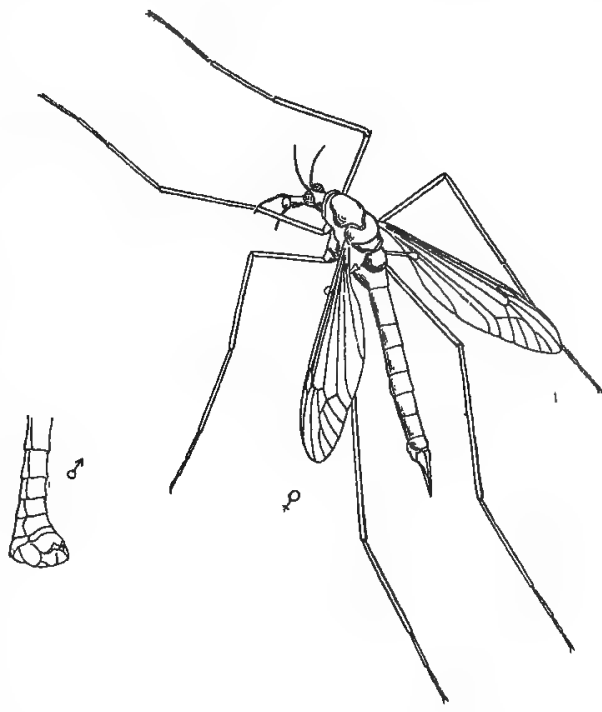

Fig. 71.-Female crane-fly, and end of abdomen of male crane-fly. distinguished

from the female by the form of the abdomen, which is blunt at the extremity, while in the female it is pointed. The pointed extremity is used in egg-laying, and ends in an upper pair of slender prominences, and a lower pair of broader ones. The two pairs can be separated or brought together like a forceps. When the female lays her eggs, she rears up her body into a vertical position, being usually supported by blades of grass, and directs her abdomen downwards. The eggs are then passed out through the forceps. Each is held for a moment, and then placed in a convenient 
situation upon or just beneath the surface of the ground. After laying a cluster of eggs, the female flies to a distance, and repeats the operation. The eggs are of small size and nearly black. Some hundreds are laid by a single female.

The insect passes the winter as an underground larva. In spring the pupæ appear, and shortly afterwards, the winged flies. Egg-laying follows, and during a great part of the summer but few flies are to be seen. In August or September a second brood of flies make their appearance, and lay eggs from which the winter larvæ are derived. The crane-fly seems to prefer damp grass, and often abounds in neglected marshy fields, though it is by no means confined to such situations.

It is easy to recognise the near relationship of the cranefly to Chironomus. The simple, many-jointed feelers, as well as the mouth-parts of the imago, indicate that it belongs to the same primary division of Diptera Nemocera. Only the Nemocera possess long palps of several joints like those of the crane-fly. The larval head, too, and the structure of the larval mouth-parts, are not unlike those of Chironomus. The most noteworthy differences between the two insects are immediately connected with the elements which they inhabit as larvæ and pupæ. The subterranean larva of the crane-fly has a large pair of open spiracles on the last segment, which is usually turned upwards when the larva is burrowing or feeding. In the aquatic blood-worm, as we have seen, there are no open spiracles at all, and gills, adapted to aquatic respiration, take their place. The pupa of the crane-fly breathes by open trumpets; the Chironomus-pupa by branched gills projecting from the same part of the body (prothorax). It is probable that the terrestrial crane-fly is the more primitive of the two; and that subterranean larvæ, inhabiting wet earth near streams, became at length adapted to live under water.

This is apt to be a most intractable pest, and it is very difficult to reach the eggs or grubs by any treatment. The draining of wet grass-land is sometimes beneficial, and the penning of sheep upon infested ground, at the time when the pupa or fly is expected, has been practised with success. 


\section{THE HESSIAN-FLY (Cecidomyía destructor)}

This little fly has long been a deadly enemy to the American farmer. Where it appears in force, wide tracts of wheat and barley become blighted, the stalks bend down, and the ears contain only starved grain. The pest first attracted attention during the American War of Independence, and was popularly believed to have been introduced by the Hessian mercenaries; hence the name of Hessian-fly. Its native country is still undetermined, and it is not even known for certain whether it originally came from the Old or the New World. Wheat, barley, and rye are the grains which it infests; the timothy-grass of meadows, and the weed known as couch-grass or quick, are also preyed upon; oats seem to escape. The fly chiefly attacks the young plant, but can also subsist on the new growths which push out from plants cut down by the sickle. Since sprouting grain can be found in most countries both in spring and in autumn, the Hessian-fly times its attacks accordingly. There are two broods in the year, and the flies appear just at the seasons when the young plants are fittest to nourish the grubs which issue from the eggs.

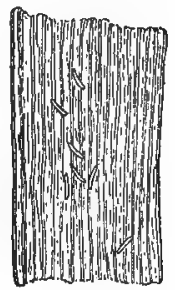

Fig. 72.-Eggs of Hessian-fly, on leaf of barley, magnified.

The Hessian-fly is Dipterous, or two-winged, and belongs to the sub-order Nemocera-i.e. with thread-like feelerswhich includes the crane-fly, the harlequin-fly, and the gnat. It resembles these insects in the general course of the lifehistory, as well as in the organisation of the larva and pupa; but the mode of pupation, as will be pointed out shortly, seems to make a transition to the more specialised Diptera, of which the blow-fly is an example-flies which bear plate-and-bristle antennæ, and whose larvæ are maggots.

The life-history of the Hessian-fly is shortly this. The eggs are laid upon a young wheat or barley plant. From them issue larvæ, which feed upon the sap. When the larva is full-fed, it comes to rest without casting the larval skin, pupates, and then remains dormant for a longer or shorter time, concealed within the food-plant. At last the 


\section{I34 INJURIOUS AND OTHER INSECTS}

larval skin bursts open, and the pupa is exposed; shortly afterwards the pupal skin also is cast, and the fly escapes, to lay the eggs from which a new generation will proceed.

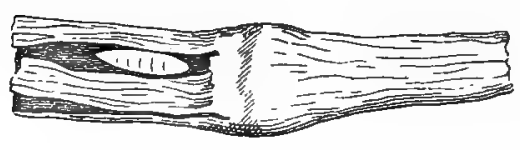

Fig. 73.-Larva of Hessian-fly, feeding above a knot, magnified.

The eggs are minute, and of red colour. One, two, or three are usually laid upon one plant. As soon as the larva becomes free it creeps down the stem to the next joint, which is near the ground. It makes its way between the haulm and the sheath (which is also the base of a leaf), and here it begins to suck the sweet, nutritive juices of the plant. More than one larva may be found feeding at the same joint. The loss of sap causes the plant to flag. The haulm bends sharply just above the joint affected, and the growth of the ear is checked. The young larva is soft, white, and footless, with a minute, retractile head. The body tapers both in front and behind. Nearly all the segments bear spiracles, except the two which in the fly support the wings and halteres. On the under side of the prothorax is a hard scale, divided into two forward-pointing prongs. A larva taken in the act of feeding shows a green line running along the centre of the body; this is the digestive tube, filled with a greenish sap, sucked out of the plant. Four weeks after hatching the grub is of full size, and about $6 \mathrm{~mm}$. ( $\frac{1}{4}$ inch) long; the original white colour has now changed to yellow. It ceases to feed, retracts its head, and changes to a seed-like object, pointed at each end. The larval skin is not

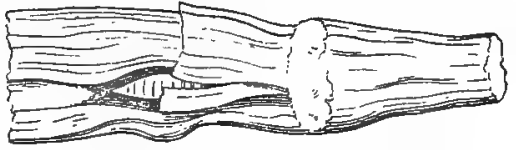

Fig. 74.- "Flax-seed," or pupa of Hessian-fly, magnified.

cast, but becomes coated over with a fluid exudation from the body, which hardens on exposure to the air, and forms a protective husk or puparium of chestnut-brown colour. In this condition the insects are called "flax-seeds." Not only the Hessian-fly, but all the insects of the same genus 
(Cecidomyia), exhibit this peculiarity, and pupate without casting the larval skin. So also do the blow-fly and its near allies, the higher Diptera.

Mr Enock has worked out the changes which take place within the flax-seed. The body of the insect first shrinks away from its envelope, "just as a ripe nut shrinks from its shell." Next it turns itself about, head for tail, within the husk-a task of some difficulty, for the space is little bigger than the body which occupies it. This reversal of the

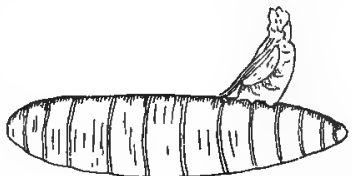

Fig. 75.-Pupa of Hessian-fly, escaping from larval skin, magnified.

two ends of the body facilitates the subsequent escape of the pupa. So long as the insect was feeding on the fluids sucked from the joint it kept the original attitude, with bead directed downwards - the attitude in which it quitted the egg, and crept down the sheath. But the first thing which the pupa has to do is to crawl up the sheath

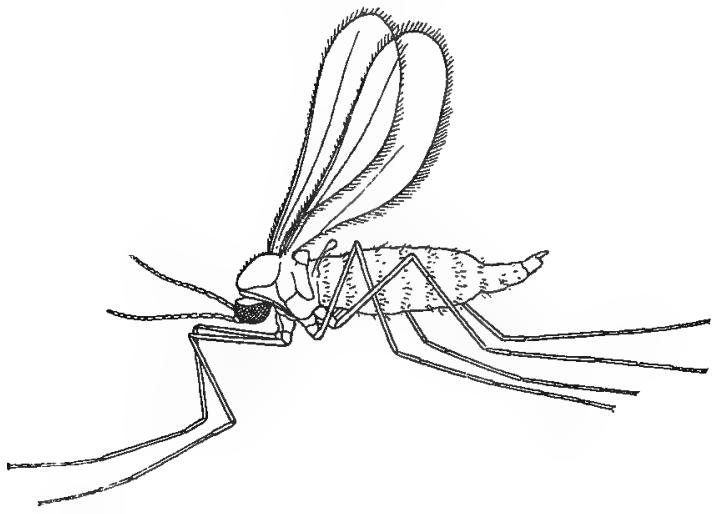

Fig. 76.-Hessian-fly. $\times$ Io.

again, and work its way out. To prepare for this, it brings the head round till it points upwards. Mr Enock believes that the two-pronged scale on the under side of the prothorax finds its special use in this turning movement. When all 


\section{I36 INJURIOUS AND USEFUL INSECTS}

is ready the husk cracks, and the pupa wriggles out. Leaving the husk behind, it climbs for some distance up the sheath, its thin and flexible pupa-skin being here, as in the harlequinfly or the gnat, no impediment to the movements of the body-segments; then, with the help of certain spines on the prothorax, it tears through the sheath and works its body out until it is half-exposed. The pupa-skin now cracks, and the fly proceeds to extricate itself. Mating and egglaying follow. The whole life-history may, under favourable circumstances, be transacted in as little as eight weeks; but there is commonly a long pause, and the pupa remains motionless within the flax-seed until the young wheat or barley is out of the ground. The fly is about $3 \mathrm{~mm}$. ( $\left(\frac{1}{8}\right.$ inch) long; it has big antennæ, every joint of which carries a whorl of hairs, large wings fringed with fine hairs, and long, slender legs. The male fly is smaller than the female, and much more active.

Since the Hessian-fly scare of 1886 , not very much has been seen of this pest in Great Britain. Wheat is not sown in this country till after the date (end of September) when the autumn flies appear. Barley has suffered in particular years, but the attacks have not hitherto approached in severity those which visit the American farmer. Should rigorous measures be called for, the dormant or flax-seed stage offers good opportunities for destruction of the insect. The flax-seeds which drop out during thrashing should be burnt or boiled, the stubble of infected fields fired, and couch-grass thoroughly extirpated.

The Hessian-fly is the victim of many minute Hymenopterous parasites, which are probably one chief means whereby its numbers are kept within bounds.

\section{8. (PRACTICAL.) THE STRUCTURE OF THE BLOW- FLY (Calliphora erythrocephala or C, vomitoria)}

An ample supply of blow-flies in every stage can be easily procured. Send to a butcher for a piece of fly-blown meat, and keep it out-of-doors under a wire screen until the maggots turn to pupæ, and the pupæ to flies. Specimens of each may be examined fresh, and others preserved in alcohol for future use. 


\section{The Larva}

The larva, or maggot, hatches out in a day or so from eggs laid in the carcasses of animals. It buries itself in the flesh, feeds voraciously, and grows very fast, attaining its full size in a fortnight or less, when it is a little less than an inch long.

Observe some live maggots ; they are soft and white, widest behind, and tapering gradually towards the head-end, which is very narrow. The body is apparently divided into eleven segments, though this is probably not the full number. Each segment is roughened at the constrictions which separate it from the next segments by annular bands of minute hooks; these are used by the footless maggot in crawling; the rest of the surface is smooth. The conical first segment, which is the prothorax, encloses the head; two other thoracic segments follow,

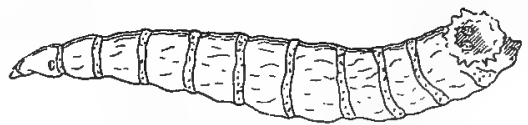

Fig. 77.-Larva of blow-fly. $\times 4$. and there are eight abdominal segments, of which the last probably represents more than one ordinary segment.

The head is reduced to a vestige, and contains little besides the jaws and their muscles; it requires to be studied by the microscope. When protruded from the first segment, it exhibits a pair of large rounded lobes, each of which bears two minute prominences, one above the other. Two large chitinous hooks will be found, one on each side of the mouth. In a freshhatched larva there also is a large median hook, placed above the mouth; this is cast at the first moult. On each side of the mouth, outside the large hooks, is a rounded lobe, marked with radiating lines. There is an internal skeleton to the head, which serves for the attachment of muscles. The brain is not lodged, as in most insects, in the head, but in the metathorax. The great simplification and reduction in size of the larval head may be attributed (I) to the ease with which the food is procured, leading to degeneration of the mouth-parts and sense-organs; (2) to the retraction of the head into the thorax, a provision not uncommon in burrowing Dipterous larvæ, and often associated with a backward displacement of the brain, as well as with a notable reduction in 


\section{I38 INJURIOUS AND USEFUL INSECTS}

the size of the head. Microscopic preparations of the head of the blow-fly larva may easily be made by cutting off the prothorax with part of the mesothorax attached. Place it in equal parts of glycerine and 5 per cent. potash solution, lay on a large cover, and apply gentle pressure. The preparation gradually increases in transparency, owing to the action of the potash.

Examine with a lens the hinder end of a larva preserved in spirit. Afterwards cut off the truncated end, turn it up, and examine again. Notice that the hinder end is obliquely truncated. It is divisible into a dorsal spiracular field, enclosed by twelve small papillæ, and a smaller ventral anal field, in which lies the prominent anus. 'The pair of large, obscurely jointed processes which lie on either side of the anus, seem to answer to the anal feet of the Chironomus-larva. The posterior spiracles, which lie in the spiracular field, are circular chitinous plates, each enclosing three respiratory slits, which are guarded by a strong chitinous network.

Next examine the small, fan-shaped anterior spiracles, which project from each side of the prothorax. These are probably little used for respiration. The longitudinal tracheal trunks proceed forwards from the posterior spiracles, and give off numerous branches to all the segments. They are connected in the mesothorax by a transverse trachea, immediately in front of which they receive branches from the anterior spiracles.

The tracheal system, the nerve-cord, and the heart, can be studied in a fresh larva by subjecting it to slight pressure in a compressorium or live box. The large tracheæ will then appear as silvery threads. At the hinder end of the body the pulsation of the heart will be observed.

\section{The Pupa}

The full-fed larva buries itself, if possible, in the earth. The head becomes permanently retracted, the alimentary canal is emptied, and the body assumes an egg-like shape. At first it can creep about when disturbed, but it soon becomes incapable of movement, owing to the detachment of the muscles from the larval skin. After two or three days the larval skin hardens, and turns successively yellow, red, and 
finally almost black. Within this hard and dry skin the larva changes to a pupa, and the pupa to a fly. If the pupating insect is examined when the pupa-case is red-coloured, it will be found to contain a creamy fluid, with little visible structure. By the help of carefully prepared microscopic sections, it has been discovered that in this stage the larval organs break up, and new (imaginal) organs take their place. The destruction of the larval structures is effected by the activity of peculiar blood corpuscles (phagocytes) which eat up the muscles, epithelial cells, etc., and ultimately transfer their own substance to the growing tissues. The new organs of the fly are developed from special cellular patches, forming part either of the epidermis, or of the epithelium of the internal cavities. These centres of development arise by infolding of the epidermis or epithelium. Such pouches or infoldings can be seen in a simpler form in late larvæ of such insects as Chironomus, Lepidoptera, etc.,

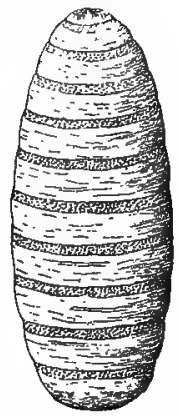

Fig. 78.-Pupa rium of blow-fly enclosing the true pupa, and consisting of the larval skin, mag. nified.

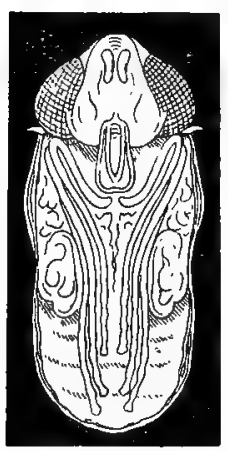

Fig. 79.-Pupa of blow-fly, removed from puparium, magnified. where the larval legs are wanting, or too short to receive the much longer legs of the pupa and imago, the bases of which, as they grow, become telescoped into the body, while the tip may be still enclosed within the larval legs. Should the legs, wings, mouth-parts, and other similar organs be almost or altogether undeveloped in the larva, but large and complex in the fly, the infoldings become deeper still, and seem to lose all connection with the epidermis or epithelium to which they belong. This is the case with the blowfly. The larva has, at most, insignificant rudiments of eyes, feelers, mouth-parts, wings, and legs, while all are of elaborate structure in the fly. Moreover, the alimentary canal and other internal organs require to be almost completely regenerated during the pupal stage of the blow-fly. The new imaginal structures develop from centres 
which are deep-seated, and were once supposed to be independent of the larval tissues. They are now known to be folds, either of the epidermis or of some other cellular layer. The process is much more intelligible in Nemoceran larvæ or in Lepidoptera, than in the blow-fly, which is highly specialised and peculiar, and forms indeed an extreme case of its kind. During this complete regeneration of the body, the insect is of necessity motionless. It is completely protected by the puparium, or hardened larval skin. Respiration is carried on through the posterior spiracles, which still remain in a functional condition.

If we remove the larval skin from a black pupa-case, we shall find within it the true pupa, a whitish object, not unlike a Lepidopterous chrysalis, with its legs and wings disposed with perfect regularity on the sides of the body. All the parts are covered by a transparent pupa-skin.

The fly escapes by raising a kind of lid, composed of the first four rings of the pupa-case. When fresh emerged, it is soft and pale; the wings are crumpled and useless for flight. A large, bladder-like frontal sac projects from the head, and it is probable that the expansion of this sac pushes off the lid of the pupa-case. After a few hours the body of the fly becomes distended with air, and darkens gradually to a blueblack colour, the chitinous cuticle hardens, the wings expand, and the insect becomes capable of flight.

\section{The Fly}

The head is largely occupied by the compound eyes feelers or antennæ, and proboscis. It is attached to the thorax by a very slender neck. Examine the front of the head with a lens, and observe the large compound eyes, nearly meeting in the male, but more widely separated in the female. Note that in male insects the eyes are often larger than in the female. Why? Observe also the three simple eyes on the top of the head, partly hidden by hairs, and the antennæe, each with three enlarged basal joints and a slender bristle, which bears a brush of fine hairs. The antennæ lie close together in a cavity which occupies the middle part of the lower half of the face. The bristle projects from the third joint near its base. A cavity will be found on 
the under side of the head, in which the proboscis can be folded up. Hold the fly between the finger and thumb, and while observing it with the lens, press gently on the sides of the head. The proboscis will then be protruded, owing to distension by air. Note the inflation of the basal parts, the movements of the maxillary palps, and the action of the joints.

The proboscis consists of a basal part (rostrum), which represents the fore part of the head, and the mouth-parts. At the junction of these two divisions of the proboscis will be seen the maxillary palps, two curved, black, single-jointed rods, covered with hairs, very unlike the long three-or-fourjointed palps of a Nemoceran fly (see p. 13I). Beyond these is the labium, a thick and jointed hollow tube, ending in an oval palette, which forms the rasping surface, while the tube is used for suction. The upper surface of the labium is

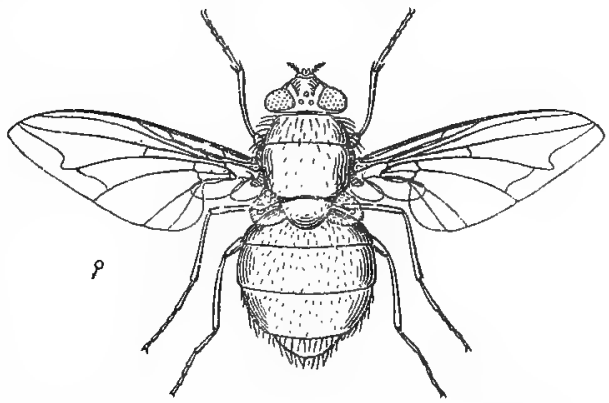

Fig. 80.-Female blow-fly, dorsal view. $\times 3$.

grooved, and upon it lies a stiff, dark-coloured rod (the labrum) shaped like a long and very narrow steel pen; the labrum is partly overlapped by the sides of the labium. In Dipterous flies with piercing mouth-parts the labrum can be raised by the insect at pleasure, when the piercing implements within are exposed; but in the blow-fly the labrum is never raised, and there is only a single needle within it, which is quite harmless. The palette at the tip of the labium consists of two lobes, sometimes called the labellæ.

Extend the proboscis by pressure on the sides of the head, and then cut it off with a pair of fine scissors, as near the base as possible. Mount it in glycerine, and examine with a low power of the microscope. A permanent preparation may be made by treating the proboscis with caustic potash solution, 
and mounting in balsam according to the instructions previously given (p. $\mathrm{r}_{3}$ ).

The proboscis and its joints will be more easily understood if you suppose that your arm above the elbow stands for the rostrum, and the fore-arm for the labium. The hand, with the palm turned downwards, will represent the palette. The maxillary palps must be imagined to project just above the elbow. Each labella is supported by a chitinous framework, formed of the radiating terminations of the salivary ducts, on which appear many transverse lines. The surface is roughened, and acts as a file; it is also moistened by the saliva. When a fly alights on a lump of sugar, it discharges a small quantity of saliva, spreads it about with the palette, rubs the moistened surface, and then sucks up the dissolved sugar. The friction of the palette of a house-fly upon a sensitive part of the body, such as the back of the hand, is described by some people as "biting," but the skin is never pierced. There is, however, a Dipterous insect, the stable-fly (Stomoxys), very like a small house-fly, which enters houses, and is able to pierce the skin with its labrum.

The thorax of the blow-fly, as seen from above, consists of three parts, one behind another. There is ( $I$ ) a short, transverse plate, (2) a large squarish plate, to which the wings are attached, and (3) a small triangular plate, pointing backwards. It would seem natural at first sight to identify these plates with the three thoracic terga; but the arrangement of the internal organs, and especially of the muscles, shows that they are all parts of the mesothorax. The true prothorax and metathorax are small, and can only be discovered by a close scrutiny. The great activity of the fore wings, and the practical suppression of the hind wings, have apparently led to an enormous development of the mesothoracic muscles, and consequently of the mesothoracic segment, while the prothorax and metathorax have been reduced in a corresponding degree.

On the under surface of the thorax, between the fore and mid legs, the large mesothoracic sternum can easily be seen. The prothoracic and metathoracic sterna are much less evident. On each side, and just dorsal to the base of the fore leg, is an oval (mesothoracic) spiracle; another (metathoracic) 
comes outside the bases of the mid and hind legs, close to the root of the rudimentary hind wing. The metathoracic spiracle is easily seen as a nearly vertical slit, the other is not so obvious.

There are at least eight segments in the abdomen. The first is concealed by the thorax, while the sixth, seventh, and eighth are telescoped into the hinder end of the body, from which they can be made to protrude by gentle pressure. In the male the segments so protruded exhibit three terga, to the last of which are attached two pairs of appendages. The outer pair of appendages are larger than the inner, and curve inwards at the tip. These are prehensile organs, used for seizing the female. The abdominal sterna do not overlap like the terga, but are separated by rather wide spaces of flexible membrane. The loose articulations of the sterna, and the sliding movements of the terga, allow of considerable distension of the abdomen. In the female the segments protruded by pressure take the form of a long conical process, consisting of several segments, four terga and five sterna being easily made out; the last carries a pair of small appendages.

Observe the wings and their insertion. At the base of each, and in the angle between the wing and the body, are two semi-circular. folded lobes of the wing, of which the inner one (the winglet) forms a dome-like covering to the haltere. The hind wings (halteres) are small, and incapable of aiding in flight. They form narrow stalks, clubbed at the ends, and may be seen on removal of the winglets.

Each of the six legs consists of a broad coxa, a short trochanter, a femur, a long and narrow tibia, and a fivejointed tarsus. The last joint of the tarsus is provided with a pair of hooks and a pair of pads. The pads adhere to smooth surfaces by means of a sticky secretion which flows from them.

The male blow-fly is easily distinguished from the female by the large size of the compound eyes, which meet upon the face. The abdomen is slighter, and seems nearly empty when pressed. Male blow-flies are seldom seen in houses, but are common in gardens, where they may be found visiting flowers, or sunning themselves on banks.

The eggs are laid in packets of various size, upon carcasses 
of animals. They are fertilised by the female immediately before laying, the sperms having been previously received from the male, and stored up in a special receptacle within the abdomen.

The blow-fly exhibits the following marks of a Dipterous insect:--(I) There is one pair of transparent wings, and a pair of halteres. (2) The mouth-parts include piercing organs (here quite insignificant), and a suctorial labium (here unusually large, and capable of protrusion and retraction).

The following points are characteristic of the sub-order Athericera :-(I) There are short antennæ, with three enlarged basal joints and a bristle. (2) The piercing mouth-parts are reduced to two slender and pointed styles, one in front of the other; there is a pair of unjointed maxillary palps, and a large suctorial labium ending in two broad lobes. (3) The pupa is enclosed in a puparium, formed by the hardened larval skin, which bursts transversely to allow of the escape of the fly.

The antennæ sunk in a cavity on the face, the plumose bristle springing from the base of the third joint of the antenna, the well-developed proboscis, and the halteres covered by a winglet, indicate that the blow-fly belongs to the Muscinæ, Muscids of the highest grade.

\section{THE BOT-FLY OF THE HORSE (Gastrophilus equi)}

Horses at pasture are often plagued with this insect. The egg-laying fly is seldom noticed; it is over half-an-inch (I3$17 \mathrm{~mm}$.) long, with brownish-black hairs, speckled wings and yellow legs. In the male fly the abdomen is nearly globular, but in the female it is drawn out into a long, curved, severaljointed extremity, which is employed as an egg-laying tube. The fly is rather sluggish, and easily caught; it flies with a humming or buzzing sound. In autumn (August to October) such flies are now and then seen about horses; they settle for a moment on the horse or the clothes of the horseman, and then fly away. After a few visits from the fly, the horse pays little attention to them, only showing by the twitching of his skin-muscles that they tickle him a little. Little does 
he know how much trouble will arise from these apparently insignificant attentions !

A female fly, bent upon laying her eggs, hovers about the horse with her body almost vertical, and now and then, hardly settling, touches his skin with the tip of her abdomen. At that instant a sticky egg is passed out and glued to one of the hairs, usually near its tip. In a very short time the sticky substance sets hard, and the egg is then so firmly cemented that no ordinary means can remove it. The eggs are not laid at random,

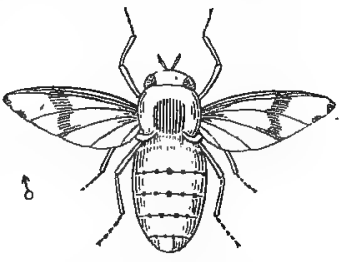

Fig. 8r--Bot-fly of horse, male. After Bracy Clark. but most commonly upon the inside of the knee, on the flanks, or on the hinder part of the shoulder, never on any part of the horse which is out of reach of his tongue. When the first egg has been made fast, the fly retreats for a moment, brings a second egg into the tube, and returns to attach it in the same way. One female fly may contain 600-700 eggs, and nearly that number will sometimes be found on a single horse. The eggs are white when quite fresh, afterwards turning yellow, and since

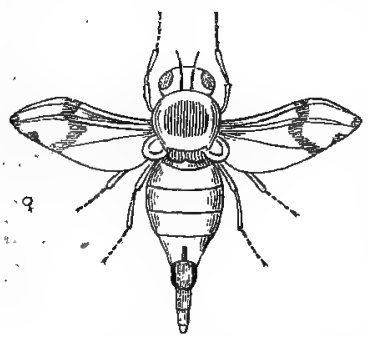

Fig. $\overrightarrow{8 \overrightarrow{2}}$-Bot-fly of horse, female. After Bracy Clark. they are large enough to be seen by the naked eye, they are sometimes very conspicuous on a darkcoloured animal. The fly delights in warm, sunny weather, and shelters during cold or rain, so that we can guess when eggs are likely to be laid; it does not.enter stables.

The eggs of the bot-fly are destined, if fortune favours them, to produce larvæ, which will enter the stomach of the horse, and there feed at his expense till they are ready to pupate. We might guess that the horse would bè induced in some way or other to swallow the egg, and so at once make himself the dupe of the fly. But this is not precisely the method of nature. The egg is cemented so fast that the horse cannot remove it. On reflection, we see that the purpose in 


\section{I46 INJUURIOUS AND USEFUL INSECTS}

view would not be effected if the horse were to lick up and swallow the egg as soon as it is laid. Four or five days are required to develop the larva within the egg, and until that is accomplished the egg, if swallowed, would merely pass with the food along the alimentary canal of the horse and be cast out. To guard against this, the egg itself is securely fixed to a hair ; it is only the larva issuing from the egg which leaves the spot, and the larva, once admitted to the stomach of the horse, has the means of staying there. The larva does not hatch out until the moment arrives when it can enter the horse, for if exposed for even a few minutes to the air, it would dry up and perish; it lies curled up within the egg until it is warmed and moistened by the horse's tongue. That is the signal for escape. A little lid at one end of the egg-shell is raised, the larva becomes free, adheres to the tongue, and enters the mouth. Bracy Clark, a veterinary surgeon, remarked this curious stratagem more than a century ago. In his full and interesting history of the bot-flies, which is printed in the third volume of the "Transactions of the Linnean Society" (I 797), he tells us that he had often clipped off hairs with eggs adhering to them, placed them in his hand, and moistened them with saliva. If they were sufficiently advanced to contain fully formed larvæ, they hatched in a few seconds. Horses not only lick themselves, but lick one another, and it is probable that they often transfer to their own mouths the larvæ hatched upon their companions. In spite of the elaborate, and so to speak, ingenious contrivances for securing the safety of the parasites, the difficulties are so great that many fail to reach their destination. Bracy Clark suspects that " near a hundred are lost for one that arrives at the perfect state of a fly." Once swallowed by the horse, and set free from the risk of being crushed by the teeth, or detained in the mouth, the larva has a fair chance of fixing itself in the stomach. The means of doing this must now be explained.

The larva of the bot-fly is a maggot, and agrees in all essentials with the larva of the blow-fly. It has the retractile and greatly reduced head, the pair of strong hooks projecting from the mouth, the transverse rows of backward-pointing spines, and the terminal pair of spiracles. The spines, acting together with the muscles of the body-wall, enable it to move through the contents of the stomach in the same fashion that 
an earthworm moves through garden-mould, pushing out its body, grasping with the spines, and then drawing up the hinder segments. When it reaches the mucous lining of the stomach, it takes firm hold with its mouthhooks and is then secure. Bots taken from the stomach of a dead horse creep and grasp with great ease; they can make their way through loose earth, or attach themselves to the skin of the hand. When it first enters the stomach the bot is very small, and much more slender in proportion to its length than afterwards. As it grows, it casts its skin more than once. When it has attained full size, the larva is $25 \mathrm{~mm}$. ( $\mathrm{r}$ inch) long, somewhat conical, tapering towards the head-end, and ending rather abruptly behind. Every segment except the two or three hindmost is furnished with a double row of backward - pointing spines, which are reddish-brown and tipped with

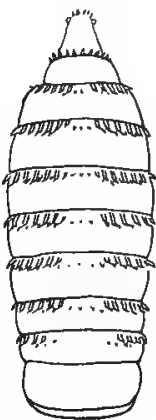

Fig. 83.-Larva of bot-fly. black. On the nearly circular surface which ends the body is a large compound spiracle, consisting of three long curved slits on one side and
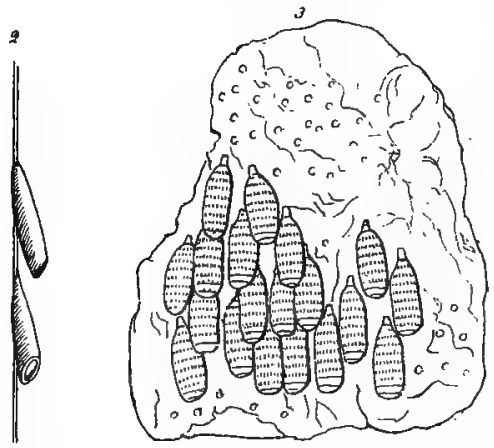
as many on the other, all lying in one chitinous plate. The slits are protected by fine gratings, andleadinto a common air-chamber, from which the main air-tubes, or tracheæ, are given off. So far the description applies pretty well to the spiracle of any maggot belonging to one of the higher families of Fig. 84. -(x) Eggs of bot-fly ; (2) the same magnified ; (3) larve in stomach of horse. After Bracy Clark.

Diptera, but an additional precaution against choking is needed in a maggot which dwells in the stomach of a living animal, and is liable to have its breathinghole obstructed by viscid liquids. The bot has a pair of 


\section{INJURIOUS AND USEFUL INSECTS}

fleshy lobes at its hinder end, which can meet and completely shut off all access to the spiracle; in the living larva these lobes open and close continually.

The bots cluster together, and fifty are sometimes found near together in one stomach. They are more commonly attached at the lower end than elsewhere. Now and then one will be met with in the intestine, or even in the œsophagus. They bury themselves in the mucous lining, and feed upon the products of the inflammation which they themselves set up. When the bots are removed holes are left where they lay. Bracy Clark tries hard to believe that bots, like the blisters and issues of the surgeon, may be beneficial to the horse. But it is not easy to persuade ourselves that so violent a remedy can be wholesome, especially when we remark that it is administered whether there is disease or not. Even if this explanation is allowed to pass, the position cannot be saved, for parasites are known which regularly cause their hosts to die a painful death-a result which no ingenuity can represent as beneficial to both parties! Horses do not appear, however, to suffer so much from bots as one would have expected. Bracy Clark tells us that few of those which are pastured on commons escape, and all horses turned out to graze in autumn run a great risk of infection, more in some districts than in others. Horses which work in cities and towns are generally exempt.

When the bot is full-fed, that is, about June, it looses its hold, and passes down the intestine. Even in this latest stage it sometimes causes the horse much annoyance by attaching itself for a time to the lower end of the rectum. Then it drops off, or is passed out with the dung. Those bots which are lucky enough to light upon soft ground, enter it and pupate. $\Lambda \mathrm{s}$ in the blow-fly, the larval skin is not cast, but retained as an outer protective envelope. At the head-end a pair of small projections protrude through holes in the larval skin. These are the breathing-holes of the pupa. After several weeks spent underground as a pupa, the fly becomes free by bursting open a defined part of the larval skin, which is raised as a circular lid. The raising of the lid is effected by the protrusion from the forehead of a bladder-like swelling, and this singular contrivance is made use of by the blow-fly, and many other Diptera, as well as by the bot-fly. Through the opening the fly creeps out, leaving both larval and pupal skins behind. 
The following remedies will considerably diminish the access of bots :-During autumn (July to October) and especially in bright weather, the horse's coat should be searched at least twice a week, and the shoulders and knees washed with warm water, to hatch out any ripe eggs. Checks have been proposed to hinder the horse from reaching those parts of his body which are the favourite egg-laying places of the bot-fly. There is no method known of destroying bots in the stomach, as they resist all drugs which it is safe to employ. Any bots that appear beneath the tail should be removed at once.

The warble-fly and the bot-fly belong to the same family (Estridæ or breeze-flies). Estridæ are closely related to the Muscidæ, of which the blow - fly is a familiar example, but differ in the following points:-CEstrid flies are nearly always hairy, and more or less resemble bees; the mouth-parts are reduced to vestiges, three simple eyes are conspicuous on the forehead, and the antennæ are sunk in deep grooves. The larvæ are parasitic upon quadrupeds (ox, horse, sheep, deer), and generally inhabit some part of the alimentary canal of their host. Nearly twenty European species are known.

\section{THE WARBLE-FLY (Hypoderma bovis)}

This insect belongs to the same family (Estridæ) as the bot-fly of the horse, and in every stage of growth it shows a similar organisation, though with differences which adapt it to its special needs. It is commonly seen only during the larval or maggot stage, when it lies within the skin of the ox, mostly along the back. The inflammation set up by the presence and movements of the parasite occasions a formation of pus, and upon this the maggot subsists. The cavity in which it lies communicates with the outer air; at first the tube of communication is narrow, but it becomes much wider as the maggot increases in size. It is by this passage that the maggot escapes, when its transformation is at hand.

The eggs of the warble-fly are laid in summer or autumn. Many may be hatched upon one beast, and it is remarked that young and vigorous cattle are more often infested than others. The attack of the female fly has been generally believed to cause whole herds of cattle to rush about in the greatest alarm, 


\section{I $5 \circ$ INJURIOUS AND USEFUL INSECTS}

with head outstretched and tail turned over the back, seeking above all things to plunge into water, whither the fly does not follow them. This belief is probably due to a confusion between warble-flies and gad-flies. The galloping cattle have been terrified by the blocd-sucking Tabanus bovinus. The warble-fly possesses no instrument capable of inflicting a wound. It has lately been said that the larvæ reach the skin of the ox in late winter, after a long course of wanderings through the tissues of the host, and that the eggs are not laid in or near the back, but on the legs, and especially on the feet. They are said to be transferred to the mouth by licking, and make their way thence to the gullet of the ox. Dr Cooper Curtice* found the young larvæ of the common American

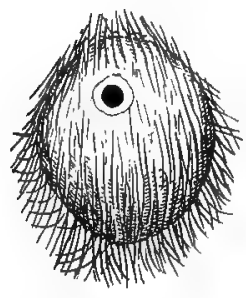

Fig. 85.-Tumour on back of ox, with opening by which the larva escapes. After Bracy Clark. warble $(H$. lineata), which is also British, in the gullet of the ox; this was in November, when there are none on the back. He believes that they make their way from the gullet to the back through the tissues of the ox, and declares that the young worms have been found near the ribs and in the muscles. When they reach the skin of the back, he supposes, they bore a hole in it for the purpose of respiration. It is only then that the skin of the larva becomes conspicuously spinous as a consequence of a moult; in the wandering larvæ the skin is nearly smooth, except at the two ends of the body. It is highly probable that the method pursued is identical in $H$. bovis and $H$. lineata. The first outward sign of the parasite is a small lump, due to the gorging with blood of the connective tissue beneath the skin of the back. By February or March the maggot has grown considerably; it is now of a brownish tint ; the cavity in which it lies is filled with pus; the passage has enlarged and the warble becomes open. From this time the larva steadily enlarges; its skin thickens and

"See Riley, in "Insect Life," vol. iv. pp. 302-317. (1892.) The question of the route by which the larva reaches the skin of the ox is of great practical importance, because it affects the place to be treated by remedies. Putting aside discussions of the probability of Dr Curtice's statements, any one who has opportunities of examining the carcasses of oxen during the last quarter of the year would do good service by reporting whether or not the statements are consistent with the facts. 
becomes deeply wrinkled, while the warble-cavity gets a special wall, derived from the connective tissue of the ox. The larva has no limbs, and only a vestige of a head, which is ordinarily retracted into the body. A pair of forks, answering to the hard and pointed hooks of the. blow-fly larva, can be protruded from the mouth-opening. The prominent transverse ridges of the body bear broken rows of small hooks, and it is by means of these that the maggot executes such limited movements as are indispensable. In the middle of the flattish surface which ends the body are two dark spots; these are the spiracles; they lead into longitudinal air-tubes, which supply every part of the body. The body is always so placed that the spiracles are directed towards the opening of

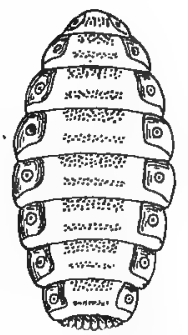

Fig, 86.-Larva of warble - fly. After Bracy Clark. the warble cavity. Just beneath the spiracles is the outlet of the alimentary canal.

In the next summer, the maggot, being now nearly a year old, is about $35 \mathrm{~mm}$. long, fat, wrinkled, and of a leaden or deep-brown colour. It squeezes through the skin, and falls to the ground, where it passes the next few weeks, with only such slight protection as it can get by hiding in a crevice or beside a stone. Its skin contracts, hardens, and acquires a deeper colour. The body becomes flat and then concave along one side, towards which both head and tail are directed. The transformation to a pupa is completely hidden, as in the blowfly, by the retention of the larval skin, which acts as an ex-

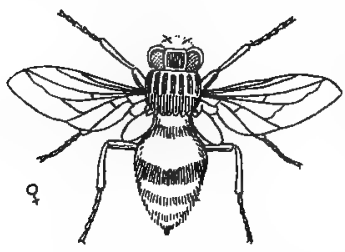

Fig. 87,-Female warble-fly. After Bracy Clark. ternal shell or cocoon. After four or five weeks on the ground, the dry skin cracks near the head, a circular cap surrounding the mouth becomes detached, and the fly escapes.

The fly is seldom seen, except when it is reared from a captive pupa; it is only about $\mathrm{r} 3 \mathrm{~mm}$. long. In most points of structure it resembles the blow-fly, but is greatly disguised by its coloured hairs, which make it superficially like a humble-bee. The face is yellow, the wings dusky yet transparent, the legs black, except for the tarsi, which are pale 
brown. The thorax is yellow and black, the abdomen pale in front, dark in the middle, and foxy red behind. As in a bee, we find almost everywhere beneath the velvety hairs a hard and black cuticle. The female fly has a long drawn-out tip to the abdomen.

Warbles cause much loss to the grazier. It is true that the wound closes as soon as the maggot has squeezed itself out and fallen to the earth. But the scar is made up of loose fibres, which break up during the vigorous handling of the tan-yard, and the hide is greatly impaired if many warbles have lodged within it. Effectual remedies against warbles are known, and if steadily applied, would soon bring about a notable abatement of the plague. In the first place the maggots can be squeezed out and destroyed. The best time for doing this is April, when the warble cavities have opened, but when the maggots are not yet ready to quit the ox. An application of some adhesive form of grease, such as the various smears sold for the purpose, or a mixture of tallow and tar, will infallibly choke the larva by cutting off its supply of air. A dab laid on the opening suffices, if it does not get rubbed off. Such remedies do not save the hide, and are only of use as a precaution against future visitations. They may usefully be combined with remedies which are calculated to deter the female fly from settling on the oxen. Train-oil, well perfumed with petroleum, is said to be effective if rubbed upon the legs and feet. * The application should be made twice a week in dry, hot weather, when the flies are much abroad; in cool or rainy weather once a week is enough. The flies are to be expected from June to October, but they occasionally show themselves in May and November also.

* It is to be remarked that the place of application depends upon exact knowledge of the place upon which the eggs are laid. This is not yet beyond dispute (see above). 


\section{巴. APHIDS AND SCALE-INSECTS (HEMIPTERA)}

31. (a) THE TURNIP APHIS (Rhopalosiphum dianthi)

(b) THE WOOLLY APHIS (Schizoneura lanigera)

(c) THE PHYLLOXERA OF THE VINE (Phylloxera vastatrix)

\section{(a) The Turnip Aphis}

IN summer and autumn the leaves of turnips are often infested by innumerable small aphids, which pierce the veins and suck the juices, causing the leaves to curl, and in bad cases to turn yellow and fall off. Associated with the species about to be described, other species, which differ in form and colour, are to be met with on turnips.

The turnip aphis has a plump oval body of green colour; when young, its tint is yellowish, and late in the season reddish individuals occur. The body is about $2 \mathrm{~mm}$. long, and swollen with a watery fluid, so that it shrivels up after death to a thin scale. It consists of three thoracic, and nine or more abdominal segments, the last of which can only be made out with difficulty. The form first to be described has no wings. There are three pairs of long and slender thoracic legs; the tarsi are two-jointed, and end in a pair of claws. The head is flattish in front, furnished with long, tapering, seven-jointed feelers, and prominent compound eyes, just behind each of which is a second and smaller compound eye. The mouth is provided with a three-jointed sucking-tube (answering to the labium); it is bent downwards in use, but can be laid along the under side of the thorax at other times. The sucking-tube is splut along its front face, and lodges three needle-like bristles. The middle one represents the two maxillæ, which are firmly held together, while the outer pair are the mandibles. These pointed weapons are employed to pierce the tissues of the plant, and the tube to draw the juices into the mouth. The 


\section{54 INJURIOUS AND USEFUL INSECTS}

long, flexible boring organ works its way through the cells of a leaf or shoot, often taking a sinuous course to avoid impenetrable structures, and at last, it may be, tapping the vessels of
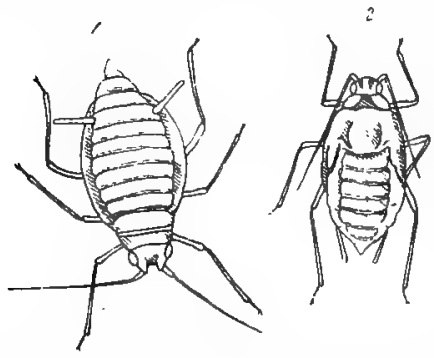

Fig, 88.-Turnip aphis, magnified, (1) wingless viviparous female; (2) immature winged form, with wing-rudiments. After Buckton. the soft bast. Other species, however, drive the proboscis straight in. Each is adapted to pierce its customary foodplant in the most effective way. The fifth segment of the abdomen bears a pair of long tubes, directed backwards and upwards, which discharge a viscid fluid, secreted by a gland at the base of each. The fluid is quite distinct from the sugary excretion discharged from the intestine, and known as honey-

dew. There are three thoracic and seven abdominal spiracles. This form of aphis is exclusively female. It lays no eggs, but brings forth its young alive, and is therefore a wingless viviparous female.

In the height of summer we find among the wingless aphids just described winged forms, which, like the others, are exclusively female and viviparous. The winged viviparous female is of slighter build than the wingless kind; it has a narrower thorax, larger compound eyes, and three simple eyes between them. The wings are four, and membranous, the front pair twice as long as the body, and greatly surpassing the hind ones

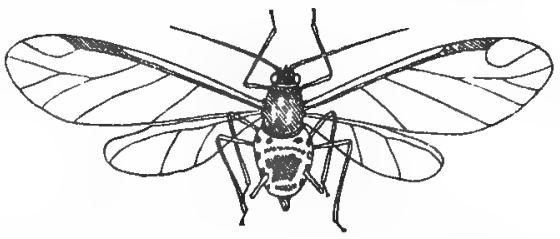

Fig. 89.-Turnip aphis, winged viviparous female. After Buckion. in size. These winged forms are particularly fitted for dispersing the species, and are produced just at those times when the food-plants are most crowded with sedentary aphids. Now and then the winged females appear in swarms which cover the whole country. Such a visitation was observed in July $\mathbf{1 8 6 5}$, 
when these small flies were everywhere to be found, getting into people's eyes and mouths, and covering the trees and fields from London to Yorkshire.

Late in autumn, but at no other season, male aphids are found in small numbers. They are always winged, smaller than the winged females, and rather different in colour; they perish immediately after pairing. Shortly after the males appear, a new kind of wingless female may be observed, which is distinguished by a sabre-shaped ovipositor projecting from the end of the abdomen. This is the oviparous female, of which only one generation is formed in a season. It lays fertilised eggs, which remain undeveloped till the following summer, when they give rise to a new succession of viviparous generations. The individuals of a season are therefore of four kinds-viz.

(I) Viviparous wingless females,

(i) Viviparous winged females,

(3) Oviparous wingless females, and

(4) Winged males.

The viviparous females really produce eggs in ovaries, like other insects, but the eggs, instead of being laid before development, are hatched in the egg-tubes of the parent. Like the males of hive-bees and the males of saw-flies, the summer generations of aphis are produced parthenogenetically-that is, without the concurrence of a male. The young are from the first almost identical with the full-grown aphis except in size and colour. A single female will often produce two a day, and sometimes more, for many days together. The young become capable of reproduction in from four to eight days, according to the temperature of the air; a hot, dry season being eminently favourable to their rapid propagation.

Many circumstances in the life of an aphid are apparently due to the extraordinary abundance of its food at a particular part of the year. Then everything is made to contribute to the rapid production of vast numbers of individuals. The slow processes which are necessary to the production of fertilised eggs are dropped; and young may be produced viviparously by aphids only a few days old, which do not cease feeding even at the instant of birth. For some reason that we cannot guess at, the eggs which have to endure the long cold of winter must be fertilised, as in Hydra, Daphnia, 


\section{I56 INJURIOUS AND USEFUL INSECTS}

and some other animals which propagate in two ways; and it is solely for these winter-eggs that male aphids and oviparous females are indispensably requisite.

It has been ascertained that an aphis may infest one plant for several viviparous generations, then forsake it for another, and afterwards return to the first for egg-laying. This happens with the aphis of the maple, that of the hop, and that of the apple.

We have seen that the aphids undergo no transformation, though the winged forms are at first devoid of wings, which are only acquired step by step, at successive moults. 'There is also no resting-stage. In these respects, and in the structure of the moith-parts, aphids resemble such insects as bugs, pond-skaters, water-scorpions, water-boatmen, cicadas, and scale-insects. All are placed together in the same order (Rhynchota or Hemiptera). The Rhynchota may be subdivided into (I) Heteroptera, with fore wings stiffer than the hind ones, and often stiffer at the base than at the apex, and (2) Homoptera, with uniformly membranous wings. In Heteroptera the wings commonly lie flat on the back, while in Homoptera they are sloped on either side, like a roof over the abdomen. The aphids belong to the sub-order Homoptera.

There has been much discussion about the origin of honeydew, which is a sugary secretion found upon the leaves of trees and many other objects in dry summer weather. The ancients supposed that it fell from heaven, or was raised from the earth by evaporation. Réaumur observed the actual exudation of viscid drops from the intestine of aphids, and proved by tasting that they had the sweetness of honey-dew. He was also aware that ants are fond of the secretion, and protect and caress the aphids for the sake of it. In spite of Réaumur's full and accurate account it was long believed that there was a second sort of honey-dew, of purely vegetable origin, which exuded from leaves and young stems at times when hardly any aphids could be found. This vegetable honey-dew is now known to be mythical, though it is often described in modern books of good repute. Büsgen has shown that all honey-dew is the product of aphids and scale-insects, with the unimportant exception of sugary fluids secreted by certain other insects and by a parasitic fungus (Claviceps). The fluid is dropped or squirted out, and may fall in a fine shower upon distant objects. 
When fresh drops are observed upon a leaf, it is instructive to place a piece of paper or a glass slip on the same spot. It will generally become sprinkled with honey-dew before long, and thus will show that the sugary fluid does not exude from the leaf, but is dropped from above. Moreover, the drops do not grow steadily, as we should expect them to do if they exuded from the plant, but increase only by running together.

These slow-moving and almost defenceless creatures have many insect-enemies. Lady-birds and their larva, the lacewing fly (Chrysopa), and the Syrphus-larva, subsist entirely upon them. It is a curious sight to watch the blind and footless Syrphus-larva looping over a bush in search of aphids, exploring every leaf, dropping fearlessly from leaf to leaf, or from a leaf to the ground, and holding up a captured aphis in the air while it devours it. But for these checks to the increase of aphids, it may be doubted whether the plants on which the higher animals depend for food would survive at all.

Ants often run about plants which are infested by aphids, and have been seen to attack and drive off the aphis-eaters. The aphis can also defend itself to some small extent by pointing its tubes towards the enemy, and discharging the fluid upon his face or jaws. The fluid rapidly coagulates, and may clog the jaws to such a degree that the assailant retires to rub them clean. But it is not common for the aphis to escape in this way.

The following remedies for aphids have been tried with fair success :-

(I) Syringing with soft soap and petroleum. Boil one part of soft soap in eight parts of water. Add one part of petroleum, and mix. Keep this as a stock solution. For use, dilute one part of the stock solution with sixteen parts of water.

(2) Syringing with resin-soap and petroleum. Resin-soap is made by boiling four parts of resin with three parts of washing soda, and fifty parts by weight of water. Boil until all is dissolved. For use, dilute one part of the solution with nine parts of water.

Single sprays, for example, of rose-bushes, may be quickly cleared of aphids by bending them down into a basin of hot water. The water should be just too hot for the finger. Momentary immersion in such water will kill aphids without injuring the spray. 


\section{(b) The Woolly Aphis}

The woolly aphis, or American blight, is a wide-spread pest, which attacks neglected apple-trees, and occasionally spreads to elms or plum-trees. The first indication of its presence is usually the appearance on the boughs of light flocks of fine white threads, looking like shreds of cotton wool. Before long the flocks grow into large masses, which can be seen at a distance of many yards. When closely examined, multitudes of small, brown insects are seen among the threads, and the microscope shows that they present the features characteristic of aphids. It must be remembered that other insects, such as some scale-insects, form cottony masses on trees, so that the identification by microscope or lens must not be dispensed with.

This aphid is distinguished by the absence of the pair of tubes which usually stand out from the fifth abdominal segment. The threads which protect the colony exude in a fluid state from glands opening on the surface of the body. Young feeding aphids of this species have very long suckingtubes, extending far beyond the end of the body, and looking like tails. The name of American blight perpetuates an impression, never clearly verified, that it was imported from America more than a century ago. A quite distinct species, Aphis mali, is found on the leaves and flowers of the apple.

The woolly aphis is known in three forms--viz. wingless viviparous females, winged viviparous females, and wingless oviparous females. These last are found in the end of summer; they are of yellowish colour, and possessing no sucking-tubes, are unable to feed. Each lays a single egg in a crevice of the bark.

The woolly aphids attack not only the stem and branches, but the roots, causing excrescences to form upon them. They stand cold well, even when exposed to the air, and winged or wingless forms may often be found in the depth of winter.

The injury done to the tree may be very serious, if the attack is not promptly dealt with. Not only does the aphis consume valuable sap, but the young wood penetrated by its boring tongue becomes first tender and then dry, while the bark cracks, and ugly wounds result. 
Scrubbing the bark with a carbolised solution of soft soap (soap, Io parts; carbolic acid, 2 parts; water to make up 100 parts) is a simple but effective remedy. The whole tree should be cleansed at the same time, and neighbouring trees carefully watched. Spraying with petroleum emulsion has also been recommended. The insects soon reappear, so that the operation must be repeated at frequent intervals. The earth about the base of the trunk should be treated with the same solution, or tobacco-dust may be dug in. Boughs cankered by the blight should be cut away. The scrubbing is most easily and thoroughly done when the boughs are bare, but an attack at any season of the year can be reduced to small proportions with little labour. Complete extermination is a work of time.

In Australia, where most apple-trees were formerly infested by the American blight, two varieties of apple (Northern Spy and Majetin) have been found to possess a bark so close and firm as to resist piercing by the aphis, and these are now regularly used as stocks.

\section{(c) The Phylloxera of the Vine}

The Phylloxera of the vine is a minute insect which has been closely studied during the last forty years on account of the frightful devastation which it has caused in the vine. yards of France. It reached Europe from North America, where it infests the native vines, though without inflicting any remarkable injury; in America it chiefly attacks the leaves, forming galls upon them. In 1863, the Phylloxera. appeared in the vineyards of Languedoc (department of Gard), and soon afterwards in those of the Gironde; it is now a dreaded enemy in the greater part of the wine-growing departments of France. The northern districts, however, and especially Champagne, are nearly exempt. With some few exceptions, all the warmer wine-growing countries of the world have now been attacked, or at least threatened by this calamitous pest, but France is much the greatest sufferer.

The insect first attracts attention by the injury which it inflicts upon the roots of the vine. The growth of the tree is checked; only few and small leaves are put forth, which become discoloured, curl backwards, and wither early; the 
grapes do not fill out, and their skin is wrinkled. When the roots of a vine which exhibits these symptoms are closely examined, very numerous swellings are found upon them, and small grains, like yellow dust, are seen adhering to them. A lens shows that the yellow grains are Aphis-like insects, which pierce the bark of the root by their long beaks, and suck up the juices. The outline of the body is oval, and the back rounded. The head is not easily distinguished, for it conforms to the general outline; but closer inspection enables us to recognise it by the small, reddish eyes, the three-jointed antennæ, and the long suctorial beak. The legs are short, and the tarsus has at first one, afterwards two, joints. No waxy or sugary exudations are produced. The insects in this stage are active for two or three days, but then drive their beaks into the roots, and move no more. They moult thrice, and attain maturity in about three weeks, when each lays about thirty unfertilised eggs, from which, as a rule, young are hatched which altogether-resemble their parents. Thus the generations succeed one another rapidly during the summer months, and the number of individuals increases at a portentous rate. As summer declines, the root-feeding insects die, but a few survive in a torpid condition till spring, when they swell, burst along the back, and emit a number of young individuals of the same form as themselves. It is in the root-infesting stage that the Phylloxera causes most injury to the vines.

In late summer a second form appears in vast numbers, which is distinguished from the first by gradually acquiring wings, and also by minor changes of form. The compound eyes become much larger, the legs longer, the body more elongate, and numerous, regularly-arranged tubercles appear on the dorsal surface. Both the wingless and the winged form proceed from precisely similar eggs, and it is probable that when fresh hatched, they do not differ perceptibly. The second form is apparently related to the first as a pupa or late larva, with more or less developed wings, is related to the larva fresh from the egg. It has a beak or suctorial proboscis as in the earlier stage, the transition from one to the other being apparently effected by additional moults and intervening periods of growth. The wings, which are the distinctive additions, first appear as minute external rudiments, 
which enlarge at successive moults until the fore pair project far beyond the body; the hind pair are shorter and narrower; both are delicate and transparent, like the wings of an Aphis, but lie flat over the back when at rest, instead of being erected. The Phylloxera of this second stage can fly, but its migration is probably due to transport by wind as much as to its own exertions. After the flight, by which the important advantage of dissemination in fresh localities is gained, the winged insects come to rest, and each lays about four eggs on the leaves, buds, and bark of the vine, or in the surface soil above the roots. These eggs are of two sizes; the larger ones produce females, the smaller ones males of the third form or stage.

In this third stage, and here only, individuals of different sex appear. The true males and females are developed rather late in the season, and possess neither wings, beak, nor alimentary canal. Being unable to feed, they last only a few days. The female, after being fertilised, lays one enormous winter-egg, which is generally attached to the bark of the vine by a hooked spine, and is protectively coloured. The winter-egg hatches in spring, and there issues from it a female, differing a little in shape and size from the first form; this is distinguished as the "stock-mother." She may produce parthenogenetically-i.e. without fertilised eggs-gallforming insects, which infest the leaves, and after one or more generations, lay unfertilised eggs, from which root-infesting Phylloxera of the first type proceed, or she may produce root-infesting forms only. The gall-forming Phylloxera may be distinguished from the other by wanting the tubercles on the skin, which are found on the adult root-parasites. In America the gall-formers appear to be regularly developed in considerable numbers, while the root-infesting form is less frequent; in Europe the gall-formers are often not developed at all, so that they cannot be considered as essential stages in the life-history.

The cycle may be shortly summarised as follows:-

I. Parthenogenetic, wingless, suctorial females, chiefly (in Europe) infesting the roots, but also making galls on the leaves. There are several generations of these.

2. Parthenogenetic, winged, suctorial females, which lay two kinds of eggs, from which are hatched: 
3. Wingless males and females, without mouth or alimentary canal. The female, after fertilisation, lays a single large winter egg, from which in the following spring is hatched:

4. The stock-mother, which produces parthenogenetically either gall-forming generations, which are succeeded by rootinfesting generations, or the latter only.

The structure of Phylloxera shows its near relationship to the aphids, from which it differs in such points as the number of joints in the antenna, and the absence of the abdominal tubules (which are not always found in aphids). Both are polymorphic, exhibiting distinct forms, which are not solely due either to differences of age or of sex, and both are capable of precocious and parthenogenetic reproduction. Phylloxera only in one particular case reproduces after that viviparous fashion, which is normal in aphids. The resemblance of Phylloxera to coccids (scale-insects) is less important, and seems to be due to similarity in the conditions of life, rather than to inheritance from common ancestors.

Phylloxera has proved a most intractable pest, partly on account of its extraordinary powers of dispersal and multiplication, and partly because it can always be reproduced from subterranean forms, which cannot easily be attacked without grave injury to the vines. Submergence of the soil in which the vines are rooted has proved serviceable in particular cases, but the insects are not drowned in less than about six weeks, and the situation of most vineyards renders such a remedy quite impossible. Of insecticides carbon disulphide, poured into holes about the vines, or injected by hand pumps, is now largely used in France; tobacco infusions have also been tried with success. Vines grown in sandy soil resist the Phylloxera better than others.

\section{THE MUSSEL-SCALE OF THE APPLE-TREE (Mytilaspis pomorum)}

Trees and shrubs of many kinds are apt to be infested by scale-insects, which are commonly small and inconspicuous, sticking close to the bark, absolutely motionless, and, unless they multiply to a great degree, passing for casual discolorations of the bark. They are not always inconspicuous, 
however. Some are clothed with white filaments which catch the eye at once. A large species, which infests the elm in Canada, and has a fluffy white investment, can easily be recognised across a wide street. There is some resemblance between scale-insects and aphids. Both are provided with piercing mouth-parts of similar construction; both feed in the same way upon the juices of the food-plant. When wings are acquired they are formed in both scale-insects and aphids, not from internal rudiments, like the wings of insects which undergo complete transformation, but as purely external growths, at first small and simple, but gradually enlarging, and becoming at length suitable for flight. In both the wings are membranous and of large size, relatively to the size of the body. On such grounds both scale-insects and aphids are placed in the same order, Hemiptera, and in the same sub-order, Homoptera (with membranous wings only). Noteworthy differences can be pointed out between the two families. Aphids, though often sluggish and sedentary, are not permanently fixed to the food-plant, but most scale-insects are fixed either for life or for the whole of the feeding-stage. Aphids are capable of producing young at frequent intervals from unfertilised eggs, which develop within the body of the mother; scale-insects are not often viviparous, but produce a multitude of fertilised eggs once a year. Wings are not a mark of sex in aphids; in scale-insects they are possessed only by the male.

We shall take as an example for description one of the commonest species, the mussel-scale of the apple-tree. This scale-insect is believed to infest many other trees besidès the apple, among the rest the lime, horse-chestnut, sycamore, elm, willow, and poplar; it also attacks broom, heather, and bilberry. The mussel-scale thrives best in warm, sheltered situations; on standard trees it is chiefly confined to the trunk and main branches, while on a tree trained against a south wall it will cover every branch and twig, and even overrun the fruit and leaves (Newstead). An infected tree, if examined in winter, shows on the younger branches a great many small raised blotches; these are from $2-2.5 \mathrm{~mm}$. long $\left(\frac{1}{12}-\frac{1}{10}\right.$ inch), of grey or violet colour, and shaped like a single valve of the common mussel. The hollow side is turned towards the bark. If one of the scales is lifted with a needle, there will 


\section{I64 INJURIOUS AND USEFUL INSECTS}

be found beneath it a full-grown female insect, alive or dead, according as it is examined in the beginning or the end of winter, and perhaps some twenty or thirty rather large eggs. The scale is in one group of scale-insects merely the body of the female, and shows under a lens the transverse divisions of the segments. In such species the dead body of the parent, becoming dry, hard and arched, conceals and defends the eggs within. But in other species, and the mussel-scale is one of these last, the female secretes from her body a waxy, resinous, or gelatinous substance, often in the form of delicate fibres, which constitute an additional outside envelope. In the mussel-scale the fibres are felted, and form the chief part of the scale, the cast skin, yellowish in colour, and perhaps dry and shrivelled, forming the narrow tip only. We may remark that the protective secretion varies greatly in different species, and in some cases yields a very useful product; shellac, out of which sealing-wax and some lacquers are made, and Chinese candle-wax are instances.

The eggs of the mussel-scale are hatched in early summer (May-June). The issuing larvæ are small ( $3 \mathrm{~mm}$. long) and of yellow colour, with eyes, short, six-jointed legs, and a pair of bristles at the tail-end. They run briskly about the tree for two or three days, then choose their feeding-places, insert the long, boring mouth-bristles, and come to rest. If, as always happens upon apple-trees, they are females, they grow fast, change their skin more than once, and gradually lose their original appearance. The hinder part of the body swells and becomes rounded; the eyes, antennæ, and legs shrivel up; the waxen shield enlarges enormously. Growth is often but not always completed before winter sets in. The male occurs on broom and heather. Those who have seen it, tell us that the body of the male insect soon ceases to enlarge, and that when full-grown it has only a quarter of the length of the female scale. When this size is attained the male ceases to suck, and the mouth-parts atrophy. Then it enters a resting-stage in which new legs and antennæ, and a pair of wings appear as growing rudiments. A true pupa-stage follows, and the insect finally emerges as a minute fly, with two membranous wings, fertilises the female, and perishes. Since males are rare, it is probable that the mussel-scale is ordinarily parthenogenetic (not requiring fertilisation). It will 
be remarked as a singular exception to the absence of a resting-stage in Hemiptera, that the male scale-insects, but not the females, undergo complete transformation. The female often produces eggs in early winter, but sometimes not till the new year; she lays from twenty to thirty, and then dies, the eggs remaining protected by her dead body and shield.

In spite of the biological interest of this curious life-history, the cultivator immediately asks how the insect can be most readily destroyed. When the branches to which the musselscales cling are strong enough to bear rough handling, scraping or rubbing briskly with coarse sacking will be effective. This is best done in winter, and may be followed up by washing thoroughly with soap and carbolic acid, or soap and petroleum (see American blight). In May the boughs should be washed again with the solution, to kill the insects before they have firmly established themselves. Coccidæ are preyed upon by beetles, lace-winged flies, and Hymenopterous parasites. $\mathrm{Mr}$ Newstead finds that the stomachs of titmice often contain the mussel and other scale-insects

The oyster-scale (Aspidiotus ostreiformis) of the apple and other fruit-trees, which occurs also on lime, willow, and poplar, is densely crowded, like the mussel-scale. The shield is circular, slightly convex, and when magnified shows yellow prominences on a dark grey ground; it consists of one or more cast skins, and the waxen exudation. The shield is easily separated from the body of the animal, which is yellow. and nearly circular in shape. The male scale, which is of frequent occurrence in this species, is not circular, but oval. The life-history is similar to that of the mussel-scale.

Currants of all kinds and gooseberries are often infested by a scale-insect of another group, in which the shield consists merely of the living or dead body of the parent, with a waxen exudation enveloping the eggs, but not forming part of the shield. The shield is much larger than in the mussel or oysterscale, and nearly hemispherical. Such scales as these often belong to scale-insects called Lecanium; the currant-scale is Lecanium ribis. A woolly scale (Pulvinaria) also attacks currants. 


\section{F. COMMON INSECTS OF OTHER ORDERS}

\section{CADDIS-WORMS AND CADDIS-FLIES (Trichoptera)}

WE shall next consider some groups of insects which are not in any important degree either injurious or useful. They are so common as to invite attention, and the most practical of entomologists should at least know what they are, and some little about their life-history. The insects in question occupy Lessons 33-36.

Among the commonest inhabitants of our ponds and streams are caddis-worms, insect-larvæ which make cases to protect themselves against fishes or predatory animals of other kinds, and swim or crawl about, carrying their cases with them. There are many different species, which vary greatly in the sort of case which they construct. Some use gravel or sand, others leaves, sticks, grass-stalks or shells. Whatever the materials, they are fastened together by silken threads, the product of the large salivary glands. The cases differ much in form and size; they may be straight or curved, open at both ends, or at one end only, free or fixed, so light as to permit the contained larva to swim about, so heavy that it cannot leave the bottom, or composed of heavy and light substances blended in such proportions as to suit exactly the strength of the current and the activity of the inmate. A few caddis-worms make no case at all, but live free in the water, usually hiding in crevices or in a sort of web of their own manufacture.

If we examine a caddis-worm extracted from its case, an operation which is easily effected by insinuating a pin or grassstalk into the hinder end, we shall find that the fore part of the body is well defended by armour, while the hind part, or abdomen, is soft and pale. The head bears biting mouth-parts, not unlike those of a caterpillar. There are three pairs of long thoracic legs, which are used in creeping, in grasping, and in swimming, should the larva swim at all. Most caddis-worms 
have numerous slender and transparent gill-filaments, arranged in regular rows on the back and sides of the abdomen. The last segment bears a pair of strong hooked feet, which are useful for holding on to the case. The first abdominal segment bears three rather long prominences, one dorsal and two lateral, which can be protruded or retracted at pleasure. These prominences are long enough to reach the inside of the case ; the lateral ones are roughened at the tip by spines or hooks, while the median one, which is particularly mobile, seems to regulate the position of the body within the case. Some such adjustment is the more necessary because the caddis-worm, like the Chironomus-larva, maintains a steady flow of water through its tube. This is set up by an undulating, up-and-down movement of the abdomen; it is no doubt important as a means of supplying the gill-filaments with a perpetually renewed supply of aerated water. Caddisworms feed largely on vegetable matter, but they do not refuse animal food. The larger ones, in particular, often devour blood-worms and other ill-defended animals of the waters. They will also attack other caddis-worms, breaking open the tubes in the middle where the inmate has neither jaws nor hooked feet to resist the attack.

When the larva is full-fed, it spins a cocoon within its case, and enters upon its resting-stage. Before pupating, it is careful to make up the ends of its tube with strainers or gratings, which exclude dangerous or irritating objects, but allow water to enter freely. Then the larval skin is cast, and the body assumes nearly the form of the fly, though it is temporarily shrouded within a thin pupa-skin. The legs and wings are not glued down as in Lepidopterous pupæ, but still retain some degree of mobility. Gill-filaments are usually found on the abdomen of the pupa, as of the larva. At the head-end of the pupa there may be seen a large pair of compound eyes, and also two long, curved, crossed mandibles, which look like weapons of attack or defence. They are neither one nor the other, but are used solely to break open the case, when the fly is ready to become free. At this time the pupa opens its case, creeps, swims, or floats to the surface, gains some place of safety out of the water, and then divests itself of the pupa-skin. Some small caddis-flies emerge from a floating pupa-case after the fashion of a gnat or harlequin-fly. 
The fly has four long wings, which are more or less opaque and hairy, resembling those of certain small moths. They slope roofwise when at rest, and the hind pair are folded like a fan. The antennæ are long, slender, and many-jointed, the mouthparts vestigial, but the maxillary and labial palps conspicuous. It is not hard to suppose that the more primitive moths of former days may have been a good deal like caddis-flies. Indeed, one surviving moth (Micropteryx) has a pupa with mobile appendages, and large mandibles for breaking down the cocoon, while the moth has palps very like those of a caddis-fly. Some Lepidoptera are aquatic in their early stages, and case-building caterpillars are known, both aquatic and terrestrial, so that the interval between the Trichoptera and the Lepidoptera is bridged in many ways.

The chief task of the fly is to get the eggs laid. Sometimes, it is said, the female fly descends into the water and attaches her eggs there. More commonly they are laid on water-plants, on trees overhanging streams, or on objects at some distance from water. The eggs of some caddis-flies are of grass-green colour, and embedded in a clear, watery jelly, so that when found in a pond or stream they may readily be taken for some colonial alga.

\section{MAY-FLIES (Ephemeridae)}

These insects, the duns, drakes, and spinners of the angler, are not very happily named May-flies, for they are more plentiful in the warmer summer months than in May. They take their learned name, which means insects of a day, from the proverbial shortness of their winged existence. Some live only a few hours in the air, many not more than two or three days. The preceding aquatic stage is longer than in most insects; many Ephemerids when they emerge have already lived a year, or even two years, as larvæ, while in one species the larval stage is believed to occupy as long as three years.

The species designated as the common May-fly (Ephemera vulgata), which is to be fished out of almost every ditch or muddy stream, is well suited for elementary study. From the eggs laid in summer issue larvæ, which, though very minute in autumn, steadily gain size during the winter. During the first 
half of the winter they are popular microscopic objects; after Christmas they become too large and opaque to be altogether convenient. The up-and-down movements of the gills are the chief point of interest. There are seven pairs of them, borne on as many abdominal segments. Each gill is forked, and most of them are fringed with long filaments. The first has no fringe, while both the first and the last are smaller than the rest, and fixed, performing no respiratory movements. These gills are traversed by tracheæ, or air-tubes, and are hence called tracheal gills. Ordinary gills, such as those of a fish, contain no gaseous air; it is the blood which becomes aerated, and oxygen circulates in the body only when dissolved. But in tracheal gills gaseous oxygen, extracted from the freshly aerated blood, is stored in the air-tubes. When full-fed, the larva is not much less than an inch long (much more, if its antennæ and tail-filaments are included). It has three pairs of long and many-jointed legs, suitable to an insect which has often to creep over the rough floor of a stream or among the leaves and twigs of a ditch; each foot ends in a single pointed claw. On the back of the thorax is a dark, lozenge-shaped mark, distinctive of this particular larva; most of the abdominal segments are more or less concealed by the gills, but the last two or three are exposed. From the extremity of the abdomen stand out three tail-filaments, which are jointed and fringed; these seem to be used as accessory breathing organs, for they are freely supplied with blood, pumped into them by a special chamber of the heart. In certain Ephemerid larvæ they are the chief or only swimming organs. On the head we see a pair of rather long feelers, three simple eyes, and a pair of compound eyes. The mouth-parts are adapted to biting, and generally resemble those of Orthopterous insects. The mandibles are extremely long and pointed; when at rest, they are crossed, and extend beyond the head. Such mandibles as these are usual in predatory insects, and the common May-fly feeds largely, though not exclusively, upon other aquatic animals. Near the base of the mandible are stout hooks and a ridged grinding surface. The larva creeps, swims, or burrows, as occasion requires. It is much preyed upon by other insects, and is, like Ephemerids of all kinds, a favourite food of fishes. When it begins to approach its full size, the peculiar organs of the fly, such as the wings and the claspers of the male, protrude from the 
body, becoming longer at each successive moult; in an old larva the fore wings are particularly evident, over-arching the fore part of the abdomen.

It is to be remarked that the fresh-hatched larva is of different form, wanting the gills and the central tail-filament. Similarly, a fresh-hatched Chironomus-larva differs from old ones in having no blood-gills, and no red colouring-matter in its blood (see p. I 25).

A year after the beginning of the larval stage the imaginal development is completed, and the insect quits the water, leaving behind it only an empty larval skin. Some Ephemerids, which inhabit muddy rivers in vast multitudes, hatch out so accurately at the same time every year that their advent can be noted in a calendar. They emerge towards night, and fill the air, like the flakes in a snowstorm. I have seen the streets covered with them the day after emergence, and the heaps into which they were swept lying piled about every lamppost. The plague, for such it is in certain places, lasts two or three nights, and is then over. Our common May-flies are less obtrusive; they come out night after night for perhaps a fortnight, at midsummer or a little earlier, and congregate in swarms of no great size, consisting usually of males only. The females quit the swarm as soon as they are fertilised, and make their way to the water in order to lay their eggs, while the polygamous males return to the swarm. The same habit is to be remarked in many gnat-like Diptera (see p. 1 I9).

A very mysterious peculiarity of Ephemerids is that the flies leave the water, clad in a thin, transparent, close-fitting pellicle, like a pupa-skin; this may subsequently be shed, either partially or wholly, but in some cases the fly mates and dies without becoming free.

The winged Ephemerid is a slightly-built fly, with ample gauzy wings, the fore pair much larger than the hind, which may disappear altogether (Chloeon dipterum). There are two or three long tail-filaments in most of the species. The legs are slender; in the male fly the fore legs are often longer than the rest, erected in the air, and used only to grasp the female. The antennæ are short, and the mouth-parts reduced to such a point that the fly is incapable of feeding. The abdomen looks plump, as if well-filled, but it is merely distended with eggs (if a female) or with air. Male flies are distinguished by 
the peculiar fore legs and by a pair of claspers which project from the last segment but one of the abdomen. The fly of Ephemera vulgata is I6-18 mm. long (body only), and has three long tail-filaments. The wings are opaque, brownish, spotted and intersected by very numerous veins, the abdomen spotted and streaked with dark colour.

There is much diversity in the mode of egg-laying. Some Ephemerids discharge all their eggs at once into the water, sometimes resting during the operation on the surface with their long tail-filaments outspread. Such species are shortlived in the winged state. Or the eggs may be laid at the surface of the water, a few at a time, but at frequent intervals. Certain others (Baetis), which as larvæ are distinguished by their unusual swimming powers, enter the water, and lay their eggs carefully among the stones. The female folds her wings until they resemble sticks protruding from the thorax, and descends into the stream, overspread by a film of air, so that her body is not wetted. After emerging she enters again at another place, and lays a few more eggs. Many Ephemerids fall victims to fishes at the time of egg-laying.

\section{DRAGON-FLIES (Odonata)}

It is needless to say that the early stages of a dragon-fly are passed in the pools over which the winged flies afterwards hover. Few aquatic insects are more familiar than this larva. Unlike the flies, which are often, though not always, gaycoloured, the larvæ are of a dull brown or green, resembling. the clayey bottom or the dusky vegetation on which they live. The body may be plump or slender according to the shape of the adult, but is nearly always thicker and shorter than it afterwards becomes. The head is distinct and usually very large. It bears slender antennæ and (in most cases) very large eyes, which we may suppose to be adapted rather to future than to present needs; they sometimes undergo a notable development during the larval stage. The jaws are suited to the wants of a fiercely carnivorous creature. The mandibles and maxillæ are long and toothed at the end; the labium very long and jointed near the middle, so that it can either be folded up, when the broad extremity covers the mouth, or 
suddenly extended like an arm. At the angles of the broad end there are sharp, curved claws, which bend inwards and impale a victim. The sluggish, dull-coloured larva lurks in some weedy recess, marks the approach of a moving animal, and then, moving the body little or not at all, stretches out the labium, which strikes but once to secure the prey. The

A

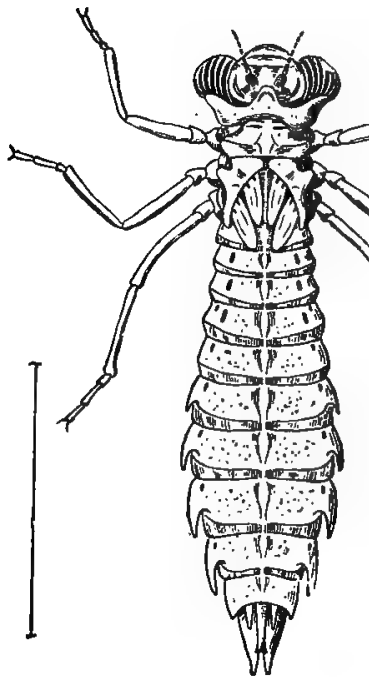

B

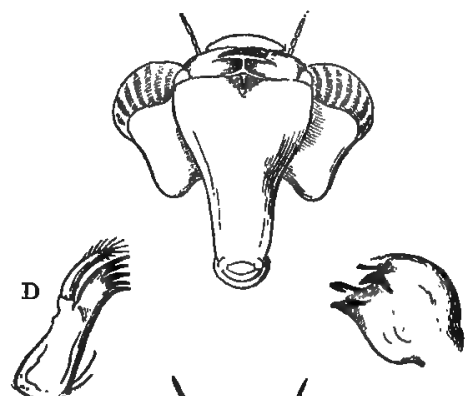

Fig. go. - A, dragon-fly larva (Aschna), with rudiments of wings; $\mathbf{B}$, head of do., seen from beneath; $C$, mandible; $D$, maxilla; $E$, mouth-parts after removal of most of the labium; $F$, fore edge of labium.

thorax, as seen from above, presents a pair of side-pieces, from beneath which, in the older larva, two pairs of wings protrude. These are not themselves the wings that will serve for flight, but rather wing-cases, within which the future wings are growing, or, if already grown, lie crumpled up. The legs are long and many-jointed, but they are not very actively employed; the larva uses them more for support than for locomotion. The segmented abdomen is generally stout, but in the larva 
of the "demoiselles," the commonest dragon-files of fenny lands, it is long and slender.

Larvæ which are completely submerged, like those of dragonflies, cannot breathe like most other insects by filling and emptying their air-tubes through spiracles. Some dragon-fly larvæ suck up water into the intestine, extract from it part of the dissolved air, and eject it again. This peculiar means of respiration may be supplemented in the demoiselle-larvæ (Agrionidæ) by three leaflets at the tail-end, which act as gills. The sudden expulsion of water from the intestine is sometimes used as a means of propelling the body. In older larvæ the air-tubes become distended with air, and spiracles open on the thorax, replacing all other means of respiration. Young larvæ, when placed in boiled water, which contains little or no dissolved air, rise to the surface, and try to take in a supply of aerated water by the intestine. Older larvæ under the same circumstances generally try to thrust the thorax out of the water.

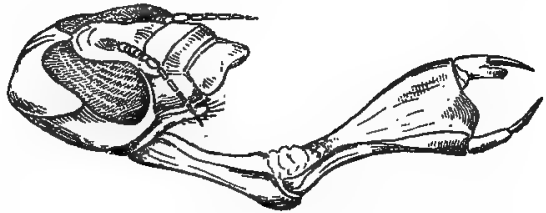

Fig. gr,-Head of dragon-fly larva, with labium extended.

There is no pupal or resting stage in the life-history of a dragon-fly. The wings and other peculiar organs of the imago develop gradually, becoming more evident at each of the later moults; at length the larva creeps out of the water, casts the larval skin, and in an hour or so is transformed into a swift, aerial creature, innocent and gay to look at, but still as hungry and as cruel as in its dingy larval state. It is worth while to observe with some care the escape of the fly, which can le done most easily by keeping a number of full-fed larvæ in a large tank. Whenever a cast skin is found on the rim of the tank, it is time to look out carefully for the emergence of the flies. They creep out of the water, grasp a plant or some other convenient object, and then rest till they are dry. At last the larval skin splits along the back of the thorax, and the soft imaginal body begins to protrude. As it becomes free, it swells and enlarges the cleft. The thorax, and a little later, the head are freed, the legs are drawn out of their sheaths, and then the fly (of some species) throws its head backwards, 


\section{I74 INJURIOUS AND USEFUL INSECTS}

sometimes resting long in this position. When the feet are sufficiently hard to hold firmly, the fly erects itself again, grasps its support, and bends the abdomen vigorously until it becomes free. During the casting of the larval skin the linings of the great air-tubes are withdrawn from the thoracic spiracles, and left adhering to the empty integument as white threads. When the fly is disengaged, it is flabby and incapable of active movement. The abdomen has not yet gained its full length, while the wings are still soft and crumpled. They slowly unfold and increase in firmness. During this expansion it can be seen with a lens that a clear fluid, no doubt the blood, is

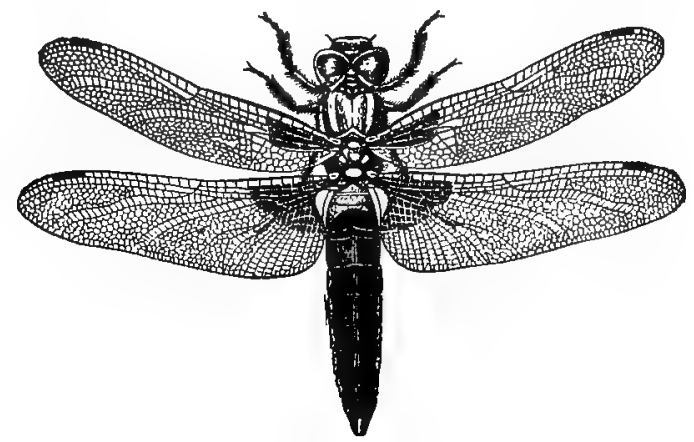

Fig. 92.-Adult dragon-fly (Libellula). After Charpentier.

injected into the veins of the wing. In a quarter of an hour the wings may be fully expanded, but they are not yet firm enough to support the body in the air. Two or three hours often elapse before the fly can trust its weight to them. During the expansion and hardening of the wings the colours of the body become more deep and vivid. The rapidity with which the tints develop, the rapidity with which they are lost after death, and the fact that little pigment can be extracted from a dragon-fly by alcohol and other solvents, suggest that the coloration is largely due to surface markings which modify the reflection of light. In insects, as in many birds and a very few mammals, bright and varied patterns may be got by interference colours with little or no use of pigment.

The fly is magnificently equipped for flight. Each of the 
four long wings is stiffened along the front margin by stout veins, while the more flexible hind part is supported by a closer and more delicate network. The powerful wings, the large thorax, which contains the muscles of flight, the great compound eyes, and the piercing jaws betoken a swift and rapacious insect. If we open the jaws of a captured dragon-fly, and examine the half-masticated flies which fill the mouth, we can form some notion of its powers as a hunter. Dragon-flies seek their prey in full daylight, when the flies on which they mostly feed are hovering or darting to and fro in the sunshine.

The eggs are laid in water, and the female, sometimes accompanied by the male, has been known to enter the water, and to attach the eggs to submerged plants. The procedure varies, however, in the different species.

Dragon-flies are commonly placed among Orthoptera, or in a separate order, not far removed from Orthoptera. Their position is supposed to be approximately determined by the biting mouth-parts and the want of a resting-stage. They seem to constitute a very isolated group, without marked affinity to any other order of insects.

\section{THREE COMMON ORTHOPTEROUS INSECTS}

A short account of three very common domestic species, the earwig, the cockroach, and the house-cricket, will serve to illustrate some of the chief peculiarities of the order Orthoptera. If the reader can make acquaintance with the grasshopper and the rather uncommon mole-cricket, and if he can further learn something about a mantis and a stick insect, he will gain a fair notion of the primary Orthopterous types.

\section{THE FARWIG (Forfícula auricularía)}

Though hated by flower gardeners, the earwig is not proved to be truly a pest. It often lurks in flowers and fruits, and annoys timid persons by dropping out unexpectedly, but the trifling injuries which it may occasionally inflict upon petals or fruits are probably at least compensated by its discouragement of more mischievous insects, such as thrips and small larvæ.

The head and mouth-parts of an earwig are altogether 
Orthopterous; the antennæ are long, many-jointed, and very like those of a cockroach or cricket. The wings are peculiar, and it is almost solely on this account that the earwigs are often placed in a separate order. The fore wings form elytra or wing-covers; they meet along a straight line, as in true beetles, and are short, as in rove-beetles. Beneath the wing-covers the flying wings are folded, a small part being regularly exposed, which is instantly detected by its brownish colour when the wing is expanded. The wings are rarely spread for flight; at such times they are seen to be of oval shape, not unlike the human ear; numerous veins radiate from a stiff plate close to the articulation with the thorax, and support the transparent membrane. When the flight is over, it is a task of difficulty to pack the wings neatly away. First, the radiating veins collapse fanwise, then the wing is twice folded in opposite directions and gathered beneath the elytra. It is said that the flexible abdomen is bent forwards over the back to assist in expanding and folding the wings. Earwigs are seldom seen to fly, but cases are related in which they have stuck to newly pitched palings during the night, the wings sometimes remaining expanded. Some other species of earwigs, and especially the small dungearwig, Labia minor, fly freely by day.

The forceps with which the abdomen terminates is an unusual feature in insects, and only one other instance (Japyx) can be quoted; the cerci, so common in Orthoptera and other orders, seem to be answerable parts, and in one Ceylonese earwig cerci actually undergo transformation into forceps during the course of the life-history, the blades of the forceps being the enlarged basal joints of the cerci.* The functions of the forceps are still doubtful; it is present in both sexes, and in wingless as well as in winged species. When attacked, the earwig seeks to defend itself by directing the forceps towards the aggressor and nipping with it, but in an ineffective manner. The forceps is usually larger, more curved, and especially more variable in the male than in the female. Bateson finds it singularly variable in size, as is not unusual with organs of extraordinary development. In the earwigs of the Farne Islands, which are present in enormous numbers, forming almost continuous sheets under every stone * Green on Dyscritina, Tr. Ent. Soc., I898, p. $3^{85}$ and plate. 
and tussock, he found that the smallest length of the forceps of the male was as low as $2.5 \mathrm{~mm}$., the greatest as high as $9 \mathrm{~mm}$. ; the forceps of the female scarcely varied at all. But for the occurrence of intermediate individuals, the males would have been considered to belong to distinct species; indeed the males with long forceps have been so separated, though afterwards reunited with the common form.*

Earwigs are mostly shy insects, coming out chiefly by night, and hiding during the day under stones or in crevices. They feed mainly upon decomposing vegetable or animal matter, but will occasionally devour fresh tissues. They propagate in autumn, having then recently come to maturity, and lay eggs at short intervals from November to early spring; the males do not outlast the depth of winter, and their dead bodies are often found in the winter retreats of the females. The female. watches and defends her young and eggs-an uncommon thing in insects, though frequent among spiders. The embryo is provided with a frontal spine for breaking the egg-shell ; after the first larval skin is cast, which happens immediately after hatching, the spine is lost. The parent dies in spring, before her brood reaches maturity.

The life-history of earwigs is similar to that of other Orthoptera. The young from the first resemble the parent, but have no wings, which subsequently develop externally and by gradual increase. There is no resting stage. The wing-peculiarities are hardly sufficient to justify the separation of the earwigs from the Orthoptera, particularly since one of the most marked of them-viz. the mode of folding-is paralleled in some cockroaches.

\section{THE COCKROACH (Periplaneta orientalis)}

The external form and some points in the anatomy of the cockroach have been described in Lessons 2, 3 and 4, so that we shall now only give a short description of its mode of life.

The common cockroach of our kitchens is not truly a native of Britain; it is indigenous to the hot countries of the East, and, taking advantage of the facilities afforded by commerce, has gradually made its way into various lands distant from

* Bateson, "Materials for the Study of Variation," p. 40. 


\section{8 INJURIOUS AND USEFUL INSECTS}

its original home. By the end of the sixteenth century it had reached England and Holland, but a hundred years later it was little known in remote villages. Ships have now carried this species to nearly all warm and temperate climates. Other cockroaches, large and small, have similarly spread by means of commerce. The American cockroach, the Australian cockroach, and the German cockroach have been introduced in many countries to which they are not native.

Cockroaches will eat almost everything that is consumed in our houses, and they do not altogether refuse very tough and indigestible substances, such as leather. They are fond of warmth, shun the light, and from the shape of their bodies and legs are able to creep into very narrow spaces. Where it is necessary to exterminate them, crevices, especially in

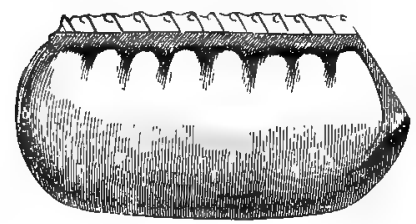

Fig. 93--Egg-capsule of cockroach, magnified.

the warmer parts of kitchens, should be carefully made up; no other remedy has more than a temporary effect.

The female cockroach lays her eggs in capsules of peculiar form, somewhat like cigar-cases. Each is about half-an-inch long and a quarter wide; it contains sixteen eggs, eight on one side alternating with eight on the other. These capsules are gradually formed, filled with eggs, and completed; the female carries one about for a time sticking out of the hinder end of her body, but at length deposits it in a sheltered place. The young are at first white with black eyes, but darken on exposure to light. After several changes of skin the hinder angles of the mesothorax and metathorax of the male begin to be produced decidedly backwards, and this is an indication that wings are about to appear. There is no resting-stage, and the larva, except for the want of wings, is very like the adult. After a change of skin the insect is for a day or two nearly pure white, and then slowly darkens. In spite of the abundance of the cockroach in our houses, the duration of the stages of growth is not accurately known. They are not easy to rear in captivity. Cockroaches live many together in the same crevices; the little ones run over the big ones or nestle under them without offence (Sharp). They keep 
themselves clean, combing all parts of their bodies with their legs, and often passing the legs and antennæ through the mouth.

Hardly any insects are known from so remote an antiquity as cockroaches. Many species, not unlike those which haunt our kitchens, have been found in the Coal Measures.

\section{THE HOUSE-CRICKET (Gryllus domestícus)}

Examine a number of captured house-crickets, and begin by learning how to distinguish the males from the females. The most obvious difference lies in the ovipositor of the female, which is long and slender; it may be recognised by being apparently single, while the other projections from the extremity of the abdomen are paired. Then remark the obvious differences between the fore wings (wing-covers) of the two sexes.

The female house-cricket is two-thirds of an inch or more in length $(16-2 \mathrm{I} \mathrm{mm}$.), the male rather smaller ( $15-20 \mathrm{~mm}$.). The colour is brown and yellow. The broad head has two transverse bands of yellow, and from it spring the long, slender, many-jointed feelers (antennæ). The prothorax is square, as seen from above. Both fore and hind wings are well developed in both sexes. In the female the fore wings (wing-covers) are generally similar to those of the male cockroach; both are covered with a rather close reticulation of veins; the hind wings are long and folded fanwise; when at rest they form two long slender projections, which may be taken at first sight for tail-like abdominal appendages. In the male the wing-covers exhibit a very different pattern, the inner two-thirds being more transparent and marked with few veins. The wings, both of the male and the female, are closely fitted to the body when at rest, lying flat on the back and bending downwards on the sides, nearly at a right angle; the junction of the two surfaces shows conspicuous longitudinal veins and a prominent edge. The legs in both sexes are strong; the hind pair have the thighs thickened for leaping, and the shins (tibix) are armed with strong spines; there is a three-jointed tarsus to each. On the fore tibia it is not hard to discover with a microscope or strong pocket- 
lens two clear oval spots, one on the outer face and a smaller one on the inner; these are believed to be organs of hearing. From the extremity of the abdomen project a pair of long, tapering cerci, which have been compared to caudal antennæ; they are well furnished with nerves and peculiar sense organs, so that they have really some analogy with antennæ, and are probably employed in the same way.

The head may be prepared and examined according to the instructions given in Lessons 2 and 3 . Note the large sockets for the antennæ, the degenerate eye-spots, the compound eyes, relatively smaller than in the cockroach, the powerful mandibles, and the maxillæ and labium, much like those of the cockroach.

If, as generally happens, immature crickets are taken among the rest, look out for wingless and imperfectly winged individuals; though the wings may be so short as not to reach beyond the first abdominal segment, they will exhibit a pattern not unlike that of the future functional wing.

The fore wing of the male cricket is very different from that of the female, and should be carefully examined. It must be flattened out, and compared with a female fore wing similarly treated. Notice the region internal to the angle, along which the wing is longitudinally folded; it is comparatively free from veins. Turn up the under side of the wing, and about a third of the length from the fore end look for a strong vein curving backwards towards the base of the wing; along this a file is developed, and it is by rubbing this file against the corresponding part of the other fore wing that the chirping sound is produced. It is possible to elicit a faint sound from a dead cricket, by rubbing one wing against another. The adjoining clear spaces of the wing take up the vibration, and themselves begin to vibrate. It is probable that each picks out and reinforces a single note, and that the chirp is a mixture of all these notes. Contrary to the rule in Orthoptera, the right fore wing of a cricket overlies the left, when at rest, but occasionally it is the left which overlies the right. Perhaps the insect can change the less efficient for the more efficient file, whenever this may be requisite.

An organ of sound-production implies an organ of hearing, and this is possessed by both male and female crickets. On 
the fore tibia are two oval spaces, each overspread by a tense membrane, not unlike the tympanic membrane on a frog's head, and serving, like it, to receive and transmit the soundvibrations of the air.

Crickets are fond of many kinds of vegetable food, especially such as contain starch. They frequent the warmest nooks that they can find during the cold season; in summer they sometimes venture out-of-doors. They leap, chiefly when they are startled or find themselves surrounded; at other times they run about; when necessary they fly readily, but are not often seen in the air. They are of nocturnal habit, beginning to chirp towards night. Unlike the field-cricket, which lays its eggs in summer, and disappears before autumn, the house-cricket, favoured by the warmth of the hearth, propagates at all seasons, so that there is no time of year when immature and mature individuals do not occur.

The native place of the house-cricket is not certainly known, and it cannot at this day be discovered as a wild species in any part of the world. The same may be said of some other animals and plants, which have become closely associated with man. We do not know precisely where our dogs and cats, nor where wheat, maize, and tobacco came from ; we cannot say with certainty what is the native country. of any one of them, nor from what wild species they have sprung. 

III

DESCRIPTIVE ACCOUNT OF THE LARGER ORDERS OF INSECTS, WITH SHORT NOTICES OF REMARKABLE FORMS 



\section{SHORT CHARACTERS OF THE ORDERS OF INSECTS}

This table is not meant to be learnt by heart, but to be used for reference. The large orders which will almost exclusively engage the attention of the beginner, are in dicated by capital letters.

Section I. Ametabolic-i.e. without transformation; never acquiring wings, and undergoing no change of form; there is no resting-stage.

Order Thysanura (bristle-tails). The abdomen consists of ten segments. A pair of long antenna-like organs project from the hinder end of the body; in one genus these are replaced by a forceps. A number of the abdominal segments bear small appendages.

Order Collembola (spring-tails). The abdomen consists of not more than six segments, the first of which bears a ventral tube or papilla. In many there is a forked spring upon the hinder end of the abdomen, which can be bent beneath the body, and usually secured by a catch. When the projections are released, they throw the insect into the air.

Section II. Hemimetabolic-i.e. undergoing incomplete transformation. With very rare exceptions (male Coccidæ, and some Thysanoptera) there is no resting-stage. The wingrudiments appear externally upon the larval thorax, and enlarge gradually at successive moults.

Order Ephemerida (May-flies). Mouth-parts vestigial in adult. There are two pairs of membranous wings with reticulate venation, not much folded; the hind pair smaller or wanting. The body ends behind in $2-3$ tail-filaments. Larva aquatic.

Order Odonata (dragon-flies). Mouth-parts biting. Antennæ short. There are two pairs of membranous, equal, and finely reticulate wings, not folded. Larva aquatic.

Order Plecoptera (stone-flies). Mouth-parts biting, but not 185 
functional in adult. Antennæ long. There are two pairs of membranous reticulate wings, the hind pair larger and folded fanwise. Larva aquatic.

Order ORTHOPTERA (cockroaches, grasshoppers, crickets). Mouth-parts biting. There

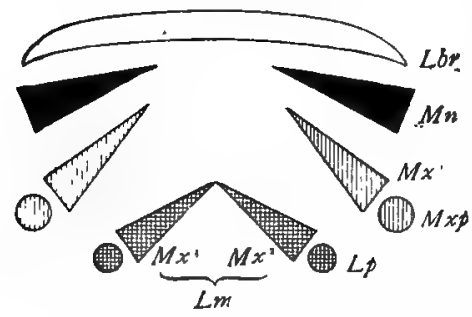

Fig. 94--Diagram of mouth-parts of Orthopterous insect. are usually two pairs of wings, which often differ in texture, the fore pair being firmer, and serving as wingcovers, the hind pair folded fanwise.

Order Corrodentia (booklice, bird-lice). Mouth biting. There may be two pairs of membranous and few-veined wings, but they are often wanting.

Order Thysanoptera or Physopoda (thrips). Mouth-parts adapted for piercing and sucking, with palps. There are two pairs of long, narrow, membranous wings, fringed with long hairs. A resting-stage in some species.

Order RHynchota or Hemiptera (bugs, water-boatmen, aphids, scale-insects, lice). Mouthparts suctorial, with a jointed beak or proboscis (labium), which encloses piercing styles; no palps. There are usually two pairs of wings, which may be similar or dissimilar. Male Coccidæ undergo complete transformation, with a resting-stage.

\section{Section III. Holometabolic}

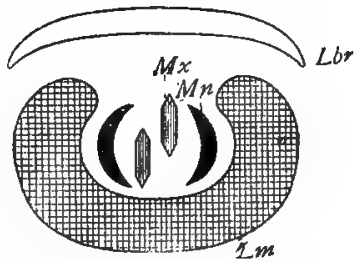

Fig. 95.-Diagram of mouth-parts of bug.

-i.e. undergoing complete transformation. There is a resting-stage, during which the insect rarely moves about, and never feeds. The wing-rudiments develop within internal pouches, and do not appear externally till the larval skin is cast.

Order Neuroptera (lace-flies, alder-flies, scorpion-flies). Mouth-parts biting. There are two pairs of equal, similar, membranous, closely reticulate wings. 
Order Trichoptera (caddis-flies). Mandibles vestigial in adult. There are two pairs of fringed wings with comparatively few veins, the hind pair often larger and folded longitudinally. Larva aquatic, usually living in a case of its own construction.

Order LEPIDOPTERA (moths and butterflies). Mouth - parts suctorial in adult, if functional; the maxilla forming a spirally wound proboscis. There are usually two pairs of wings, covered with minute scales, and provided with few transverse veins.

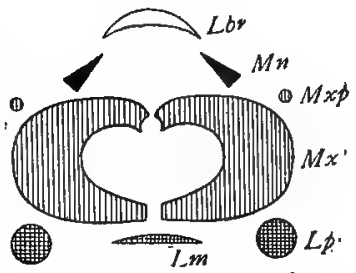

Fig. 96.-Diagram of mouth-parts of Lepidopterous insect. The identity of the parts marked $M_{n}$ with true mandibles has been questioned. The larva is a caterpillar.

Order Diptera (flies, gnats, midges, fleas). Mouth-parts of adult usually adapted for piercing and sucking, often with a labial proboscis.
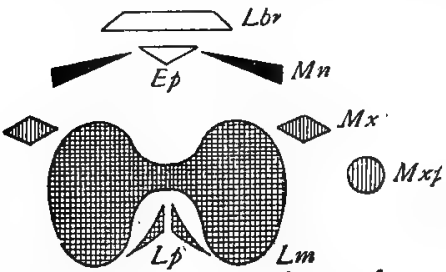

Fig. 97.-Diagram of mouth-parts of Dipterous insect (gadfly).

A fore pair of transparent functional wings, often with scattered scales, and a pair of vestigial hind wings (halteres). Larva footless, or with pseudopods only. Fleas are probably aberrant wingless Diptera.

Order Coleoptera (beetles). Mouth-parts biting, very rarely sucking. The fore wings are nearly always dense, and form wing-covers (elytra) which meet accurately along a straight line; they are sometimes soldered; the hind pair membranous, and folded both longitudinally and transversely in most cases, sometimes reduced or wanting.

Order Strepsiptera (internal parasites of bees and wasps). Mouth-parts vestigial. There are two pairs of wings in the male, the fore pair vestigial and rolled-up at the tip, the hind pair large and folded fanwise; the female is wingless. Strepsiptera are often regarded as aberrant Coleoptera.

Order HyMENOPTERA (saw-flies, wasps, bees, ants, ichneumon- 
flies, gall-flies). Mouth-parts of adult adapted for biting, or for biting and sucking. There are usually two pairs of unequal, membranous, rather few-veined wings, which are sometimes wanting. The female

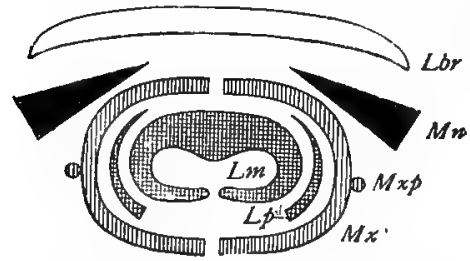

Fig. 98.-Diagram of mouth-parts of bee. is provided with saws, a sting, or an ovipositor.

\section{ORTHOPTERA}

Structural peculiarities. - Orthoptera are never very minute, and some of them are among the largest of insects. The organisation generally conforms pretty closely to that of the cockroach (Lessons 2, 3, 4, and 36). The wings form externally, instead of being telescoped into the body; they often increase by slow degrees, the new wings being crumpled up within the preceding ones, and liberated at the next moult. They are often useless for flight, sometimes wanting altogether; in other cases only the fore or only the hind pair are developed, or wings appear in one sex only. In the Saltatoria (leaping Orthoptera), the wings may be largely subservient to sound-production, the chirping organ being variously constructed in the different families. In Acridiidæ the inner face of the hind thigh is rubbed against the roughened outer face of the fore wing. In Locustidæ the bases of the fore wings are rubbed together; the inner surface of the left wing bears a file, and the outer surface of the right wing a prominent edge, whose vibration sets up a musical note; a transparent area adjacent to the vibrating edge appears to act as a resonator, and to enforce the sound. Both of the fore wings bear files in Gryllidæ. The musical organs are possessed only by the male insects, though the females may be provided with non-functional vestiges. Auditory organs are very frequent in both sexes; they occur on the fore tibia (Locustidæ and Gryllidæ) or on the dorsal surface of the first abdominal segment (Acridiidæ). Leaping Orthoptera are distinguished by the great length and muscular enlargement of the hind thighs. The adult female, and often the immature female also, has generally an evident ovipositor, but this may be 
withdrawn into the abdomen, as in the cockroach. The peculiar forceps of earwigs appears to be a singular modification of the cerci, paired and usually many-jointed appendages of the ninth abdominal segment, which are common in Orthoptera, as in other insects'with incomplete transformation.

Life-History, etc.-The eggs of Orthoptera are laid, one or many together, in capsules, which are usually carried about for some time in the ovipositor of the female, and then deposited in the earth. The young in many cases quickly acquire the habits which they will retain for the rest of their lives, and it is not till the time of sexual maturity (perhaps not even then) that a noteworthy change takes place. Sometimes, however, sexual maturity and the acquisition of wings set up migratory and gregarious instincts of a striking kind. Most Orthoptera are vegetable feeders, but some are indiscriminate, and the large tropical family of Mantidæ is predatory. Many Orthoptera are remarkable for singularities of form and colour. Sometimes the appearance is simply odd, or at least admits as yet of no adequate explanation, but in other cases the resemblance to sticks, leaves, and even flowers, is very striking, and evidently enables the insect to escape its enemies, or to steal unseen upon its prey. Conspicuous examples of such protective or aggressive resemblance are not found among British Orthoptera, and this renders any detailed account inadmissible here. The British representatives of the order are few. They comprise earwigs, cockroaches (the indigenous species being of small size, and rarely observed), locusts (note that true locusts do not belong to the family Locustidæ, but to the Acridiidæ), grasshoppers, and crickets.

\section{The Families of Orthoptera}

$A$. Cursorial, formed for running only.

I. Forficulidæ (earwigs). Fore wings meeting in a straight suture, short, not concealing the abdomen; hind wings folded fanwise and transversely. The abdomen ends in a forceps.

2. Blattidæ (cockroaches). Body flattened, the three pairs of legs similar in form. 
$B$. Saltatorial, the hind legs elongate, and formed for leaping.

3. Acridiidæ (locusts and short-horned grasshoppers). Antennæ short. Tarsus three-jointed. Ovipositor of female short and concealed.

4. Locustidæ (long-horned grasshoppers). Antennæ long. Tarsus four-jointed. Ovipositor of female usually long and exposed.

5. Gryllidæ (crickets). Antennæ long. Tarsus usually three-jointed. Ovipositor of female usually long and exposed.

\section{RHYNCHOTA (Hemiptera)}

Structural peculiarities. - A very peculiar proboscis is almost universal in Rhynchota; it is found in the larva as well as in the adult. The proboscis consists largely of a flexible 3-4-jointed labium, which is grooved along its front surface, and encloses slender piercing implements, the styles. At the base of the proboscis is a spine-like piece (probably the labrum), which overlaps the groove to a greater or less extent in front, and helps to keep the styles in place. The styles are four in number, and appear to answer to the mandibles and anterior maxillæ; they are extremely fine, flexible, and sharp; the outer pair, or both pairs, are often barbed. There is a sucking chamber within the head, which by its dilatation draws fluids along the grooved labium into the mouth. Palps are entirely wanting. The proboscis, when at rest, is laid along the under surface of the body. When it is to be brought into action, it projects vertically downwards. The styles are then slid along the sheath (labium), and penetrate the object of attack. The sheath gives useful support to the styles, and also forms a split tube, capable, in all probability, of conducting liquids. By the mutual apposition of the styles, an inner split tube is formed, which is just as effective for the passage of liquids as a complete tube would be, perhaps more effective, for the interval between the styles can be enlarged or narrowed at pleasure. It is clear that the styles, independent of the sheath, are capable of conducting liquids, for they can often be seen to project far beyond the sheath while the insect is 
engaged in sucking. Both leaf-sucking and blood-sucking Rhynchota employ a proboscis of the same kind, but in the latter the styles are usually stiffer and stronger, while the spinelike labrum generally becomes available for stabbing. There are usually three joints in the tarsus, but only one in Coccidæ. The female often possesses an ovipositor, which may be used to make incisions as well as to lay eggs.

Life-history.-The young differ little from the adult as a rule. The proboscis is present from the first, and the mode of feeding does not undergo change. As in Orthoptera, the wings are developed outside the body, and increase at successive moults. In male coccids there is a resting-stage with histolysis, and a near approach to complete metamorphosis. Parthenogenesis occurs in aphids and coccids, and in aphids there is polymorphism among the individuals of the same generation which, in certain cases, brings about an unparalleled complexity in the life-history.

Mode of life, etc. - Most Rhynchota are vegetable feeders, but a good many are bloodsuckers. Many make galls upon plants. Some are aquatic, and even marine.

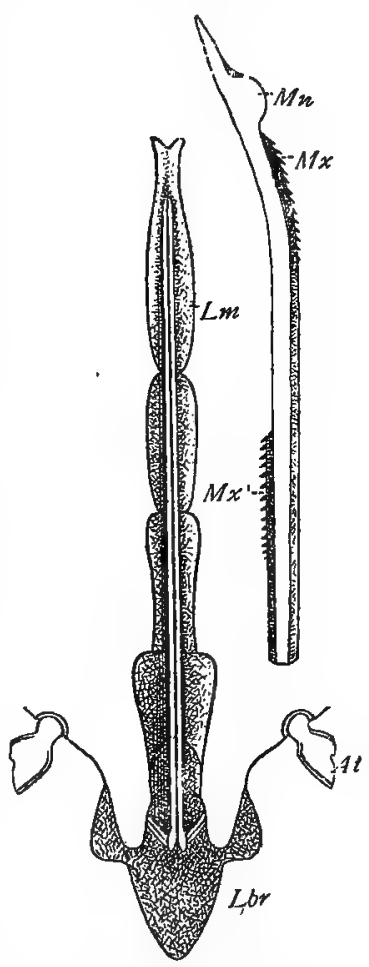

Fig. 99.-Mouth-parts of bug. Copied from Landois.

\section{The Sub-orders of Rhynchota (Hemiptera)}

Sub-order I.-Heteroptera (i.e. with dissimilar wings). The fore pair are tough and protective, except at the tip, which is usually membranous; when at rest they are folded flat upon the back. 
Here come the various families of tree-bugs, water-bugs (pond-skaters, etc.), and bed-bugs.

\section{Sub-order II.-Homoptera (with similar wings).}

There are usually two pairs of membranous wings, one or both being sometimes wanting; when at rest they are usually erected over the back.

To this sub-order belong the cicadas, lantern-flies, cuckoospits, aphids (see p. 153), and coccids or scale-insects (see p. I62).

The genus Aphis (see Lesson 3I) is characterised by the long, apparently seven-jointed antennæ (often longer than the body), and in most species by the two abdominal tubes. The rose aphis $(A$. rose $)$, the corn aphis $(A$. cerealis), the hop aphis $(A$. humuli), the plum aphis $(A$. pruni $)$, the apple aphis ( $A$. mali), the cabbage aphis ( $A$. brassica), and the bean aphis $(A . f a b a)$, are all common and mischievous.

In the rest of the family Aphidæ the antennæ are shorter, and only five to six-jointed; the abdominal tubes are wanting, or reduced to warts, and a cottony exudation from the body is general. American blight (Schizoneura lanigera), the Lachnus of pines and other trees, and the Pemphigus of poplars are examples. In Chermes the legs are short, and the antennæ have often only three joints. In Phylloxera the legs are short, the antennæ three-jointed, and the wings, unlike those of all other aphids, lie flat over the back. Chermes and Phylloxera, like some other aphids, make galls. Chermes forms a cottony exudation, which is not found on Phylloxera. These two genera are often placed in a separate family, Phylloxeridæ.

Aphids are known sometimes to migrate from one foodplant to another, and to set up a fresh cycle of generations at each migration. There may be no botanical affinity between the two food-plants; thus the aphis of the apple may migrate to corn or other grasses, and back again to the apple. The migrating forms are winged; the true sexual forms, if female, appear to be always wingless, but the males are sometimes winged, and sometimes wingless.

In Chermes several cases of a complicated migration have been investigated. This is a gall-making aphid, and its galls, which have a remarkable resemblance to natural cones, are 
not uncommon on coniferous trees. There are several species, which differ slightly in details of structure, and inhabit different kinds of conifers.

Chermes is aphis-like, but has relatively short antennæ and legs. The dorsal surface is covered with perforated shields, from whose pores waxy threads are often exuded (these do not appear till after the first change of skin). The wingless asexual forms have very long and flexible piercing beaks, and three-jointed antennæ, while the winged forms have the beak short, and the antennæ five-jointed. The beak is also short in the sexual wingless forms. In winged Chermes the fore wings are large, the hind wings very small.

The life-history of the Spruce Chermes may be supposed to begin in spring, when there may be found here and there on the bark of the fir a minute yellow or greenish wingless insect, thickly covered with a waxy exudation, which looks like wool. Sometimes two or three are found lurking together in one crevice. These are the hibernating females. As soon as the shoots begin to push, the female Chermes selects a young shoot, pierces the base of the bud with her long' proboscis, and sets up the distorted growth known as the false cone. As summer advances the cone enlarges till it is as big as a filbert, or even bigger. In June it is bright green, composed of regularly arranged scales, and looking much like a true fir-cone, from which, however, it can be distinguished by the foliage-leaves which grow from it. The hibernating female, after three changes of skin, lays her eggs and dies. Each egg has a transparent waxy envelope, which is drawn out at one end into a thread for attachment; about 200 may be laid by a single female. The larvæ, when hatched, attach themselves to the false cone, and apparently creep into cavities enclosed between its scales. In July or August the cones are hard and ripe; the scales shrivel, and the cavities open, disclosing numerous larvæ, which are at first green, afterwards reddish; when closely examined, they are found to possess wingrudiments. After a final change of skin, the wings are fully expanded, and the migrating females are complete; they are larger than the hibernating females, and reddish or orangeyellow in colour. Some of them remain on the spruce, and lay eggs, from which hibernating females are produced; others migrate to larches, and lay eggs whose product is again a 


\section{I94 INJURIOUS AND USEFUL INSECTS}

generation of hibernating females. From these in the following summer winged females may proceed, wingless forms being regularly produced at the same time. The winged flies make their way back to the spruce, and from their eggs are hatched true males and females, capable of producing fertilised eggs; hence the winged generation born on the larch are distinguished as the sexuparous females. Each fertilised female lays a single egg in autumn, and from this issues a hibernating female, such as that with which we began.

The scale-insects are very aberrant Hemiptera, to which, however, wax-secreting aphids make some approach. Some true scale-insects, such as Dactylopius and Orthezia, still retain the power of moving slowly about. The foot in all scale-insects is one-jointed, and ends in a single claw. The males pass through a pupa-stage, and acquire wings, besides minute halteres, or hind wings; a few species are wingless; and one, the Chionaspis of the willow and other trees, has both winged and wingless males (Newstead). Some scaleinsects secrete honey-dew, which is devoured by ants, wasps, and other insects.

The Anoplura (lice) are often regarded as a third sub-order of Rhynchota. They are wingless parasites of mammals, and have a minute sucking-tube for drawing up fluids, with a circle of hooks around the base.

\section{NEUROPTERA}

The insects called Neuroptera in many entomological books are a very puzzling group. To begin with, the word has no constant signification. With some writers it denotes a large primary division of insects; others apply it to a collection of a very few families. Those who give it a wide extension, admittedly include in the order a number of families which have no close affinity; for the sake of practical convenience they throw over the principle that classification should rest upon demonstrated relationship alone. It seems to us so anomalous to include dragon-flies, May-fies, scorpion-flies, and lace-winged flies in one group, that we would rather submit to the inconvenience of a mere enumeration which makes no pretence to natural arrangement. No reason can be given for 
placing the Odonata (dragon-flies) near to any other insect group, and the same may be said of the Ephemeridæ (Mayflies).

Out of the so-called Neuroptera of most elementary books, which have no demonstrable affinity, it is better to separate such as undergo complete transformation, and possess biting mouth-parts, besides four similar membranous wings, which are not folded when at rest. These may usefully bear the restricted name, Neuroptera. The other families, such as the dragon-flies and May-flies, are best treated as independent until we are better informed as to their origin and history.

The Neuroptera (in the stricter sense of the term) answer more or less to the Planipennia (flat-winged Neuroptera) of Latreille and some other authors. They include the Sialidæ (alder-flies and snake-flies), the Panorpidæ (scorpion-flies), the Myrmeleontidæ (ant-lions) and their near allies, and the Chrysopidæ (lacewing-flies).

Sialis lutaria (the alder-fly) is a common British insect, used as a bait by anglers. The first stage is passed in water, especially muddy water, where the predatory larva seeks and devours other aquatic insects. It has formidable pointed mandibles, three pairs of rather long legs, and seven fivejointed abdominal appendages, which curve outwards into the water and serve as gills. The larva quits the water to pupate in earth, and shortly afterwards emerges as a sluggish fly, with black body and four large wings, which are clear but blackveined. The female lays patches of dark brown eggs on leaves, sticks, or stones near the water's edge.

Scorpion-flies take their name from the sting-like termination of the abdomen of the male fly, which is curved over the back as in real scorpions. The resemblance is purely superficial, for the scorpion-fly does not sting, and the peculiar tail is only used to grasp the female. The scorpion-fly possesses a more formidable weapon in its long, down-pointing beak, which is a prolongation of the head, and bears the minute mouth-parts at its extremity; with this it sucks the bodies of (usually) dead insects. The flies are not uncommonly seen hovering over bushes and herbs on summer days. The larvæ live in moss or damp earth, and possess abdominal pseudopods as well as three pairs of thoracic legs, so that they resemble saw-fly larvæ. Of the other Neuroptera we can only glance at the lacewing. 


\section{I96 INJURIOUS AND USEFUL INSECTS}

flies. These are beautiful insects, with long antennæ, slender body, large gauzy wings, and iridescent eyes. Like the ladybird larva and the Syrphus-larva, the larva of the lacewing preys upon aphids. The eggs are mounted on long, elastic stalks, and fixed among the aphids. The larvæ are longlegged, bristly, and narrowed both in front and behind. They spear their helpless prey with the pointed mouth-parts, and suck their juices. One common British species, $C$. perla, seems to be particularly fond of the rose-aphis. Not only true aphids, but scale-insects and other plant-parasites are devoured by the lacewing larva. Syrphus-larvæ in their turn often suck the lacewing larvæ instead of the aphids which are their habitual food. Some Chrysopa-larva have the peculiar habit, not unknown among other insects, of concealing their bodies by fastening around them the skins of their victims. Among the larvæ which practise this disguise, for such it probably is, are those of our commonest species, $C$. perla.

Before pupation the larva spins a cocoon in a crevice, or in a rolled-up leaf, or between pine-needles, according to the species. Many lacewings, when handled, emit a very disagreeable odour, and our common species is one of these. The lady.bird larva does the same.

\section{LEPIDOPTERA}

Structural peculiarities.-The head of the imago is furnished with compound eyes and often with two simple eyes, which are wanting in butterflies. The antennæ are often long; in butterflies they are clubbed at the tip; in some moths (Bombycidx, etc.) they exhibit a single or double comb, especially in the male. The mouth-parts found in biting insects become vestigial in a lepidopterous imago, except the maxillæ and the labial palps. The maxillæ (strictly, the galeæ of the maxillæ) are much prolonged, united by interlocking processes, and converted into a proboscis, which is usually wound spirally when not in use. The proboscis itself becomes vestigial in many moths, which do not take food: The labial palps are relatively large, and stand on each side of the base of the proboscis; in some families the maxillary palps are well developed. Sometimes all the mouth-parts are reduced to microscopic vestiges (e.g. Hepialus, Psychidæ). 
The body and legs are covered, as a rule, with dense hairs. Four wings are usual, and these are nearly always clothed on both sides with extremely numerous scales of peculiar shape, which can readily be recognised in the microscopic examination of dust, etc. Sometimes, as in the clearwings, the scales are not developed over large parts of the wings, or fall off immediately, so that these moths acquire a mimetic resemblance to wasps, hornets, ichneumons, and other Hymenoptera, which is greatly enhanced by the colouring, the attitudes and the diurnal habits of the mimics. The wings are not much folded when at rest, though the hind wings are often concealed by the fore pair; in butterflies, they are commonly erected above the back when the insect settles: An interlocking ap-

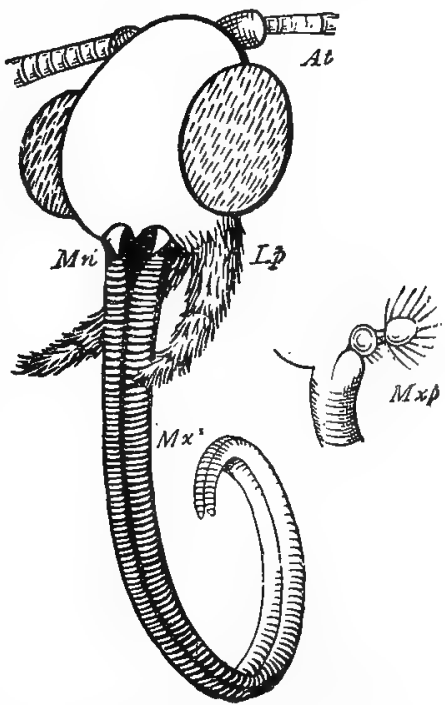

Fig. 100.-Mouth-parts of burnet moth. The identity of the parts marked $M n$ with true mandibles bas been questioned. paratus usually attaches the hind wings to the fore pair. The six legs are long and hairy;

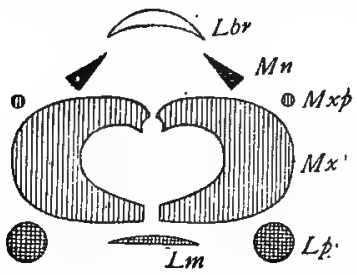

Fig. Ior.-Diagram of mouthparts of moth. the fore pair are useless for walking in some butterflies.

Life-history etc.-Male Lepidoptera are often smaller than the females of the same species, brighter coloured, and with more complex antennæ. Female moths are not infrequently wingless. In such cases, the larva feeds upon social plants, or indiscriminately on the leaves of a number of plants which are likely to occur together. The careful dispersal of the eggs in sufficiently distant spots, which is one motive for the development 
of wings, ceases to be a necessity for such insects. Parthenogenesis occurs occasionally (silk-moth, etc.) or normally in some moths (Psychidæ). The larva is nearly always a vegetable feeder, and is adapted by its form, colour, the structure of its legs and mouth-parts to a sedentary life on green plants. Exceptional adaptations to life in water, in the trunks of trees, in the combs of bees, etc. are known. The mandibles are the only mouth-parts which are directly concerned in feeding during the larval stage. The larva usually moults four times. As the time of pupation approaches it often conceals itself, and may make use of its power of spinning silk to form a cocoon, either composed of silk only, or of silk interwoven with the larval hairs, or leaves woven together, etc. The pupa or chrysalis may be described as an imperfectly developed moth or butterfly covered by a thin pupa-skin, and having its limbs cemented down by a viscid secretion which flows from the body, and hardens on exposure to the air. The proboscis, legs, and wings are tolerably complete externally, but imperfectly organised within. Nevertheless the insect, at the time of pupation and before the secretion is poured out, has often a certain power of moving its limbs. Afterwards they lose more or less the power of movement, but some can wriggle out of holes in the earth or galleries in the trunks of trees, so as to reach the air before the moth emerges. In these movements they are aided by spines or rows of spines attached to the abdomen. Many Lepidoptera pass the winter as pupæ, some as larvæ, a few as torpid winged insects, many enclosed in the eggs.

\section{The Families of Lepidoptera}

The classification here adopted is only provisional, but will be of some use in placing butterflies and moths. The arrangement of the families on natural lines is still very incomplete, and much too difficult a study for beginners.

\section{BUTTERFLIES (Rhopalocera)}

Antennæ clubbed. Wings more or less erected when at rest. Body slender.

The only butterflies of much practical importance are the cabbage whites (see Lesson I 5 ). 


\section{MOTHS (Heterocera)}

Antennæ of various form, rarely clubbed. Wings usually sloped roofwise, or expanded horizontally when at rest. Body often thick, but slender in Geometridæ.

\section{Division I.-Sphinges (hawk-moths)}

Large moths, with thick bodies and long, rather narrow fore wings, which are obliquely cut at the end, and sometimes hooked at the tip. Antennæ often prismatic, narrowed at the base, and sometimes enlarged towards the tip. Proboscis usually long and spirally folded. Larva cylindrical, usually with a dorsal horn at the hinder end of the body.

The death's-head moth (Acherontia atropos) is the largest European moth; it feeds on potato and other plants; visits hives for the sake of honey; and makes a shrill sound by rubbing its finely ridged palps against the proboscis.

\section{Division II.--Bombyces}

Antennæ tapering from the base, often pectinate, and larger in the male. Body thick and rather short. The larvæ are mostly hairy and spin a thick silken cocoon.

Family Arctiidæ (tiger-moths). The moths are usually variegated with bright colours, and the larvæ clothed with long hairs. (See Lesson I4.)

Family Saturnidæ. Wings broad, each with an eye.

The only British species is the emperor-moth.

Family Bombycidæ (true silkworms). The family, as restricted here, is not European, but peculiar to hot countries. The silkworm is described in Lesson 17 .

Family Lasiocampidæ (eggars, lappet-moths). One mischievous species of this family is the lackey-moth (Clisiocampa neustria). It is perhaps most common on hawthorn hedges, but most exasperating on orchard trees, where it spins great webs, in which scores or even hundreds of larvæ live together. They are rather long and slender, and hairy, like most larvæ of this family. When superficially examined they appear to be of dark grey colour, but when more closely studied, coloured stripes, scarlet or orange and blue, are seen along the sides, and a pair of dark spots just behind the head. The 
larvæ make feeding excursions by day, but return to the web at night, or during rain. When disturbed, they often let themselves down by threads, up which they climb again when the danger is past. In July the larvæ are full-fed and spin cocoons on or near the trees on which they fed. The moth appears in late summer; it is of rusty yellow, with darker bands across the middle of the fore wings. The eggs are laid in close spiral bands round the twigs of trees, and are often to be seen in infested places during autumn or winter. Cutting the webs away with shears and burning them is the most certain remedy. The lackey-moth, like some other insect pests, is often plentiful for some years together and then disappears for a time; the cause, we suspect, is to be found in the variety or abundance of its insect-parasites (see p. 98).

Family Notodontidæ. The buff-tip often does much damage to the foliage of trees. The puss-moth and lobster-moth have remarkable larvæ. The puss-moth larva is protectively coloured, and when disturbed, withdraws its head into the first bodyring, inflating the margin, which is of a bright red colour. There are two intensely black spots on this margin in the appropriate position for eyes, and the whole appearance is that of a large flat face, which is probably terrifying to the vertebrate enemies of the caterpillar; when touched ever so lightly, it assumes the terrifying attitude and turns its face towards the enemy. The body ends in two prongs, from which pink whips can be swiftly protruded and brandished over the head. If further attacked, the larva can defend itself by ejecting a strongly irritant fluid from an opening beneath the head. The rare larva of the lobster-moth feeds on beech, and when at rest is concealed by its resemblance to a withered leaf. If attacked, it assumes a terrifying attitude, mimicking a large spider. The first pair of legs are held out like jaws, the next two pairs, which are very long, being held wide apart, and made to quiver, as if about to seize their prey. The hinder part of the body is turned over the head, and the two claspers somewhat resemble a pair of antennæe. The coloration of the body adds to the spider-like appearance. On the fourth and fifth body-rings there is a black patch sunk below the general surface and concealed by a flap. When the caterpillar is irritated, the flap is lowered, and the patches become very conspicuous. It is probable, as Hermann Müller has suggested, 
that these marks imitate the wounds made by an ichneumon, and suggest that a parasite is already in possession.*

Liparidæ (tussock-moths). Dull-coloured moths, often with zigzag streaks on the fore wings; the female is often wingless. Antennæ conspicuously pectinate in male; slightly so in female, when winged. Larva usually hairy and often tufted.

The vapourers, with wingless females (see Lesson I8), the gipsy-moth, the black arches-moth, the gold-tail and the brown-tail, are destructive insects belonging to this family. Two of the worst, the gipsy-moth and the black arches-moth ("Nonne"), are comparatively rare in Britain.

\section{Division III.-Noctuæ (owlets)}

Night-flying moths, usually of sombre colours, grey or brown, but sometimes conspicuously coloured, like the yellow underwing. The fore wing is often variegated, and shows a pattern called the Noctua-marking. Three zigzag streaks cross the wing, and a little nearer to the point of attachment there is an imperfect fourth; between the second and third streaks are two spots, one circular and the other oval.

The cabbage-moth (Mamestra brassica) is particularly injurious to cauliflowers and cabbages; it eats into the heart and spoils far more than it devours. 'The moth has the characteristic Noctua-marking, and shows the brown and grey colours characteristic of the division; it is about $22 \mathrm{~mm}$. (nearly an inch) long. The larvæ are naked, and usually of a dull green colour, varied with yellow, brown, and black. They winter in the earth as pupæ. Other species of Mamestra devour lettuces, peas, etc.

The figure- of-eight moth (Diloba caruleocephala) is sometimes mischievous in orchards. The so-called surfacecaterpillars (Agrotis) do much injury to turnips. The antlermoth (Charceas graminis) is occasionally very destructive to grasses.

\section{Division IV.-Geometridæ (loopers)}

Body slender. Wings expanded when at rest. The larvæ have fewer prolegs than usual, walk by looping the body, and when resting, stick out like twigs.

* This account of the puss-moth and the lobster-moth is taken from Poulton's "Colours of Animals," Chap. XIV. 
The magpie-moth (Abraxas grossulariata) is a common species, which does much mischief to the foliage of currants and gooseberries. Some common Geometrids, which are injurious to fruit-trees and other vegetation, like the March moth, the winter-moth and the umber-moth, have wingless females, a feature generally associated with indiscriminate feeding, or subsistence upon social plants (see p. 79).

\section{Division V.-Pyralides}

These small moths have usually simple, tapering antennæ and long legs. The larvæ are generally smooth and of active habits; some of them live submerged and feed on water-plants. The little grass-moths are very common on lawns. The plume-moths (which are often treated as a primary division of Lepidoptera) have the wings subdivided into from two to four feathers, while in Alucita each wing is divided into six feathers.

\section{Division VI.-Tortrices}

Small moths with simple bristle-like antennæ. The larvæ often roll leaves, but others make galls, or live in buds or fruits. The Tortrix of the oak sometimes strips the trees of their foliage. The larva of the codlin-moth gnaws a hole into the heart of an apple, which falls before it is ripe. The peamoth eats young peas in the pod. Other Tortrices gnaw the buds of pine-trees, and one is destructive to the hop, drawing the leaves together by its silken threads and devouring them.

\section{Division VII.-Xylotropha (wood-borers)}

Antennæ tapering, sometimes pectinate (comb-like). Wings rather narrow. The larvæ, which usually burrow in the wood of trees, are smooth and without dorsal horn.

Family Sesiidæ (clear-wings). The wings are more or less transparent, owing to the shedding of the scales, except along the veins. These moths often resemble wasps or other Hymenoptera in coloration, and like them, fly by day.

Family Hepialidæ (swifts). The larvæ of this family feed on roots below ground.

Family Cossidæ (goat-moths). Stout, hairy moths, with densely scaly wings. Antennæ pectinate in the male. No functional proboscis. 
The goat-moth is described in Lesson 16 . The woodleopard moth (Zeuzera asculi) in its larval stage devours the wood of various trees.

\section{Division VIII.-Tineidæ}

Small moths with long and narrow fringed wings. Antennæ usually simple. The clothes-moths, of which several species are troublesome, the white corn-worm (larva of Tinea granella), which devours stored grain, and the flat-bodies, small moths which infest the carrot, are among the best known Tineid pests.

The diamond-back moth (Plutella cruciferarum) is a Tineid $7 \mathrm{~mm}$. long, with the grey-white colour and fringed wings so frequent in this sub-order. When the wings are at rest a row of whitish diamonds appear along the junction, and this gives the name of diamond-back. The eggs are laid on cabbages, cauliflowers, turnips, swedes, and other Cruciferous plants, wild or cultivated. The larva is greenish, nearly bare, narrowed a little at head and tail, and has the prothorax dotted with black, while each of the next two segments bears a yellow spot on either side of the middle line; it attains a length of $10 \mathrm{~mm}$. When full-fed it spins a loose cocoon on the food-plant or on the ground, and pupates. There are commonly two broods, one in early, and one in late summer, and the autumn pupæ remain unchanged till the following season. The larvæ devour all parts of the food-plant, but the riddling of the leaves is generally the first token of their presence.

The small ermine-moths (Hyponomeuta), of which several species are commonly found, devour as larvæ the leaves of shrubs and fruit-trees. H. padella is common in hedges and orchards; $H$. euonymella on spindle-tree and bird-cherry. The fore wing in these moths is white, speckled with rows of black spots, hence the name of ermine-moth, which has been most inconveniently applied to quite different moths (Spilosoma), which have rows of spots on the abdomen, and often spotted wings. It is therefore necessary to note that the species of Hyponomeuta are the small ermine-moths. The hind wings are grey-brown. Length of body 8-9 $\mathrm{mm}$. The caterpillar of $H$. padella is brownish, dotted with black; it feeds on hawthorn and other trees, a number living together 
in a common web, like the larvæ of the lackey-moth; the larvæ of $H$. euonymella are similar in mode of life, but yellow in colour.

\section{DIPTERA}

Structural peculiarities.--The head of a Dipterous fly is very mobile, and much of its surface is usually occupied by

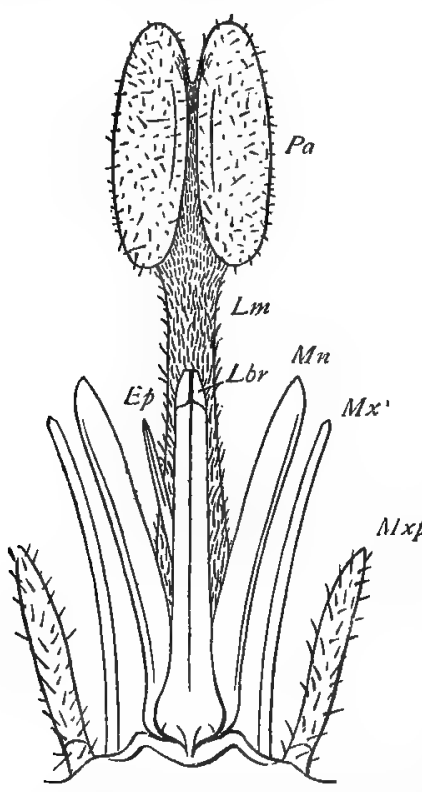

Fig. I02.-Mouth - parts of gad-fiy (Tabanus). Lbr, labrum; $e p$, epipharynx; IIn, mandible; $h x$, maxilla; $M x p$, maxillary palp; $L m$, labium ; $P a$, palette of two labellae. and in many Diptera can be thrown into rapid vibration; they are richly supplied with nerves.

Life-history.-Diptera undergo a complete transformation, with resting stage. The larva never possesses jointed legs, 
and is often reduced to a maggot, without feet of any kind, and with only a vestige of a head. Some Dipterous larvæ, however, belonging to less specialised families, have one, two or several pairs of pseudopods (false feet) and a fully formed head, with functional eyes, antennæ, and mouth-parts. Transitional forms between these and the maggot are frequent. It is a general rule that the higher the organisation of the fly, the more degraded is the larva. The pupa is free-limbed, and may be more or less active in aquatic Diptera of the lower division, though it never feeds. In higher Diptera the resting larva undergoes very complicated changes without casting the larval skin; almost all the larval organs may be reduced to a cellular pulp ; certain rudiments, however, survive, and from them the organs of the fly are developed. The pupa of such flies is lodged within the hard, dry, barrel-shaped larval skin.

A few Diptera are viviparous. The Sarcophagidæ are often hatched within the oviduct of the parent, while in the Pupipara nearly the whole of the larval stage is passed in the oviduct.

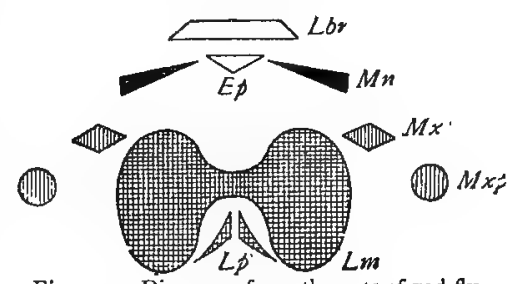

Fig. 103.-Diagram of mouth-parts of gad-fly.

Mode of life, etc.-Dipterous larvæ feed upon almost every kind of animal and vegetable substance, dead or alive. Many mine leaves, or form galls on trees ; others (Tachinids) devour the viscera of living larvæ, or (bot-fly larvæ) inhabit the bodies of quadrupeds. The flies often do not feed at all; some suck ripe fruits or the blood of many kinds of animals; others (Empidæ, etc.) are raptorial, capturing smaller insects and sucking their fluids; many, especially the Syrphidæ, feed upon the honey of flowers. The carcasses of animals, sewage, rotting fungi, and other offensive organic matter are largely converted into the bodies of living flies, and thus scattered over the face of the country. It is a set-off to this service to public health that certain blood-sucking Diptera spread malarial and other diseases.

Some Diptera (Syrphids, Bombylius, etc.) resemble wasps and various bees in form, colour, and mode of flight; this re- 


\section{6}

\section{INJURIOUS}

AND USEFUL INSECTS

semblance no doubt protects them from insectivorous birds.

\section{The Sub-orders of Diptera}

The classification of the Diptera as set forth in recent textbooks presents the greatest possible difficulties to beginners. It is often uncertain, owing to incomplete knowledge; it involves characters taken from the pupa, and therefore is not capable of verification by those who have only the fly before them; lastly, it rests in great part upon minute and obscure details. We shall substitute for the purposes of this book a simpler grouping of the families.

Two sub-orders of Diptera can be easily distinguished. These are the Nemocera and the Athericera, ${ }^{*}$ of which the Nemocera are relatively primitive, while the Athericera are specialised in a very high degree. The student who is familiar with the structure and life-history of the harlequin-fly and the blow-fly, can take these as types of the two divisions. In Nemocera the antenna never contains fewer than six joints, which are similar to one another, and look like a row of beads; the second joint, however, may be enlarged, especially in the male (see the harlequin-fly, Lesson 23). The larval skin is cast at pupation in the usual way, and the pupa is in its main features like a Coleopterous or Hymenopterous pupa, consisting merely of the body of the fly enclosed in a transparent pupa-skin. In the Athericera the antenna always takes the plate-and-bristle form. There are three basal joints, the third being much longer than the rest, and the bristle springs nearly from its base. The larval skin is not cast at pupation, but shrinks into a barrel-shape, hardens, and protects first the resting larva, afterwards the pupa. The fly escapes from the larval skin by pushing off with its head the anterior segments, which separate along a transverse line. $\dagger$

* Nemocera-i.e. with thread-like antennæ; Athericera-i.e. with bristle-bearing antennæ.

+ The classification here adopted is that of Baron Osten Sacken, who explains his views in these words (slightly abridged):

"Macquart had two sub-Orders, Nemocera and Brachycera; Brauer had also two, Orthorrhapha and Cyclorrhapha, but the dividing line between them was at a different place from that of Macquart's. I adopt three sub-Orders, and call them Orthorphapha Nemocera, Orthorrhapha Brachycera, and Cyclorrhapha Athericera. In other words, I adopt 
The two sub-orders of Nemocera and Athericera are readily distinguished and remembered. The next thing to note is that there are very many connecting forms, which are not wholly Nemoceran, nor wholly Athericeran. Thus the antenna may have more than three joints, though they are not so numerous, nor so similar to one another as in Nemocera; the third joint may be more or less divided into segments, and the bristle, if present, may be terminal, instead of springing from the base of the third joint; lastly, the larval skin may be retained only for a short time. Various combinations of such characters are also met with. Thus Cecidomyia (Hessian-fly, etc.), a Nemoceran, retains the larval skin like an Athericeran, but has a true Nemoceran antenna. We shall here recognise the existence of a transitional group, Brachycera, the members of which are to be recognised only by the negative character that they are not truly either Nemoceran or Athericeran.

\section{Sub-order I.-Nemocera}

Antenna beaded, of six or more joints, the second of which is often enlarged. The palps are 4-5-jointed, and often conspicuous. The larval skin is cast at pupation, the pupa consisting of the body of the fly enclosed in a temporary skin.

The gall-midges (Cecidomyida) are a very numerous

Brauer's nomenclature, except that his Orthorrhapha Brachycera I consider as a separate sub-Order, while he considered it as a division, which, together with his division Orthorrhapha Nemocera, formed his sub-Order Orthorrhapha. His sub-Order Cyclorrhapha I call Cyclorrhapha Athericera.

"The three names of the sub-Orders which I adopt have the advantage of being descriptive of a character taken from their metamorphoses on one side, and of another character taken from the imago and its principal organ of orientation (the antennæ) on the other. The nanies Orthorrhapha and Cyclorrhapha were very happily chosen by Brauer to characterize the metamorphoses of each of the groups, and should therefore be preserved. The names Nemocera and Athericera were adopted for two groups by Latreille, and should likewise be retained. Finally, the name of Orthorrhapha Brachycera was used by Brauer himself for a division which I consider as a sub-Order. The position of the Pupipara I leave an open question.

"The arrangement which I conceive at present is, therefore, as follows :-

I.-Orthorrhapha Nemocera.

II. -Orthorrhapha Brachycera.

III.-Cyclorrhapha Athericera." 


\section{8

family of minute and delicate Nemoceran flies, with long, thread-like or beaded antennæ, I3-jointed in the female, 29-36-jointed in the male, where they may be as long as the body, and furnished with conspicuous whorls of hairs. The proboscis is short, the wings relatively large, fewveined, and fringed, the legs very long and slender, adapted for running. The end of the female abdomen is drawn out into a long, jointed extremity (inaccurately described as an ovipositor) which can be grasped by the large and hooked claspers of the male. The eggs are very few and large.

In the larval stage the gall-midges are remarkable for their very diverse mode of life. Some simply feed on leaves or bark; others make galls upon a great variety of plants; or subsist upon the galls made by other insects; a few prey upon aphids, acari, and other small animals. The larvæ are usually red, orange, or yellow, the body is often flattened, narrowed at both ends, and apparently composed of more than the usual number of segments. This is probably due to the retractile head, which can be completely withdrawn into the body, when the fore part of the body-wall becomes infolded. One or more transverse folds are thus produced, which give an appearance of additional segments. From the ventral surface of the prothorax a chitinous spine projects, which is nearly always forked, but sometimes ends in a simple point; in some larvæ this can be used like a foot in reversing the position of the body; perhaps, in other species, it may be opposable to the head. False feet may be present on the abdomen, but they are generally absent. A number of the spiracles are open. The larvæ are never aquatic; some are capable of viviparous reproduction, though still unprovided with sexual organs of the ordinary kind. In many the larval skin is not cast at pupation, but hardens over the pupa; in others the larval skin is cast, and the pupa is protected only by a silken cocoon. To this family belongs the Hessianfly (see Lesson 27).

The wheat-midge (Cecidomyia tritici) lays eggs in the flowers of wheat, by means of the long and slender tip of the abdomen (the so-called ovipositor). The larvæ feed a number together on the growing grain, and are often called from their colour red maggots. They pupate in the earth or in the husk, and the flies appear in the following season. 
The pear-midge (Diplosis pyrivora) lays eggs in the flower-buds of the pear. The larvæ, which are only about $5 \mathrm{~mm}$. long when full grown, live a number together in the core of the growing fruit. They leap when disturbed like cheese-maggots, clasping the head with the tail and then suddenly extending the body. About midsummer the dwarfed pears fall to the ground, and if opened the grubs are found in cavities within. When the pears crack the grubs enter the earth, form cocoons and rest till spring, when they pupate and turn to flies.

Among the other families of Nemocera are the Chironomidæ, to which the harlequin-fly belongs (see Lesson 23), the Culicidæ, or gnats (see Lesson 25), and the Tipulidæ, to which the crane-fly (see Lesson 26 ) belongs.

\section{Sub-order II.-Brachycera}

Antenna neither truly Nemoceran nor truly Athericeran; if beaded, it always has the joints of various lengths, and generally fewer than in Nemocera; if it takes the plate-and-bristle form, the bristle is terminal, or else the third joint is segmented. The palps have never more than two joints. The larval skin is cast at pupation, or retained as a defence for the pupa; it splits longitudinally and often transversely as well.

To the Brachycera belong Stratiomys, with its curious aquatic larva (star-tailed maggot), the Tabanidæ (popularly named cleggs, horse-flies, and gad-fiies) which draw blood by the lancets of the proboscis, which is usually prolonged; as in gnats, it is only the female that draws blood. The robber-flies (Asilida) superficially resemble hairy bees. They kill and suck insects of all kinds, while the larvæ prey upon other insect larvæ. The large family of Empidæ includes many predatory forms which pierce and suck flies; some are very commonly seen hovering over water.

\section{Sub-order III.-Athericera}

Antenna of the plate-and-bristle form, with three basal joints, the bristle springing from the base of the third joint. The palps have never more than two joints. The larval skin is retained during the pupal stage, and cracks transversely to allow the fly to escape. 
The Athericera include three great families, Syrphidæ, Muscidæ, and Estridæ, besides several small ones.

The Syrphidæ are distinguished by the absence of cavities on the face for the antennæ, and by the "spurious vein," a mark which runs along the wing between the third and fourth longitudinal veins. The proboscis is often long, and well suited for exploring the recesses of flowers. Many resemble bees or wasps in their coloration. The flies are remarkable for their activity in pollinating flowers. In sunny weather during summer they can nearly always be seen hovering over flowers. The larvæ differ greatly in their mode of life. Some devour aphids (Syrphus), others inhabit the foulest pools (Eristalis, the rat-tailed maggot), others dwell as scavengers in the nests of bees and wasps (Volucella); some are vegetable-feeders.

The Muscidæ include about a third of the known Diptera, and constitute, therefore, a family of enormous extent. Many of them are so similar to the blow-fly in all that relates to the structure of the head as to be pretty easily recognised as Muscids by all who know that one insect in detail. But the various features alter one by one, sometimes almost insensibly, and it is apparently impossible to draw a clear line anywhere between a typical Muscid like the blow-fly and flies which are notably different. The proboscis is always well developed, but shorter than in many Syrphidæ. If the antennæ are sunk into a cavity on the face, and if the halteres are covered by a winglet, the fly is certainly a Muscid of the most typical kind (sub-family Muscinæ), but these characters do not obtain throughout the family.

To the Muscidæ belong the Tachina-flies, with habits similar to those of ichneumons. They do not, like ichneumons, pierce the skin of the caterpillar, but lay their eggs on it the issuing larvæ bore their way into the victim. The flesh-flies resemble in structure and mode of life some typical Muscids, such as the blow-fly. Many of the Anthomyids are destructive to crops, such as the cabbage-fly, root-fly, radish-fly, mangold-fly, and onion-fly. The much dreaded tzetze-fly of South Africa is allied to the stable-fly of Engtand (Stomoxys); both are nearly related to the blow-fly and common house-flies.

Muscidæ are often distinguished from one another by minute characters, which escape an ordinary observer. The inexperienced entomologist thinks he knows a house-fly when 
he sees it, but he may give that name to any of the following distinct species:-(r) Musca domestica, the true house-fly; (2) Homalomyia scalaris, very plentiful from early summer to late autumn, a little smaller than the last, and identified by a tubercle on the inner side of the middle tibia; (3) H. canicularis, known by a yellow patch on the side of the first and second abdominal segments; (4) Cyrtoneura stabulans, a grey fly with reddish legs, rather larger than the house-fly; (5) Stomoxys calcitrans, the stable-fly, armed with a proboscis which can pierce the human skin. In spite of a general resemblance which deceives all but a practised observer, there may be marked differences of habit, and the larvæ may differ greatly, not only in mode of life and choice of food, but in appearance and structure.

The gout-fly (Chlorops taniatus) is a Muscid, whose larva does great damage to barley, and sometimes to other grain. It is believed to be particularly prevalent on wet land, and to attack late-sown crops with more effect than others. The damage is done to the ear, which does not unfold, but remains enclosed in its sheath. On examination a furrow is seen to run along one side of the ear down to the base of the enclosing leaf, and here the full-fed larva or the pupa will often be found. The larva is yellowish, and shaped like a blow-fly maggot with narrow head-end and broad tail-end; it is small, only attaining a length of $6 \mathrm{~mm}$. The pupa is red or brown, somewhat flattened, and enclosed in the hardened larval skin, as in all the more specialised Diptera. The fly appears at harvest; it is $3-4 \mathrm{~mm}$. long, yellow, but with three dark stripes running lengthwise along the thorax, and four dark transverse stripes on the abdomen. The male has the abdomen blunt at the end, while it is pointed in the female. The wings are longer than the body. It is probable that the autumn eggs are laid in wild grasses, and that the females of the spring brood lay their eggs in the young barley-head.

The frit-fly (Oscinis frit) is a small black fly which attacks oats and sometimes barley, the larva devouring the heart of the young shoot, so that the plant turns brown and withers.

The Estridæ (bot-flies) are large flies, with very short sunk antennæ, the proboscis and mouth-parts usually vestigial. The winglet is often large and hides the baltere. The larvæ are parasitic on mammals. 
At the end of the series of Diptera may be placed two anomalous sub-orders, the Pupipara and the Aphaniptera.

\section{Sub-order IV. - Pupipara (forest-flies, bat-ticks, sheep-ticks, etc.)}

Very abnormal flies, parasitic upon mammals and birds. Some are winged, others wingless. The egg is hatched within the parent, and the maggot is not passed out till it is ready to pupate.

\section{Sub-order V.-Aphaniptera (fleas)}

Often regarded as Diptera which have become degraded by parasitism. They are wingless; the body is laterally compressed; the mouth-parts show some resemblance to those of such Diptera as Tabanus, though with noteworthy differences, such as the presence of two pairs of palps; the metamorphosis is complete.

\section{COLEOPTERA}

Structural peculiarities.-Beetles are protected by a strong chitinous integument, useful to insects which are so often subterranean or otherwise hidden. The legs are usually strong, and often adapted for burrowing. The hind wings are so large that they require to be elaborately folded beneath the elytra; sometimes, however, they are greatly reduced or even totally wanting; in such beetles the elytra may be soldered together. The elytra are short in the rove-beetles, and vestigial in the oil-beetles (Meloe). The mouth-parts resemble those of a more primitive order, the Orthoptera.

Life-history.--Beetles undergo a complete transformation, with resting-stage. The larvæ vary much in the different families. Three pairs of thoracic legs are usual; many of the larva have a peculiar anal prop, which reaches the ground; it is traversed by the intestine, and is really a body-segment. The larvæ of rove-beetles most closely resemble the adults; in chafers the body becomes thick and fleshy, and the legs relatively short; weevil-larvæ, which 
live on or in their food, are footless grubs. The pupa is generally soft and pale, enclosed in a cocoon, and concealed in earth or wood. A thin and transparent pupa-skin covers the body, which is practically the body of the future beetle; the appendages of concealed pupæare often nearly or altogether free. Exposed pupæ may resemble Lepidopterous pupæ in being covered with a protective varnish, which glues the limbs to the body. The duration of the preliminary stages varies greatly according to the food, as is the case with other orders of insects also. Larvæ which burrow in the ground or in the trunks of trees are of slow growth, and may feed for two or three years, usually resting in the winter. On the other hand, some leaf-eating beetles condense the whole life-history into a few summer weeks.

Mode of life, etc.-Beetles often pass their whole life underground or in concealment, and are then usually darkcoloured. Many that appear on the bark of trees are brown, and leaf-eating species are often green. The coloration is not, however, always directly protective. Some beetles which are conspicuously coloured are either acrid or particularly hard-shelled, so that they are distasteful to birds. In very many cases the advantage of the peculiar coloration bas not been discovered.

Beetles are eminently a dominant order of insects, abounding both in species and in individuals; the species are often very hard to distinguish. It seems to be a general mark of dominant groups that in them species which differ very slightly can maintain themselves side by side.

\section{The Families of Coleoptera}

None of the many attempts to arrange the Coleoptera in a few large groups can be considered altogether successful. The number of the joints in the tarsus and the form of the antennæ yield useful characters, but if they are employed too rigidly, natural groups are broken up. The primary groups of beetles, as defined by recent students, and the chief families found in the British Isles, are characterised in the following table, where short notices will be found of interesting beetles which we have not space to describe at length. 


\section{Sub-order I.-Lamellicornia (lamellicorn beetles)}

Tarsus five-jointed in all the legs. Last joints of antenna usually enlarged on one side, forming a club of movable leaves.

Family Lucanidæ (stag-beetles). Last joints of antenina merely enlarged, not flattened.

The stag-beetle is the largest British beetle. The male is remarkable for its large and very variable mandibles.

Family Scarabæidæ (chafers). Last joints of antenna flattened.

I. Sub-family Coprinæ (dung-chafers). Everybody knows the dor-beetle or dumbledor, the "shard-borne beetle" of Shakespeare, the "drowsy beetle" of Gray's Elegy. It may often be seen creeping among the grass in a pasture, or flying in a heavy, blundering fashion on a fine evening in summer or autumn. Most of us have held this beetle in our hands, and have noticed the yellow fleas which run about its body (they are not really fleas, however, but mites). The female digs a burrow beneath a patch of cow-dung, some of which she carries down into the earth, and lays on it a single egg. The larva subsists on this food, and pupates underground.

2. Sub-family Melolonthinæ (leaf-chafers). The cockchafer (Lesson 5) is placed in this sub-family.

3. Sub-family Cetoninæ (rose-chafers).

\section{Sub-order II.-Adephaga (predatory beetles)}

Tarsus five-jointed in all the legs. Antennæ slender and tapering. Jaws piercing, pointed and toothed. The larva is usually long-legged and very active.

Family Cicindelidæ (tiger-beetles). Differ from Carabidæ only in small details of structure.

We may often find in sandy fields, or in waste places where the soil is dry and loose, the bright-coloured and vivacious tiger-beetle (Cicindela campestris). It flies swiftly in the sunshine, soon alighting, but taking flight again whenever we attempt to draw near. The beetle is of no great size (I 4-I $5 \mathrm{~mm}$. long), but conspicuous by its activity in running or flying, and by its bright coloration. The body is of a rich green above, and marked on the elytra, or wing-covers, by white or yellowish spots, usually five or six on each side; the margins 
of the elytra and the legs are reddish, the under side of a metallic green; the top of the abdomen appears, when the wings are spread, of a shining blue. The beetle gives out a faint odour like that of sweetbriar. Its head is large, with prominent eyes, and jaws which at once reveal murderous propensities. The larva can be discovered by digging in the loose sandy bank over which the beetles congregate. Its body is long and of awkward shape, for it is bent twice at an angle, and takes the shape of the letter $Z$. A number of hard plates defend the back, and this, we may remark, is frequently the case with larvæ which burrow, or hide in narrow crevices. The head is large and the jaws formidable, though not quite so ferocious as those of the adult beetle. There are four simple eyes on each side of the head, the upper two being larger than the lower ones. Each segment of the thorax bears a pair of rather long and slender legs. If we look at the eighth segment behind the head (the fifth abdominal), we see a hump on its upper surface, which bears a pair of strong hooks. These are of special use when the larva is lurking in the ground and waiting for a victim to come within reach. The larva has its retreat-a vertical burrow which often runs many inches into the ground. In bringing up the earth and sand to the surface, it bends its body to the Z-like figure, and gets the same kind of hold with the pair of hooks on its back that a man climbing a rocky. cleft would get with his knees. The earth is said to be carried up on the broad, shovel-shaped head. When the burrow is completed, the larva climbs up it, and holds on with its legs and dorsal hooks, the head and first segment of the thorax closing the hole like a lid. As soon as a crawling insect, such as an ant or a small beetle, comes near enough to be seized, the tiger-beetle larva suddenly throws its head backwards, clutches the prey, and drags it into the burrow, where it sucks the juices and leaves little more than an empty skin behind.

Towards the end of summer the larva pupates. The pupa inhabits the same burrow, and is, like many other subterranean pupæ, furnished with spines, which enable it to climb to the surface before the winged insect emerges.

Some of the winged beetles appear in autumn, two or tbree weeks after pupation, but the majority lie hid till spring, when they fly about in the sun, and lay eggs. 


\section{I6 INJURIOUS AND USEFUL INSECTS}

Family Carabidæ (ground-beetles). All the legs adapted for running.

There are many species of the same general structure and mode of life. We see them run across the paths of a garden or field; we notice their agility, their long legs, their slender antennæ, and their habit of lurking by day in hidden recesses. A few species, however, are bold enough to show themselves freely. Black or dark colours are prevalent, but some are gay with metallic hues. The tarsi are always five-jointed, and the jaws are adapted to piercing. Some of them eject an acrid liquid when handled.

Family Dytiscidæ (diving-beetles). Hind legs adapted for swimming.

Dytiscus marginalis is described in Lesson 6.

\section{Sub-order III.-Clavicornia (clavicorn beetles)}

Tarsus five-jointed in all the legs (many exceptions occur). Antennæ often clubbed. An unsatisfactory division.

Family Gyrinidæ (whirligig-beetles). Feelers short. The compound eyes divided into two pairs unlike in structure. Middle and hind legs short, broad, adapted for swimming.

Family Hydrophilidæ (water scavenger-beetles). Feelers short, clubbed. Palps long, resembling antennæ. There are two sub-families :-

I. Sub-family Hydrophilinæ. Legs fringed. First joint of tarsus of hind leg very short. Aquatic beetles.

2. Sub-family Sphæridiinæ. Legs not fringed. First joint of tarsus of hind leg long. Terrestrial or partially aquatic beetles.

Family Silphidæ (carrion-beetles).

Family staphylinidæ (rove-beetles). Wing-covers short, exposing most of the abdomen, whose segments are very mobile.

To this family belongs the devil's coach-horse, or cocktail, a common beetle, well-known to schoolboys, who see it running on pathways, or turn it out from beneath large stones. It is about an inch long, and of a dull black in every part except the tip of the antenna, which is rust-coloured. When threatened, it opens its jaws, erects its tail like a scorpion, and looks as terrible as its size permits. At the same time it discharges from a pair of glands at the tip of the tail a fluid, which volatilises immediately and diffuses a pungent odour. 
If the beetle is imprisoned in a closed vessel, the odour soon becomes strong and unpleasant. The devil's coach-horse feeds upon small insects of all kinds, and has the sharp, pointed jaws of a carnivorous beetle. In this and other rovebeetles, probably so called because they are often found straying in an apparently aimless fashion, like creatures that have no home, the short elytra render it possible to erect the tail, which no ordinary beetle with long and rigid elytra can do. Though the elytra of rove-beetles are short, they meet along the back in a straight suture. The wings, when extended, are of tawny colour, and ample size. The devil's coach-horse, like most other rove-beetles, can fly very well. When it alights, the wings are crumpled into a surprisingly small space and completely concealed beneath the short elytra. The egg of the devil's coach-horse is reputed to be the largest laid by any British insect; it is about $2 \mathrm{~mm}$. long, and $1.3 \mathrm{~mm}$. broad. The larva is subterranean, hunting for small insects and worms in holes and crevices, so that it is rarely seen. It resembles the adult beetle in its long, narrow body, its piercing jaws, and its active, predatory habits. The legs are rather long for a beetle-larva, though not nearly as long as those of the adult, the head is broad and flat, the general colour yellow, but the head dark and the prothorax reddish; the upper surface of the body is protected by firm shields, and a pair of slender, antenna-like appendages (cerci) stick out from the last segment. Rove-beetles are particularly difficult to rear, and not very much is known of their life-history. In spring or early summer the larva makes for itself a cell in the earth, and changes to a straw-coloured pupa, which is loosely invested by a thin pupal skin. The pupa is particularly soft, wanting all the defences of the larva and imago. When the beetle first emerges it is pale, but soon darkens on exposure to light and air. The pupal stage lasts for a little more than a fortnight. Most rove-beetles are similar to the devil's coachhorse in form and habits, but a few are vegetable-feeders. Some burrow in the banks of streams, or in the sand of the sea-shore, and several species are found only in ants' nests.

Family Coccinellidæ (lady-birds). Hemispherical, or nearly so. Tarsus apparently three-jointed. See Lesson 9 .

The family Dermestidæ includes a number of small clavicorn beetles, with distinct 3 -jointed club on the antenna. 
The larvæ are hairy and dark-coloured, so that they resemble small caterpillars; they devour fur, hides, carpets, horse-hair, food-stores of many kinds, and dried animal substances. Some (Dermestes lardarius, D. vulpinus, Attagenus pellio, Anthrenus museorum) are common plagues in collections of stuffed animals.

\section{Sub-order IV.-Serricornia (serricorn beetles)}

Tarsus five-jointed in all the legs (with some exceptions). Antennæ often serrate or pectinate-i.e. with each joint projecting more or less inwards at its further end. An unsatisfactory division.

Family Ptinidæ. Small, rounded beetles, with slender antennæ and 5-jointed tarsus.

The larvæ of some species of Anobium drill holes in furniture; another is the "weevil" of sailors, which devours. shipbiscuits. Ptinus fur is often very destructive in museums. Some make a ticking noise as a signal to their mates, and are on this account (like Psocidæ) called death-watches.

Family Elateridæ (click-beetles). Antennæ variable, often serrate. Prothorax movable on mesothorax. Can leap when placed on their backs (see Lesson 7).

Family Lampyridæ (glow - worms). Antennæ variable. Many emit light from the hinder part of the abdomen. In some the female beetle has the wings short or absent.

The females, which alone emit a bright light, are wingless, and resemble larvæ. The males are winged, and are gifted with much larger eyes than the females. It is probable, therefore, that one chief purpose of the light is to allure the males. The males, however, and even the eggs, are slightly luminous. The glow-worm is concealed by day, but makes herself more evident at night by climbing upon stalks or low shrubs. The light is intermittent, being given out in the form of flashes, which succeed one another with great rapidity. When alarmed or disturbed, the glow-worm can extinguish its light. Close examination shows that the glow proceeds from a fatty substance which shines through the transparent parts of the skin on the hinder segments of the abdomen. The luminous substance contains no phosphorus, and it is believed that the light is caused by the slow oxidation of oily matter. 


\section{Sub-order V.-Heteromera (heteromerous beetles)}

Fore and middle legs with five-jointed tarsus, hind legs with four-jointed tarsus.

Family Tenebrionidæ (darkling beetles). Mostly darkcoloured, often ground-dwellers, with soldered elytra.

The meal-worm (Tenebrio molitor) is a well-known pest in mills and granaries; it is long, narrow, and rust-coloured, with small head, and pointed behind; there are three pairs of rather short thoracic legs and two minute appendages on the last segment. These larvæ are bred by bird-fanciers as food for captive birds.

Family Cantharidæ (oil-beetles). In the only common British species the adult is incapable of flight and the wingcovers do not meet. The blister-beetles of pharmacy belong to this family.

\section{Sub-order VI.-Phytophaga (leaf-eating beetles)}

All the tàrsi apparently four-jointed.

Family Cerambycidæ (longicorns). Body often elongate and parallel-sided, wing-covers marked by a regular pattern of fine hairs. Antennæ long.

Family Chrysomelidæ (leaf-beetles). Antennæ often long. Elytra usually polished. Less elongate and smaller, as a rule, than Cerambycidæ.

The mustard-beetle or black-jack (Phcedon armoracice) is a broadly oval small beetle $3-3.5 \mathrm{~mm}$., of metallic blue or green and black colour. The elytra are marked with rows of minute punctures. The larvæ are black-headed, warty, rather hairy, and feed in numbers together on the leaves. They pupate in the earth, and emerge as beetles about a fortnight later. There is more than one brood in the season. During winter they shelter in crevices, or among reeds. This beetle attacks rape, kohl rabi, and other Cruciferæ, as well as mustard. Mustard is liable to be injured by the turnip-flea, the turnip blossom-beetle (Meligethes) and weevils (Ceutorhynchus), as well as by the proper mustard-beetle.

The asparagus-beetle (Crioceris aspargi) is elongate, blueblack, with red thorax bearing two spots, elytra yellowish, with dark bands, longitudinal and transverse, forming a kind of 
cross. 5-6 mm. long. The larva is thick, fleshy, with thoracic legs and "anal foot," slate-coloured, often covered protectively with its own slimy excrement; when disturbed, it emits an inky fluid from the mouth. The eggs are laid on the leaves and shoots of asparagus. The larva is full-fed in about a fortnight, when it enters the earth, makes a cell, and pupates, the beetle emerging in another fortnight. There may be three generations in one year. This beetle is sometimes a serious pest to asparagus growers; it is local, but often abundant where it occurs. It is hardly found in England except in the southern counties.

Family Bruchidæ (pea-weevils). Small beetles, whose larvæ live in seeds, especially of leguminous plants. There is no distinct beak, the antennx are not elbowed, and the wing-covers are short, not covering the whole abdomen.

The larva, as in Rhynchophora, is footless, or bears mere vestiges of limbs. The eggs are laid in young flowers, and the larvæ enter and feed upon the growing seeds. Before pupating they gnaw a hole which almost reaches the surface, and is only covered by a thin skin, which the emerging beetle tears open. The seeds affected can be distinguished by their lightness (they generally float in water) and by a depression in the skin, or a hole, if the beetle has already emerged.

\section{Sub-order VII.-Rhynchophora (snout beetles)}

Head prolonged into a beak or snout, with the mouthorgans at its extremity. Tarsus four-jointed, the third joint at least expanded. Larvæ usually without legs.

Family Curculionidæ (weevils). Antennæ elbowed, with long basal joint.

The most injurious and frequent pests among the weevils are the following :-

Clover-weevil (various species of Apion). The larvæ are small grubs which devour the flower-heads of clover and other leguminous plants.

Garden-weevils (various species of Otiorhynchus, see p. 44), which are often serious pests in greenhouses and vineries, or attack raspberries, strawberries, and other garden plants.

Pea-weevil (Sitones lineatus). This is sometimes found on peas in vast numbers, feeding on the leaves, which become 
notched at the edges, and at length eaten up to the veins; it feeds also on clover, vetches, and other leguminous plants. There is more than one brood, and the attack may last from early spring to late autumn.

Pine-weevil (Curculio abietis). The larva feed on stumps or felled trees of larch, spruce, and Scotch fir, or bore into the young wood, causing the resin to flow. The full-grown beetles attack the young shoots, especially of young trees, and sometimes completely bare the branches. This is a common and very injurious pest.

Apple-weevil (Anthonomus pomorum). The larvæ devour the flower-buds of apple and other fruit-trees, which never completely open, and sometimes do great damage in cidergrowing districts.

Nut-weevil (Balaninus nucum). The larvæ are not uncommon in filberts and other nuts; other species attack acorns. As soon as the nut is set the female bores a hole into it, and lays an egg; the larva feeds till autumn; and when the nut falls to the ground, enters the earth to pupate; the beetle appears in the following spring. The beak of the female beetle is a little longer than the body in this species, but shorter than the body in the male.

Cabbage-weevils (Ceutorrhynchus). Three species of weevil attack cabbages and turnips, besides other Cruciferæ. $C$. pleurostigma makes galls on the roots of cabbages and swedes; $C$. assimilis devours the pods of turnip, mustard, and other Cruciferæ; while $C$. contractus, a minute species, only I mm. long, mines turnip-leaves, much like the larvæ of the turnip-flea.

Grain-weevils (Calandra granaria). This weevil is very injurious to stored wheat; it may be recognised by the very long thorax and the curved beak; a very similar but smaller species attacks rice. The generations succeed one another rapidly, and the increase of numbers in one season may be , very great.

Family Scolytidæ (bark-beetles). Beak short. Antennæ clubbed, usually not elbowed. Mostly wood and barkfeeders.

The elm-bark beetle is described in Lesson $\mathbf{I}$.

Many species of bark-beetles tunnel beneath the bark of trees, and make radiating or labyrinthine patterns on 
the surface of the wood. They generally belong to the Rhynchophora, and either to the family Scolytidæ (Scolytus, Hylesinus), or to that of Curculionida (Hylobius, Pissodes). A few beetles of other groups (Agrilus, Molorchus, etc.) make burrows beneath bark, but are less important as destroyers of standing trees.

\section{HYMENOPTERA}

Structural peculiarities.-The head is usually furnished, especially in the male, with large compound eyes, three pairs of simple eyes, and long antennæ which can be moved briskly. The waist is usually narrowed for greater flexibility, but there is a section of the order with sessile abdomen. The wings are membranous, narrowed at the base, with few radiating veins, and usually connected during flight by a row of hooks on the fore edge of the hind wing, which catch a fold or rim on the margin of the fore wing, and so keep the web extended. In large Hymenoptera there are expansions of the air-tubes in the abdomen, which increase the buoyancy of the insect. In ants the workers are wingless, and the fertilised females lose the wings previously used for flight. The mouth-parts are primarily adapted for biting, but may become suctorial as well, by the prolongation of a kind of tongue (see p. 84). The females are nearly always provided with an ovipositor, for laying the eggs in narrow spaces. The ovipositor may be converted into a saw, a borer, or a sting, all of which are present in females only.

Winged Hymenoptera are often brightly coloured, and in the stinging families black and gold are frequent colours. Bands of black and gold, with clear wings, rapidly vibrated, and the habit of poising over flowers in the sun, will give to any insect the appearance of a wasp or bee, and this fact is taken advantage of by flies, moths, bugs, and beetles, certain species of which mimic (of course, unconsciously) the widely known and dreaded stinging Hymenoptera.

The ovipositors of insects.-The last segments of the abdomen are often modified for purposes of reproduction in both male and female insects. We shall here shortly consider some of the special forms which these segments 
may assume in the female. In many Dipterous female flies the hindmost segments become slender, and may either be protruded considerably, or telescoped into the body, except when actually employed in egg-laying. In a female blow-fly there is such a telescopic tail, while in the wheat-midge or bot-fly it is more or less protruded at all times. There may be three or four segments thus narrowed, and the last may have the dorsal and ventral plates opposable and capable of grasping. Such an apparatus is called a "tubular ovipositor," but it is to be remarked that it is traversed by the intestine, which at once distinguishes it from the second, or true ovipositor, next to be described.

In many Orthoptera, Hemiptera, Odonata, and Hymenoptera there are three segments at the end of the abdomen (the 8th, 9th, and roth, as commonly reckoned*), which bear peculiar limb-like, and sometimes jointed projections. In a cockroach the 8th segment bears an anterior pair of appendages, and the $9^{\text {th }}$ two posterior pairs. The anterior pair enclose the others, and underlie them, forming the lower jaw of a forceps, whose upper jaw is formed by the two posterior pairs. This forceps can be used to grasp the eggs as they issue from the oviduct, and to deposit them in a place of safety. What appear to be the same parts are borne upon the same segments in a bee, but when fully developed, they take a different form, and become adapted to totally different functions. The anterior pair, borne on segment eight, furnish the darts, the outer posterior pair the sting-palps, and the inner posterior pair fuse to form the guide. In Sirex the anterior pair form the darts, the outer posterior pair the valves, the inner posterior pair the guide, while the palp-like organs seen on the last segment answer not to the sting-palps of the bee, but to the cerci of the cockroach. In a saw-fly again, the saws are the darts of the bee's sting, and the guide is still to be found; the two-jointed, hairy pieces which enclose the saws answer to the valves of Sirex, and the sting-palps of the bee. Lastly, the piercing ovipositor of an Ichneumon

* It is not 'so easy as might be supposed to count the segments of an insect's abdomen. Segments may be lost during development at the fore end of the abdomen, and what appears to be a single segment may turn out to be a fusion of two or even three segments. 
shows the very same parts. It has been long debated whether the paired constituents of the ovipositor represent limbs or not. This is certainly more than can be affirmed at present; recent study of the early stages of development complicates instead of simplifying the problem, and we know little or nothing of the original form and function of the parts of the ovipositor.

Life-history.-All Hymenoptera are metabolic. The larvæ of saw-flies travel in search of food, and have the form of caterpillars, with much resemblance to those of Lepidoptera. They differ, however, in the number and position of the pseudopods (false feet). The larvæ of the wood-wasps, being unable to leave their galleries, have only vestiges of limbs. All the petiolate Hymenoptera (with narrowed waist) produce footless larvæ, which depend for food upon the exertions or the forethought of the parent. Here, as in Diptera (p. 8I), high intelligence and activity in the parent may bring about simplification, even amounting to degeneration, in the larva. This is one extreme of a series which includes many grades. The other extreme is found in insects where there is no transformation at all, and where the larva runs about and feeds after the manner of its parent, from which it differs only in size (Thysanura and Collembola). The Hymenopterous pupa is inactive, free-limbed, and usually enclosed in some kind of cocoon or cell.

Parthenogenesis-i.e. reproduction by the female without the co-operation of the male - is frequent, the unfertilised eggs, contrary to what is observed in Hemiptera, usually yielding males only. The parthenogenesis of Hymenoptera is not, however, of this kind only. Sometimes it yields only males, or only females (certain gall-flies never produce males at all), sometimes both males and females in a regular succession of sexual and asexual generations. One species of gall-fly (Cynips) found on the oak exhibits an alternation of unisexual and bisexual generations. The winter eggs produce females only; these in summer form galls, from which male and female flies proceed, and thus the fertilised winter eggs are produced. The two generations differ structurally, and are contained in galls of different appearance. Parthenogenesis seems to be connected, like viviparous reproduction, with abundance of food. It is observed to occur where the 
season of the year, or a store laid up by the parent, provides an unlimited supply for the new generations. Then, it would appear, the ordinary process of reproduction may safely be abridged. Hard conditions, on the other hand, such as scarcity of food, or low temperature, require the reproduction of fertilised eggs. It is generally believed that the queen-bee has the power of producing either fertilised (female) or unfertilised (male) eggs at pleasure, and that the worker-bees can transform the larva of an ordinary worker into a queen by a change of food; the latter power is well authenticated, and finds a parallel in other social insects (Termites).

Mode of life, etc.-Bees, wasps, and ants furnish the most familiar examples of insect-communities. Division of labour, either among the members of a family or of a colony, has at length resulted in the establishment of three kinds of individuals (males, females, and workers). Bees and ants are remarkable for the complexity of their social organisation, and for the many highly developed instincts which they employ for the good of the whole society. Only the Termites, among nonHymenopterous insects, exhibit so well ordered a common life.

Hymenoptera resemble in their external features some of the miscellaneous collection of insects called Neuroptera, but there is no proof of close relationship between the two orders. The wings of Neuroptera, except in some minute forms, are intersected in several directions by veins, so that a great many small polygonal cells are produced; in the Hymenopterous wing the number of the cells is limited. In Neuroptera the waist is not narrowed, as in the majority of Hymenoptera; and the first abdominal segment is not united with the thorax.

The simplest and most primitive Hymenoptera are those with sessile abdomen (wood-wasps, saw-flies, etc.). A few of these are gall-makers. Then comes the family of the gall-flies (Cynipidce), many of which lay eggs in the tissues of living plants, where the irritation sets up abnormal growths. All vegetable galls are not, however, produced by Hymenoptera. Some are due to the attacks of Hemiptera (Aphis, Phylloxera), Diptera (Cecidomyide), Coleoptera (some weevils) or Acarina (Phytoptus). Some Cynipidæ are parasitic on other insects. These lead up to the Ichneumons of various kinds. The ruby-wasps (Chrysidida), and perhaps the Braconidæ, among 
the Ichneumons, make a kind of transition to the bees, wasps, fossorial or digging Hymenoptera, and ants, which constitute the aculeate or stinging Hymenoptera. We can roughly picture the relations of the different families by putting the wood-borers and saw-flies in the middle, and grouping the rest outside according to our notions of their affinities.

\section{The Families of Hymenoptera}

Hymenoptera are divisible into three sub-orders:-(I) Sessiliventres, with sessile abdomen; (z) Parasitica, with petiolate (stalked) abdomen, but no sting ; (3) Aculeata, with petiolate abdomen and sting (usually). If the sting should be wanting, an aculeate form can generally be recognised by having the trochanter undivided; it is nearly always two-jointed in the Parasitica.

\section{Sub-order I.-Sessiliventres}

Family Siricidæ (wood-wasps or horn-tails). The female has a long ovipositor, which projects externally. The trochanter is two-jointed. The larvæ live in the wood of trees (see Lesson $2 \mathrm{I}$ ).

Family Tenthredinidæ (saw - flies). The female is usually furnished with a pair of saws, which are employed in egg-laying. The trochanter of the hind leg is double. The larva often superficially resembles a Lepidopterous caterpillar, but has usually more numerous prolegs; there is always one on the second abdominal segment of a saw-fly larva, if it has prolegs at all; while a Lepidopterous caterpillar never has prolegs on that segment.

The gooseberry saw-fly (see Lesson 20 ) is a familiar example of Tenthredinidæ.

The pine saw-fly (Lophyrus pini) does great damage in the larval stage to pine-woods. The male fly is only about $6 \mathrm{~mm}$. long; but the wings are relatively long; the antennæ are pectinate on both sides; the body is black, but part of the legs is yellow. The female fly is larger by a third, and pale yellow, with black on the head, thorax, and centre of the abdomen. The larva may be $25 \mathrm{~mm}$. (I in.) long; it has eleven pairs of feet, and is greenish-yellow, with darker spots along the sides. The eggs are laid in spring on the 
leaves of pines. The larvæ live socially, feeding on the leaves and young shoots, and resting on the leaves, with the head bent to one side. In July they form relatively small cocoons (about $6 \mathrm{~mm}$. long) on the leaves or twigs, from which the flies emerge a fortnight later. A second brood is then produced, which, when full-fed, enters the earth, or hides in fallen leaves, moss, etc., about the roots, and yields the flies of spring. But larvæ of the early brood occasionally pupate in the earth, and the second brood may remain long unchanged underground. Several other species of Lophyrus are found on pines. Trees which are well exposed to light and air are more often attacked than others.

The turnip saw-fly (Athalia spinarum) is best known in the larval stage. The eggs are laid in May or June in slits on the margin of turnip-leaves. The larvæ resemble small black caterpillars, and are hence called "blacks," "niggers," etc. They feed in great numbers on the leaves of the turnip and other Cruciferæ, gnawing the edges, and at length leaving only the larger veins. They have eleven pairs of feet, and are at first pale, then green, and finally dark, except beneath and along the side, where there is a pale stripe. They are fond of warmth, and feed most busily in hot weather. Young larvæ, when disturbed, let themselves down by a thread; older ones drop to the ground. They become full-fed in about five weeks, and are then $17 \mathrm{~mm}$. long. They enter the earth, make a silken cocoon, and pupate. A second brood of flies appears in August. The autumn larvæ enter the earth, and remain unchanged till spring, when they pupate, turning to flies in early summer. The fly is $7 \mathrm{~mm}$. long, of orange-yellow colour, with the head, part of the thorax, and the extremities of the legs, black. The wings are yellow at the root and black along the fore edge of the fore wing, a coloration very common in saw-flies.

The corn-saw-fly (Cephus pygmaus) differs in some particulars from other saw-flies, though it has the characteristic saws; it probably represents a primitive section of the family. The fly has an elongate thorax and a pointed abdomen; it is yellowcoloured, and $7 \mathrm{~mm}$. long. The eggs are laid on young stems of corn, and the larvæ which issue from them are soft, yellow, and apparently footless grubs ; on close examination, however, minute thoracic legs can be discovered. A larva eats its way 
up the inside of the growing haulm, and when full-fed, descends to near the ground, where it girdles the haulm, biting it nearly through, so as to provide for its own escape as a fly. Then it descends lower still, makes a cocoon, and winters below the surface, changing to a pupa in May, and appearing as a fly when the corn has gained a fair height. 'The girdled haulms are greatly impoverished and easily snap across in a wind. Though the corn-saw-fly is a serious pest on the Continent, and common in Britain, it rarely does great damage here.

\section{Sub-order II.-Parasitica}

Family Cynipidæ (gall-flies). Small, sometimes very small flies, which as larvæ inhabit galls or dwell parasitically in the bodies of other insects. A variety of galls are formed on the oak, and one is common on rose-trees. Cynips tinctoria forms galls on Quercus infectoria, which are known in commerce as Aleppo, Turkey, or Levant galls, and are largely used in tanning, dyeing, and ink-making.

Family Proctotrypidæ. Ichneumon-like parasites, many of them egg-parasites.

Family Chalcididæ. Gall-makers or parasites. To this family belong the very curious fig-insects (Blastophaga) which are essential to the pollination of the cultivated fig. * The females are winged and the males wingless, a singular exception to what is found in other insects (see pp. 78-8r).

Family Ichneumonidæ (the true ichneumon-flies. See Lesson 22).

Family Braconidæ. Ichneumon-like parasites. It is to be remarked that the habit of laying eggs in the bodies of other insects seems to have been acquired independently by distinct families of Hymenoptera; also that there is no sharp distinction between gall-makers and insect-parasites; some families include both.

\section{Sub-order III.-Aculeata}

Family Chrysididæ (ruby-wasps). These are small, brightcoloured, and very active insects, which usually lay their eggs in the cells of other Hymenoptera.

* See a very full and interesting report on Smyrna fig-culture in the United States, by Dr L. O. Howard (Year-book of U.S. Dept. of Agriculture, 1901). 
Family Apidæ (bees). Clothed with feather-like hairs. the first joint of the hind foot (tarsus) is lengthened and sometimes expanded in width also. No wingless forms occur. Social (with workers) or solitary.

The hive-bee is described in Lesson 19.

Family Fossores (digging-wasps). In this family the wings are not folded, the segments of the waist are not unequally thickened, and there are only two kinds of individuals (males and females) in each species.

Family Diploptera (true-wasps). The fore wings are folded lengthwise when at rest. Some wasps are solitary, others social, living in communities of males, females, and workers.

Family Formicidæ (ants). The antennæ are elbowed. The first abdominal segment is joined to the thorax; the second is small, mobile, and thickened in the middle ; the third may also be narrowed in one sub-family, the workers of which sting. Ants live in communities of males, females, and workers, the workers being always wingless. The larvæ are footless grubs reared by the workers.

No solitary ants are known; they live in communities, which are in many respects the most completely organised known among animals. Though the society provides for its various needs by division of labour, sometimes carried to an extraordinary point, and by the industry and devotion of its members, the intelligence of the individuals is not remarkable. With very few exceptions the society consists of at least three kinds of individuals, males, females, and workers (imperfect females).* The males and females are winged, the workers wingless. As among bees and wasps, the workers are incomplete females, which have not altogether lost the power of laying eggs, but cannot be fertilised, and therefore produce only males. In summer the development of a new generation, from egg to imago, only occupies a few weeks, but in winter the larvæ remain long unchanged, and do not undergo their final transformation till the ensuing warm season. Ant-larvæ are footless grubs; the pupæ, popularly called "ant-eggs," are either naked or enclosed in cocoons. The winged flies, which are always male or female, are reared in the ant-hill, escape in swarms on hot summer days, and mate in the open air. The males then perish; the females cast or bite off their wings, and

* The slave-making Anergates is believed to have no workers. 
seek shelter. Now and then, it would appear, one is permitted to join a colony already existing; cases are also known in which a female has entered the ground, laid eggs, and reared workers. The great majority, even of the females, perish of starvation, or are eaten by birds. One ant-hill may contain a number of queens, which live peaceably together. The workers perform all the ordinary work of the community, constructing and defending the ant-hill, collecting food, and rearing the young. Many ants dig their nests in the earth; a few build as well as excavate. Some common English ants raise a dome over the nest, and cover the dome with little sticks and fallen pine-needles. Ants devour insects, fruit, the honey of plants, and the honey-dew of aphids; some may almost be said to cultivate plants for food; thus the harvesting ant of Texas feeds upon the seeds of Aristida ("ant-rice"), and allows no other plant but this to grow upon cleared spaces near the nest; some ants of southern Europe lay up grain for the winter, and know how to hinder it from germinating in the damp, underground granaries. The worker, having collected and perhaps partly digested some food, can regurgitate a part to feed the larvæ, the queens, or even other inmates of the ant-hill, which are not ants at all. Particular species of ants exhibit very remarkable instincts. A few make slaves of the workers of other species; some may be said to have domesticated aphids for the sake of their honey-dew.

Ants have acted upon the structure of many flowering plants, though far less powerfully than bees and moths. Being unable to fly, the honey-loving worker-ant can only creep from flower to flower, and if allowed free access, would nearly always transfer the pollen to another flower on the same plant. Such close fertilisation does not meet the wants of the plant, which requires cross fertilisation. Further, the ant, being accustomed to nip with its jaws any object which is passed into its lurking place, would soon deter bees and moths, the visitors which are really profitable to the plant, from exploring the flowers. It is therefore best that the plant should exclude ants altogether, or at least hinder their access to the flowers. Sticky glands, slippery and inclined surfaces, moats of water, self-closing or very narrow corollas are among the devices which hinder the honey-loving ant from rifling the flowers which it cannot benefit in return. In hot 
countries, where ants abound beyond anything that we have experience of, the flowering plant and the ant sometimes cooperate and help one another, the ant defending the plant from mischievous insects, and the plant providing the ant either with sugary food, or a place of shelter, or both. The antshelters, developed out of the living tissues of the plant, are sometimes large and complete structures well suited to the habits of the insect, and serving no other purpose than that of lodging them.

Characteristic structures of ants are the petiole or stalk of the abdomen (p. 229), the elbowed antenna, the 5-jointed tarsus, ending in a pair of strong claws, and the comb on the fore tarsus. The comb is similar to that of bees, and is used to keep the body clean. The sub-family of Myrmicidæ have a sting; in other ants the sting is little developed and not functional ; poison may be secreted in stingless ants, but it is shot out instead of being injected into a wound.

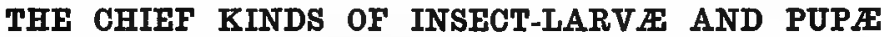

Insect-larvæ are distinguished from worms and other nonarthropod animals by their jointed thoracic legs (not always present), as well as by their tracheal tubes and spiracles, which are very nearly universal. Other Arthropods, which may happen to resemble insect-larvæ in general form, differ as under:-Centipedes (Myriopoda) have many pairs of jointed legs. Woodlice, which are terrestrial Crustacea, have many pairs of jointed legs, and no tracheal tubes or spiracles. Mites and ticks (Arachnida) have four pairs of legs, and the head, instead of being distinct from the body, as in most insect-larvæ, is fused with the thorax.

Three types of insect-larvæ are readily recognised, but the existence of intermediate forms renders strict definition almost impossible. These three types are:-

I. The long-legged larva, such as that of the cockroach and of many predatory beetles. The head is well-developed, with biting jaws, and often with long antennæ. The thoracic legs are long, and several-jointed. There are no pseudopods. The last segment often bears a pair of long, many-jointed appendages (cerci). The body is usually defended by dense chitinous armour, or, at least, by dorsal plates. This larva 


\section{$23^{2}$ INJURIOUS AND USEFUL INSECTS}

is sometimes called the Campodea-larva, because it nearly resembles Campodea and other adult insects of the lowest grade, which undergo no metamorphosis, and are probably the most primitive of still-surviving insects. This larva occurs in the ametabolic orders, as well as in Coleoptera and Neuroptera.

The two following larvæ are special modifications of the long-legged larva.

The Lamellicorn or Chafer-larva (Coleoptera). This is the long-legged larva, altered by an inactive, subterranean life. The abdomen is large and soft, especially behind, and bears no appendages. There are three short thoracic legs.

A footless larva, which differs from a maggot in having a well-developed head, with biting mouth-parts. It may be derived from the chafer-larva, or direct from the long-legged larva, and is characteristic of insects in which the larva is not compelled to travel in search of food. The best examples are found in Coleoptera (longicorns, weevils), and in those Hymenoptera which lay up food for their young, or are bred in living insects.

2. The Caterpillar. - The head is well developed, and bears biting jaws and inconspicuous antennæ. The body is soft, and often cylindrical. Three pairs of short thoracic legs, and a variable number of abdominal pseudopods, or false feet, are usual. This larva occurs in Lepidoptera, Panorpæ, and some Hymenoptera (saw-flies). It is sometimes preceded in the life-history by the long-legged larva, from which it is evidently derived.

The larvæ of caddis-worms (Trichoptera) resemble caterpillars in some respects, but have at most one pair of pseudopods, or false feet, on the last segment. They are specially adapted to aquatic life, and dwell in movable cases. Their origin cannot be traced, though they are no doubt derived in some way or other from the long-legged larva. The Nemoceran (Dipterous) larva has no jointed legs, but pseudopods, or false feet, may occur on a few or several segments. The head is either completely external and well developed, or more or less retractile into the thorax, and reduced. Some Nemoceran larvæ have no feet of any kind, and only posterior spiracles. The maggot is the extreme term of this series. 
The caterpillars of different orders may be distinguished as follows:-Lepidopterous caterpillars have never more than five pairs of abdominal pseudopods, carried on the third, fourth, fifth, sixth, and last segments, and these nearly always bear hooks. The caterpillars of Panorpæ have hookless pseudopods on all the abdominal segments. Saw-fly caterpillars have hookless pseudopods on various abdominal segments, but never on precisely those which bear pseudopods in a Lepidopterous caterpillar. The second abdominal segment always bears pseudopods in a saw-fly larva, never in a Lepidopterous one.

The following are exceptional Lepidopterous caterpillars :Geometers and some Noctuids walk by looping, and may grasp their support by the hinder legs only. They have fewer than the ordinary number of pseudopods. Some caterpillars have a forked tail, and then the last segment bears no pseudopods. Some have a dorsal horn on the last segment (Sphinges or hawk-moths). Caterpillars which burrow in wood or earth have usually horny plates on the dorsal surface of the segments, sometimes on the prothorax only. Footless caterpillars occur in a few Lepidopterous families.

3. The Maggot.-The head is reduced to a vestige, which can be completely withdrawn into the thorax, and bears neither eyes nor antennæ, nor true jaws. There are no legs or pseudopods. There is a pair of large spiracles (often the only ones) on the truncated hinder end of the body. This larva is found only among the higher Diptera.

There are three well-marked kinds of pupa :

I. The free-limbed ("incomplete") pupa.-Here the fly, more or less complete in internal structure, and usually complete externally, is enclosed in a temporary pupal skin, which accurately fits every part of its body. Each limb has its own sheath, and may be freely mobile (Trichoptera). Examples of the free-limbed pupa occur in Coleoptera, Hymenoptera, Neuroptera, Nemoceran Diptera, and Trichoptera.

2. The agglutinate ("obtected") pupa.-Herè the fly, after emerging from the larval skin, and enclosed only by the temporary pupal skin, exudes a fluid, which sets on exposure and glues down all the appendages, rendering the surface dense and shiny. Nearly all Lepidoptera and some Coleoptera (Staphylinidæ and Coccinellidæ) have pupæ of this kind. 


\section{INJURIOUS AND USEFUL INSECTS}

3. The included ("coarctate") pupa.-Here the larval skin is retained as an outer defence. Most of the higher Diptera and male Strepsiptera have pupæ of this kind.

Examples are known of pupæ intermediate between groups $\mathrm{I}$ and 2 , and between groups $\mathrm{I}$ and 3 . 


\section{IV \\ THE DESTRUCTION OR MITIGATION OF INSECT-PESTS}





\section{THE DESTRUCTION OR MITIGATION OF INSECT-PESTS}

Wherever vast quantities of the same plant are grown together, and especially where the same crop is grown year after year on the same fields, an opportunity, quite unparalleled in wild nature, is offered to vegetable-feeding insects, and no ordinary ingenuity can perfectly defend plants reared under such conditions. It is as if we created an immense vacuum, and expected to prevent the air from making its way in. No common precautions will prevent insects from multiplying prodigiously whenever abundant food is provided for them, and we must hope rather to check than altogether to stay their ravages.

German science, especially when it was a question of forestmanagement, was long looked to for the best examples of successful treatment of injurious insects. A large body of scientifically trained men, devoting their lives to the study of injurious insects, could hardly fail to learn and record much that is valuable in practice, and German books often contain original and thorough investigations of insect devastations. In other European countries the state of knowledge, for lack of an expert class, is far inferior. In England we have the useful book of Curtis on Farm Insects, but very nearly all the rest is mere compilation. Here and there old knowledge has been applied to new outbreaks, or a life-history has been studied by some isolated enthusiast, but the lack of scientific knowledge and practical experience is lamentable. In the United States and Canada, where the English indifference to scientific studies still to a great extent prevails, a long series of disasters to the crops has led to the adoption of a wiser policy. Trained Stateentomologists are now numerous in the United States, and a national Department of Agriculture, served by officers who possess both scientific and practical knowledge in a high de- 
gree, is ready to make good the inevitable deficiencies of local advisers. The defence of the crops against insects and parasitic plants, as well as the best treatment of the land, are now being studied methodically with excellent results. Two cases in which scientific method has been called in to deal with insect attacks on a great scale are worth relating in some detail for the instruction of the English farmer and his advisers. The two cases in question are the Gipsy-Moth plague in Massachusetts and the Orange Scale plague in California.

\section{THE GIPSY-MOTH IN MASSACHUSETTS *}

The gipsy-moth belongs to the same family (Liparida) as the vapourer, the black arches, or nun-moth (a terrible plague in the pine-forests of Germany), the gold-tail, the brown-tail, and the tussock moths. All agree pretty well in the dissimilarity of the sexes when adult, in the complex antenna of the male only, the sedentary habit of the female, the hairy larva, and the protective cocoon. Nearly all are indiscriminate in their food. The gipsy-moth is very common in many parts of Europe and Northern Asia, but is almost unknown in England, and is not indigenous to any part of America.

This pernicious insect was imported into Massachusetts by Professor Trouvelot, of the astronomical observatory at Harvard, who had some intention of making experiments upon the silk of various moths. The eggs or larvæ were accidentally dispersed from Trouvelot's house in Medford about r 868-69. Being aware of the ravages of the moth in Europe he gave warning that it was at large and beyond his control, but neither he nor any public officer took any adequate measures of repression. Close to his house was an extensive wood, with abundant undergrowth, and in this the insect established itself without much notice. For ten years little was seen or heard of the escaped moths, but then they rather suddenly became a serious plague in the immediate neighbourhood of Trouvelot's house. The neighbouring gardens and orchards were steadily invaded in spite of the vigorous but unsystematic exertions of the owners. Before long the larvæ covered the trees, entered

"See "Report on the Gipsy-Moth," by Forbush and Fernald (Boston, 1896). 
the houses, and began to establish themselves in the woods and parks. In the summer of 1889 they covered the pavements, crowded one another off the trees, and overran all places within a limited district, which grew wider every day. Boiling water, burning petroleum, sweeping and scraping, destroyed millions of caterpillars, but the supply was inexhaustible. The sound of their jaws was compared to the clipping of scissors. All the trees in the eastern part of the town were stripped, many were killed, and property lost value. In 1890 , when "the walls and almost every tree were almost wholly covered with nests" (egg-clusters) the matter was at last taken in hand by the public authorities. The Massachusetts Legislature voted 25,000 dollars for the extermination of the pest. The infected area, which had been supposed to be less than one square mile, was found on a preliminary and incomplete inspection to cover fifty square miles. In r $89 \mathrm{I}, 50,000$ dollars were voted, and 250 men set to work. During the first six weeks of the year three-quarters of a million egg-clusters, each of several hundred eggs, were destroyed. Spraying the trees with Paris green was a favourite remedy at this time, but it provoked opposition, and was occasionally resisted by force. Stories of arsenical poisoning in consequence of spraying were widely current. At the end of $18 \mathrm{gr}$ the moths were reported from thirty townships and from over two hundred square miles of country. Seventy-five thousand dollars were now voted for the following year, but the grant was made so late that the field-force of $\mathrm{r} 8 \mathrm{gr}$, which had become trained, was almost entirely dispersed. In September I 892 all the workers except forty were again discharged for lack of money. One hundred and sixty-five thousand dollars were asked for in 1893 , but only one hundred thousand were voted, and this so late that many of the workers had found other employment, and several weeks of the best working time were lost. In I 894 the same difficulties recurred. Only one hundred thousand dollars were voted, and three weeks of the best working time were lost. In 1895 one hundred and fifty thousand dollars were voted, but not until field-work had been suspended for three months and the workers disbanded.

In 1897 I had an opportunity of visiting the scene. The great devastation was now a thing of the past, but dead trees, sometimes in patches of many acres, showed how serious the danger had been. Cocoons and egg-clusters were still to be 
seen in small numbers. The staff, now thoroughly instructed in their duties, were reducing the moths within smaller and smaller limits, and it seemed as if extermination were within reach if an army of trained men could be kept at work for a single season. But though much was being done the public anxiety did not justify the great initial cost of thorough measures, and it was clear that the gipsy-moth might long survive in diminished numbers.

The more recent history is to be found in "The Gipsy-Moth in America," by Dr L. O. Howard, Entomologist to the United States Department of Agriculture, * and the Report on the GipsyMoth made to the Massachusetts Board of Agriculture (1899). Dr Howard reported in November I 897 that the condition of the infested territory was greatly improved, but that large colonies of the insect were still discovered from time to time, and that a thorough inspection of the border towns was called for. In the beginning of 1898 it had again been found necessary to cut down the field-force on account of delay in voting supplies, and the spring destruction of eggs was omitted. One hundred and eighty thousand dollars were voted for the year. Owing to almost continual rain spraying was comparatively ineffective. An autumn campaign of egg-destruction was carried on. The spread of the moth had been checked, and in certain directions its range had been materially narrowed, while the severity of the attack within the infested district showed distinct improvement. Two hundred thousand dollars were asked for the following year ( 1899 ). The last news received from America is discouraging. 'The appropriations for 1900 were not renewed, and the insects are once more increasing in number.

The spread of the pest was of course promoted by such local facilities as abundance of vegetable food and secure retreats. In dense underwoods the moths multiplied incredibly, and slowly spread thence in a variety of ways. The gipsy-moth, like most other Liparidæ, is an indiscriminate feeder, and, therefore (see p. 79), there is less necessity that the female moth should fly. She has ample wings, but hardly ever uses them, and what we might consider to be the most natural mode of dispersal is ineffective. The larvæ are active and move about continually, but do not undertake long excursions

$$
\text { * Bull. Dept, of Agr. No. I I, N.S. (1897). }
$$


if trees and shrubs with green foliage are close at hand. The spread of the pest to towns, villages, and farms miles away from the original centre of infection was therefore hard to explain until the circumstances were closely studied. It was then remarked that towns were more affected than villages, villages more than isolated farms, and farms more than agricultural land without houses. The moths spread by preference along main roads to populous places, which soon became new centres of infection. In the end it was discovered that the chief means of transport were the vehicles driven along the roads. Caterpillars dangling by threads were knocked off the trees, carried along by the waggon or carriage, and set down in a place where they had a fair chance of finding food and shelter. Any regular communication by road between an infected and a non-infected site was sure before long to serve as a means of transporting the caterpillars. Nor were vehicles essential. People carried the caterpillars about on their clothes, and thus unconsciously brought them into favourite places of resort, such as the grounds enclosing public monuments. In the Mount Auburn cemetery at Cambridge the trees around the graves of the national poets, Lowell and Longfellow, were so regularly supplied with fresh caterpillars that they had to be specially watched and cleared.

The methods adopted by the Massachusetts field-force have been fully set forth in the report by Forbush and Fernald already quoted. The chief means of extermination were these:

I. Destruction of the egg-clusters.-The most effectual method of destruction is heat (a temperature of not less than I 40 degs. F. or 60 degs. C. is required). The clusters may be collected in tin cans and put into a fire. If heated in an open vessel the clusters explode, and some eggs may be scattered without being harmed. In other cases a flame was directed upon the clusters in situ. Owing to the low conductivity of a mass of eggs and hair, a passing flame is not effectual. Petroleum discharged continuously from a 15 -gallon tank in the form of ignited spray was found to answer well. Creosote and tar in various mixtures are tolerably effective cold applications. In the search for egg-clusters field-glasses and pocket-mirrors were of use, the mirrors being employed to examine the under surface of a rail near the ground, or other 
surfaces not easily commanded by the eye, and also to illuminate dark recesses by reflected sunlight. Special knives, with the end of the blade bent at an angle, were much used to scrape off the clusters. Of late years spraying with crude petroleum (unignited) has been found an effectual means of destroying the egg-clusters in stone walls.

2. Destruction of the larvæ.-Several different methods were adopted:-

(A.) Banding.-Large trees, which are difficult to search, were often kept free of the caterpillars by bands smeared with a mixture of tar, printers' ink, and petroleum. The bark is smoothed, enclosed by cotton waste, and this by a narrower strip of tarred paper, the whole being then tied round with cord. The bands should be applied shortly before the emergence of the larvæ, and repainted twice a week. They should be fixed at such a height that they are not liable to be rubbed by cattle. In Germany Raupenleim, a kind of crude vaseline, is much used for smearing the bands.

(B.) Spraying.-Paris green (aceto-arsenite of copper), finely powdered, was mixed with water, in the proportion of from I to 4 lbs. to 150 gallons. The weak mixture did not injure foliage, but was too weak to kill many caterpillars; the strong mixture injured foliage greatly, and could not be counted upon to kill older larvæ. It was not expected that the larvæ would be killed by the direct application of the arsenical solution, but by feeding on the poisoned leaves. On the whole this method was pronounced "ineffective and unsatisfactory." London purple (arsenite of lime) had about as much effect as Paris green upon the caterpillars but injured the foliage more. Arsenate of lead, mixed with water in the proportion of one to five or six, was a new insecticide brought into use by the Massachusetts Board. It has proved more effective than any other arsenical compound, adhering better to the leaves, which it does not seriously injure. All these insoluble substances are difficult to apply. The mixture must be continually stirred, and the nozzles of the pumps often get choked. Petroleum emulsions and various soap-washes were found advantageous only where the larvæ were dense. In general, spraying with poisonous fluids is most successful, and least injurious to foliage if practised early in the season. Trees in blossom should never be sprayed. The blossoms are injured, the 
pollen washed off, and there is some risk of poisoning the bees and the honey.

(C.) Clearing with fire.-This was resorted to in the case of dense underwood or particularly bad infestations of woodland tracts. It was sometimes necessary to fell the trees and clear the ground completely. Where the trees are to be spared autumn is the best season for clearing.

(D.) Burlaps.-It was observed that the larger caterpillars, half-grown and over, sheltered themselves from the heat of the sun in crevices or beneath rubbish, and this suggested the laying of traps for them. Strips of 8 oz. burlap (a coarse canvas), 12 in. wide, were bound round infected trees. The canvas in rolls is carried on the shoulder, passed round the tree, cut with a sharp knife, a margin being allowed for shrinkage, tied with string along the middle of the strip, and then turned down, so that the two flaps hang from the string like a piece of linen hung out to dry. The workers visit each tree daily, and kill the caterpillars found in the burlaps. The upper flap is turned up or down on alternate days, so that it may be seen at a glance whether the tree has been examined or not. Either plan will answer, as the caterpillars generally hide between the bark and the canvas. Other traps, such as empty tin cans, or wisps of hay and straw were found serviceable, but the burlaps are the best of all in a wooded district. The labour of the frequent visits is the only drawback to this very effective remedy.

Birds were seen to devour the larvæ and moths in great numbers, but they did not destroy the eggs to any material extent. It is otherwise in Europe, where tits, wrens, and other tree-haunting birds have been observed to devour the eggs with avidity. Insect-parasites were not so numerous as in Europe.

\section{THE FLUTED SCALE IN CALIFORNIA}

About the year I 880 the orange-groves of South California seemed to be infected with a kind of leprosy. White patches appeared on the trunks and branches, which at length ran together and covered the bark, the leaves turned yellow, and no fruit could be ripened. The plague spread with rapidity, and all the time-honoured remedies were found to be in- 
effectual. It was soon made known that the symptoms described were due to the attack of a scale-insect, known in America as the fluted scale, or cottony cushion-scale (Icerya purchasi).

This formidable plague gradually increased its range, in spite of the vigorous use of poisonous washes. It was not till I888 that an effectual remedy was found. The late C. V. Riley, Entomologist to the United States Department of Agriculture, had anxiously considered the ways of checking the fluted scale. He found out that it came from Australia, where it infested the bushes called wattles (Acacias), that it had been introduced into California about $\mathbf{r} 868$, probably on Acacias, that in its native country it was not a serious plague, although no remedies were employed. He concluded that it must be kept down in Australia by natural enemies of some kind, which did not exist in California, and that the real policy was to discover and import these enemies, whether parasitic or predatory. Official difficulties hindered the execution of the plan. Funds were not to be had, and the rules of the treasury required that money granted for scientific experiments in agriculture should be expended only within the national territory. It was not till 1888 that he found himself able to act. In that year Congress voted money for sending public officers to the Melbourne Exhibition. Riley was able to send a trained entomologist, Albert Koebele, to visit Australia, examine the gardens, and report. He found that the fluted scale, though widespread, was kept in check by several insect-foes. The most promising of these for Californian purposes was considered to be an Australian lady-bird known to naturalists as Vedalia cardinalis. This beetle, both as larva and adult, greedily devours the scaleinsect and its eggs, preys upon no other species, and is very prolific. Koebele was diligent in procuring an abundant supply both of Vedalia and other insects destructive of the fluted scale. He kept them torpid in the ice-house of the steamer, and landed them in California without loss. The lady-birds were soon distributed, and found plenty of occupation. In a year and a half they had practically rid California of the pest.

By a curious coincidence, almost at the same time that the Vedalia was, by the foresight of Riley, brought to the help of the Californian orange-growers, the same insect was accidentally introduced into New Zealand, where the fluted scale was making 
great ravages. The infested district was cleared without labour or cost in about two years.

The treatment of the fluted scale by the importation of Vedalia is now widely recognised as one of the most beneficent applications of scientific method to the alleviation of public ills.

\section{REMEDIES FOR INJURIOUS INSECTS}

\section{Washes and Sprays}

These are either laid on with brushes or hand-sprinklers or spraying machines. The most effective and far-reaching machines are of American construction.

Spraying is sometimes the only expedient that can be resorted to, as, for instance, when the insects attack the leaves of high trees. Its effect may be greatly diminished if the leaves throw off liquids easily. The destruction of insects by direct contact is not so much aimed at as the poisoning of their food. There is often serious risk of injuring foliage, young shoots, or fruits. The strength of solution can seldom be precisely given, as much depends upon the plant affected, the insect which infests it, and other variable circumstances. The following insecticide solutions have proved particularly useful in American practice :-

I. Arsenical solutions.-For detailed and practical instructions on the use of arsenical and other preparations the reader may advantageously consult C. L. Marlatt's "Important Insecticides" (Farmer's Bulletin, No. 127). This is issued by the United States Department of Agriculture, and distributed free in the United States. A condensed statement of part of this pamphlet follows.

The chief arsenical compound in common use is Paris green (aceto-arsenite of copper). Scheele's green (copper arsenite) and lead arsenite are less known. Mr Marlatt points out that Scheele's green is a finer powder than Paris green, and therefore more easily kept in suspension; it is less harmful to foliage, quicker in action, and costs only half as much. Lead arsenate is safer for use on delicate plants than any other arsenical. The fresh-prepared mixture adheres better to foliage than that which has been dried and repulverised. 


\section{INJURIOUS AND USEFUL INSECTS}

Arsenicals are applied as spray, or, in the case of certain low plants not immediately to be eaten, as a dry powder. The mixture used in spraying is $\mathrm{I} \mathrm{lb}$. to I00-250 gallons of water

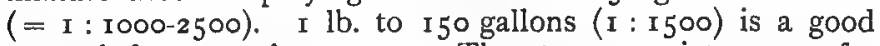
strength for general purposes. The stronger mixtures are for such foliage as that of the potato, and the greater dilutions for the more tender foliage of the peach or plum. The poison should be first made into a thin paste with a small quantity of water, an equal amount of quicklime being added to take up free arsenic, and remove or lessen the danger of scalding. An excess of lime will do no harm. The poisons thus mixed should be strained into the spray-tank or reservoir, care being taken that all the poison is pulverised and washed through the meshes of the strainer. The use of the lime is especially desirable in the case of the peach and plum, the foliage of which, particularly the former, is very tender and easily scalded. To the stronger foliage of the apple and most shade-trees Paris green may be applied without danger at the strength of $\mathrm{I} l \mathrm{lb}$. to 150 gallons of water.

The arsenate of lead is prepared by carefully pulverising and combining, in a small quantity of water, the weight of the two ingredients indicated by the capacity of the spray-tank. The chemical combination is effected in a few minutes, and the resulting milky mixture is ready for the tank. Lime is not needed with this arsenical.

It must be remembered that these arsenicals are very poisonous and should be so labelled. If ordinary precautions are taken there is no danger to man or team attending their application. With some individuals the arsenate of lead, when in strong mixture, affects the eyes; but this is unusual, and, with a little care in spraying, the mist need not strike the operator at all.

The poison disappears from the plants almost completely within twenty to twenty-five days, and even if the plants were consumed shortly after the application an impossible quantity would have to be consumed to get a poisonous dose. To illustrate, in the case of the apple, if the entire fruit were eaten, core and all, it would take several barrels at a single sitting to make a poisonous dose (Riley), and with the cabbage, dusted as recommended above, twenty-eight heads would have to be eaten at one meal to reach this result (Gillette). It is prefer- 
able, however, to use other insecticides in the case of vegetables soon to be eaten, and thus avoid all appearance of danger.

The strongest repugnance is felt in many parts of England to any kind of application of arsenic to food crops. A very similar feeling formerly prevailed in the United States, but has been dispelled by the frequency of arsenical treatment, and the practical absence of injury to man or the higher animals.

2. Petroleum emulsion.-Crude petroleum, applied as fine spray is occasionally useful-e.g. in destroying egg-clusters of the gipsy-moth in stone walls. For application to living plants an emulsion may be employed, such as the following:-

Soft soap is dissolved in twice its bulk of boiling water. While the solution is still boiling hot petroleum is added equal to half the bulk of the soft soap, and the whole thoroughly mixed with a force-pump. The emulsion is diluted immediately with an equal bulk of cold water and kept till required. It may now be used as a wash for dormant wood, but should be further diluted before application to foliage or young wood (say two parts of water to three of emulsion).

3. Soap and tobacco solution.-One part of soft soap should be dissolved in sixteen parts of hot water: when cold, add one part of strong tobacco decoction. For application to dormant wood, or (further diluted) to growing tissues and to earth containing root-feeding larvæ.

4. Resin soap solution.-Broken up resin is dissolved with washing soda and boiling water in a kettle. Three parts of soda will dissolve about four parts of resin. Enough water should be added to cover the resin, and the soda should be dissolved before heat is applied. When the resin is completely dissolved and a clear, brown mixture $(a)$ obtained, more water may be added, little by little, with constant stirring, till the solution is sufficiently dilute for use. If the strong solution $(a)$ is diluted with twice its bulk of water it can be kept indefinitely, and further diluted before application. Fifteen parts of water to one of resin make a strong wash, twenty parts of water to one of resin a wash suitable for application to living tissues.

This preparation is particularly useful in the case of Aphids and other soft-bodied, sedentary insects.

Poisonous sprays should not be applied to fruit-trees in bloom, as there is risk of destroying bees and other useful insects, as well as of damaging the flowers: 


\section{INJURIOUS AND USEFUL INSECTS}

\section{Dusting}

Soot, powdered quicklime, etc., may be applied as dust. Paris green has been much used in this way in America. Mr Marlatt ("Important Insecticides") recommends the following method:-

A pole five to eight feet long and about two inches in diameter is taken, and a $\frac{3}{4}$-inch hole bored through it within six inches of each end. Near each end is securely tacked a bag of "8-ounce Osnaburg cloth," one foot wide and eighteen inches to two feet long, so that the powdered poison may be introduced into the bags, with a funnel through the holes at the end of the pole. The bags are filled with undiluted Paris green, and the apparatus is carried on horseback through the fields, dusting two or four rows at once. The shaking induced by the motion of the animal going at a brisk walk or at a trot is sufficient to dust the plants thoroughly, or the pole may be jarred by hand. The application is preferably made in early morning or late evening, when the dew is on, to cause the poison to adhere better to the foliage. From one to two pounds are required to the acre, and from ten to twenty acres are covered in a day. The occurrence of heavy rains may necessitate a second application, but frequently one will suffice. This simple apparatus, on account of its effectiveness and cheapness, is employed throughout the cotton belt to the general exclusion of more complicated and expensive machinery. The cost frequently does not exceed twenty-five cents per acre, and the results are so satisfactory that the leaf-worm is no longer considered a serious factor in cotton culture. If small garden patches are dusted with poison by this or similar means from bags or with hand bellows it is advisable always to dilute the poison with ten parts of flour, or preferably lime, and for application to vegetables which will ultimately be used for food, as the cabbage, one ounce of the poison should be mixed with six pounds of flour or ten of lime, and dusted merely enough to show evenly over the surface. Arsenicals should not be applied to lettuce or other vegetables the fresh leafage of which is eaten.

\section{Soil-poisoning}

Gas-lime is often used with effect to destroy underground larvæ. It should be evenly distributed on land that has 
been ploughed, and may with advantage be worked into the soil by the harrow or grubber. Two tons an acre are perfectly safe (much larger quantities have been used with good results).

\section{Poisoned Bait}

Mr Marlatt ("Important Insecticides") recommends laying poisoned slices of potato or bunches of clover in fields or beds infested by insects. The bait should be dipped in a strong arsenical solution, or dusted thickly with a dry arsenical, and renewed as soon as it becomes dry. This is said to succeed with wireworms and surface-larvæ.

\section{Weed Destroying}

Weeds in neglected corners are often nurseries for insectpests; fallen trees harbour bark - beetles; stubble and chaff protect corn-ravaging flies during the winter. Prompt destruction of rubbish of every kind is a precaution of no small value. Compost-heaps made-of weeds often become breedingplaces for insects, and when the heap is carted on to the land as a top-dressing, the eggs and larvæ are distributed as well: The heaps should be turned over now and then, so as to prevent grass growing on them, and forming a shelter.

\section{Traps}

Slices of potato or turnip, and strips of canvas ("burlaps") fastened round tree-trunks (p. 243), come under this head. Wood-piles, old sheds, etc., are often excellent insect-traps, and lodge many pupæ; but, being nearly always left unsearched, they favour instead of hindering the enemy. Rapedust is very attractive to wire-worms, and may be used as a trap.

\section{Grease and Tar-Bands}

Fastened about trees, to prevent larvæ ascending from the ground (p. 242).

\section{Mechanical Disturbance}

Trampling, harrowing, rolling, rope-drawing, and sheepdriving have been found effective where multitudes of insects 
are feeding upon low plants. Shaking of boughs is sometimes a means of dislodging great numbers of insects, especially beetles, which are to be caught in sheets and destroyed immediately.

\section{Hand-Picking}

In a few cases this is the least laborious way of removing insects. Nothing is so effectual a remedy against the gooseberry saw-fly as picking off every leaf that has eggs on it.

\section{Change of Crop}

This is often the best remedy for an obstinate pest, and is a useful preventive, even when insects are not troublesome.

\section{Encouragement of Crop}

Where a young crop is threatened by the attacks of insects good manuring will often help it through until it has strength enough to stand the loss, or until the insects cease to feed.

\section{Insectivorous Bírds}

Birds of all kinds are best let alone where only field-crops are grown. Nets are often necessary to protect fruit.

\section{Insect-destroying Fungi}

Inoculation with bacteria or moulds sometimes, under natural conditions, sets up deadly disease among caterpillars, and this has suggested that destructive caterpillars may be infected by laying infected matter among them. The method has not yet been sufficiently experimented with to give results of practical importance.

\section{Egg Destruction}

Where the eggs of an insect-pest are collected in visible patches they may sometimes be destroyed very rapidly with fire, petroleum, or creosote (p. 24I). 


\section{Spraying Machines}

Purchasers will find detailed and recent information in the publications of the United States Department of Agriculture. See, for example, the article by Dr L. O. Howard in the Yearbook for 1896 , which gives descriptions and figures of the chief machines now in use.

\section{THE VALUE OF EXPERT KNOWLEDGE}

Remedies for injurious insects should not be applied blindly, without considering how the enemy can be best attacked. Does the egg, the larva, the pupa or the fly furnish the best opportunity? The way in which the insect feeds must also be taken into account. A leaf-eating larva may be destroyed by poisoning its food, but this is not the way to treat sucking insects, which feed upon nutritive fluids drawn from the inner tissues. "Contact poisons," such as petroleum emulsions or caustic washes, will be more promising in such cases as these. All farm and garden insects breathe by spiracles, and where other means fail, they can generally be forced to inhale poiśonous vapours. Liquids, even if non-poisonous, may destroy by obstructing the spiracles, and soot, as well as other fine powders, is sometimes effective in the same way. The structure and mode of life of the plant attacked must also be studied. It is in most cases useless to spray leaves which throw off all.liquids, and poisons, incautiously administered, may do more harm to the crop than the insect pest.

The value of special knowledge and experience in dealing with destructive insects is so great that in the United States insect-killing is often practised as a profession, and experts undertake the treatment of trees and crops at a fixed charge. It is much to be desired that the practice may spread to other countries. The cost of knowledge and skill is often insignificant in comparison with the advantages secured. The cotton crop of the United States was formerly, in bad years, injured to the value of thirty million dollars by the leaf-worm, but in consequence of treatment with arsenicals such losses are now unknown. The fruit-growers of Cali- 


\section{INJURIOUS AND USEFUL INSECTS}

fornia have been saved from ruin by the discovery of methods of exterminating scale-insects, and the new industry of dried figs (which entirely depends upon fertilisation by a minute Hymenopterous insect) has been set up in California by the labours of the Department of Agriculture.* Pasteur's experimental researches upon the diseases of silkworms restored an industry of the first importance, which was threatened with total extermination. The damage done to British hides by the warble-fly has been estimated at several million pounds a year, but so inadequately has this insect been studied that we do not know for certain where the eggs are laid, and which part of the ox is to be protected from the fly. England needs such national laboratories as those of the Department of Agriculture in Washington, or the Departments of Agriculture and Forestry in the Gesundheitsamt in Berlin. The cost of these establishments is much more than repaid by the benefits which they secure for agriculture, and we ought to regard it as one form of that wise expenditure which is true economy.

* Dr L. O. Howard on Smyrna Fig Culture in the United States. Yearbook of the United States Department of Agriculture, 1900, p. 78. 


\section{N D E X}

Abraxas, 202

Acridiidæ, 190

Adephaga, 2I 4

Agriotes, 37

Alder-fly, I95

American blight, 158

Anopheles, I 28

Anoplura, I94

Ants, 1 57, 229

Apanteles, 106

Aphaniptera, 212

Aphidius, 108

Aphids, I 53, 192

Aphis, I53, 192

- turnip, I 53

Apis, 82

Apple-tree, mussel-scale of, 162

Arachnida, 5, 23I

Arctia, 58

Arthropods, 3

Asparagus-beetle, 219

Aspidiotus, 165

Athericera, 144, 209

Bateson on variability of earwigs, I76

Bee, 82

- sting of, 88, 98, 106, 223

Bee-like insects, 82

Beetles, 25

Blattidx, I 89

Blow-fly, 136

Bombyces, 199

Bombyx, 68

Bot-flies, 2 I I

Bot-fly, I44

Brachycera, 209

Braconidx, 108
Burgess on mouth of Dytiscus-larva, 36

Biisgen on honey-dew, I 56

Butterflies, 198

Cabbage-moth, 201 white butterflies, 62

Caddis-flies, 166

- - worms, I66

Caterpillar, dissection of, $5 \mathrm{I}$; how to inflate, 55 ; how to keep, 58 ; legs of, 96 ; characters of, 232

Calliphora, I 36

Chalcididx, IO8, 228

Chermes, I92

Chinese candle-wax, I64

Chionaspis, 194

Chironomus, I Io; development of, I 22

Chlorops, 2 I I

Chrysopa, I 57, I95

Cicindela, 2 I 4

Clark, Bracy, on bot-fly, I46

Clavicornia, 216

Click-beetles, 37, 2 I8

Coccida, 162

Coccinella, 42

Cockchafer, 25 ; Midsummer cockchafer (Rhizotrogus), 3 I

Cockroach, 177, 189; external parts of, 6; male and female of, II ; mouth parts of, 12; dissection of, I 5 ; ovipositor of, 98,223

Coleoptera, 25, I87, 212

Collembola, I85

Corrodentia, I86

Cossus, 65

Crane-fly, 129

Crickets, I9o; house crickets, 179 
Crioceris, 219

Crustacea, 5

Culex, 125

Curculionida, 220

Currant-scale, 165

Curtice, Cooper, on American warble, 150

Dactylopius, 194

Daddy-long-legs, 129

Death's-head moth, 199

Diamond-back moth, 203

Diptera, I10, 187, 204

Dragon-flies, I7 I, 185, 195

Dytiscus, 32

Earwig, 175, 189

Elm-bark beetle, 47

Embryonic fission, 109

Encyrtus, 109

Ephemeridæe, 168, I85

Ermine-moths, small, 203

Expert knowledge, value of, 25 I

Fleas, 212

Fluted scale, 243

Forficula, I 75

Forficulidx, I89

Frit-fly, 2 I I

Frontal sac, I40

Garden chafer (Rhizotrogus), 3 I

- weevil (Otiorhynchus), 44

Gastrophilus, I44

Geometridæ, 2OI

Gipsy-moth, 20r, 238

Glow-worm, 218

Gnat, 125

Goat-moth, 65

Gooseberry saw-fly, 94

Gout-fly, 2 II

Grasshoppers, I90

Gryllus, I79

Gryllidæ, 190

Hæemoglobin in blood, 113

Harlequin-fly, I10; development of, 122
Hawk-moths, 199

Hemiptera, I 53, 186, 190

Hessian-fly, I33

Heterocera, 199

Heteromera, 219

Heteroptera, I 56, I9I

Hive-bee, 82

Homoptera 156, 192

Honey-dew, 156

Howard on fig-insect, 228, 252 ; on the gipsy-moth, 240 ; on spraying machines, $25 \mathrm{I}$

Hymenoptera, 82, 187, 222; narrow waist of, 97 ; ovipositor of, 100, IOI, IO4; resting larva of, 96, 102; parasitic, 104

Hypoderma, I 49

Hyponomenta, 203

Iapyx, I 76

Ichneumons, 50, 65, 98, 102

Insects, characters of, 3 ; killing of, 25 ; relaxing of, 25 ; aquatic, 36 ; serviceable to man, 68 ; flight of, 79 ; wingless, 80 ; bee-like, 82 ; development of, 122 ; orders of, 185 ; injurious, remedies for, 240,245

Labia, 176

Lace-winged $\mathrm{Ay}, \mathrm{I} 57,195$

Lackey-moth, 199

Lady-bird, 42, I 57, 2 I 7

Lamellicornia, 214

Lampyridæ, 218

Larvæ of insects, characters and kinds of, 23 I

Larval stage, duration of, 66

Laveran on malaria-germs, 128

Leather-jacket, 129

Lecanium, I65

Lepidoptera, 51, 187, 196; veins of wings of, 62 ; and Trichoptera, 168 ; families of, 198

Lice, 194

Locustidæ, 190

Maggot, characters of, 233

Magpie-moth, 202 
Malaria and mosquitoes, 128

Mamestra, 20I

Manson on malaria-germs, 129

Marlatt's "Important Insecticides," 245

May-fly, I68

Mealworn, 2 I9

Microgaster, 106

Micropteryx, 168

Midsummer cockchafer (Rhizotrogus), 3 I

Mosquitoes and malaria, I 28

Moths, I99; and butterflies, 5I ; how to set, 55 ; mouth-parts of, $6 \mathrm{I}$

Muscidæ, 2 Io

Muscinæ, 144, 2 10

Mussel-scale, 162

Mustard-beetle, 2 I9

Myriopoda, 5

Mytilaspis, I62

Nematus, 94

Nemocera, I I 7, I 32, I33, 207

Neuroptera, I86, 194

Noctuæ, 201

Odonata, I7I, I85, 195

Cistridæ, I 49, 2 I I

Oil-beetle, 219

Ophion, I05

Orgyia, 77

Orthezia, 194

Orthoptera, I86, I88; three common, I75

Oscinis, 2 I I

Otiorhynchus, 44

Ovipositor of cockroach, etc., 98, IOO; of Hymenoptera, IOO, IOI, I04; of various insects, 222

Oyster-scale, I 65

Parthenogenesis, I55, I6I, 164, 224

Pasteur's remedies for diseases of silkworm, 76, 252

Pea-weevil, 220

Periplaneta, I77

Phædon, 219
Phagocytes, I39

Phyllotreta, 39

Phylloxera, I 53, I 59

Physopoda, I 86

Phytophaga, 219

Pieris, 62

Pimpla, I05

Platygaster, 108

Plecoptera, I85

Plutella, 203

Pupa, 59, 60

Pupæ, characters of, 233

Pupipara, 212

Puss-moth, 200

Pyralides, 202

Réaumur on Microgaster, I06; on honey-dew, I 56

Remedies for injurious insects, 245

Rhopalocera, 198

Rhopalosiphum, I 53

Rhychophora, 220

Rhynchota, I 56, I86, 190

Ross on malaria-germs, 129

Rove-beetles, 216

Saw-files, 226

Saw-fly, gooseberry, 94

Scale-insects, I 53, 194

Schizoneura, 153

Scolytus, 47

Scorpion-fly, 195

Sialis, I95

Silkworm, 68

Sirex, 99, 106

Shellac, 164

Sphinges, I99

Staphylinida, 216

Sting of bee, $88,98,100,106$; of insects, 223

Strepsiptera, 187

Syrphidæ, 210

Syrphus, I 57

Tachinidæ, 104

Taylor on swarms of harlequin-flies, I I9

Thysanoptera, I86

Thysanura, I 85

Tiger-beetle, 2 I4 
256

Tiger-moth, 58

Tineidæe, 203

Tipula, 129

Tomicus, 50

Tortrices, 202

Trichoptera, 187; and Lepidoptera, 168

Turnip-aphis, 153

Turnip-flea, 39

Vapourer-moth, 77

\section{INDEX}

Warble-fly, I $49,25^{2}$

Water-beetle (Dytiscus), 32

Weevils, 45, 50, 220

Weismann on wingless insects, $8 \mathrm{r}$, note

Wire-worm, 37

Wood-wasp, 99

Woolly aphis, 153,158

Xylotropha, 202 



